\title{
Natural Tracers and Multi-Scale Assessment of Caprock Sealing Behavior: A Case Study of the Kirtland Formation, San Juan Basin
}

\section{Topical Report}

Reporting period:

September 1, 2007 - November 15, 2010

Authors:

Jason E. Heath ${ }^{1}$, Brian J.O.L. McPherson ${ }^{2}$, and Thomas A. Dewers ${ }^{3}$

Report issued:

December 2010

U.S. Department of Energy

DOE Award No.: DE-FC26-05NT42591

Submitting organization:

Sandia National Laboratories

Department of Geophysics and Atmospheric Sciences

P.O. Box 5800, MS 0750

Albuquerque, NM 87185-0750

Affiliations:

${ }^{1}$ Department of Geophysics and Atmospheric Sciences, Sandia National Laboratories, Albuquerque, NM 87185-0750

${ }^{2}$ Department of Civil and Environmental Engineering, University of Utah, Salt Lake City, UT 84112-0561

${ }^{3}$ Department of Geomechanics, Sandia National Laboratories, Albuquerque, NM 87185-0751 


\section{Disclaimer}

\section{U.S. Department of Energy}

This report was prepared as an account of work sponsored by an agency of the United States Government. Neither the United States Government nor any agency thereof, nor any of their employees, makes any warranty, express or implied, or assumes any legal liability or responsibility for the accuracy, completeness, or usefulness of any information, apparatus, product, or process disclosed, or represents that its use would not infringe privately owned rights. Reference herein to any specific commercial product, process, or service by trade name, trademark, manufacture, or otherwise does not necessarily constitute of imply its endorsement, recommendation, or favoring by the United States Government or any agency thereof. The views and opinions of authors expressed herein do not necessarily state or reflect those of the United States Government or any agency thereof. 


\begin{abstract}
The assessment of caprocks for geologic $\mathrm{CO}_{2}$ storage is a multi-scale endeavor. Investigation of a regional caprock - the Kirtland Formation, San Juan Basin, USA — at the porenetwork scale indicates high capillary sealing capacity and low permeabilities. Core and wellscale data, however, indicate a potential seal bypass system as evidenced by multiple mineralized fractures and methane gas saturations within the caprock. Our interpretation of ${ }^{4} \mathrm{He}$ concentrations, measured at the top and bottom of the caprock, suggests low fluid fluxes through the caprock: 1) Of the total ${ }^{4} \mathrm{He}$ produced in situ (i.e., at the locations of sampling) by uranium and thorium decay since deposition of the Kirtland Formation, a large portion still resides in the pore fluids. 2) Simple advection-only and advection-diffusion models, using the measured ${ }^{4} \mathrm{He}$ concentrations, indicate low permeability $\left(\sim 10^{-20} \mathrm{~m}^{2}\right.$ or lower) for the thickness of the Kirtland Formation. These findings, however, do not guarantee the lack of a large-scale bypass system. The measured data, located near the boundary conditions of the models (i.e., the overlying and underlying aquifers), limit our testing of conceptual models and the sensitivity of model parameterization. Thus, we suggest approaches for future studies to better assess the presence or lack of a seal bypass system at this particular site and for other sites in general.
\end{abstract}




\section{TABLE OF CONTENTS}

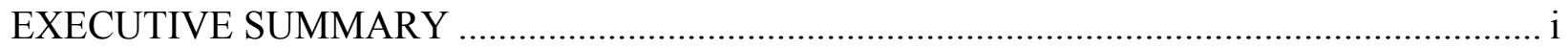

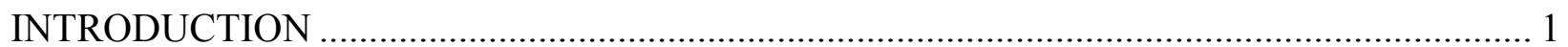

SITE LOCATION AND GEOLOGIC AND HYDROGEOLOGICAL SETTINGS ………............. 3

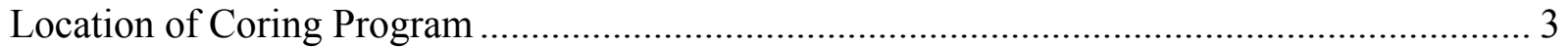

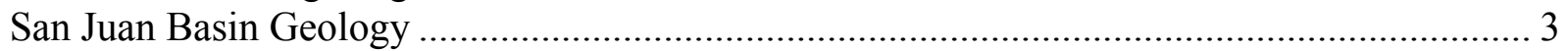

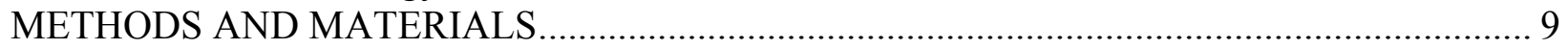

Coring Program, Field Sample Preservation, and Well Logging .............................................. 9

Petrographic, Petrophysical, and Geologic Characterization ................................................. 10

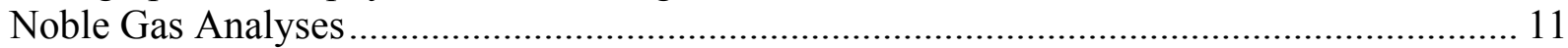

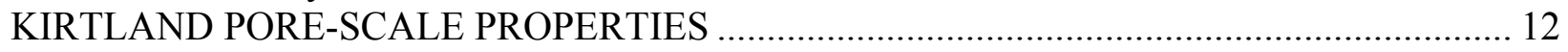

Nano-Scale FIB/SEM Imaging and Pore-Scale Modeling ................................................. 12

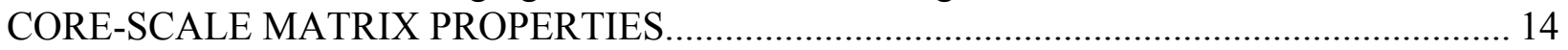

Mercury Intrusion Porosimetry Results and Sealing Efficiency.............................................. 14

Petrography, Petrophysical Properties, and Geologic Characterizations.................................. 16

FRACTURE CHARACTERISTICS FROM FMI LOGS AND CORE ....................................... 20

FORMATION-SCALE NOBLE GAS RESULTS AND CROSS-SEAL TRANSPORT ............ 24

Helium and Neon Concentration Profiles ......................................................................... 24

Testing Conceptual Models of Helium Transport ................................................................. 30

Steady-State ${ }^{4} \mathrm{He}$ Advection, Diffusion, and In Situ Generation ............................................. 33

DISCUSSION AND CONCLUSIONS: MULTI-SCALE EVALUATION OF SEAL BYPASS

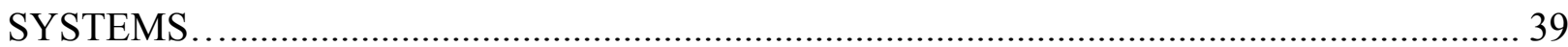

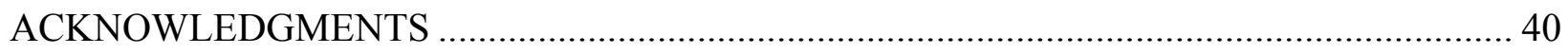

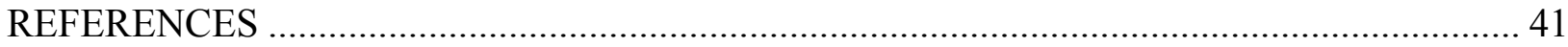

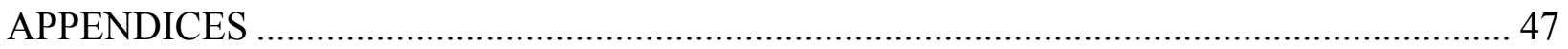

Appendix A. Field Core Handling Report ……………...................................................... 47

Appendix B. Core Handling and Data Collected by TerraTek, a Schlumberger Company ..... 61

B.1 Petrologic Evaluation of Kirtland Shale Core - San Juan BU EPNG Com A Inj \#1 Well,

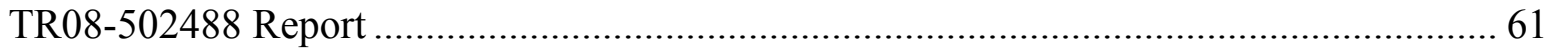

B.2 Photomicrographs from Petrographic and SEM Analysis ………………………….... 72

B.3 Photo Log of Slabbed Core ……………………….................................................. 91

B.4 Gas Breakthrough Experiment Data ........................................................................ 99

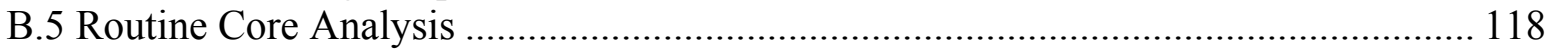

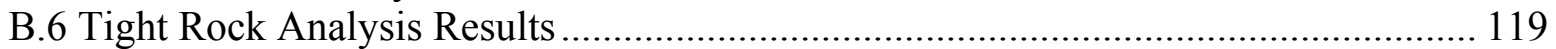

B.7 Gamma Ray on Core ......................................................................................... 120

Appendix C. Mercury Intrusion Porosimetry Data Collected by Poro-Technology .............. 129

Appendix D. Inventory of Thin Sections and Billets.......................................................... 163

Appendix E. Mud Log of Well EPNG Com A Inj \#1 .......................................................... 169 


\section{EXECUTIVE SUMMARY}

The assessment of caprock for underground $\mathrm{CO}_{2}$ storage is challenging due to geologic heterogeneity at multiple scales. Caprocks impede movement of fluids by means of viscous and capillary forces, due to their small pores. However, larger-scale fractures, faults, or other "seal bypass systems" can circumvent the pore networks and potentially lead to significant fluid migration through a caprock. This topical report presents a site-specific study by the Southwest Regional Carbon Sequestration Partnership (SWP) to develop multi-scale assessment methods that incorporate natural tracers. Natural tracers are already present at all sequestration sites and represent a resource for investigating the long-term and spatially-distributed transport properties of a caprock without the need for injecting applied or "exotic" tracers into the system. The multiscale assessment is not based on upscaling a variety of data sets, but simply comparing different types of data collected at different scales to determine if the data are coherent. As shown in this study, some small-scale data may indicate a different type of caprock sealing quality than data that apply at a larger scale.

Study of a regional caprock - the Kirtland Formation, San Juan Basin, USA — at the porenetwork scale indicates high capillary sealing capacity and low permeabilities. Core and wellscale data, however, indicate a potential seal bypass system as evidenced by multiple mineralized fractures and methane gas saturations within the caprock. Our interpretation of ${ }^{4} \mathrm{He}$ concentrations, measured at the top and bottom of the caprock, suggests low fluid fluxes through the caprock: 1) Of the total ${ }^{4} \mathrm{He}$ produced in situ (i.e., at the locations of sampling) by uranium and thorium decay since deposition of the Kirtland Formation, a large portion still resides in the pore fluids. 2) Simple advection-only and advection-diffusion models, using the measured ${ }^{4} \mathrm{He}$ concentrations, indicate low permeability $\left(\sim 10^{-20} \mathrm{~m}^{2}\right.$ or lower $)$ for the thickness of the Kirtland Formation. These findings, however, do not guarantee the lack of a large-scale bypass system. The measured data, located near the boundary conditions of the models (i.e., the overlying and underlying aquifers), limit our testing of conceptual models and the sensitivity of model parameterization. Thus, we suggest approaches for future studies to better assess the presence or lack of a seal bypass system at this particular site and for other sites in general.

With the permission of the Center for Graduate Studies at the New Mexico Institute of Mining and Technology, this report reproduces Chapter 5 and the associated appendices of the Ph.D. dissertation by the lead author (Heath, 2010). 


\section{INTRODUCTION}

Processes acting over a large range of spatial and temporal scales affect the ability of "sealing sequences", "seals", or "caprocks" to retain hydrocarbons or other fluids within a reservoir. These terms in quotations refer to generally low permeability, high capillarybreakthrough pressure geologic units that overlie a reservoir, and "seal" can also apply to faults that impede fluid flow (Cartwright et al., 2007). Nanometer- to $\mu \mathrm{m}$-scale pore networks contribute resistance to multiphase fluid transport by viscous and capillary forces (Hildenbrand et al., 2004). However, larger-scale, high-permeability "seal bypass systems" can cause significant fluid migration through a sealing sequence. Examples include fracture networks, faults, injectites, or sedimentary facies changes (Ingram et al., 1997; Cartwright et al., 2007). Seal bypass systems can evolve through time due to coupled hydrological, geochemical, or geomechanical processes (Eichhubl and Boles, 2000). Engineered activities, such as underground storage of $\mathrm{CO}_{2}$, require prediction of the response of the seal/reservoir system to induced perturbations (Rohmer and Bouc, 2010).

The majority of research on sealing sequences has focused on two major scales - the plug scale or smaller and that of large faults. The scale in between, however, has received much less attention. Researchers use measurements on core plugs or smaller samples to determine capillary-breakthrough pressures and permeability of the matrix in order to estimate hydrocarbon or $\mathrm{CO}_{2}$ column heights retained by capillarity, characterize capillary breakthrough, describe mechanisms of overpressure generation, and estimate potential fluxes of fluids through unfractured matrix (Berg, 1975; Schowalter, 1979; Aplin et al., 1999; Hildenbrand et al., 2004; Yang and Aplin, 2007). The scale of large faults or other high permeability features (e.g., dissolution pipes) typically includes those features that are resolvable by seismic surveys (Boult and Kaldi, 2005; Cartwright et al., 2007). Additionally, wellbores can constitute a significant risk as a man-made seal bypass system (Nordbotten et al., 2009).

Faults, fractures, or other potential seal bypass systems not resolvable by seismic surveys can be difficult to identify and characterize. Even when identified (e.g., via well logging by microresistivity methods), knowledge of their spatial dimensions, their connectivity through a sealing sequence, and their ability to transmit fluids is difficult to ascertain. Numerical modeling is typically used to predict reactivation and potential transport behavior (Chiaramonte et al., 2008).

$\mathrm{CO}_{2}$ storage, in particular, poses challenges of predicting seal behavior under perturbed conditions. It may be implemented at the large scale in deep, "saline" aquifers/reservoirs below sealing sequences where few deep wells have been drilled (IPCC, 2005; Orr, 2009). In such systems, the a priori ability of sealing sequences to contain buoyant, non-aqueous phases is not immediately apparent as hydrocarbons may never have been in these systems (IPCC, 2005). Recent research addresses possible migration of $\mathrm{CO}_{2}$ through preferential flowpaths with a focus on geochemical, geomechanical, and multiphase flow effects (Johnson et al., 2005; Carey et al., 2007; Gherardi et al., 2007; Andreani et al., 2008; Chiaramonte et al., 2008; Pruess, 2008; Zhang et al., 2008; Heath et al., 2009; Nordbotten et al., 2009; Silin et al., 2009). However, little work has focused on formation-scale bypass systems that may be difficult to resolve with well logging or seismic survey methods. Evaluation of the extent to which pore network properties are bypassed by larger-scale features at field and basin scales, and how these features evolve in time, is a major research challenge (DOE, 2007). 
Natural noble gases, especially helium isotopes (i.e., ${ }^{3} \mathrm{He}$ and ${ }^{4} \mathrm{He}$ ), represent a potentially powerful tool to evaluate the presence (or lack) of seal bypass systems in hydrocarbon or $\mathrm{CO}_{2}$ systems. Many studies demonstrate that, for aquitard/seal and aquifer/reservoir systems, noble gases facilitate qualitative and quantitative assessment of rates and patterns of groundwater flow, interaction between aquitards and aquifers (e.g., cross-formational flow) over local (e.g., well or field) to regional scales, the presence of preferential flowpaths and associated fluid flow (e.g., connected fractures), residence time distributions, the dominance of diffusion or advection, and interactions between groundwater and a separate fluid phase (e.g., oil, methane, or $\left.\mathrm{CO}_{2}\right)($ Castro et al., 1998; Bethke et al., 1999; Rubel et al., 2002; Lippmann et al., 2003; Ma et al., 2005; Bethke and Johnson, 2008; Gilfillan et al., 2008). Consequently, these tracers seem suited to addressing the challenge of characterizing the transmissive nature of seal bypass systems that may exhibit slow leakage over local to regional scales (DOE, 2007). The application of natural noble gases to explicitly characterize potential seal bypass features at hydrocarbon traps or $\mathrm{CO}_{2}$ storage sites has so far received little attention, according to our search of the literature (Lafortune et al., 2008).

In this study, we investigate the extent to which $\mu \mathrm{m}$ - to m-scale features and processes govern sealing behavior of the Kirtland Formation, San Juan Basin, USA. We restrict our study to the site of a $\mathrm{CO}_{2}$ injection demonstration in deep (>880 m) unmineable coal seams by the Southwest Regional Partnership on Carbon Sequestration (SWP), a project sponsored and managed by the National Energy Technology Laboratory (NETL) of the U.S. Department of Energy (DOE) (Litynski et al., 2008). Our data collection program facilitates investigation of both pore-scale phenomena and possible larger-scale discontinuities or other features that could act as seal bypass systems. These data, in turn, support a multi-scale assessment of the likelihood of $\mathrm{CO}_{2}$ migration from the storage site.

After a review of the geologic and hydrogeologic setting and the Methods and Materials Section, we sequentially present data and interpretations of caprock transport properties at the pore network scale, the core scale (i.e., hand-sample identification of fractures) and well-log scale, and finally at the scale of the full thickness of the caprock based on noble gas data. Data for each particular scale of assessment is presented with discussion and conclusions on sealing behavior for that scale. We examine progressively lager scale data and the coherency of the data sets in terms of the sealing behavior.

A unique aspect of this work involves the use of natural noble gas data, namely helium and neon, collected from within the upper and lower portions of the Kirtland Formation, to characterize transport properties and sealing behavior over geologic time scales. Our interpretation of the noble gas data, using models of fluid flow and helium transport through the Kirtland Formation, suggests low fluid fluxes through the caprock and does not invoke a seal bypass system to explain the data. However, our findings do not guarantee the lack of a bypass system due to limitations in the data and models. Thus, we suggest approaches for future studies to better assess the presence or lack of a seal bypass system at this particular site and for other sites in general. 


\section{SITE LOCATION AND GEOLOGIC AND HYDROGEOLOGICAL SETTINGS}

\section{Location of Coring Program}

The study location is the Pump Canyon Site in the north central portion of the San Juan Basin, New Mexico (Figure 1). The SWP oversaw drilling of a $\mathrm{CO}_{2}$ injection well, EPNG Com A Inj 1, in May and June, 2008 (Figures 1 and 2). The injection site lies within the high permeability Fruitland Fairway, the world's largest and most prolific coalbed methane gas play (Ayers, 2003).

Information on San Juan Basin geology and hydrology follows to facilitate investigation of sealing behavior and transport of natural tracers through the Kirtland Formation. Formations above and below the Kirtland Formation can impact tracer transport and hence are described here.

\section{San Juan Basin Geology}

The Kirtland Formation includes a lower shale member, the Farmington Sandstone Member, and an upper shale member (Fassett and Hinds, 1971). Stone (1983) and Molenaar and Baird (1992) developed cross sections for the San Juan Basin using wireline logs, which illustrate a one-to-three member division of the Kirtland Formation depending on the location in the basin and the degree of difficulty in identifying the members due to heterogeneity. Based on wireline logs, a mud log, and core at the Pump Canyon site, we designate an upper shale member as a unit consisting predominately of interbedded mudstone and sandstone. These data also help delineate the Farmington Sandstone Member, the lower shale member, and the Fruitland Formation (Figure 3). The depth of the base of the Ojo Alamo Sandstone, which overlies the upper shale member of the Kirtland Formation, is at the location of a scour and disconformity. The top of the Farmington Sandstone Member divides a sequence of silt- and sand-bearing and sandy/silty argillaceous mudstones from a sequence of interbedded sandstones and mudstones. The top of the lower shale member of the Kirtland Formation is at the location of the overall downward-fining sequence, in which the sandstone lenses become less dominant with depth. The top of the Fruitland Formation is at the location of the last carbonaceous mudstone bed within the Fruitland Formation.

Kirtland Formation lithology includes interbedded mudstones (i.e., claystone/shale and siltstone) and sandstone. Existing data suggest it was deposited in the late Cretaceous in an alluvial plain with floodplain and channel environments, landward of the swampy environments of the underlying Fruitland Formation (Fassett and Hinds, 1971; Klute, 1986). The Kirtland Formation lies conformably on the Fruitland Formation throughout most of the basin except in the east where uplift and erosion occurred during the Miocene (Figure 1f). Thickness of the undivided Farmington Sandstone and upper shale members ranges from $\sim 0-457 \mathrm{~m}(0-1500 \mathrm{ft})$. The lower shale member varies from $\sim 0-137 \mathrm{~m}(0-450 \mathrm{ft})$ in thickness with an average of $\sim 61-$ $76 \mathrm{~m}$ (200-250 ft) (Fassett and Hinds, 1971). At Pump Canyon, thicknesses of the upper shale, Farmington Sandstone Member, and lower shale members are, respectively, $30.8 \mathrm{~m}$ (101 ft), 123 $\mathrm{m}$ (404 ft), $83.5 \mathrm{~m}$ (274 ft) (Figure 3). 
Figure 1. Maps of the San Juan Basin with geologic and hydrologic features. (a) Position of basin within Colorado and New Mexico. (b) Locations of the $\mathrm{CO}_{2}$ injection well, the outcrop of the combined Fruitland and Kirtland Formations (after Kernodle et al., 1990), the Fruitland Fairway, the structural hingeline, and the area of artesian overpressure in the Fruitland Formation (after Scott et al., 1994). (c) Depth to top of Kirtland Formation (after Kernodle et al., 1990). (d) Thickness of the combined Kirtland and Fruitland Formations (after Kernodle et al., 1990). (e) Potentiometric surface map of the Fruitland Formation based on equivalent fresh water head (after Kaiser et al., 1994). (f) Regions where members of the Kirtland Formation and the Fruitland Formation are absent in the subsurface (after Fassett and Hinds, 1971). 


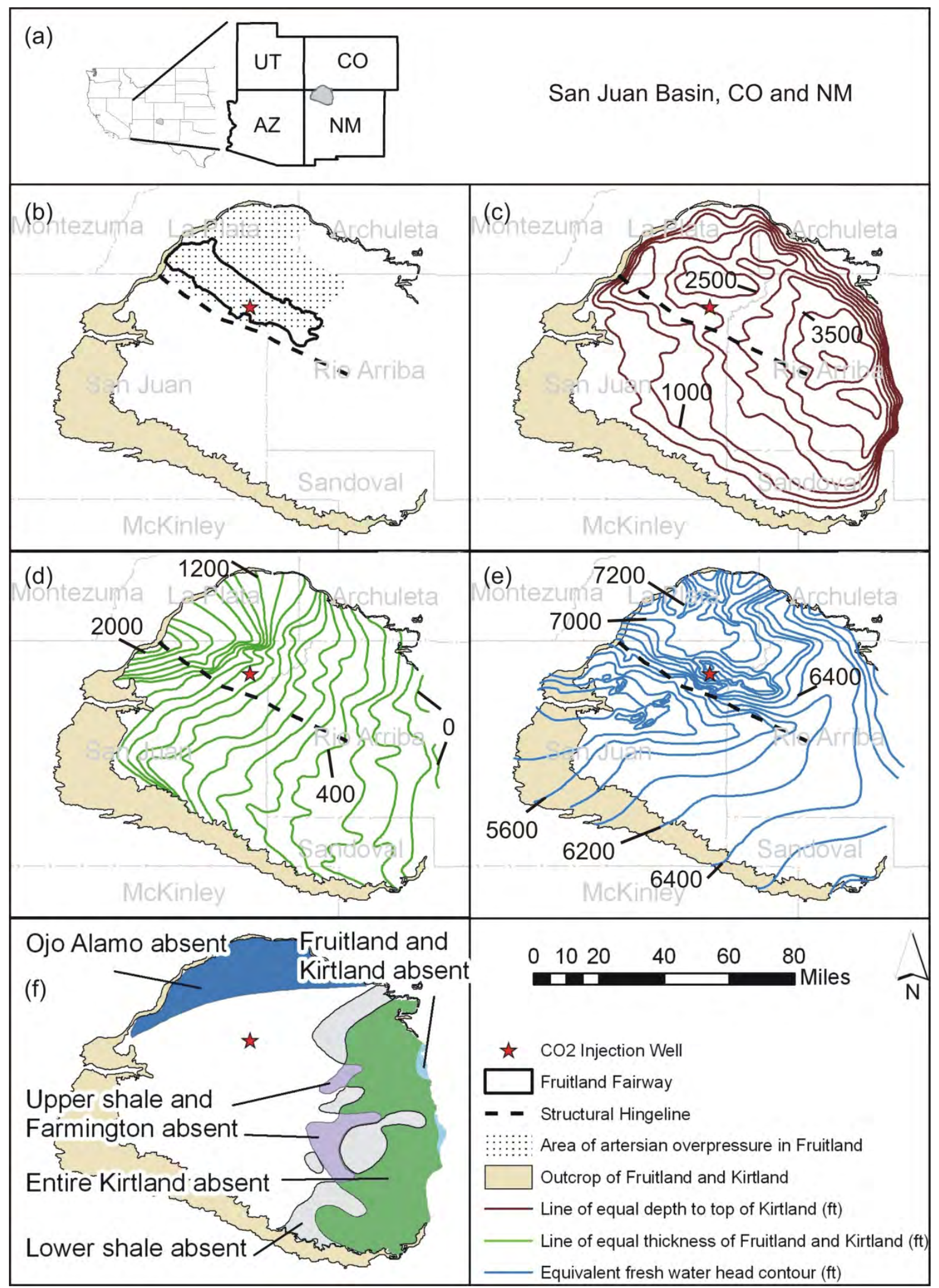




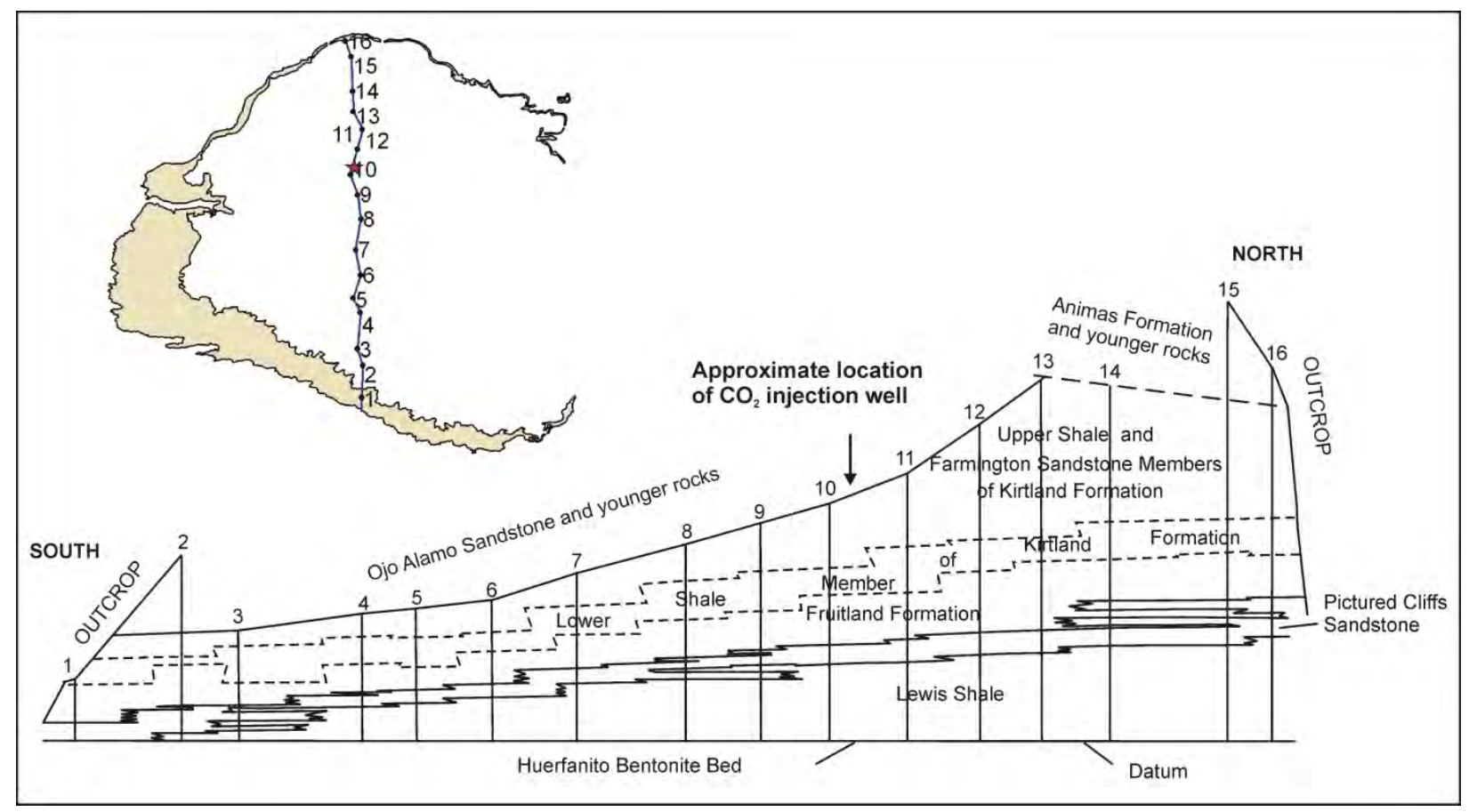

Figure 2. North-south cross section through the San Juan Basin with vertical lines that represent wells (adapted from Fassett and Hinds, 1971). The star indicates $\mathrm{CO}_{2}$ injection well. Numbers on the inset map correspond with the numbers on the cross section. 


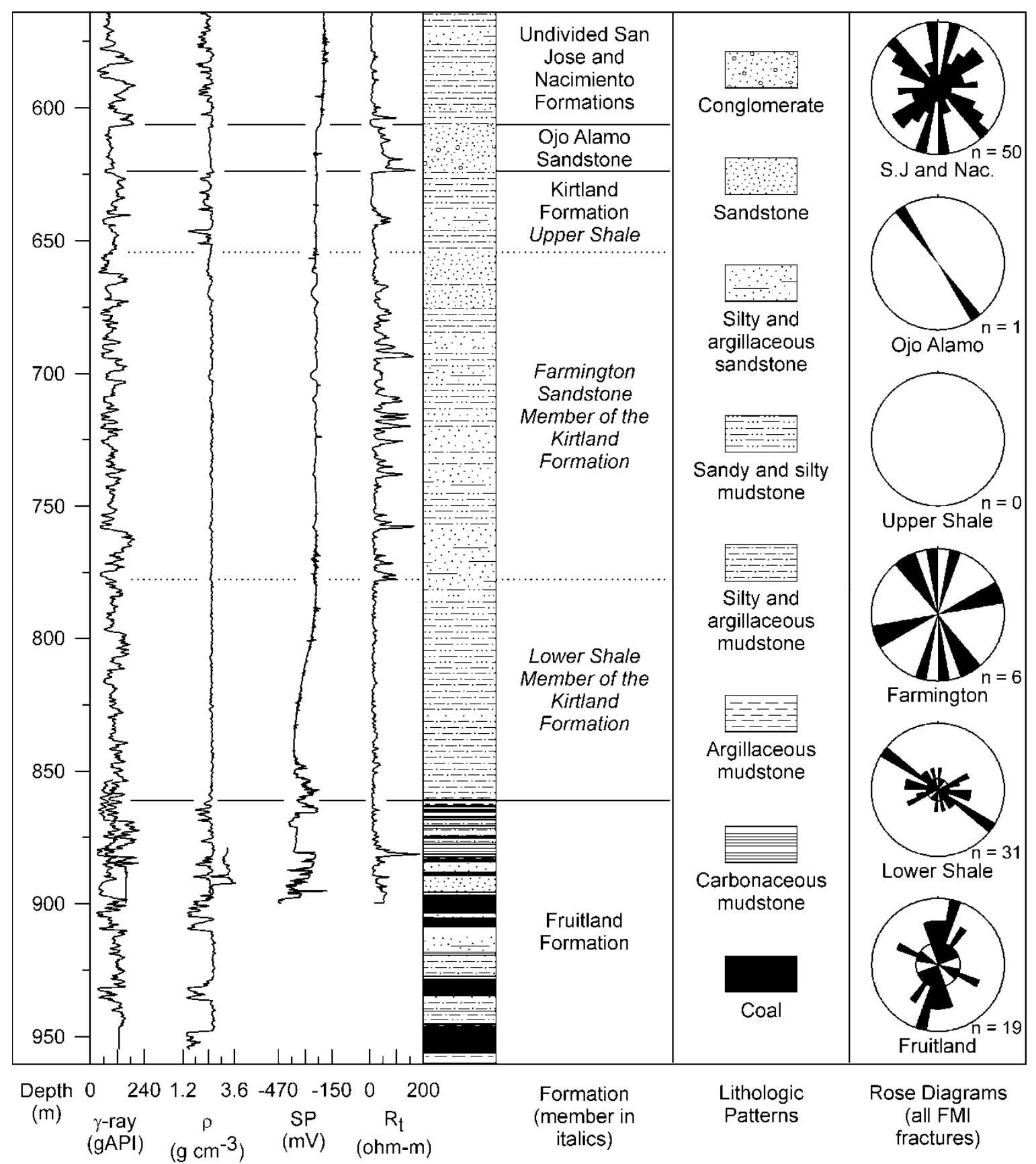

Figure 3. Selected wireline logs, lithologic interpretation, and rose diagram fracture orientations from fullbore formation microimager (FMI) logs for well EPNG Com A Inj 1. The lower logging section, starting at a depth of $\sim 696.2 \mathrm{~m}(2284 \mathrm{ft})$, was logged on a different date than the upper section. The mismatch of logging data near that depth may be due to casing before the second logging run. The first circle outward from the middle of the rose diagrams corresponds to a fracture measurement of one in the direction of the radial class intervals. North is at the top of the rose diagrams. 
The Fruitland Formation contains the primary coal reserves of the San Juan Basin (Ayers, 2003) and extensive sandstone beds that constitute a regional aquifer (Stone et al., 1983). The Fruitland Fairway (Figure 1a) is the world's most prolific coalbed methane play (Ayers, 2003). The Fairway trends northwest in the direction of the structural hingeline of the basin (Figure 1a).

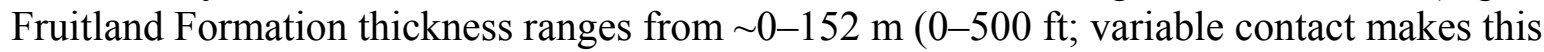
estimate uncertain) with an average of $\sim 91-107 \mathrm{~m}(300-350 \mathrm{ft})$ (Fassett and Hinds, 1971). $\mathrm{CO}_{2}$ injection by the SWP targeted coals at depths between $\sim 889.2 \mathrm{~m}(2917 \mathrm{ft})$ and $956.5 \mathrm{~m}(3138 \mathrm{ft})$ (below ground surface; bgs).

The Tertiary Paleocene Ojo Alamo Sandstone disconformably overlies the Kirtland Formation throughout most of the basin except for the far northern portion of the basin where the Kirtland may be overlain by other Tertiary formations (Figures 1f, 2, and 3; Fassett and Hinds, 1971).

\section{Hydrogeologic Setting and Properties}

Although hydrogeologic investigations of Upper Cretaceous and Tertiary formations have focused on the Ojo Alamo Sandstone, Kirtland Formation, Fruitland Formation, and Pictured Cliffs Sandstone, the Fruitland Formation has received the greatest attention due to its coalbed methane plays (Stone et al., 1983; Phillips et al., 1989; Kaiser and Ayers, 1994; Castro et al., 2000; Snyder et al., 2003; Zhou and Ballentine, 2006). Based on potentiometric surface mapping, pressure data, and hydrochemical evaluations, the Fruitland Formation aquifer system is divided into three areas with distinct conditions: Area 1, a region of artesian overpressure north of the basin's structural hingeline in the northwestern area of the basin (Figure 1b); Area 2, the underpressured and regional discharge area south of the structural hingeline in the westcentral part of the basin; and Area 3, the underpressured region in the south-central and eastern portions of the basin (Ayers et al., 1994; Kaiser and Ayers, 1994). Some studies include the upper portion of the Pictured Cliffs Formation as a hydrostratigraphic unit with the Fruitland Formation due to similar head values between the two Formations (Kaiser and Ayers, 1994). Area 1 is described here in detail because it contains the Pump Canyon Site, and the hydrogeology is relevant to our sealing assessment.

Recharge of the groundwater system in Area 1 occurs in the northern outcrops of the Fruitland Formation as indicated by the potentiometric surface and outcrop locations (Figure 1e). Groundwater flow is generally southward towards the basin's structural hingeline (Figure 1e). Overpressure is attributed to natural artesian conditions, driven by topographic forcing, and does not reflect fossil geopressure (Ayers, 2003). The structural hingeline is a location of permeability reduction in the Fruitland Formation, which greatly impacts the regional flow system by causing a strong upward pressure gradient at the hingeline (Figure 1e) due to possible pinching out of aquifer coal seams, other sedimentary facies changes, or faulting associated with the hingeline (Kaiser et al., 1994). In the Sedro Canyon-Meridian 400 area, near to the $\mathrm{CO}_{2}$ injection well, the vertical pressure gradient is $\sim 0.018 \mathrm{MPa} / \mathrm{m}(0.79 \mathrm{psi} / \mathrm{ft})$, which is greater than the hydrostatic gradient of $0.00979 \mathrm{MPa} / \mathrm{m}(0.433 \mathrm{psi} / \mathrm{ft})$ and indicates an upward flow gradient (Kaiser and Ayers, 1994).

The artesian hydrodynamic conditions probably developed during the Middle Pliocene (Kaiser and Ayers, 1994) after Miocene uplift and erosion. Maximum heat flow occurred during the Oligocene when the San Juan Mountain volcanic field erupted (Law, 1992; Zhou et al., 2005). Pore waters in the Fruitland Formation north of the hingeline (Area 1) are meteoric as 
indicated by isotopes of water, chlorinity, potentiometric surface maps, and estimates of groundwater residence time (Kaiser et al., 1994; Zhou et al., 2005).

Direct measurements of hydrologic properties of the Kirtland Formation are scarce. Farmington Sandstone Member hydraulic conductivity, measured from oil producing well El Paso Natural Gas Company No. 4 Riddle, $36.8651^{\circ} \mathrm{N}$ and $105.9902^{\circ} \mathrm{W}$ (sec. 4, T. 30 N., R. 9 W., NMPM), ranges from $6 \times 10^{-9}$ to $9 \times 10^{-8} \mathrm{~m} / \mathrm{s}\left(0.002\right.$ to $0.03 \mathrm{ft} /$ day; permeability is $6 \times 10^{-16}$ to $9 \times 10^{-}$ ${ }^{15} \mathrm{~m}^{2}$ ) (Fassett and Thomaidis, 1978). Kernodle (1996) presents a calibrated three-dimensional (3D) groundwater model for a combined Ojo Alamo, Kirtland Formation, and Fruitland Formation with vertical hydraulic conductivities of $4 \times 10^{-10}$ to $2 \times 10^{-8} \mathrm{~m} / \mathrm{s}\left(1 \times 10^{-4}\right.$ to $0.006 \mathrm{ft} / \mathrm{day}$; permeability is $4 \times 10^{-17}$ to $\left.2 \times 10^{-15} \mathrm{~m}^{2}\right)$ and horizontal conductivity of $7 \times 10^{-7} \mathrm{~m} / \mathrm{s}(0.2 \mathrm{ft} / \mathrm{day}$; permeability is $7 \times 10^{-14} \mathrm{~m}^{2}$ ) near the Pump Canyon Site (Kernodle, 1996; his figures 40c and 41). Estimates of the hydrologic properties of the Kirtland Formation can be inferred from a 2D model of regional groundwater flow by Kaiser et al. (1994) for a northeast-southwest cross section through Area 1 and Area 2. Simulations that best fit measured hydraulic head data used horizontal permeability values of $10^{-17} \mathrm{~m}^{2}$ (corresponding hydraulic conductivity is $1 \times 10^{-10} \mathrm{~m} / \mathrm{s}$ or $3 \times 10^{-5} \mathrm{ft} /$ day), $10^{-16} \mathrm{~m}^{2}$ (hydraulic conductivity is $1 \times 10^{-9} \mathrm{~m} / \mathrm{s}$ or $3 \times 10^{-4} \mathrm{ft} /$ day), and $10^{-17} \mathrm{~m}^{2}$ (corresponding hydraulic conductivity is $1 \times 10^{-10} \mathrm{~m} / \mathrm{s}$ or $3 \times 10^{-5} \mathrm{ft} /$ day) for the lower shale, the Farmington Sandstone Member, and upper shale, respectively, with an anisotropy ratio of $\mathrm{k}_{\mathrm{h}} / \mathrm{k}_{\mathrm{v}}=$ 100. For comparison, Stone et al. (1983) reported transmissivity tests ranging from $6 \times 10^{-7}$ to $1.40 \times 10^{-4} \mathrm{~m}^{2} / \mathrm{s}\left(0.6\right.$ to $130 \mathrm{ft}^{2} /$ day $)$ with a calculated hydraulic conductivity of $3.5 \times 10^{-6} \mathrm{~m} / \mathrm{s}(\sim 1.0$ $\mathrm{ft} / \mathrm{day}$; corresponding permeability is $3.6 \times 10^{-13} \mathrm{~m}^{2}$ ) for coal beds and associated sediments within the Fruitland Formation.

\section{METHODS AND MATERIALS}

\section{Coring Program, Field Sample Preservation, and Well Logging}

Fresh core from the lower and upper shale members (Figure 3) was obtained for noble gas isotopic determination and for petrographic and petrophysical examination. Two sections of $0.10-\mathrm{m}$ (4.0-in) diameter conventional core were retrieved from the upper and lower members of the Kirtland Formation, beginning in the overlying Ojo Alamo Sandstone at a depth of $615.1 \mathrm{~m}$ (2018 ft) (bgs), including $9.04 \mathrm{~m}$ (29.7 ft) of Ojo Alamo Sandstone and $6.85 \mathrm{~m}$ of upper shale member of Kirtland Formation, respectively. Coring in the lower shale member targeted a clayrich zone, began at a depth of $819.9 \mathrm{~m}(2690 \mathrm{ft})$, and retrieved only $2.53 \mathrm{~m}(8.3 \mathrm{ft})$. Difficulties in coring, such as the bit becoming "packed off" with clay, resulted in less core than the intended 18.29-m (60-ft) core barrels for each depth.

Core preservation for noble and other pore fluid gases followed procedures similar to Osenbrück (1998). Prior to field work for this study, specially designed canisters were built from high-vacuum service equipment to seal samples against atmospheric contamination or significant pore fluid degassing (see Appendix A). After sub-sampling of core, sample plugs were weighed and placed into the canisters. A purging and vacuum pumpdown process evacuated atmospheric noble gases from the canisters (see Appendix A).

Core preservation, in addition to the plugs for noble-gas samples, included transporting core in the aluminum barrels to TerraTek — a Schlumberger company, Salt Lake City—where the core was pieced together and wrapped in cellophane. Six pieces of whole core, each $\sim 0.3 \mathrm{~m}$ (i.e., 
$1 \mathrm{ft}$ ) in length, were preserved in wax against drying before slabbing of the core. After slabbing, six thick (butt) sections were preserved against drying.

Schlumberger ran fullbore formation microimager (FMI) microresistivity logs from

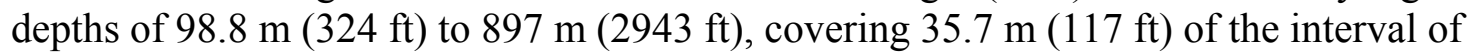
sandstone and mudstone within the Fruitland Formation above the significant coal seams (Figure 3). Schlumberger analysts compiled fracture orientation data from the FMI logs. A suite of other wireline tools were run, including a SonicScanner tool, that are further described by Wilson et al. (submitted). Fracture characterization data were extracted from the FMI results, and then presented and evaluated with true dip and dip direction. Dipset data were used in the study of the fractures.

\section{Petrographic, Petrophysical, and Geologic Characterization}

Mercury intrusion porosimetry (MIP) is used to estimate sealing capacity. For sake of convenience, we define the sealing capacity as the height of a hydrocarbon or $\mathrm{CO}_{2}$ column that would be retained by a brine-saturated seal (Berg, 1975; Dewhurst et al., 2002). To obtain $\mathrm{CO}_{2}$ column heights for the Kirtland Formation, omni-directional and directional MIP was performed by Poro-Technolgy, Sugar Land, Texas, using small pieces and plugs from the core, the plugs being $\sim 0.02 \mathrm{~m}(0.8 \mathrm{in})$ long by $\sim 0.02 \mathrm{~m}(0.8 \mathrm{in})$ in diameter. The MIP tests were run on a Micromeritics AutoPore IV 9500 Series porosimeter. To investigate anisotropy, two plugs were cut perpendicular and parallel to bedding and jacketed with epoxy.

TerraTek performed X-ray diffraction (XRD) to determine whole rock mineralogy, including $<4 \mu \mathrm{m}$ grain-size (i.e., clay size fraction), as well as total organic carbon (TOC) analysis, standard petrographic analysis, and scanning electron microscopy (SEM) with energy dispersive X-ray spectroscopy (EDS). Routine core analysis was performed for porosity, gas permeability, and bulk and grain density on three plugs from the Ojo Alamo Sandstone. Seven samples of the Kirtland Formation were analyzed for (pressure-decay) permeability, porosity, bulk and grain density, and fluid saturations using TerraTek's suite of Tight Rock Analysis (TRA) methods.

Additional thin sections and fluorochrome-epoxied billets were made from samples containing natural, mineralized fractures made parallel with the dip direction or parallel with visible slickenlines. Thick sections or billets up to $1.8 \mathrm{~cm}$ thick were prepared from core pieces, also prepared with the fluorochrome epoxy, so that epoxy-filled pore bodies would fluoresce during laser scanning confocal microscopy.

Connected porosity and organic material was imaged using a Zeiss 510-Meta Laser Scanning Confocal Microscope (LSCM). Three-dimensional sections were measured at $5 \times$ (voxel size of $1.8 \mu \mathrm{m}$ in $\mathrm{x}$ and $\mathrm{y}$ and $1.0 \mu \mathrm{m}$ in $\mathrm{z}$ ) using a Zeiss $5 \mathrm{x} / 0.13 \mathrm{NA}$ HD DIC EC EpiplanNeofluar lens and at $50 \times$ (voxel size of 0.36 or $0.18 \mu \mathrm{m}$ in $\mathrm{x}$ and $\mathrm{y}$ and $1.0 \mu \mathrm{m}$ in $\mathrm{z}$ ) using a Zeiss $50 \mathrm{x} / 0.55 \mathrm{NA}$ DIC LD EC Epiplan-Neofluar lens. Porosity and organic material (including that associated with pyrite nodules) were simultaneously imaged using $543 \mathrm{~nm}$ excitation from a HeNe laser and a 560-nm long-pass filter for emissions from the rhodamine-dyed epoxy occupying connected pore spaces, and 477-nm excitation from an Ar laser and a 745-525 nm band-pass filter for emissions from organic material.

Geometry of submicron-scale 3D pore networks were obtained for Kirtland Formation samples using a FEI Company Helios ${ }^{\mathrm{TM}} 600$ Nanolab DualBeam ${ }^{\mathrm{TM}}$ focused ion beam/scanning 
electron microscopy (FIB/SEM) system (Yao, 2007). The FIB creates serial sections, which are imaged in sequence with a field-emission SEM. Successive milling and imaging yields a series of $2 \mathrm{D}$ images that can be stacked and processed to reconstruct 3D pore networks. Additional backscattered electron imaging of fracture mineralization was performed on a JEOL JSM59002V SEM with a JEOL Shadow Backscatter Detector with EDS mapping using a Zeiss SUPRA 55VP instrument equipped with a Bruker quad silicon drift detector.

Upper and lower member Kirtland Formation core was examined for the presence of natural and induced fractures and lithology. Since the core was extremely friable, especially upon drying, much of the core was reviewed while still wrapped in cellophane.

\section{Noble Gas Analyses}

Neon-20 $\left({ }^{20} \mathrm{Ne}\right),{ }^{3} \mathrm{He}$, and ${ }^{4} \mathrm{He}$ from pore fluids of preserved core plugs were analyzed at the University of Utah's Dissolved and Noble Gas Laboratory. As described above, core plugs were collected and sealed in vacuum-tight canisters on May 7 and 9, 2008, immediately after two sections of core were brought to ground surface. Due to low solubility of noble gases in water, the gases partitioned from the pore water into the surrounding canister volume (Osenbruck et al., 1998). After transfer of the gases into a purification line, analysis followed methods described by Hendry et al. (2005). Each sample had high methane concentrations, which necessitated removal of all gases during purification except helium and neon. Thus, concentrations of other gases are unknown except for measurements made during mud logging (see Appendix E). Two analysis runs were completed, one in September 2008 and the other in October 2009. The second run was intended as a check on the quantitative release of the noble gases from the pore fluids. Helium and neon data from the two runs were combined to obtain the "total" quantitative release of these gases from the pore space. Due to high helium concentrations, splitting of the original gas samples into aliquots of $1 \%$ or $10 \%$ was necessary for all samples of the first run except the field blanks; whereas $50 \%$ splitting was necessary for two samples during the second run. Helium was diverted into a MAPL 215-50 sector-field linear mass spectrometer for determination of ${ }^{3} \mathrm{He}$ and ${ }^{4} \mathrm{He}$. Neon-20 was analyzed on a quadrupole mass spectrometer. Non-linearity corrections were required for some samples. Analytical precision is approximately $1 \%$ for helium and $2 \%$ for neon, respectively.

The greatest uncertainty in the concentration of the noble gases is due to the field sampling procedure and estimation of pore volumes. Estimates of uncertainty of noble gas concentration from the core plug samples are based on uncertainties of pore volumes (estimated from the volume of sample material removed from the core and the porosity values) and laboratory analysis using error propagation methods (Harris, 2007). Uncertainty due to possible sampling-related degassing (e.g., due to pressure release during drilling and coring) and loss of noble gases prior to sealing of canisters is not explicitly estimated here. Previous work using similar core sample collection methods estimated noble gas loss prior to sample preservation in canisters to be $<20-30 \%$ (Osenbruck et al., 1998; Sacchi et al., 2001). This previous work used estimates of atmospheric ${ }^{20} \mathrm{Ne}$ in groundwater samples to assess the degree of degassing (Osenbruck et al., 1998). However, this uncertainty estimate of noble gas loss may not be appropriate here because wireline well and mud logs (see Appendix E) indicate separate-phase gas (i.e., predominately methane) at various depths within the Kirtland Formation and the overlying Ojo Alamo Sandstone, which may be responsible for some loss of noble gases from 
the groundwater by degassing (i.e., partitioning of noble gases between the groundwater and the separate gas phase) in situ, not just during the time period after coring and before preservation of samples in the canisters. Osenbruck et al. (1998) studied a system that did not have the situation of in situ partitioning processes involving noble gases, groundwater, and a separate gas phase (e.g., methane). Furthermore, our system may contain aqueous or sorbed methane that degassed due to pressure release, which is an additional difference from Osenbruck et al.'s (1998) study. Thus, we use the measured concentrations of noble gases for interpretations while being cautious of possible in situ or sampling-related degassing.

Atmospheric solubility equilibrium concentrations, or "air saturated water (ASW)" concentrations, of dissolved noble gases in recharging groundwater are a starting reference for interpreting measured concentrations (Kipfer et al., 2002). Methods for estimating ASW concentrations require knowledge of pressure, temperature, and salinity conditions at the recharge area. Elevation is used to estimate pressure. The recharge area for groundwater in the Farmington Sandstone Member of the Kirtland Formation and the Fruitland Formation is most likely along the northern margin of the San Juan Basin (Figure 1e). The elevation and mean annual air temperature (from 1900 to 1909) vary, respectively, from approximately 2,173 to 2,660 $\mathrm{m}$ and 5.0 to $6.2^{\circ} \mathrm{C}$, for the recharge area (PRISM, 2009; USGS, 2009). Assuming that mean annual ground temperatures can be up to $2^{\circ} \mathrm{C}$ higher than air temperatures for this area, and that ground temperatures may have been up to $5.5^{\circ} \mathrm{C}$ cooler during recharge in the past than modern recharge (Stute et al., 1995), and assuming salinity is negligible, we assign a temperature range of 0.5 to $8.2^{\circ} \mathrm{C}$ and the above elevation range for calculating solubility equilibrium concentrations of ${ }^{20} \mathrm{Ne}$ and helium for ASW using equations by Weiss (1971), as implemented by Kipfer et al. (2002).

\section{KIRTLAND PORE-SCALE PROPERTIES}

\section{Nano-Scale FIB/SEM Imaging and Pore-Scale Modeling}

This section begins the presentation of data, starting at the nano or pore scale, with discussion and statements on sealing behavior for the scale in question before moving to a larger scale of characterization. A $\mathrm{Ga}^{+}$-ion-beam-milled image of upper Kirtland Formation mudstone pore and sedimentary structures from a depth of $624.75 \mathrm{~m}(2049.7 \mathrm{ft})$ is shown in Figure 4a. This image is one in a set of 319 serial images taken at $25 \mathrm{~nm}$ spacing. Backscattered electron imaging was used to image each section, which allows visualization of mineral phases that differ in mean atomic number. Pore bodies (near black gray level) are narrow and slit-shaped, some of which are correlated with mineral phases indicated by variations in grayscale.

Chapter 3 of Heath (2010) examines pore structures in the Kirtland Formation in detail, and compares mudstone pore types and pore network statistics and topology among several depositional facies. Results suggest that the dominant pore types in the Kirtland Formation are 


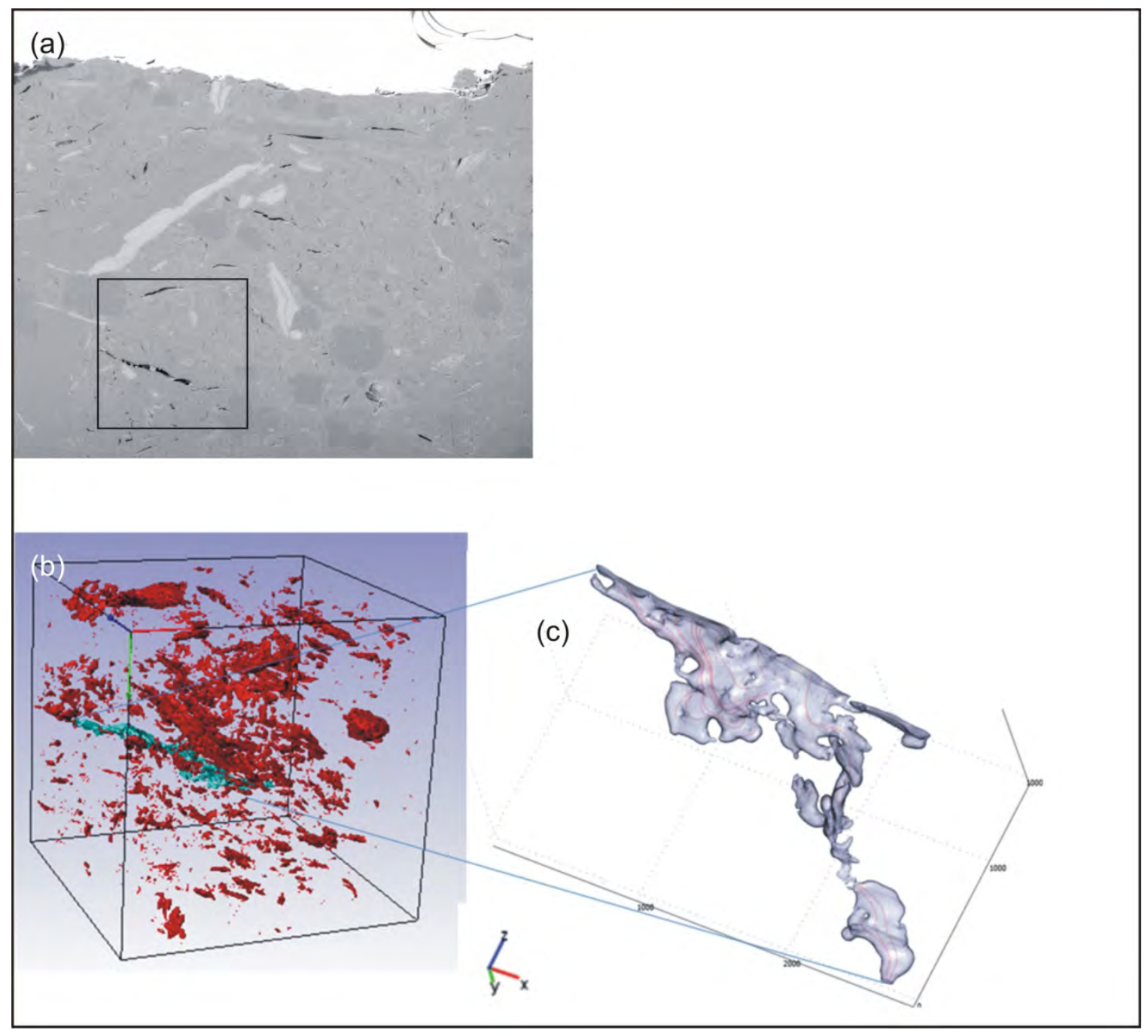

Figure 4. Results of focused ion beam/scanning electron microscopy and image analysis. (a) Backscattered electron image of a vertical surface of a trough milled in an upper Kirtland Formation sample. The horizontal field of view is $16 \mu \mathrm{m}$. Darkest areas are pore space. The inset box shows the location of the 3D pore model, show in part b. (b) 3D "flood-fill" rendering of pore space in red. Cyan pore was used in pore-scale modeling. (c) Image of pore used in porescale fluid modeling. The inlet location for flow modeling was at the bottom right hand-side of the model, and the outlet was at the upper left.

slit-like pores that often parallel clay mineral planar fabric. Figure $4 \mathrm{~b}$ shows a 3D pore network geometric model constructed from the sequence of images, of which Figure 4a is an example. To examine pore-scale hydraulic conductivity, we use this 3D pore network model (see Chapter 3 of Heath, 2010, for more details on this particular example from the upper Kirtland Formation and a sample from the lower Kirtland Formation).The red portions render pores in a cubic $101.5 \mu^{3}$ digital region at 15.6-nm voxel size (see Chapter 3 of Heath, 2010). Shown in blue is a single connected pore network (Figure 4c), which is expanded to the right of the figure. Note that the 
connected pore network consists of large flattened pores several $\mu \mathrm{m}$ in size separated by a small pore throat.

To determine single phase hydraulic conductivity of this pore network subset, we ran a 3D computational fluid dynamics simulation at low Reynolds number for this pore network using the COMSOL Multiphysics software. A small $\left(10^{-4} \mathrm{~Pa}\right)$ pressure gradient was imposed across the sample inlet and outlet, and hydraulic conductivity for the network was calculated by applying Darcy's law using the modeled pressure gradient and distance across the network. The calculated permeability for this pore network is approximately $1.0 \times 10^{-19} \mathrm{~m}^{2}$. TerraTek's Tight Rock Analysis Klinkenberg-corrected value for the upper member of the Kirtland Formation is $7.2 \times 10^{-20} \mathrm{~m}^{2}$, which suggests consistency among pore network and core conductivities.

We emphasize the limited nature of this conclusion as the modeling was very simple (e.g., ignoring the changing properties of water in the nm-sized pores) and does not account for heterogeneity beyond the few microns in the digital sample. Nonetheless, this result would suggest that core plug-scale matrix flow properties are representable by types of pore networks imaged in Figure 4b.

\section{CORE-SCALE MATRIX PROPERTIES}

\section{Mercury Intrusion Porosimetry Results and Sealing Efficiency}

Results of MIP measurements for eight samples, seven from the upper member of the Kirtland Formation and one from the lower member of the Kirtland Formation, are shown in Figure 5 as mercury saturation versus injection pressures. The sample for the lower Kirtland Formation (red curve) shows the highest injection pressures and thus has the potentially better sealing quality. The samples for the upper Kirtland Formation, including two directional core plugs, all show somewhat similar shapes and thus pore throat distributions except for the sample at $624.35 \mathrm{~m}$ (bgs) (green curve), which shows a bimodal distribution. Additional samples, which were taken from depths near to $624.35 \mathrm{~m}$ and analyzed for Chapters 3 and 4 of Heath (2010), also show similar bimodal distributions.

Sealing efficiencies in hydrocarbon systems are often cast as the column height of buoyant gas or oil that a sealing lithology can support prior to capillary intrusion. Equations used to convert threshold pressures from a mercury-air-rock system to a $\mathrm{CO}_{2}$-brinerock system are detailed by Dewhurst et al. (2002). Carbon dioxide column heights are calculated using:

$$
h_{\mathrm{CO} 2}=\frac{P_{t h}}{\left(\rho_{b}-\rho_{\mathrm{CO} 2}\right) g}
$$

and

$$
P_{b / C O 2}=P_{a / m} \frac{\left(\sigma_{b / C O 2} \cos \theta_{b / C O 2}\right)}{\left(\sigma_{a / m} \cos \theta_{a / m}\right)}
$$


where $h_{\mathrm{CO} 2}$ is the $\mathrm{CO}_{2}$ column height; $P_{t h}$ is the breakthrough pressure (i.e., the pressure at which the non-wetting phase forms a continuous filament across the sample; Chiquet et al., 2007a; Dewhurst et al., 2002); $\rho_{b}$ and $\rho_{\mathrm{CO} 2}$ are the density of seal formation water or brine (formation water and brine are used synonymously here) and $\mathrm{CO}_{2} ; g$ is the gravitational acceleration; $\mathrm{P}_{\mathrm{b} / \mathrm{CO} 2}$ and $\mathrm{P}_{\mathrm{a} / \mathrm{m}}$ are capillary pressure for brine- $\mathrm{CO}_{2}$-rock and air-mercury-rock systems, respectively; $\sigma_{\mathrm{b} / \mathrm{CO} 2}$ is interfacial tension for the brine- $\mathrm{CO}_{2}$ pair; and $\theta$ is the contact angle for the brine- $\mathrm{CO}_{2}$ rock or air-mercury-rock systems, as indicated by the subscripts.

Table 1 gives values of the parameters of Equations 1 and 2 used in this study. Estimates of interfacial tension values for the brine- $\mathrm{CO}_{2}$ system were obtained from Bachu and Bennion (2009) and Chiquet et al. (2007b) and assume hydrostatic pressure and a geothermal gradient of $25^{\circ} \mathrm{C} / \mathrm{km}$ (Table 1). Air-mercury(-rock) interfacial tension and contact angle were obtained from Pittman (1992). A range of brine- $\mathrm{CO}_{2}$ contact angle values was chosen after reviewing wettability experiments using quartz and mica by Chiquet et al. (2007).

(a)

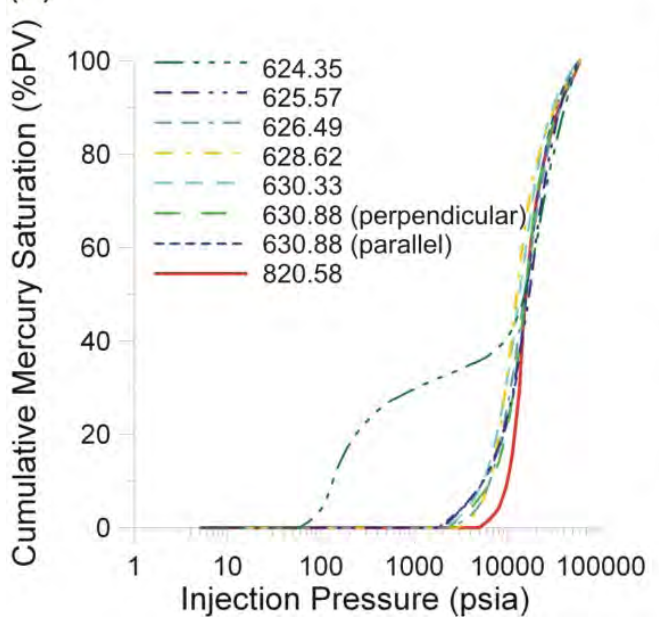

(b)

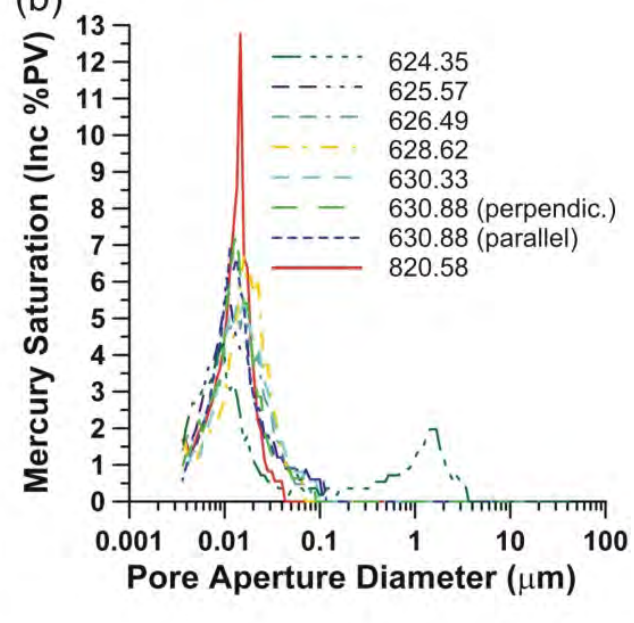

Figure 5. Mercury intrusion porosimetry data. (a) Cumulative mercury saturation versus pressure. (b) Incremental (inc) mercury saturation versus pore aperture diameter, based on data from (a) and the Washburn equation. Capillary pressure data were corrected for closure pressure (i.e., mercury that had not intruded the pore network was not included in the saturation curves). Depths of samples are given in $\mathrm{m}$ in the legend. "PV" stands for pore volume.

$\mathrm{CO}_{2}$ column heights that could be retained by the Kirtland Formation at various depths, calculated using Equations 1 and 2, the values from Table 1, and breakthrough pressure from the MIP data, range from a few tens of meters (for the upper Kirtland Formation sample at $624.35 \mathrm{~m}$ bgs) to a kilometer or more (for the lower Kirtland Formation sample at $820.6 \mathrm{~m} \mathrm{bgs}$ ) depending on the values of contact angle used (Figure 6). Thus, sealing capacity in terms of column heights is very high for the upper and lower Kirtland Formation. 
Table 1. Information used for calculations of $\mathrm{CO}_{2}$ column heights

\begin{tabular}{lr}
\hline Air-mercury interfacial tension $\left(\mathrm{N} \mathrm{m}^{-1}\right)$ & 0.481 \\
$\mathrm{CO}_{2}$-brine interfacial tension - upper Kirtland $\left(\mathrm{N} \mathrm{m}^{-1}\right)$ & 0.040 \\
$\mathrm{CO}_{2}$-brine interfacial tension - lower Kirtland $\left(\mathrm{N} \mathrm{m}^{-1}\right)$ & 0.031 \\
Density of brine - upper Kirtland $\left(\mathrm{kg} \mathrm{m}^{-3}\right)$ & 1030 \\
Density of brine - lower Kirtland $\left(\mathrm{kg} \mathrm{m}^{-3}\right)$ & 1030 \\
Density of $\mathrm{CO}_{2}$ - upper Kirtland $\left(\mathrm{kg} \mathrm{m}^{-3}\right)$ & 176 \\
Density of $\mathrm{CO}_{2}$ - lower Kirtland $\left(\mathrm{kg} \mathrm{m}^{-3}\right)$ & 338 \\
Air-mercury-rock contact angle & $140^{\circ}$ \\
$\mathrm{CO}_{2}$-brine-rock contact angle - low value & $40^{\circ}$ \\
$\mathrm{CO}_{2}$-brine-rock contact angle - high value & $60^{\circ}$ \\
Temperature - upper Kirtland & $27^{\circ} \mathrm{C}$ \\
Temperature - lower Kirtland & $32^{\circ} \mathrm{C}$ \\
\hline
\end{tabular}

Note: Brine (i.e., formation water) density for the Kirtland Formation is unknown at this time and the value above was assumed.

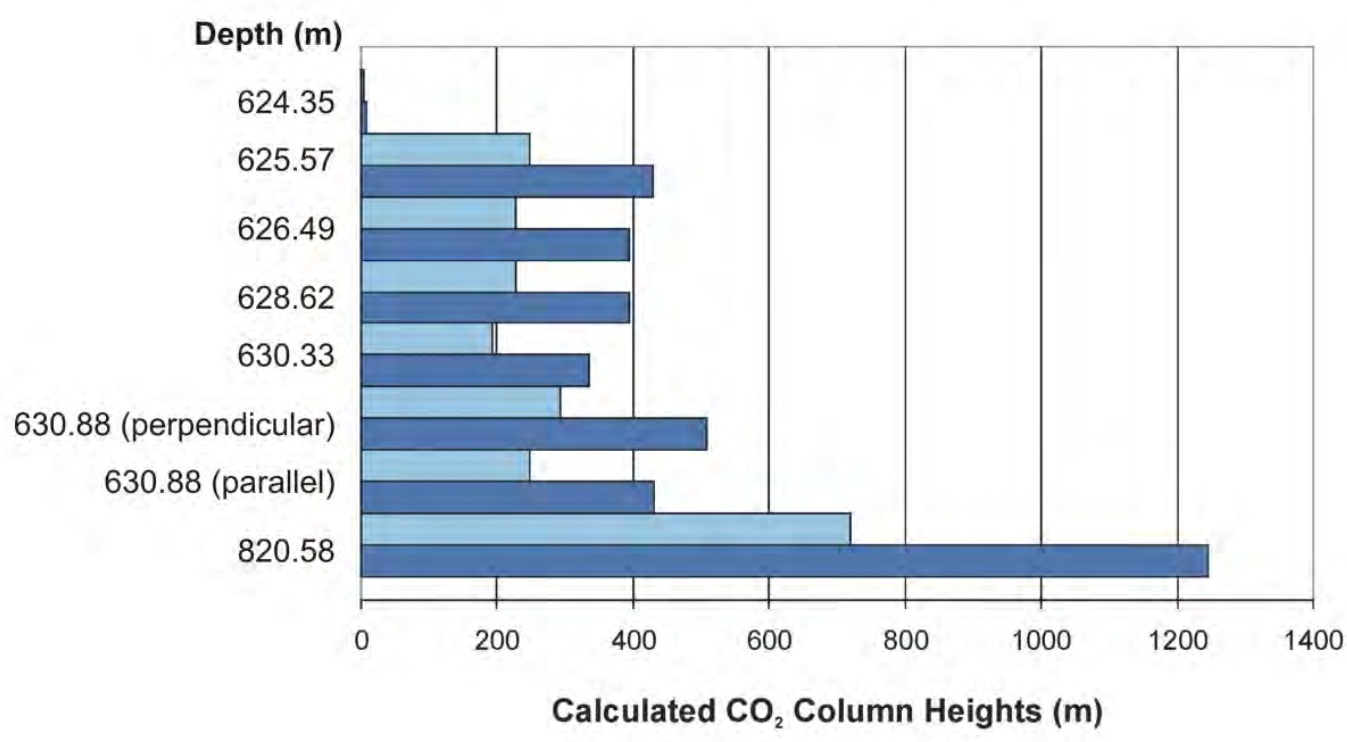

Figure 6. $\mathrm{CO}_{2}$ column heights plotted by depth for the upper and lower Kirtland Formation. The two columns per depth (in different colors) correspond to the two values of contact angles given in Table 1.

\section{Petrography, Petrophysical Properties, and Geologic Characterizations}

Representative optical, LSCM, and SEM photomicrographs from upper and lower Kirtland Formation samples are summarized by Figures $7 \mathrm{a}-\mathrm{c}$ and $8 \mathrm{a}-\mathrm{c}$. MIP pore aperture size 
distributions are given in Figures $7 \mathrm{~d}$ and $8 \mathrm{~d}$. The optical photomicrographs show that upper Kirtland Formation samples are classified as argillaceous mudstones or sandy argillaceous mudstones based on the matrix-supported texture and matrix composition. Samples from the lower shale member of the Kirtland Formation were argillaceous or silty argillaceous mudstones based on the same criteria. In thin section, "mottled" colors along with apparent root material and illuviation structures suggest soil formation at several horizons as was seen in hand-sample descriptions of the core. Silt- to sand-sized grains are quartz, alkali feldspar, some plagioclase, and volcanic rock fragments. Some micas, including biotite, are seen as depositional flakes. Authigenic mineralogy observable in thin section is dominated by quartz cement and overgrowths, replacing portions of volcanic rock fragments and lithic grains. Results of XRD analysis, although not shown, indicate that the Kirtland samples have very little carbonate cement ranging from 0 to 3\% (by weight) at most, although what calcite and dolomite does exist is ferroan in composition. XRD clay mineral fractions in the upper Kirtland are dominated by smectite and illite or mica, while the lower Kirtland Formation is dominated by illite-smectite mixed-layered clays. The abundance of these clay types as matrix material induces a roughly 15$40 \%$ expandability to the mudstones. There is also significant iron-bearing chlorite in both upper and lower Kirtland samples. The SEM photomicrographs show pedogenic (soil forming) illuviation textures (Figure 7c) as well as expandable clay fabric with moderate lamination (Figure 8c).

LSCM imaging of pores impregnated with fluorescing epoxy are shown in Figures $7 \mathrm{~b}$ and $8 \mathrm{~b}$. Porosity is shown in green. Figure 7c shows much more interconnected porosity in the upper versus lower shale member of Kirtland Formation in Figure 8c. All LSCM images show a planar pore fabric as well as microfractures oriented subparallel to bedding. (The "up" or younging direction in the LSCM images is towards the top of the page of the figures.) Much of this porosity is probably enhanced by unloading and/or clay mineral desiccation after coring. Such induced porosity is inferred from the lack of mineral fill, slickenlines, illuviated clays, or plume structures that would indicate natural fractures (as seen in hand sample). Illuviation textures may represent primary porosity. (An example of this is seen in the sub-vertical structure in upper left corner of Figure 7b, left panel.) The interconnectedness and spatial extent of these features likely do not represent much interconnected porosity on length scales larger than thin section.

Petrographic analysis reveals several pore types in the samples, with the most dramatic likely reflecting unloading and dehydration processes, as discussed above. Induced porosity ( 0.005 to $0.02 \mathrm{~mm} ; 5$ to 20 microns) is the most pervasive pore type in the samples and is typical of rocks with significant amounts of expandable clays. Induced pores are not present in situ and may introduce error in porosity and permeability measurements. A second pore type in the Kirtland Formation is due to decay of organic material associated with root and organic particle casts ( 0.002 to $0.02 \mathrm{~mm} ; 2$ to 20 microns), observed both in thin section and SEM results. This pore type is associated with well-aligned clays and probably does not contribute to interconnected effective porosity on length scales of interest for subsurface carbon storage. The 

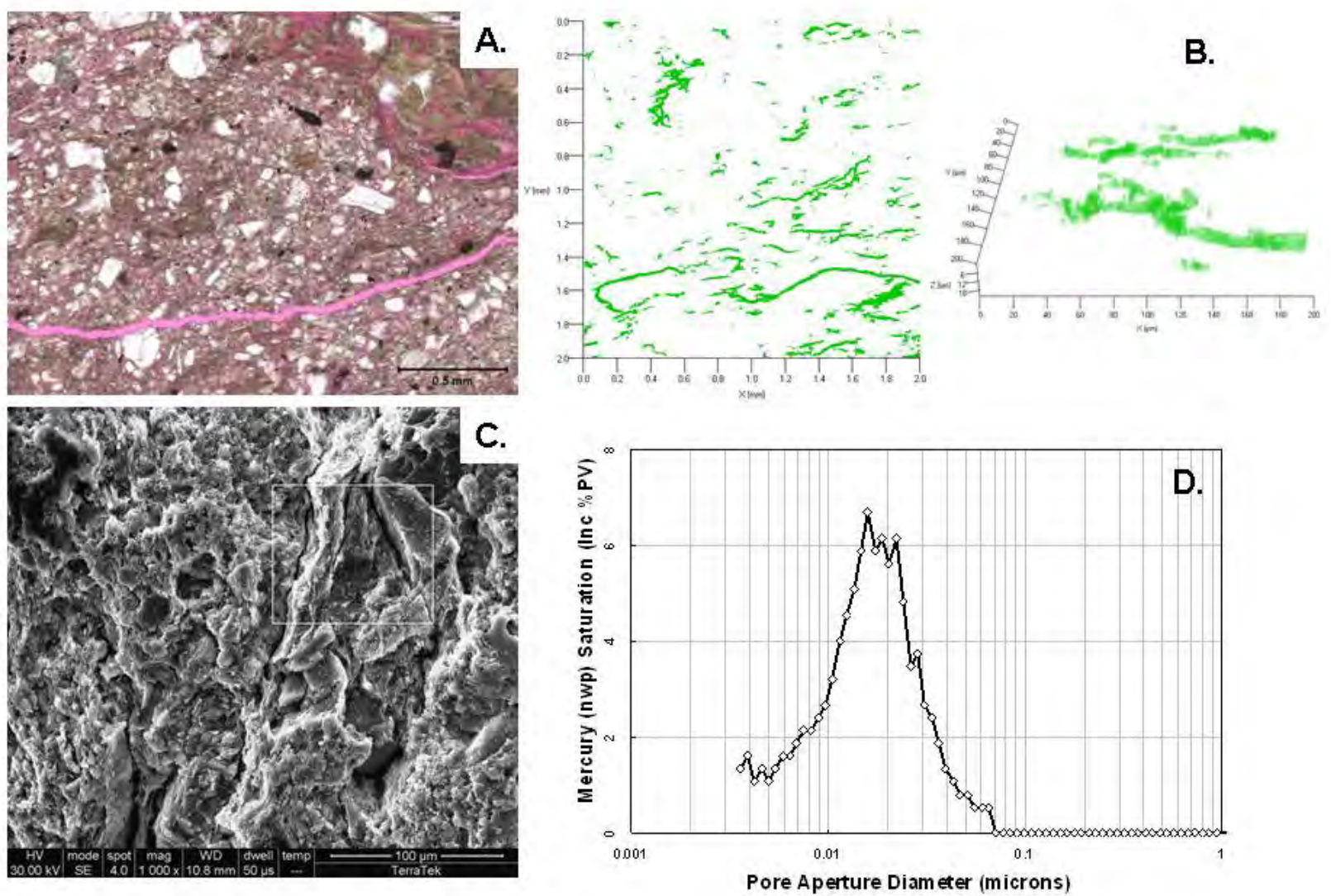

Figure 7. Upper Kirtland photomicrographs and pore size distribution from mercury intrusion porosimetry (MIP) measurements. (a) Optical plane-polarized light photomicrograph of sandy argillaceous mudstone from the unstained portion of slide from depth $628.59 \mathrm{~m}$ (see Appendix B.2). The scale bar is $0.5 \mathrm{~mm}$. Information from TerraTek states that "Sharp feldspar, quartz, and rounded chert-replaced volcanic clasts are supported by a mixed smectitic matrix. Induced fractures are pervasive, as represented by the magenta lines (stained epoxy). The fabric exhibits blocky ped structure, especially when viewed under cross-polarized light, and the aligned, curved illite material at upper right is likely a result of illuviation." (b) LSCM image of $2.0 \mathrm{~mm}$ by $2.0 \mathrm{~mm}$ by 50 micron (left) and 200 by 200 by 15 micron (right) portions of an upper Kirtland sample, showing interconnected fractures and matrix porosity, likely induced from coring, unloading, and dehydration. (c) SEM image with a scale bar of 100 microns (see Appendix B.2). TerraTek's information on this photomicrography is the following: "Medium magnification view of sandy argillaceous mudstone with poorly laminated and mottled, irregular texture. Angular to subangular quartz and feldspar sand are scattered throughout the clay matrix, showing approximately vertical microfractures filled with illuvium. Spot EDS analysis identifies the dark grains at upper right and center right edge as alkaline feldspars." The boxed area denotes an illuviation (soil-forming) texture. (d) Pore aperture size distribution of matrix determined by MIP analysis. 

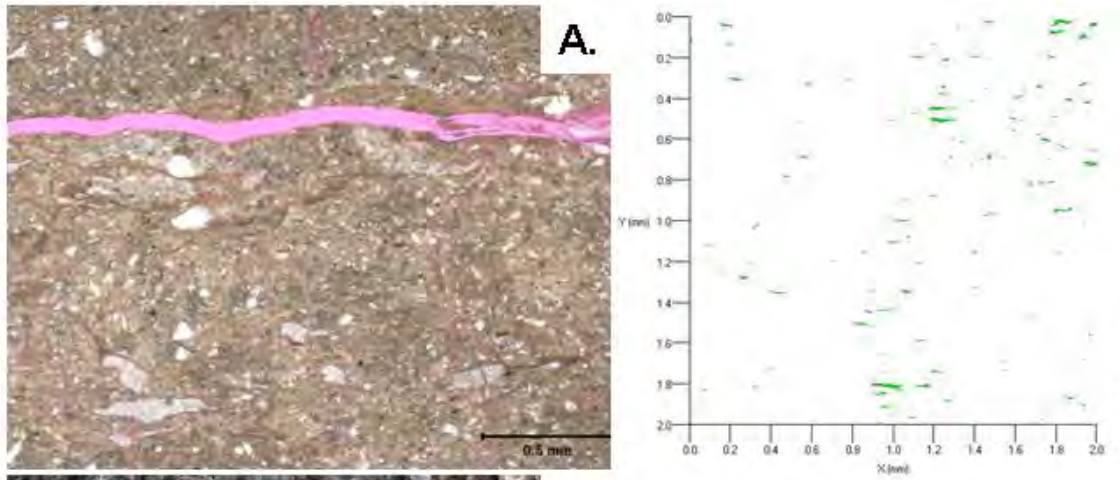

B.
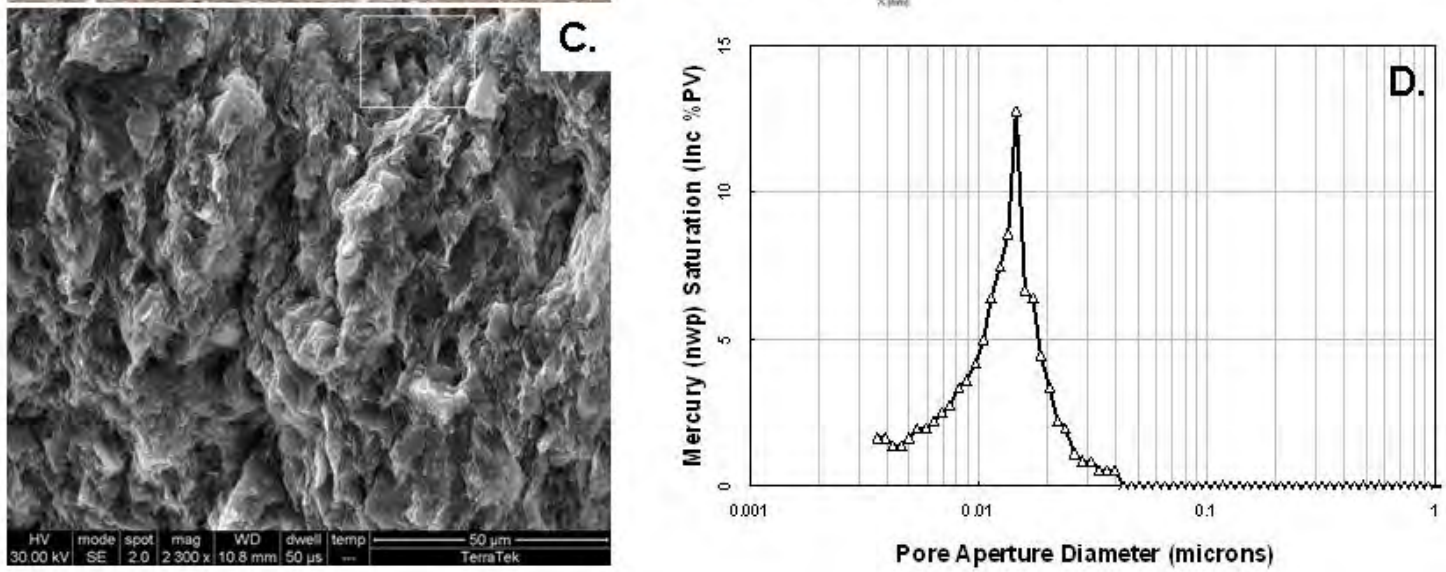

Figure 8. Lower Kirtland photomicrographs and pore size distribution from MICP measurements. (a) Optical plane-polarized light photomicrograph of an argillaceous mudstone from the unstained portion of slide from depth $820.60 \mathrm{~m}$ (see Appendix B.2). The scale bar is 0.5 $\mathrm{mm}$. TerraTek's information on this photomicrograph is the following: "Argillaceous mudstone at lower magnification exhibits scattered silt and sand in a mixed clay matrix, with expandable $\mathrm{I} / \mathrm{S}$ and chlorite as the predominant clay species (XRD). The crystals with cross-hatched cleavage in the lower part of the image are ferroan calcite (unstained). The horizontal fracture (magenta) is interpreted as an induced, stress-release or dehydration feature." (b) LSCM image of $2.0 \mathrm{~mm}$ by $2.0 \mathrm{~mm}$ by 50 micron (left) and 200 by 200 by 15 micron (right) portions of lower Kirtland sample, showing relative lack of interconnected fractures and matrix porosity seen in the upper Kirtland (compare Figure 7b). (c) SEM image of argillaceous mudstone with a scale bar of 50 microns that displays, according to TerraTek, "moderate lamination parallel to bedding, near vertical in this image. Scattered silt and sand are supported in a lumpy, clay-rich matrix. An example of a large pore is seen in the boxed area at upper right" (see Appendix B.2). (d) Pore aperture size distribution of matrix determined by mercury injection capillary pressure analysis.

third type is the matrix-hosted intercrystalline microporosity $(<0.005 \mathrm{~mm})$ and is the in situ porosity in typical mudstones. This microporosity is found between clay particles and cements, as seen in Figure 4a. MIP analysis suggests that pore apertures associated with microporosity are log-normally distributed with modal size at approximately $0.015 \mu \mathrm{m}$. Some are visible at the highest resolution in LSCM. The pores are tiny and poorly connected. In the case of expandable clays, due to dehydration, the microporosity visible under SEM is a maximum size. At in situ 
conditions, the microporosity will probably be even smaller or absent. Chapter 3 of Heath (2010) discusses pore volume and pore throat size distributions in detail, and shows a power-law character to the matrix porosity as determined from MIP that closely matches the power law distribution of pore types determined by FIB/SEM and shown in Figure 5.

\section{FRACTURE CHARACTERISTICS FROM FMI LOGS AND CORE}

The presence of several mineralized and open fracture types, as described below, leads to the question of seal bypass associated with flow along potentially-connected fracture sets. While Kirtland Formation matrix properties indicate good sealing potential, as described above, the fracture sets may represent potential leakage pathways.

Fracture data from interpreted FMI logs and core examination are given in Figure 9a-b. The first column indicates lithology, the second column contains dip magnitude of fractures measured from core (left side of column is $0^{\circ}$ and right side is $90^{\circ}$ ), the third column includes location of core collection, and the fourth column details fractures from FMI-log interpretations, including orientation information by "tadpoles", which indicate dip azimuth (i.e., the direction of bearing that is perpendicular to the strike of a fracture or planar feature).

Open, healed, and partially-healed interpreted fractures were more dominant in the lower Kirtland Formation member than the upper member (Figure 9a-b). Petal or other induced fractures (Lorenz and Hill, 1992) that would provide information on in situ stress orientations were not identified. In both the upper and lower Kirtland Formation, pervasive induced fractures were prevalent as disc fractures (i.e., orientation was $\sim$ perpendicular to core axis) and desiccation fractures - such fractures being common in core with abundant expandable clays.

In the upper member of the Kirtland Formation, several mineralized fractures were found in the core within the depth range of $625.8 \mathrm{~m}$ to $627 \mathrm{~m}$ (2053 to $2057 \mathrm{ft}$; depths from Kelly Bushing) (Figures 9 and 10). Fracture mineralization includes apatite, calcite, barite, and quartz, as identified via energy-dispersive X-ray spectroscopy (EDS) elemental mapping (Figure 10). Cross-cutting relationships seen in microscopic analysis of thin sections indicates that some calcite-filled fractures cut apatite-filled fractures. The apatite-filled fractures existed prior to the formation of the calcite-filled fractures. These calcite-filled fractures are cut by barite- and quartz-filled fractures (Figure 10). In EDS images (Figure 10), caries texture (i.e., "bite-like" or irregular curved boundaries) is at the interface between quartz (the guest mineral) and barite (the host mineral). Relics of barite and calcite occur within the quartz mineralization, which indicate that quartz has followed the calcite and barite, either during direct replacement or following prior dissolution of barite and calcite at the margins of the fractures. Thus, these fractures indicate multiple episodes of fluid flow by different types of fluids. The fluid flow and mineralization probably occurred at different depths of burial and, since the orientation of the fractures are not all the same, at different stress states. The lower member of the Kirtland Formation contains calcite-filled fractures that do not show quartz at the fracture margins. The history of fluid for the lower member of the Kirtland Formation is different than that of the upper member.

A burial curve reconstruction determined from the thermal modeling of Law (1992) is shown in Figure 11 for the boundary between the lower member of the Kirtland Formation and the Fruitland Formation. Annotation on this figure summarizes relevant hydrogeological, diagenetic, and tectonic events that have shaped fracture development and mineral infill. Fracture 


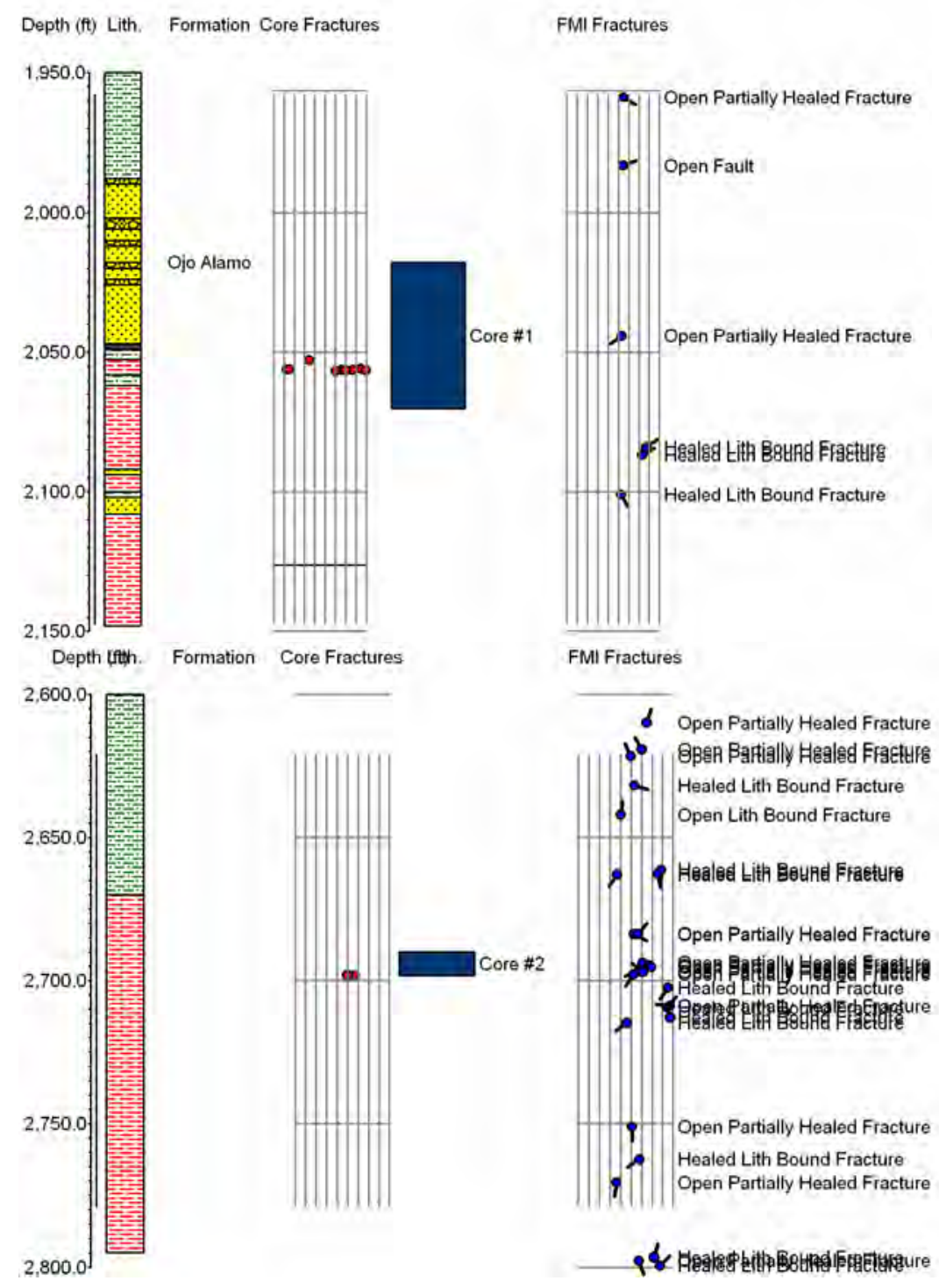

Figure 9. Lithologic and fracture data from core examination and formation microresistivity imaging (FMI) well log interpretation for the upper (the upper panel) and lower members of the Kirtland Formation (the lower panel). The first column from the left for each panel is the mud $\log$ and core-based lithology (see Appendix E for the legend of the lithologic symbols). The second column shows locations of mineralized fractures identified in core. The third column shows the location of core collection. The last column indicates fractures from the FMI log. The FMI fractures are organized by type. The azimuthal dip direction of FMI fractures is given by the "tadpoles." Dip magnitude for both core (column two) and FMI fractures (column four) is given by the placement of the red circles or tadpoles from left to right. Far left is $0^{\circ}$. Far right is $90^{\circ}$. Fracture type labels are given to the right of the tadpoles (labels overlap when multiple fractures occur in close vicinity to each other). 


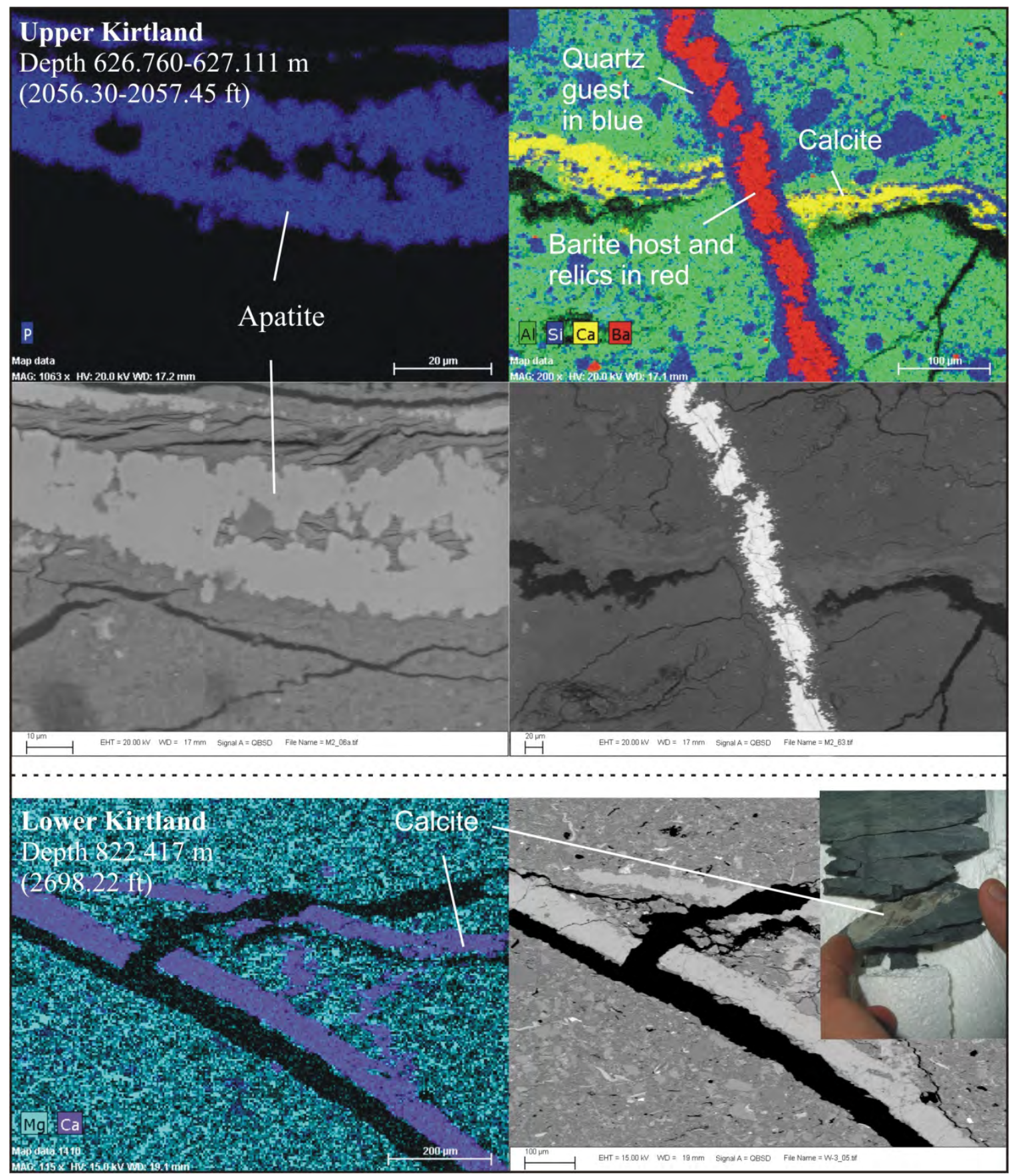

Figure 10. Montage of fractured-related images for rock samples from the upper and lower members of the Kirtland Formation. Images include the following: backscattered electron images (i.e., grayscale images), energy-dispersive X-ray spectroscopy elemental maps (i.e., color images with legends for mapped elements), and a hand sample photograph of slabbed core that shows a fracture with mineralization. The younging direction is towards the top of the photomicrographs. The photomicrograph in the upper right hand corner shows a clear cross-cutting relationship between a calcite/quartz-filled fracture and a barite/quartz-filled fracture. 


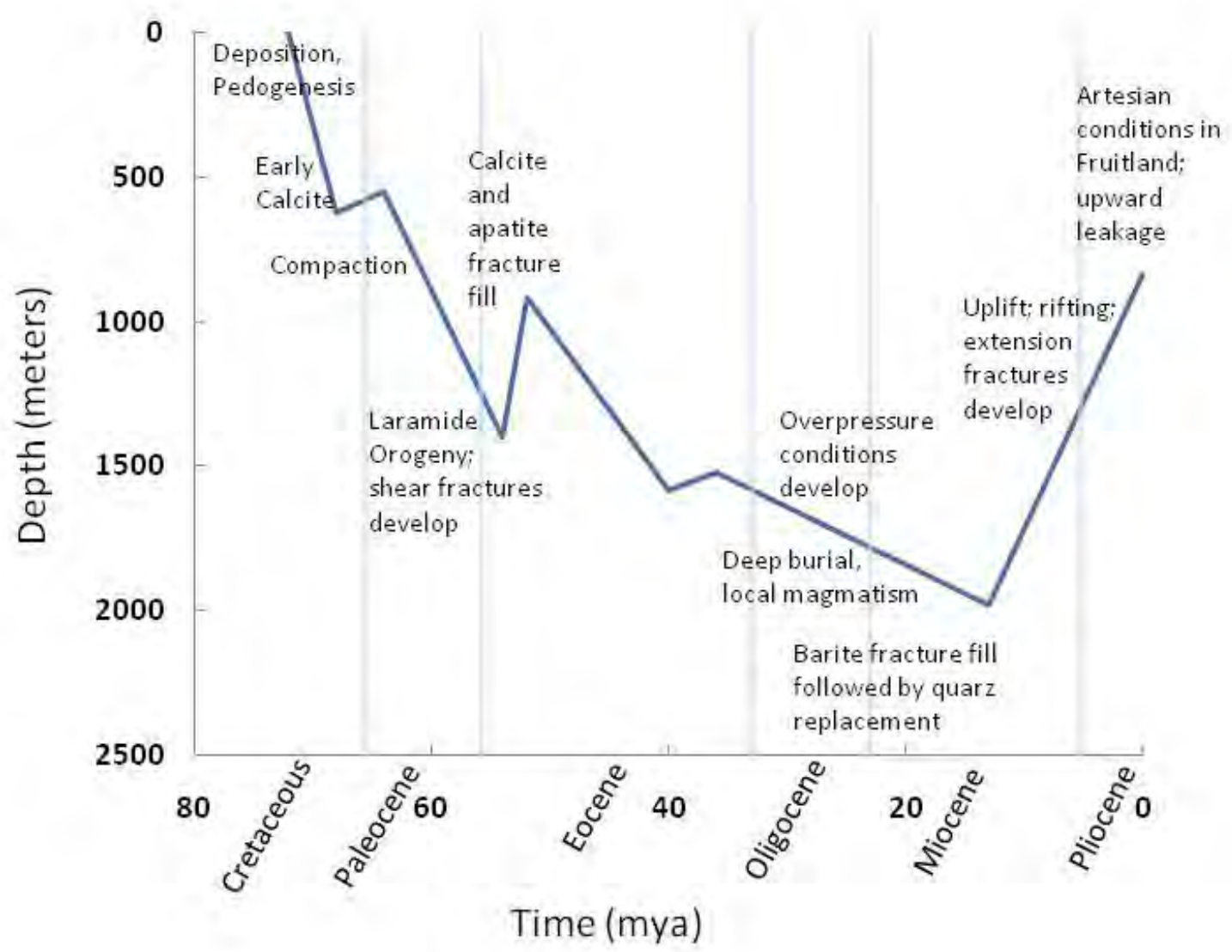

Figure 11. Burial history, annotated with paragenesis of fracture mineralization and tectonic and hydrologic information (modified from Law, 1992).

types observed in this study include: 1) those formed early in the history of the sediments by pedogenic (i.e., soil forming) processes; 2) compactional/dewatering fractures that can be related to soft-sediment deformation and are not typically greatly influenced (in terms of orientation) by tectonic stresses (these fractures can be prevalent in low-permeability sediments/rocks); and 3) fractures formed by tectonic processes. The latter include shear fractures with orientations consistent with Laramide stress states and a fracture-formation model discussed by Lorenz and Cooper (2003). These are mineralized by calcite and apatite and contain microstructures with shear-sense indicators. These also show later offset by barite and quartz mineralized fractures, which are largely mode I extensive fractures.

We hypothesize that quartz from barite mineralization in the upper member of the Kirtland Formation may indicate fluid flow from as deep as the Fruitland Formation through the entire seal, during the deepest portions of burial in the Oligocene, when thermal gradients were highest in the San Juan Basin (Law, 1992). This hypothesis could be tested by isotopic analysis of the barite and calcite fracture filling (i.e., sulfur, carbon, and oxygen isotopes) to determine if the fluids in the upper Kirtland were sourced from the Fruitland. Barite fracture-fills might have arisen from upward migration of reducing barium-sulfide fluids and subsequent oxidation and barite deposition. 
The fracture mineralization indicates that fluid have been transmitted through parts of the Kirtland Formation in the past. However, these fracture descriptions are nonconclusive with regard to large-scale transport through the entire Kirtland Formation. To address the hypothesis that the observed fracture sets will act as seal bypass systems for subsurface $\mathrm{CO}_{2}$ storage, we now turn to noble gas tracer analysis as a means to estimate large-scale conductivities.

\section{FORMATION-SCALE NOBLE GAS RESULTS AND CROSS-SEAL TRANSPORT}

\section{Helium and Neon Concentration Profiles}

Results from noble gas concentration analysis are presented first, followed by brief discussion of general observations. We discuss ${ }^{20} \mathrm{Ne}$ concentrations first because they indicate interaction between the groundwater and a separate phase (i.e., methane). We then present and discuss conceptual and quantitative models to evaluate ${ }^{4} \mathrm{He}$ transport and the existence of a seal bypass system that may be present due to the fractures observed in core and by the FMI logging (see Section Fracture Characteristics from FMI Logs and Core).

For the samples taken at different depths, Figures 12 and 13 present the measured ${ }^{20} \mathrm{Ne}$, ${ }^{4} \mathrm{He}$, and ${ }^{3} \mathrm{He}$ concentrations and the ratios of ${ }^{3} \mathrm{He} /{ }^{4} \mathrm{He},{ }^{4} \mathrm{He} /{ }^{20} \mathrm{Ne}$, and ${ }^{3} \mathrm{He} /{ }^{20} \mathrm{Ne}$. These data are based on the combined amount of helium and neon from the two analysis runs. The concentrations are given as $\mathrm{cm}^{3}$ of neon or helium at standard temperature and pressure (STP) per $\mathrm{cm}^{3}$ of pore volume (i.e., the volume of the pore/void space). Because laboratory analysis on fresh core indicated gas saturations (see Appendix B.6), we present the concentrations using pore volume as opposed to typical methods of presenting concentrations per gram of groundwater for systems that are fully saturated by groundwater. We do not a priori assume that the samples were fully saturated with groundwater at depth. The figures also present the ratios of the two separate laboratory analysis runs of helium and neon.

Ratios of the two separate analysis runs (first columns in Figures 12 and 13), for helium and neon, indicate that most samples degassed significantly into the preservation canisters after the second run (values closer to zero indicate greater degassing). However, two samples show incomplete degassing for helium (values $>2 \%$; Figure 12), and one shows incomplete degassing for neon (value $>2 \%$; Figure 12). Thus, in our interpretations below, we use the data that show incomplete degassing with caution. (Note that by "degassing" we mean the quantitative release of the helium and neon into the canisters prior to analysis. In the discussion below, we use "degassing" in the sense of a noble gas partitioning process due to interaction between groundwater and a separate fluid phase.)

For all except one sample, the measured ${ }^{20} \mathrm{Ne}$ concentrations are lower than estimates of ASW concentrations, the atmospheric solubility equilibrium concentrations (indicated by blue lines on the second column of Figure 12). Typically, waters recharging a groundwater system have ${ }^{20} \mathrm{Ne}$ concentrations that reflect conditions at the recharge area (see Subsection Noble Gas Analyses in the Methods and Materials section), such as temperature, pressure, salinity, and the fluctuations in water table elevation that can trap and result in dissolution of air bubbles (i.e., the processes that produce "excess air"; Kipfer, 2002). Neon-20 typically does not have a source in 


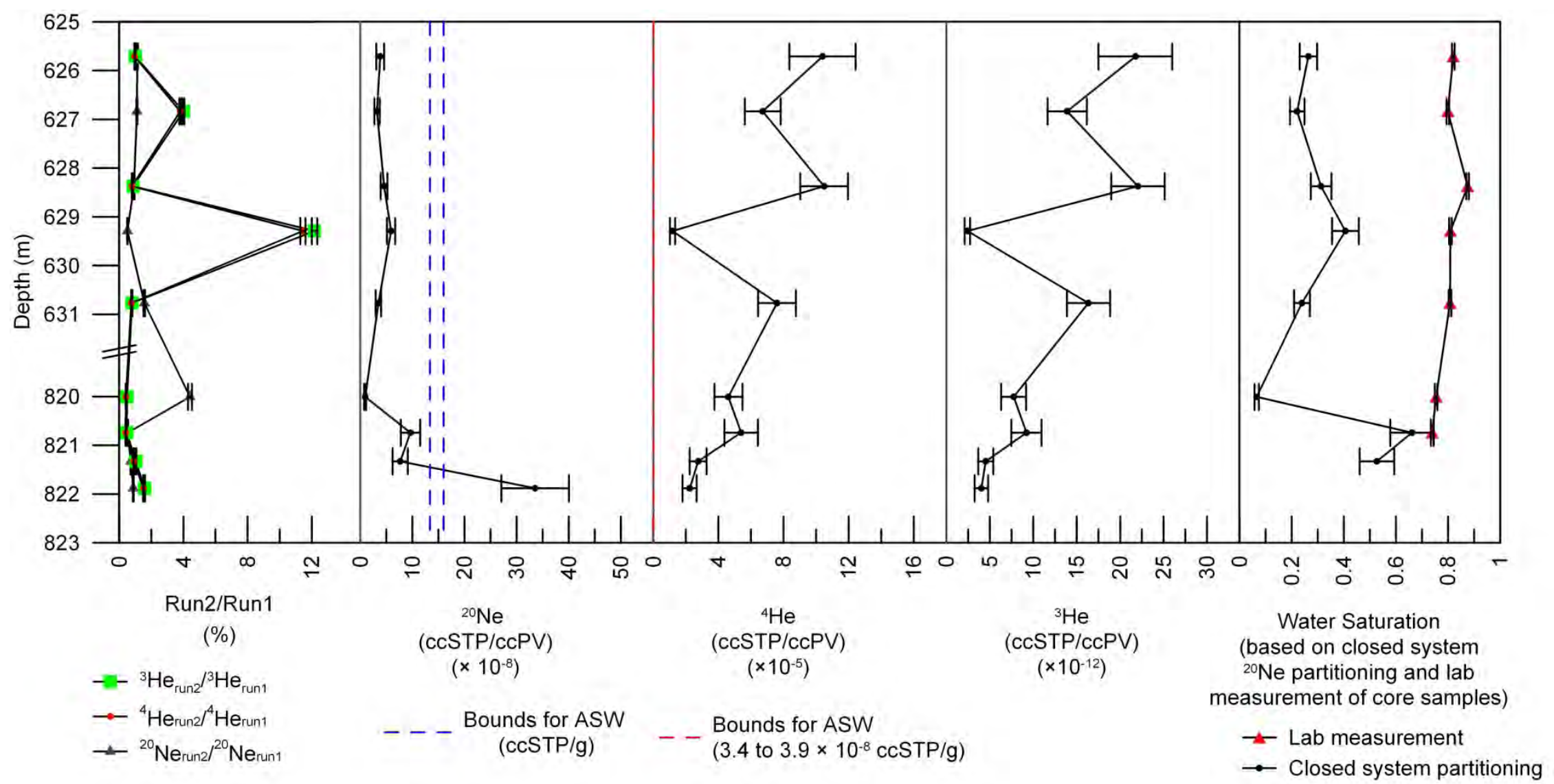

Figure 12. Depth profiles of noble gas concentrations and water saturations. Laboratory analysis Runs 1 and 2 were performed in September 2008 and March 2009, respectively. "ccSTP" is $\mathrm{cm}^{3}$ of helium or neon at standard temperature and pressure. "ccPV" stands for pore volume in $\mathrm{cm}^{3}$. "ASW" is "air saturated water" and has units of ccSTP of ${ }^{20} \mathrm{Ne}$ or ${ }^{4} \mathrm{He}$ per gram of groundwater. Water saturations include those from calculations of closed system partitioning and the laboratory measured values of TerraTek (see Appendix B.6). The closed system partitioning estimated water saturations needed to match the difference between measured and expected $\mathrm{ASW}{ }^{20} \mathrm{Ne}$ concentrations. Error bars are based on uncertainty in pore volume and laboratory analysis, using error propagation methods. 


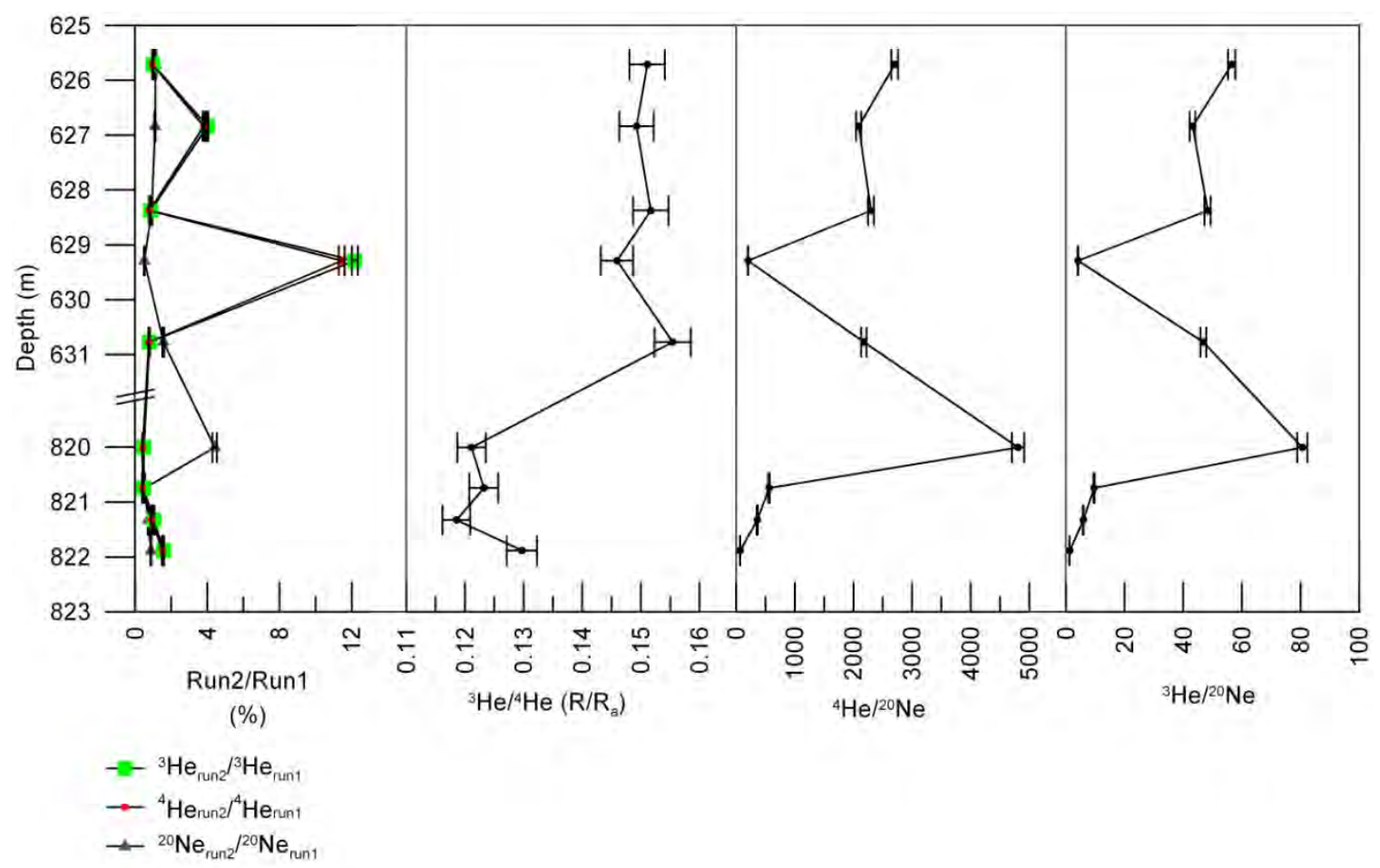

Figure 13. Depth profiles of noble gas ratio data. $\mathrm{R}=$ measured ${ }^{3} \mathrm{He} /{ }^{4} \mathrm{He} \cdot \mathrm{R}_{\mathrm{a}}=$ atmospheric ${ }^{3} \mathrm{He} /{ }^{4} \mathrm{He}\left(1.384 \times 10^{-6}\right.$; Kipfer et al., 2002). Error bars are based on uncertainty in laboratory analysis.

the subsurface in sedimentary basins that would increase the ASW concentration from that imparted at the recharge area. The units of ${ }^{20} \mathrm{Ne}$ concentration of ASW are $\mathrm{cm}^{3}$ STP per gram of groundwater. These units are equivalent to those of the measured ${ }^{20} \mathrm{Ne}$ values, which are concentration per pore volume, if one assumes that the one gram of water equals $1 \mathrm{~cm}^{3}$. Thus, the comparison of measured ${ }^{20} \mathrm{Ne}$ and those of the ASW concentrations indicates a degassing/partitioning process that decreased the measured ${ }^{20} \mathrm{Ne}$ below their expected ASW concentrations.

Processes that may have decreased the measured ${ }^{20} \mathrm{Ne}$ from the ASW concentrations include both in situ and sampling-related possibilities. Noble gases will partition between groundwater and a separate fluid phase (or phases) that are in contact (Ballentine et al., 2002). In situ partitioning requires the presence of a separate phase (e.g., methane or oil) at depth. Sampling-related partitioning would require the development of a separate phase (e.g., methane) from the groundwater due to pressure release after drilling/coring and prior to sealing of the samples in the preservation canisters. Such a separate phase, if generated, may have been extracted during the purge-and-pumpdown procedure that removed gases from the canisters (see Appendix A). Analysis by TerraTek on fresh core (see Appendix B.6) indicates gas saturations (i.e., "saturation" here meaning that part of the pore space is filled with a separate phase in addition to groundwater) that range from $\sim 11$ to $\sim 24 \%$. In contrast, the ELAN well log (Schlumberger's Elemental Analysis on wireline logs) (Figure 14) indicates no separate-phase gas saturations at the depths where core plugs were taken except for one plug (at the depth of $\sim 626.8 \mathrm{~m}$ ). Note that gas saturations are indicated (usually within quartz- and sandstone-rich 
Figure 14. Interpretation of well logs in terms of mineral phases and fluid phases (Schlumberger's ELAN log) for the Ojo Alamo Sandstone and the upper member of the Kirtland Formation. Upper contacts of the geologic units are labeled. The ELAN log does not indicate gas saturations at the depths of the core plugs within the lower member of the Kirtland Formation (not shown). 


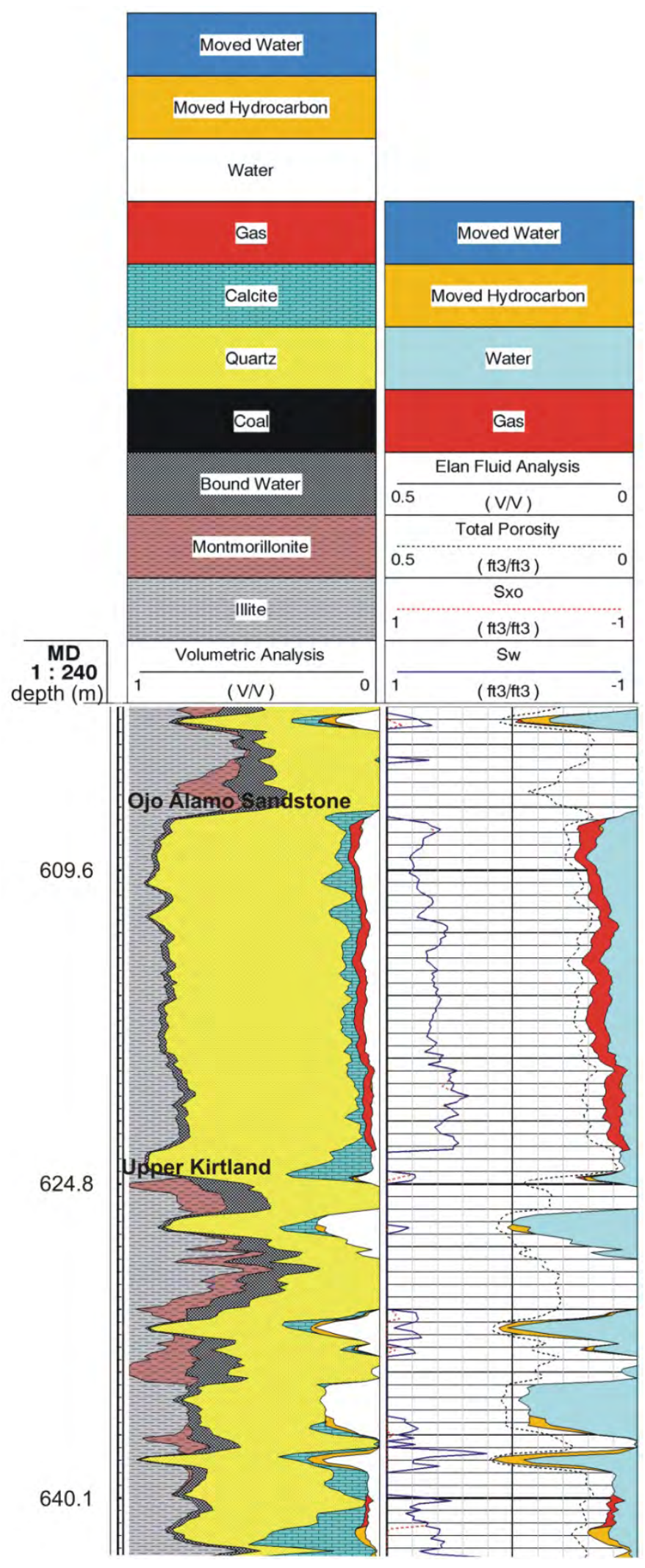


interbeds) in the Ojo Alamo Sandstone and at various depths within the upper and lower members of the Kirtland Formation, the Farmington Sandstone Member, and the Fruitland Formation. The ELAN well log supports the assumption that all but one of the core plugs were fully saturated by groundwater. We suggest that the core, in general, may have degassed after sampling to produce the saturations measured by TerraTek (see Appendix B.6). The mud log (see Appendix E) indicates methane was present within the Kirtland Formation. Considering both the mud log and the ELAN log, some dissolved or sorbed methane is likely at the depth of the core plugs.

We are still left with the possibilities that: 1) desorbing or exsolving methane due to pressure release after drilling/coring may have produced a methane phase into which ${ }^{20} \mathrm{Ne}$ may have partitioned and then was lost during the purge-and-pumpdown process; 2) groundwater within the upper and lower members of the Kirtland Formation that is (or was in the past) in contact with methane within the Ojo Alamo Sandstone and Kirtland Formation caused in situ partitioning; and 3) some combination of the first two possibilities occurred. For the upper member of the Kirtland Formation, differences in the amount of plug material and in pore structure amongst the samples probably would have caused variation in the degassing/release of the methane and stripping of ${ }^{20} \mathrm{Ne}$ prior to sealing of the plugs in the canisters. However, the concentrations are similar to each other. Hence, we suggest that the uniformity of the measured ${ }^{20} \mathrm{Ne}$ concentrations support in situ degassing as the dominant degassing mechanism that affected the upper member of the Kirtland Formation core plugs.

The ${ }^{4} \mathrm{He} /{ }^{20} \mathrm{Ne}$ values of the upper member of the Kirtland Formation range from 2177, $202,2300,2087$, to 2702 , respectively, from the lowest to highest depths (note that the sample with the value of 202 had not fully degassed into the canister in the sense of quantitative release measured by Run2/Run1; see Figure 13). The ${ }^{4} \mathrm{He} /{ }^{20} \mathrm{Ne}$ ratio calculated for ASW is $\sim 0.25$ (based on equations in Kipfer et al., 2002). Thus, the atmospheric contribution of ${ }^{4} \mathrm{He}$ to the upper Kirtland Formation samples is negligible.

The ${ }^{20} \mathrm{Ne}$ concentrations of the lower member of the Kirtland Formation (Figure 12) are not uniform and more difficult to assess. Possible explanations include little to no in situ or sampling-related degassing and/or some degree of atmospheric contamination in the preservation canisters. The ${ }^{20} \mathrm{Ne}$ values range from lower-than-ASW to higher-than-ASW concentrations (see depths of $\sim 820$ to $822 \mathrm{~m}$ on Figure 12). The ${ }^{4} \mathrm{He} /{ }^{20} \mathrm{Ne}$ values for the lower Kirtland Formation are approximately $12,67,359,557$, and 4807 , respectively, from the lowest to the highest sample depth (see Figure 13; note that sample at depth $820 \mathrm{~m}$ has a relatively large Run2/Run1 ratio, indicating that a relatively large percentage of ${ }^{20} \mathrm{Ne}$ is still left in the sample). The trend of higher ${ }^{20} \mathrm{Ne}$ concentration with lower ${ }^{4} \mathrm{He} /{ }^{20} \mathrm{Ne}$ may indicate input of atmospheric ${ }^{20} \mathrm{Ne}$ due to contamination during the sample preservation procedure since ASW has a ${ }^{4} \mathrm{He} /{ }^{20} \mathrm{Ne}$ value of $\sim 0.25$. The same purge-and-pumpdown procedure was used for upper and lower Kirtland Formation samples, but with different vacuum pumps (the pump used for the upper Kirtland Formation failed at the beginning of acquiring samples from the lower Kirtland Formation). Field measurements of pressure within the canisters during pumpdown were similar, however, for both vacuum pumps. Thus, we suggest atmospheric contamination as a reason of the relative increase in ${ }^{20} \mathrm{Ne}$ of lower Kirtland Formation samples or less in situ degassing than the upper Kirtland Formation samples. Other noble gas data (e.g., Ar, Kr, and Xn) not collected could have further constrained possible sources of atmospheric contamination or in situ degassing processes (Lippmann et al., 2003). 
In situ degassing can occur via multiple processes: 1) closed system equilibrium partitioning of the noble gases between groundwater and a separate phase (e.g., methane or oil) (Lippmann et al., 2003); 2) diffusive degassing in a non-equilibrium state (i.e., rapid degassing without reaching equilibrium); and 3) local equilibrium in an open system (Rayleigh degassing process).

To evaluate Process 1, closed system equilibrium partitioning, we use a simple massbalance approach (after Ballentine et al., 2002) to estimate the volumes of liquid and separate phase gas needed to partition the expected ASW ${ }^{20} \mathrm{Ne}$ to match the measured ${ }^{20} \mathrm{Ne}$ concentration. Relevant assumptions for pressure and temperature conditions at depth were used to estimate Henry coefficients. Results shown in Figure 12 (last column) present the calculated volume of liquid-to-gas ratios, expressed as water saturations. These water saturations fall within the range of values seen on the ELAN well log for the Ojo Alamo Sandstone, which vary from 0.14 to 0.74 (as calculated from the ELAN data of total porosity and volumetric water content). Figure 12 also presents the water saturations measured by TerraTek (see Appendix B.6). The close system equilibrium calculations suggest that in situ equilibrium partitioning may have occurred for the upper member of the Kirtland Formation. The other two non-equilibrium or open system partitioning processes may be operative; however, they are difficult to assess without additional noble gas concentrations (e.g., Ar, Kr, and Xn; see Lippmann et al., 2003).

In summary, we suggest that degassing is less dominant for the lower member of the Kirtland Formation than the upper member. Possible atmospheric contamination occurred in the lower Kirtland Formation, although this is difficult to explain due to the similar purge-andpumpdown procedures used for both upper and lower data sets. The upper member of the Kirtland Formation likely experienced in situ degassing. Estimating the relative degree-ofdegassing loss of noble gases due to in situ or sampling-related processes is problematic. Previous studies demonstrate the use of elemental fractionation of a suite of noble gases (Ar, $\mathrm{Kr}$, and Xn; see Lippmann et al., 2003, and Ballentine et al., 2002) for constraining in situ or sampling-related degassing. We are not able to apply this fractionation "finger-printing" due to the loss of these other noble gases during sample purification.

In the following discussion, we use the measured concentrations of ${ }^{4} \mathrm{He}$ to assess fluid transport processes within the Kirtland Formation, while being cautious of possible in situ degassing. The lower Kirtland Formation data, in terms of the helium values and possible atmospheric contamination, are probably more robust than the neon data since the atmospheric concentrations of helium are much lower than the measured values (see Figure 13; the ASW concentrations are orders of magnitude lower than the measured ${ }^{4} \mathrm{He}$ concentrations).

\section{Testing Conceptual Models of Helium Transport}

To understand the evolution of ${ }^{4} \mathrm{He}$ in Kirtland Formation pore waters and infer sealing behavior, discussion of helium sources and sinks is in order. In general, total pore water ${ }^{4} \mathrm{He}$ can be derived from air or water table interactions, produced in situ by $\mathrm{U}$ and Th decay, or derived from external fluxes (Ballentine et al., 2002):

$$
\left.\left[{ }^{4} \mathrm{He}\right]=\left[{ }^{4} \mathrm{He}\right]_{A S W}+\left[{ }^{4} \mathrm{He}\right]_{e a}+\left[{ }^{4} \mathrm{He}\right]\right]_{i s}+\left[{ }^{4} \mathrm{He}\right]_{\text {external flux }}
$$


where $\left[{ }^{4} \mathrm{He}\right]$ is the concentration in the groundwater, $\left[{ }^{4} \mathrm{He}\right] \mathrm{ASW}$ is the ASW concentration, $\left[{ }^{4} \mathrm{He}\right]_{e a}$ is the "excess air" contribution that can occur due to dissolution of air bubbles when fluctuations in the groundwater table occur at the recharge area, $\left[{ }^{4} \mathrm{He}\right]$ is is radiogenically produced ${ }^{4} \mathrm{He}$, and $\left[{ }^{4} \mathrm{He}\right]_{\text {external flux }}$ is the portion of the ${ }^{4} \mathrm{He}$ concentration that is derived from sources external to the location of measurement.

As a starting point of interpretation, we estimate the in situ production of ${ }^{4} \mathrm{He}$ for the important components of our systems: the Fruitland Formation, the lower and upper shale members of the Kirtland Formation, and the overlying Ojo Alamo Sandstone. We neglect $\left[{ }^{4} \mathrm{He}\right]_{A S W}$ and $\left[{ }^{4} \mathrm{He}\right]_{e a}$ as their concentrations are small compared to the measured values $\left(10^{-8}\right.$ vs. $10^{-5} \mathrm{ccSTP} / \mathrm{g}$; see Figure 12). Helium-4 production is estimated via equations presented by Castro et al. (2000):

$$
\begin{aligned}
& P\left({ }^{4} \mathrm{He}\right)=1.207 \times 10^{-13}[\mathrm{U}]+2.867 \times 10^{-14}[\mathrm{Th}] \mathrm{cm}^{3} \text { STP } g_{\text {rock }}^{-1} \mathrm{yr}^{-1} \\
& {\left[P_{4 \mathrm{He}}\right]_{\mathrm{H} 20}=P\left({ }^{4} \mathrm{He}\right) \times \rho_{\text {rock }} \times \Lambda \times \frac{1-\phi}{\phi} \mathrm{cm}^{3} \mathrm{STP} \mathrm{cm}_{\mathrm{H} 2 \mathrm{O}}^{-3} \mathrm{yr}^{-1}} \\
& {\left[{ }^{4} \mathrm{He}\right]_{i s}=\left[P_{\mathrm{He}}^{4}\right]_{\mathrm{H} 2 \mathrm{O}} \times t}
\end{aligned}
$$

where $P\left({ }^{4} \mathrm{He}\right)$ is the in situ production rate of ${ }^{4} \mathrm{He}$ due to $\mathrm{U}$ and Th decay, $[U]$ and $[T h]$ are the $\mathrm{U}$ and Th concentrations (in ppm), $\left[P^{4}{ }_{\mathrm{He}}\right]_{\mathrm{H} 2 \mathrm{O}}$ is the accumulation rate of ${ }^{4} \mathrm{He}$ in the groundwater, $\rho_{\text {rock }}$ is the mass density (in $\mathrm{g} \mathrm{cm}^{-3}$ ), $\Lambda$ is the transfer efficiency of ${ }^{4} \mathrm{He}$ from the rock matrix to the groundwater (usually assumed to equal 1), $\varphi$ is the porosity, and $t$ is time (in years). Parameters of Equations 4 and 5 for this study are given in Table 2. The measured $\left[{ }^{4} \mathrm{He}\right]$, given in units of $\mathrm{cm}^{3}$ STP (standard temperature and pressure) of gas of helium per pore volume, is approximately one order of magnitude or more lower than $\left[{ }^{4} \mathrm{He}\right]_{i s}$ (Table 2). These calculations indicate that after millions of years ( $\sim 73$ to $\sim 74 \mathrm{Ma}$ for the upper and lower shale members, respectively) up to $\sim 10 \%$ of produced ${ }^{4} \mathrm{He}$ (Table 2 , last column) is still within the pore fluids!

Conceptual explanations of the observed trends include:

(1) variation in production of ${ }^{4} \mathrm{He}$ in the upper and lower Kirtland Formation;

(2) diffusive transport driven by concentration gradients in both groundwater and a gas phase (e.g., methane) and possible free gas saturations in the overlying Ojo Alamo Sandstone (gas saturations in the Ojo Alamo Sandstone are indicated by mud log and other well logs; see Appendix E and Figure 14);

(3) advective transport of helium via groundwater or a separate gas phase or both through the system driven by the artesian hydrologic conditions; equilibrium or non-equilibrium partitioning of noble gases between groundwater and a separate gas phase (e.g., methane) within the caprock during the advective transport; and impact on ${ }^{4} \mathrm{He}$ concentrations in the upper and lower Kirtland Formation by meteoric waters in the Fruitland and Ojo Alamo aquifer systems.

Next, we test conceptual models of noble gas transport to evaluate large-scale permeability of the Kirtland Formation. 
$\underline{\text { Table 2. Estimation of in situ }{ }^{4} \mathrm{He} \text { production, parameters, and measured }{ }^{4} \mathrm{He} \text { concentration from the core }}$

\begin{tabular}{|c|c|c|c|c|c|c|c|c|c|c|c|}
\hline Formation & $\begin{array}{l}\text { Depth } \\
\text { (m) }\end{array}$ & $\begin{array}{c}\rho_{\text {rock }} \\
\left(\mathrm{g} \mathrm{cm}^{-3}\right)\end{array}$ & $\varphi$ & $\begin{array}{c}{[\mathrm{U}]} \\
(\mathrm{ppm})\end{array}$ & $\begin{array}{c}{[\mathrm{Th}]} \\
(\mathrm{ppm})\end{array}$ & $\begin{array}{c}\mathrm{P}\left({ }^{4} \mathrm{He}\right) \\
\left(\mathrm{cm}^{3} \mathrm{STP}\right. \\
\left.\rho_{\text {rock }}^{-1} \mathrm{yr}^{-1}\right)\end{array}$ & $\begin{array}{l}{\left[\mathrm{P}_{\mathrm{He}}^{4}\right]_{\mathrm{H} 2 \mathrm{O}}} \\
\left(\mathrm{cm}^{3} \mathrm{STP}\right. \\
\left.\mathrm{cm}^{-3}{ }_{\mathrm{H} 2 \mathrm{O}}\right)\end{array}$ & $\begin{array}{c}\text { Age of } \\
\text { deposition } \\
\text { (Ma) }\end{array}$ & $\begin{array}{c}{\left[{ }^{4} \mathrm{He}\right]_{\text {is }}} \\
\left(\mathrm{cm}^{3} \text { STP }\right. \\
\left.\mathrm{cm}^{-3}{ }_{\mathrm{H} 2 \mathrm{O}}\right)\end{array}$ & $\begin{array}{c}\text { Measured } \\
{\left[{ }^{4} \mathrm{He}\right]} \\
\left(\mathrm{cm}^{3} \mathrm{STP}\right. \\
\left.\mathrm{cm}^{-3} \mathrm{PV}\right)\end{array}$ & $\begin{array}{c}\text { Measured } \\
{\left[{ }^{4} \mathrm{He}\right] /} \\
{\left[{ }^{4} \mathrm{He}\right]_{\text {is }}} \\
(\%)\end{array}$ \\
\hline \multirow[t]{3}{*}{ Ojo Alamo } & 616.34 & 2.66 & 0.12 & 0.836 & 6.482 & $2.87 \mathrm{E}-13$ & $5.38 \mathrm{E}-12$ & 65.04 & $3.50 \mathrm{E}-04$ & & \\
\hline & 620.12 & 2.67 & 0.09 & 3.706 & 0.000 & $4.47 \mathrm{E}-13$ & $1.15 \mathrm{E}-11$ & 65.04 & 7.45E-04 & & \\
\hline & 623.96 & 2.73 & 0.02 & 2.408 & 6.003 & $4.63 \mathrm{E}-13$ & 7.66E-11 & 65.04 & $4.98 \mathrm{E}-03$ & & \\
\hline \multicolumn{12}{|l|}{ Upper } \\
\hline \multirow[t]{5}{*}{ Kirtland } & 625.71 & 2.61 & 0.06 & 2.891 & 0.699 & $3.69 \mathrm{E}-13$ & $1.42 \mathrm{E}-11$ & 73.04 & $1.04 \mathrm{E}-03$ & $1.04 \mathrm{E}-04$ & 10.0 \\
\hline & 626.84 & 2.65 & 0.08 & 4.906 & 8.321 & $8.31 \mathrm{E}-13$ & $2.65 \mathrm{E}-11$ & 73.04 & $1.94 \mathrm{E}-03$ & $6.73 \mathrm{E}-05$ & 3.5 \\
\hline & 628.38 & 2.65 & 0.09 & 4.391 & 0.000 & $5.30 \mathrm{E}-13$ & $1.35 \mathrm{E}-11$ & 73.04 & $9.87 \mathrm{E}-04$ & $1.05 \mathrm{E}-04$ & 10.6 \\
\hline & 629.29 & 2.65 & 0.09 & 4.619 & 4.658 & $6.91 \mathrm{E}-13$ & $1.76 \mathrm{E}-11$ & 73.04 & $1.29 \mathrm{E}-03$ & $1.19 \mathrm{E}-05$ & 0.9 \\
\hline & 630.77 & 2.63 & 0.08 & 4.094 & 3.108 & $5.83 \mathrm{E}-13$ & $1.72 \mathrm{E}-11$ & 73.04 & $1.26 \mathrm{E}-03$ & $7.60 \mathrm{E}-05$ & 6.0 \\
\hline \multicolumn{12}{|l|}{ Lower } \\
\hline \multirow[t]{4}{*}{ Kirtland } & 820.00 & 2.68 & 0.07 & 0.653 & 9.585 & $3.54 \mathrm{E}-13$ & $1.33 \mathrm{E}-11$ & 74.44 & $9.90 \mathrm{E}-04$ & $4.62 \mathrm{E}-05$ & 4.7 \\
\hline & 820.74 & 2.68 & 0.07 & 0.942 & 3.510 & $2.14 \mathrm{E}-13$ & $8.06 \mathrm{E}-12$ & 74.44 & $6.00 \mathrm{E}-04$ & $5.40 \mathrm{E}-05$ & 9.0 \\
\hline & 821.33 & 2.68 & 0.07 & 3.994 & 5.301 & $6.34 \mathrm{E}-13$ & $2.38 \mathrm{E}-11$ & 74.44 & $1.77 \mathrm{E}-03$ & $2.76 \mathrm{E}-05$ & 1.6 \\
\hline & 821.88 & 2.65 & 0.06 & 2.732 & 12.349 & $6.84 \mathrm{E}-13$ & $2.62 \mathrm{E}-11$ & 74.44 & $1.95 \mathrm{E}-03$ & $2.24 \mathrm{E}-05$ & 1.1 \\
\hline Fruitland ${ }^{*}$ & & 1.79 & 0.15 & 1.5 & 4.6 & $3.13 \mathrm{E}-13$ & $3.17 \mathrm{E}-12$ & 74.56 & $2.37 \mathrm{E}-04$ & & \\
\hline
\end{tabular}

*Values for the Fruitland Formation are taken from Zhou et al. (2006) 


\section{Steady-State ${ }^{4}$ He Advection, Diffusion, and In Situ Generation}

As a base case, we first evaluate single-phase, fully-saturated-by-groundwater, steadystate, 1D-advection-only transport through the Kirtland Formation, with homogeneous material properties (e.g., uniform $U$ and $T h$ concentration, porosity, etc.) and a constant helium production source term. The hydrologic gradient just north of the structural hingeline has been thought by many workers to be essentially vertical (Kaiser and Ayers, 1994), and thus we suggest such a 1D approach is appropriate. This simple case allows an initial evaluation of the importance of upward advective transport through the system, which is the major concern of the assessment of the potential seal bypass system. A following model tested herein subsequently adds diffusion. These models form the foundation for a discussion of the ${ }^{4} \mathrm{He}$ trends and sealing behavior. Due to the restricted nature of these models, we present our conclusions with the caveat that additional conceptual models (e.g., lateral flow in the Farmington Sandstone Member) are possible to explain these data. We discuss our conclusions in the context of these other conceptual models.

One-dimensional, advection-only transport is represented by the following equation:

$$
V_{z} \frac{\partial c}{\partial z}=\frac{G^{*}}{\phi}
$$

where $V_{z}$ is the vertical groundwater velocity, $c$ is the concentration of ${ }^{4} \mathrm{He}, z$ is depth, $G^{*}$ is the ${ }^{4} \mathrm{He}$ release rate from solid rock grains, and $\varphi$ is porosity. Letting $G^{*} / \varphi$ be equal to $g$ (i.e., the accumulation of ${ }^{4} \mathrm{He}$ in $\mathrm{cm}^{3} \mathrm{STP}$ per $\mathrm{cm}^{3}$ of pore water per year, which is calculated by Equation 5), the solution is the following:

$$
V_{z}=g \frac{z_{u}-z_{l}}{c_{u}-c_{l}}
$$

where $z$ and $c$ represent depths and corresponding concentrations in the upper (subscript " $u$ ") and lower (subscript "l") members of the Kirtland Formation. As molar concentration units are conserved, we conveniently use measured concentration values in $\mathrm{cm}^{3}$ STP per $\mathrm{cm}^{3}$ pore water

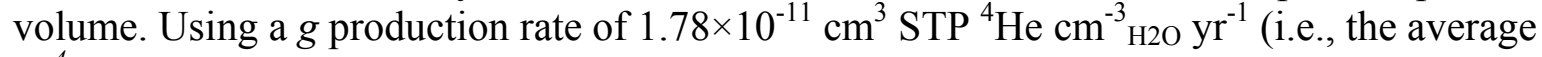
$\left[P^{4}{ }_{\mathrm{He}}\right]_{\mathrm{H} 2 \mathrm{O}}$ for the upper and lower Kirtland Formation samples, based on Table 2), and upper and lower concentration values that correspond to the most robust measured data points (see the discussion in the immediately previous section), a value of $6.9 \times 10^{-5} \mathrm{~m} / \mathrm{yr}$ is obtained for $V_{z}$ (Figure 15). 


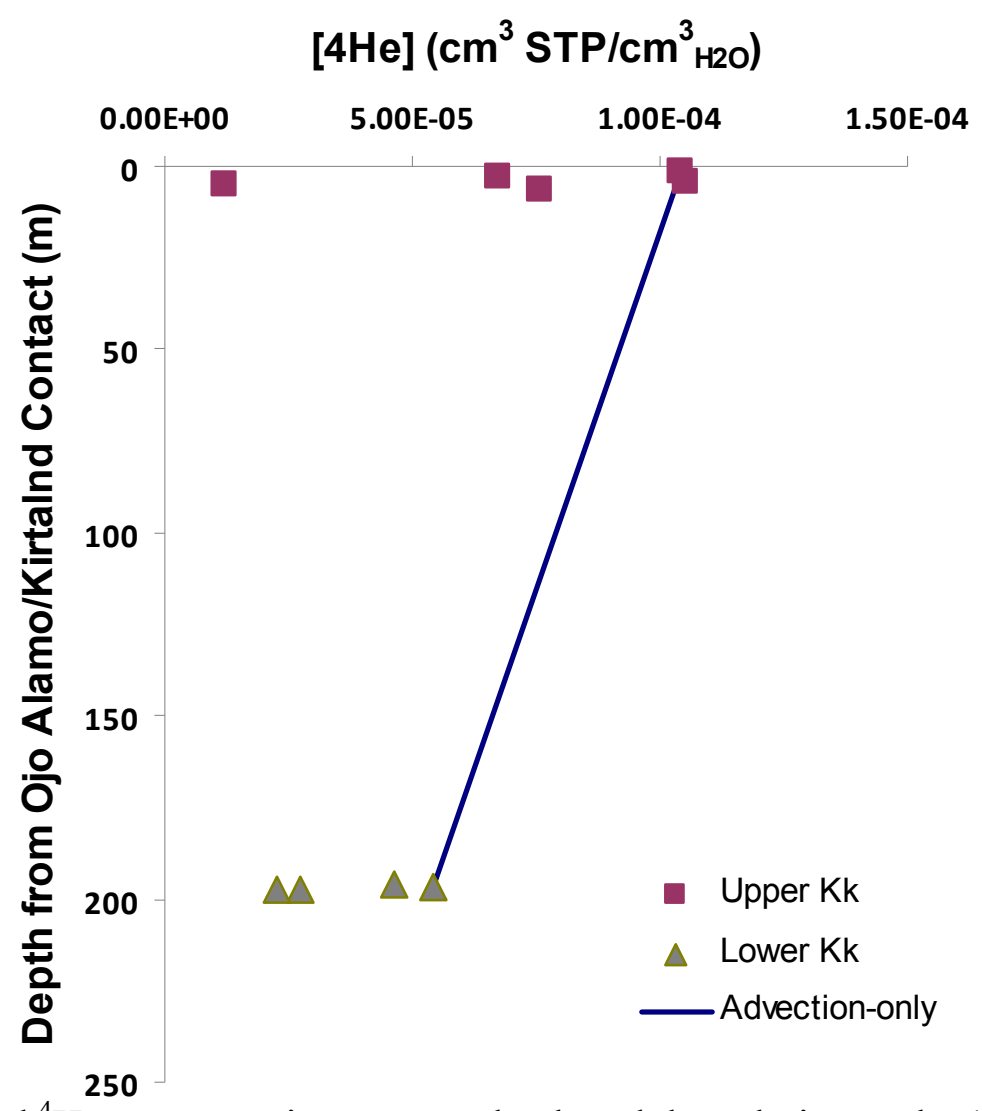

Figure 15. Measured ${ }^{4} \mathrm{He}$ concentrations versus depth and the solution to the $1 \mathrm{D}$ advection-only model with in situ ${ }^{4} \mathrm{He}$ production (blue line).

To obtain permeability from $V_{z}$, we estimate a hydraulic gradient, solve Darcy's Law for hydraulic conductivity (while multiplying $V_{z}$ by the average porosity), and convert for permeability. Measurements of hydraulic head were not performed during the Pump Canyon project; however, Kaiser et al. (1994) listed a measured head in the Fruitland Formation from a well near the Pump Canyon site of $1170 \mathrm{~m}(3840 \mathrm{ft})$ above a datum of $933 \mathrm{~m}(3060 \mathrm{ft})$ above mean sea level. A 2D groundwater model by these authors, along a N-S cross section line running close to the Pump Canyon site, gives an upper head value (Kaiser et al., 1994) of $884 \mathrm{~m}$ $(2900 \mathrm{ft}$ ) above datum (Kaiser et al., 1994, their Figure 8.24). Note that a 3D groundwater model by Kernodle (1996) includes the study area; however, Kernodle's model simulated the entire San Juan basin and grouped the Fruitland, Kirtland, and Ojo Alamo Formations as a single hydrogeologic unit. We also estimated the hydraulic head in the Ojo Alamo Formation using the potentiometric map of Thorn et al. (1990). With these data and using the Kirtland Formation thickness at Pump Canyon of $240 \mathrm{~m}$, we constrain the vertical hydraulic gradient at the Pump Canyon site to be 0.6 to 1.2 (dimensionless). Given the estimated $V_{z}$, (using the average porosity value of 0.08), we obtain hydraulic conductivity and permeability estimates, respectively, of $4.6 \times 10^{-6}$ to $9.3 \times 10^{-6} \mathrm{~m} / \mathrm{yr}$, and approximately $1 \times 10^{-20}$ to $3 \times 10^{-20} \mathrm{~m}^{2}$. These low values suggest that advection through the system is extremely low. For this particular conceptual model, the 
matrix properties, such as the TerraTek-measured permeability, seem to represent the formationscale permeability. We reassess this conclusion in light of other conceptual models given below.

Next we add diffusion to the model. We also add boundary conditions as controlled by the overlying and underlying aquifers. The Kirtland Formation is bounded by two aquifers, the Ojo Alamo Sandstone and the Fruitland Formation, both of which have been studied for their noble gas systematics. Zhou et al. $(2005,2006)$ have compiled an extensive data set of Fruitland Formation noble gases in produced methane in both the over-pressured (artesian) portion north of the structural hingeline, and in the under-pressured portion south of the line. Castro et al. (2000) examined ${ }^{4} \mathrm{He}$ in the Ojo Alamo Sandstone and the overlying formations. Both authors focus mostly on a portion of the San Juan Basin west and south of the Pump Canyon site of interest here, but spatial coherency in both data sets allow us to draw some general conclusions about ${ }^{4} \mathrm{He}$ in the Ojo Alamo Sandstone and Fruitland Formation.

The simple 1D advection-diffusion model for helium transport (Rubel et al., 2002; Sheldon et al., 2003) is given in Equation 9 for the fully groundwater saturated case. The 1D equation applicable in the vertical direction, $\mathrm{z}$, for a homogeneous aquitard of thickness $\mathrm{L}$ bounded by two aquifers, is (e.g., Solomon et al., 1996):

$$
V_{z} \frac{\partial c}{\partial z}-D \frac{\partial^{2} c}{\partial z^{2}}=\frac{G^{*}}{\phi} \quad 0<z<L
$$

where $V_{z}, c, D, G^{*}$, and $\varphi$ are the same as above. If ${ }^{4} \mathrm{He}$ generation and transport in the bounding aquifers are at steady state (Zhou et al., 2006, and Castro, 2000, suggest that this is the case for the Fruitland Formation and Ojo Alamo Sandstone, respectively), then we can apply the following boundary conditions:

$$
\begin{aligned}
& c(z=0)=c_{U} \\
& c(z=L)=c_{L}
\end{aligned}
$$

where $c_{U}$ and $c_{L}$ are the steady-state concentrations of ${ }^{4} \mathrm{He}$ in the Ojo Alamo Sandstone and Fruitland Formation, respectively. As before, letting $g$ denote the ratio $G^{*} / \varphi$, the solution to Equations 9 and 10 is:

$$
c(z)=\left(c_{L}-\frac{g L}{V_{z}}\right) \frac{\left(1-\exp \left(z V_{z} / D\right)\right)}{\left(1-\exp \left(L V_{z} / D\right)\right.}+c_{u}\left(\frac{\exp \left(z V_{z} / D\right)-\exp \left(L V_{z} / D\right)}{1-\exp \left(L V_{z} / D\right)}\right)+g z / V_{z}
$$

If $c_{u}$ is equal to zero, Equation 9 reverts to the solution presented by Solomon et al. (1996; Equation 4).

A range of values for groundwater helium concentration $c_{L}$ can be estimated from the $\left[{ }^{4} \mathrm{He}\right]$ measured in methane gas samples in the Fruitland Formation by Zhou et al. (2005). We do this assuming equilibrium partitioning of ${ }^{4} \mathrm{He}$ between methane and pore waters. We use Equation 2 in Ballentine et al. (2002) and their Figures 5 and 2, respectively, for the values of Henry's coefficient and the fugacity coefficient. Our estimates use an in situ temperature of $36^{\circ} \mathrm{C}$ and pore pressure of 8.2 MPa. As an example, the Stull100 well in Zhou et al. (2005) contains a $\left[{ }^{4} \mathrm{He}\right]$ content in produced methane gas of $0.42 \mathrm{ppm}$, from which we calculate a $\left[{ }^{4} \mathrm{He}\right]$ in pore 
water of $2.6 \times 10^{-6} \mathrm{~cm}^{3}{ }^{4} \mathrm{He} \mathrm{STP} / \mathrm{cm}^{3}{ }_{\mathrm{H} 2 \mathrm{O}}$. In general the methane gas phase $\left[{ }^{4} \mathrm{He}\right]$ values reported by Zhou et al. (2005) for the over-pressured Fruitland Formation are one to two orders of magnitude less than values reported for the under-pressured region, ranging from 0.0443 to 2.32 ppm. Zhou et al. (2005) suggested the lower values north of the hingeline are due to gas stripping during biogenic methane production that was initiated after artesian conditions developed in the Fruitland Formation during the Pliocene.

A value for pore water $\left[{ }^{4} \mathrm{He}\right]$ in the Ojo Alamo Sandstone can be derived from the work of Castro et al. (2000), who suggested evolution of $\left[{ }^{4} \mathrm{He}\right]$ as a function of recharge distance (see their Figure 11). Upper bounding values from the base of the Ojo Alamo Sandstone from these authors' work range from 1.0 to $2.0 \times 10^{-5} \mathrm{~cm}^{3}{ }^{4} \mathrm{He} \mathrm{STP} / \mathrm{cm}^{3}{ }_{\mathrm{H} 2 \mathrm{O}}$ for recharge distances of $\sim 20$ to $35 \mathrm{~km}$. This is an order of magnitude larger than the value we determined from the Fruitland Formation; this may be a result of pore water ${ }^{4} \mathrm{He}$ being stripped by biogenic gas production. (It is unknown how much $\left[{ }^{4} \mathrm{He}\right]$ variation is caused by gas production, or whether this could affect our steady-state assumption.)

To calculate steady-state profiles of [ $\left.{ }^{4} \mathrm{He}\right]$, we need values for $g, D$, and $V_{z}$ of Equation 9 . The value for $g$ is simply that calculated earlier for the Kirtland Formation, equal to $1.7 \times 10^{-11}$

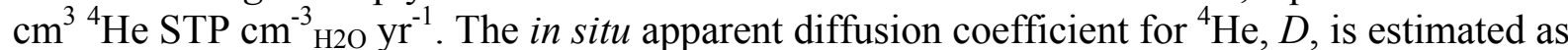
$0.001 \mathrm{~m}^{2} / \mathrm{yr}$ (Rubel et al., 2002). To constrain $V_{z}$, we assume a Darcy vertical flux (divided by porosity) equal to the vertical hydraulic conductivity multiplied by the vertical hydraulic gradient (using the range from above of 0.6 to 1.2). Given a vertical velocity, we can then use Equation 11 to calculate vertical helium profiles. We use this steady state model and the measured $\left.{ }^{4} \mathrm{He}\right]$ concentrations to constrain $V_{z}$ and bulk vertical permeability of the Kirtland Formation.

Figure 16a shows $\left[{ }^{4} \mathrm{He}\right]$ profiles as a function of depth for varying velocities of minus (indicating upward groundwater movement) $2.5 \times 10^{-6}, 2.5 \times 10^{-5}, 7.5 \times 10^{-5}, 2.5 \times 10^{-4}$, and $2.5 \times 10^{-3}$ $\mathrm{m} / \mathrm{yr}$, corresponding to Peclet numbers (equal to $L V_{z} / D$ ) of $0.6,6,18,60$, and 600 , respectively,

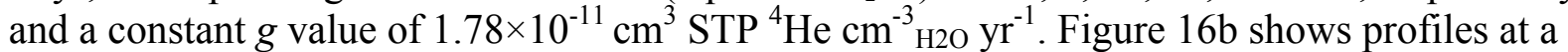
constant $V_{z}$ of $-2.5 \times 10^{-5} \mathrm{~m} / \mathrm{yr}$ and a range of $g$ values from $5.0 \times 10^{-12}$ to $1.78 \times 10^{-11}$ (the average

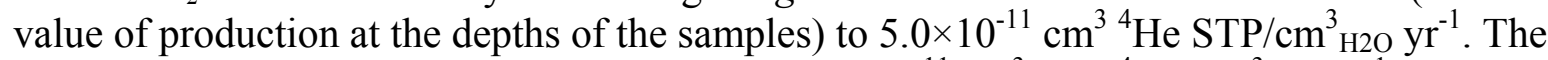
qualitative best fit model involves a $g$ value of $5.0 \times 10^{-11} \mathrm{~cm}^{3} \mathrm{STP}^{4} \mathrm{He} \mathrm{cm}^{-3} \mathrm{H} 2 \mathrm{O} \mathrm{yr}^{-1}$, about twice the calculated value in Table 2 , and a velocity of $-2.5 \times 10^{-5} \mathrm{~m} / \mathrm{yr}$. This corresponds to a hydraulic conductivity of $1.7 \times 10^{-6}$ to $3.3 \times 10^{-6} \mathrm{~m} / \mathrm{yr}$ or a vertical permeability of approximately $5 \times 10^{-21}$ to $1 \times 10^{-20} \mathrm{~m}^{2}$. These permeability values are lower, but comparable to those of the advection-only model. The scenarios of advection-dominated transport from Figure 16a do not fit the measured data very well due to the $\left[{ }^{4} \mathrm{He}\right]$ at the boundary conditions (note that the upper Kirtland Formation data point with the lowest $\left[{ }^{4} \mathrm{He}\right]$ is suspect due to incomplete gas release from the core plugs). The lowest velocity case $\left(V_{z}=-2.5 \times 10^{-6} \mathrm{~m} / \mathrm{yr}\right)$ of Figure 16 a covers the range of values seen in the measured data better than the higher velocity scenarios. A higher ${ }^{4} \mathrm{He}$ production term than that measured at the depths of the upper and lower Kirtland Formation samples improves the correspondence of the model and the measured data (Figure 16b). The higher production

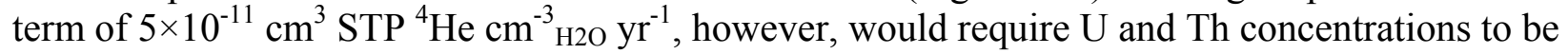
more than double their current value, which may not be realistic. In general, the scenarios of Figure 16 suggest that the diffusion-dominated cases, with higher ${ }^{4} \mathrm{He}$ production than what was estimated from measured $U$ and $T h$ concentrations, correspond better with the measured data than the advection-dominated cases. 
a)

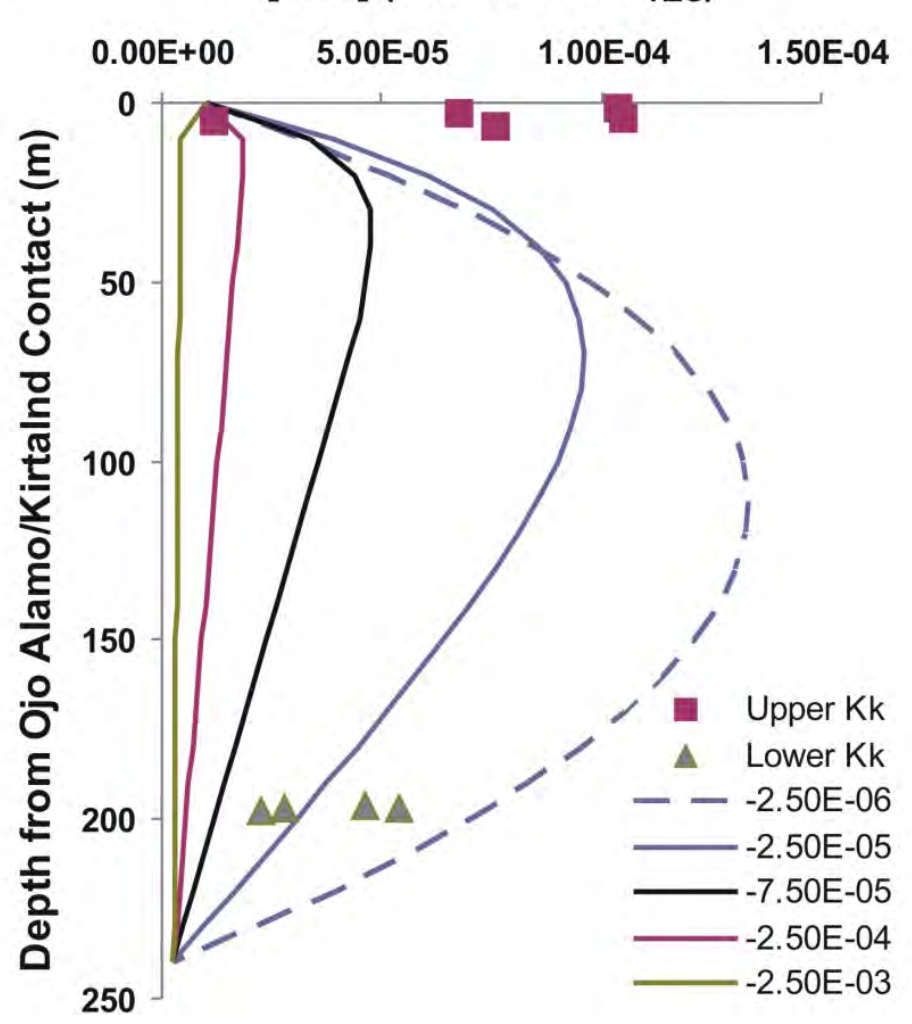

b) $\quad[4 \mathrm{He}]\left(\mathrm{cm}^{3} \mathrm{STP} / \mathrm{cm}^{3}{ }_{\mathrm{H} 2 \mathrm{O}}\right)$

$0.00 \mathrm{E}+00 \quad 1.00 \mathrm{E}-04 \quad 2.00 \mathrm{E}-04 \quad 3.00 \mathrm{E}-04$

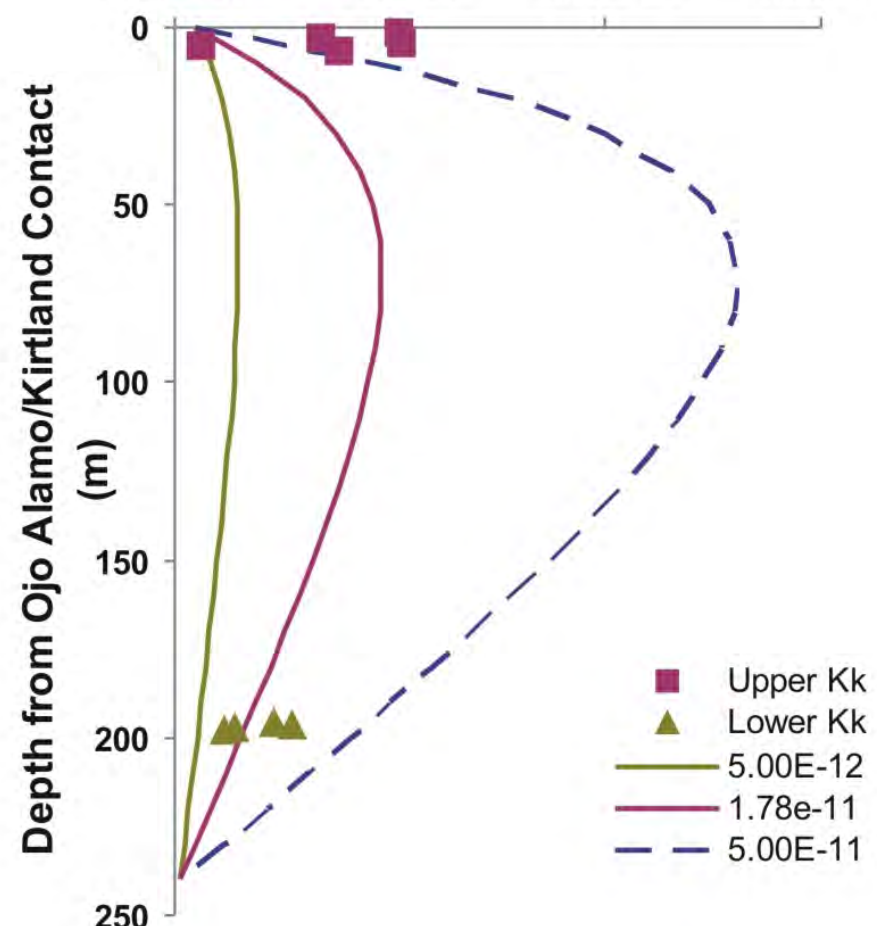

Figure 16. Helium concentration versus depth profiles for measured and modeled data. a) Profiles with varying groundwater velocity $V_{z}$ (given in legend) and a constant ${ }^{4} \mathrm{He}$ production value of $g=1.78 \times 10^{-11} \mathrm{~cm}^{3} \mathrm{STP}{ }^{4} \mathrm{He} \mathrm{cm}^{-3} \mathrm{H}_{20} \mathrm{yr}^{-1}$. b) Profiles with varying in situ helium production (in units of $\mathrm{cm}^{3} \mathrm{STP}^{4} \mathrm{He} \mathrm{cm}^{-3} \mathrm{H}_{2} \mathrm{Or}^{-1}$; values given in legend) and constant $V_{z}=2.5 \times 10^{-5} \mathrm{~m} \mathrm{yr}^{-1}$. 
An interesting finding is that both the advection-only and advection-diffusion models suggest permeability on the order of $10^{-20} \mathrm{~m}^{2}$ or less for this system. We cannot say whether the system is advection- or diffusion-dominated. Being at an order of magnitude lower than the values based on core plug measurements values and the pore-scale model result $\left(\sim 10^{-19} \mathrm{~m}^{2}\right)$, these advection-only and advection-diffusion models suggest that the bulk Kirtland Formation permeability is even lower (at least one order of magnitude) than the core-scale measured values. In summary, both core permeability and the ${ }^{4} \mathrm{He}$ data and analysis suggest that the fluid flux through the Kirtland Formation is low. We warn the reader, however, that other conceptual models are possible to explain the ${ }^{4} \mathrm{He}$ data.

Additional transport scenarios for the Kirtland Formation include the following: 1) lateral fluid flow in the Farmington Sandstone Member, which contains abundant sandstone interbeds that are probably permeable (see Appendix E for mud log that shows the sandstone interbeds); 2) variation in production of ${ }^{4} \mathrm{He}$ throughout the system; and 3) a gas phase that is either stagnant or advecting relative to the groundwater. If the Farmington Sandstone Member is a significant aquifer and transmits fluids from the recharge area, then the helium concentrations would be lowered relative to the situation of the Farmington Sandstone Member not acting as an aquifer (i.e., if an aquifer, the Farmington Sandstone Member may contain significant, relatively young groundwater with relatively low ${ }^{4} \mathrm{He}$ concentrations). These scenarios are currently difficult to test due to little data on the Farmington Sandstone Member. The in situ ${ }^{4} \mathrm{He}$ production rate does not seem to be greatly different from the upper and lower members of the Kirtland Formation and probably does not have a strong impact on the difference in ${ }^{4} \mathrm{He}$ concentration here.

We find it difficult to evaluate transport models when the measured data are located near model boundary conditions. The location of the data limits our ability to test different model conceptualizations and parameterizations. Data points within the Farmington Sandstone Member would have allowed us to test if these 1D models are appropriate or if other conceptualizations (e.g., lateral flow in the Farmington Sandstone Member or higher or lower ${ }^{4} \mathrm{He}$ production) would correspond better with the data. Furthermore, we have inferred the ${ }^{4} \mathrm{He}$ concentration in the Ojo Alamo Sandstone and the Fruitland Formation from previous work without direct measurement at the Pump Canyon site. When planning the coring program, the lead author's original conceptual model of helium transport focused on helium gradients across a caprock as an important metric of sealing quality, and thus core was collected in the upper and lower members of the Kirtland. Furthermore, the cost of drilling and coring restricted the number of separate lengths of core that could be collected. However, the Kirtland Formation may experience upward and downward (diffusional) transport of helium towards the Ojo Alamo Sandstone and the Fruitland Formation (and possibly transport upward or downward toward the Farmington Sandstone Member from the lower and upper shale members, respectively). This bidirectional diffusion within the Kirtland Formation was not properly anticipated when designing the coring program. The possible transport of ${ }^{4} \mathrm{He}$ by a separate gas phase adds to the complexity of assessing transport, which could have been evaluated with a suite of noble gases $(\mathrm{Ne}, \mathrm{Ar}, \mathrm{Kr}$, and Xn) as done in previous studies (see Lippmann et al., 2003).

In spite of the nonconclusive findings (i.e., the body of evidence supports, but does not guarantee the lack of a bypass system), we emphasize the simple calculations of the large percentage (up to $\sim 10 \%$ ) of the in situ produced ${ }^{4} \mathrm{He}$ still remaining in the pore fluids after millions of years (Table 2, last column). Active, advective fluid flow has not flushed out the produced ${ }^{4} \mathrm{He}$, which suggests low fluid fluxes occur in the system. With this finding and the indication of low fluid fluxes by the 1D advection-only and advection-diffusion models, we 
propose that the Kirtland Formation is controlled more by the matrix-scale data than a largerscale seal bypass system. We submit that what we inferred as potential seal bypass features (seismic and sub-seismic fractures and faults) in the FMI log likely do not create an appreciable cross-Kirtland Formation seal bypass. These statements are not guaranteed by our analysis, and further work is needed. We recommend additional sampling within the Farmington Sandstone Member and collection of other noble gases to assess multiphase partitioning and flow processes.

\section{DISCUSSION AND CONCLUSIONS: MULTI-SCALE EVALUATION OF SEAL BYPASS SYSTEMS}

This section addresses the multi-scale assessment of caprock sealing quality for the Kirtland Formation and other sites in general. Our Kirtland Formation-specific investigation involves data collected from the pore, core, well log, and formation scale (i.e., helium data collected at the top and bottom of the Kirtland Formation). Our multi-scale assessment is not based on upscaling a variety of data sets, but simply comparing different types of data collected at different scales to determine if the data are coherent.

Mercury intrusion porosimetry (MIP), permeability measured on core, FMI log-based fracture measurements, and other pore-, core-, and well log-scale data do not provide clear indication of the connectedness of transmissive features over the vertical scale of the entire Kirtland Formation. The MIP and core-scale permeability indicate high sealing capacity. However, the core and well log data indicate potentially transmissive fractures, such as open and mineralized fractures. The mineralization and methane gas saturations within the Kirtland Formation and the overlying Ojo Alamo Sandstone suggest possible large-scale connectivity. Thus, the natural tracer data - helium and neon - are especially important since they are affected by actual transport through the seal. The goal is to determine if the tracer data indicate connectedness and relatively high permeability at the scale of the entire Kirtland Formation. If this is the case, then fractures or other features would have to be invoked as a seal bypass system to explain the data.

Our analysis of the noble gas data supports a low fluid flux through the Kirtland Formation. Key findings supporting this statement are: 1) a large percentage of the radiogenically produced ${ }^{4} \mathrm{He}$ is in the pore fluids of the Kirtland Formation, indicating low advective fluid flow from the surrounding aquifers; and 2) simple advection-only and advectiondiffusion models estimate low permeability $\left(\sim 10^{-20} \mathrm{~m}^{2}\right.$ or lower $)$ for the entire thickness of the Kirtland Formation. Thus, following our multi-scale approach, we propose that the formationscale data are coherent with those of the pore-scale (e.g., permeability and MIP). However, our findings do not guarantee low fluid fluxes and the lack of a seal bypass system. Our models rely on restricted conceptualizations (e.g., 1D, fully groundwater saturated fluid flow with homogeneous formation properties). Furthermore, the measured data points are located near the boundary conditions of the models, which are the overlying and underlying aquifers. Tests of different conceptualizations (e.g., lateral flow in the Farmington Sandstone Member) and model parameterization are limited by the location of these data. In situ advective transport of a gas phase may also be possible, which we are not able to constrain with only neon and helium data.

The limitations of our analysis indicate the need for careful feasibility studies prior to coring and drilling programs to ensure that the collected natural tracer data will support tests of different conceptualizations. Future studies should tailor data collection programs to the system 
of interest in terms of flow units, sampling locations, and the types of tracers. Analytical or numerical modeling should be used prior to data collection to optimize the sampling locations. We sought to use natural helium and other noble gases because they occur in all groundwater systems and reflect transport processes. However, in addition to these tracers, our investigation would have benefited from examining the methane in the system, which may have been an effective tracer at indicating the degree of large-scale transport. Other sites may have particular, local, natural tracers that would be valuable in addition to the noble gases.

Our study is part of the effort, encouraged by the $\mathrm{CO}_{2}$ research community (DOE, 2007), to develop approaches for large-scale caprock assessment for $\mathrm{CO}_{2}$ storage. Industrial-scale $\mathrm{CO}_{2}$ storage may involve reservoir/caprock evaluation at the scale of entire sedimentary basins (Birkholzer and Zhou, 2009). Previous work using noble gases, especially helium, have assessed basin-scale aquifer transport in terms of large-scale permeability and groundwater residence times (Castro et al., 1998; Bethke et al., 1999; Bethke and Johnson, 2008). The goal, however, has not been the diagnosis of seal bypass systems. Future work can build on these studies and ours presented herein to assess basin-scale reservoir-aquifer/caprock systems with a focus on identifying and characterizing seal bypass systems.

\section{ACKNOWLEDGMENTS}

We gratefully acknowledge the U.S. Department of Energy's (DOE) National Energy Technology Laboratory (NETL) for sponsoring this project. DOE's Basic Energy Science Office funded the dual-beam focused ion beam/scanning electron microscopy analysis, confocal microscopy, and pore-scale modeling.

We thank Dr. D. Kip Solomon for his review of this dissertation chapter in preparation for later journal publication. He and Alan Rigby performed the noble gas analysis at the Dissolved and Noble Gas Laboratory, University of Utah. We thank them for helpful discussions on noble gas geochemistry and sample collection. We also appreciate the assistance of Dr. Martin Stute, Lamont-Doherty Earth Observatory, with the design of the noble gas preservation canisters and guidance for field sampling.

Scott Cooper assisted with background geologic information and planning the coring program. We thank Ryan Frost, Eddie Pippin, and Tom Cochrane from ConocoPhillips for executing the coring program under the auspices of the Southwest Regional Partnership on Carbon Sequestration, a project supported by the DOE and managed by NETL. William Holub, Randy Everett, Lee Harris, and Dr. Reid Grigg helped with core handling and sample preservation in the field. We thank John Keller and Mary Milner of TerraTek-a Schlumberger company, Scott Wagner of Wagner Petrographic, and Dr. John Neasham of Poro-Technology for petrophysical and petrographic core analysis, thin section preparation, and mercury intrusion porosimetry, respectively. Dan McGinn of Softrock Geological Services, Inc., provided geologic characterization and assistance in choosing core points. We thank Alex Rinehart for assistance with interpretation of the noble gas data.

Sandia National Laboratories is a multi-program laboratory managed and operated by Sandia Corporation, a wholly owned subsidiary of Lockheed Martin Corporation, for the U.S. Department of Energy's National Nuclear Security Administration under contract DE-AC0494AL85000. 


\section{REFERENCES}

Andreani, M., P. Gouze, L. Luquot, and P. Jouanna, 2008, Changes in seal capacity of fractured claystone caprocks induced by dissolved and gaseous $\mathrm{CO}_{2}$ seepage: Geophysical Research Letters, v. 35, p. 6.

Andrews, J. N., 1985, The isotopic composition of radiogenic helium and its use to study groundwater movement in confined aquifers: Chemical Geology, v. 49, p. 339-351.

Aplin, A. C., A. J. Fleet, and J. H. S. MacQuaker, 1999, Muds and mudstones: Physical and fluid-flow properties, in A. C. Aplin, A. J. Fleet, and J. H. S. Macquaker, eds., Muds and mudstones: Physical and fluid-flow properties, v. 158: London, Geological Society [London] Special Publication 158, p. 1-8.

Ayers, Jr., W. B., 2003, Coalbed methane in the Fruitland Formation, San Juan Basin, western United States: A giant unconventional gas play, in M. T. Halbouty, ed., Giant oil and gas fields of the decade 1990-1999, AAPG Memoir 78, p. 159-188.

Ayers, Jr., W. B., W. A. Ambrose, and J. S. Yeh, 1994, Coalbed methane in the Fruitland Formation, San Juan Basin: Depositional and structural controls on occurrence and resources: Coalbed Methane in the Upper Cretaceous Fruitland Formation, San Juan Basin, New Mexico and Colorado, New Mexico Bureau of Mines and Mineral Resources Bulletin 146, p. 13-40.

Bachu, S., and D. B. Bennion, 2009, Interfacial Tension between $\mathrm{CO}_{2}$, Freshwater, and Brine in the Range of Pressure from (2 to 27) MPa, Temperature from (20 to 125) degrees $\mathrm{C}$, and Water Salinity from (0 to 334000$) \mathrm{mg}(.) \mathrm{L}(-1)$ : Journal of Chemical and Engineering Data, v. 54, p. 765-775.

Ballentine, C. J., R. Burgess, and B. Marty, 2002, Tracing fluid origin, transport and interaction in the crust, in D. Porcelli, C. J. Ballentine, and R. Wieler, eds., Noble Gases in Geochemistry and Cosmochemistry: Reviews in Mineralogy and Geochemistry, v. 47: Washington, DC, Mineralogical Society of America, p. 539-614.

Berg, R. R., 1975, Capillary pressures in stratigraphic traps: AAPG Bulletin, v. 59, p. 939-956.

Bethke, C. M., and T. M. Johnson, 2008, Groundwater age and groundwater age dating: Annual Review of Earth and Planetary Sciences, v. 36, p. 121-152.

Bethke, C. M., X. Zhao, and T. Torgersen, 1999, Groundwater flow and the He-4 distribution in the Great Artesian Basin of Australia: Journal of Geophysical Research-Solid Earth, v. 104, p. 12999-13011.

Birkholzer, J. T., and Q. L. Zhou, 2009, Basin-scale hydrogeologic impacts of $\mathrm{CO}_{2}$ storage: Capacity and regulatory implications: International Journal of Greenhouse Gas Control, v. 3, p. 745-756.

Boult, P., and J. Kaldi, eds., 2005, Evaluating Fault and Cap Rock Seals: AAPG Hedberg Series, No. 2: Tulsa, Oklahoma, American Association of Petroleum Geologists, 268 p.

Carey, J. W., M. Wigand, S. J. Chipera, G. WoldeGabriel, R. Pawar, P. C. Lichtner, S. C. Wehner, M. A. Raines, and G. D. Guthrie, 2007, Analysis and performance of oil well cement with 30 years of $\mathrm{CO}_{2}$ exposure from the SACROC Unit, West Texas, USA: International Journal of Greenhouse Gas Control, v. 1, p. 75-85.

Cartwright, J., M. Huuse, and A. Aplin, 2007, Seal bypass systems: AAPG Bulletin, v. 91, p. 1141-1166. 
Castro, M. C., P. Goblet, E. Ledoux, S. Violette, and G. de Marsily, 1998, Noble gases as natural tracers of water circulation in the Paris Basin 2. Calibration of a groundwater flow model using noble gas isotope data: Water Resources Research, v. 34, p. 2467-2483.

Castro, M. C., M. Stute, and P. Schlosser, 2000, Comparison of He-4 ages and C-14 ages in simple aquifer systems: implications for groundwater flow and chronologies: Applied Geochemistry, v. 15, p. 1137-1167.

Chiaramonte, L., M. D. Zoback, J. Friedmann, and V. Stamp, 2008, Seal integrity and feasibility of $\mathrm{CO}_{2}$ sequestration in the Teapot Dome EOR pilot: Geomechanical site characterization: Environmental Geology, v. 54, p. 1667-1675.

Chiquet, P., D. Broseta, and S. Thibeau, 2007, Wettability alteration of caprock minerals by carbon dioxide: Geofluids, v. 7, p. 112-122.

Dewhurst, D. N., R. M. Jones, and M. D. Raven, 2002, Microstructural and petrophysical characterization of Muderong Shale: Application to top seal risking: Petroleum Geoscience, v. 8, p. 371-383.

DOE, 2007, Basic Research Needs for Geosciences: Facilitating $21^{\text {st }}$ Century Energy Systems, Report from the Workshop Held February 21-23: U.S. Department of Energy, Office of Basic Energy Sciences, available in pdf format at http://www.sc.doe.gov/bes/reports/list.html.

Eichhubl, P., and J. R. Boles, 2000, Rates of fluid flow in fault systems-Evidence for episodic rapid fluid now in the Miocene Monterey Formation, coastal California: American Journal of Science, v. 300, p. 571-600.

Fassett, J. E., and J. S. Hinds, 1971, Geology and fuel resources of the Fruitland Formation and Kirtland Shale of the San Juan Basin, New Mexico and Colorado, U.S. Geological Survey Professional Paper 676, p. 76.

Fassett, J. E., and N. D. Thomaidis, 1978, Oil and gas fields of the Four Corners area, Volumes I and II, Four Corners Geological Society.

Gherardi, F., T. F. Xu, and K. Pruess, 2007, Numerical modeling of self-limiting and selfenhancing caprock alteration induced by $\mathrm{CO}_{2}$ storage in a depleted gas reservoir: Chemical Geology, v. 244, p. 103-129.

Gilfillan, S. M., C. J. Ballentine, G. Holland, D. Blagburn, B. S. Lollar, S. Stevens, M. Schoell, and M. Cassidy, 2008, The noble gas geochemistry of natural $\mathrm{CO}_{2}$ gas reservoirs from the Colorado Plateau and Rocky Mountain provinces, USA: Geochimica et Cosmochimica Acta, v. 72, p. 1174-1198.

Harris, D. C., 2007, Quantitative Chemical Analysis, Seventh Edition: New York, New York, W. H. Freeman and Company, 44-49 p.

Heath, J., B. McPherson, F. Phillips, S. Cooper, and T. Dewers, 2009, Natural helium as a screening tool for assessing caprock imperfections at geologic $\mathrm{CO}_{2}$ storage sites, in $\mathrm{J}$. Gale, H. Herzog, and J. Braitsch, eds., Greenhouse Gas Control Technologies 9: Energy Procedia, v. 1, p. 2903-2910.

Heath, J. E., 2010, Multi-Scale Petrography and Fluid Dynamics of Caprock Seals Associated with Geologic $\mathrm{CO}_{2}$ Storage, Ph.D. dissertation: Socorro, New Mexico, New Mexico Institute of Mining and Technology. 
Hendry, M. J., T. G. Kotzer, and D. K. Solomon, 2005, Sources of radiogenic helium in a clay till aquitard and its use to evaluate the timing of geologic events: Geochimica et Cosmochimica Acta, v. 69, p. 475-483.

Hildenbrand, A., S. Schlomer, B. M. Krooss, and R. Littke, 2004, Gas breakthrough experiments on pelitic rocks: comparative study with $\mathrm{N}_{2}, \mathrm{CO}_{2}$ and $\mathrm{CH}_{4}$ : Geofluids, v. 4, p. 61-80.

Ingram, G. M., J. L. Urai, and M. A. Naylor, 1997, Sealing processes and top seal assessment, in P. Moller-Pedersen, and A. G. Koestler, eds., Hydrocarbon Seals: Importance for Exploration and Production: NPF Special Publication 7: Singapore, p. 165-174.

IPCC, 2005, IPCC special report on carbon dioxide capture and storage, prepared by Working Group III of the Intergovernmental Panel on Climate Change: Cambridge, United Kingdom and New York, NY, USA, Cambridge University Press, 442 p.

Johnson, J. W., J. J. Nitao, and J. P. Morris, 2005, Reactive transport modeling of cap rock integrity during natural and engineered $\mathrm{CO}_{2}$ storage, in $\mathrm{S}$. M. Benson, ed., Carbon Dioxide Capture for Storage in Deep Geologic Formations-Results from the $\mathrm{CO}_{2}$ Capture Project, Vol. 2: Geologic Storage of Carbon Dioxide with Monitoring and Verification: London, England, Elsevier, p. 787-814.

Kaiser, W. R., and W. B. Ayers, Jr., 1994, Coalbed methane production, Fruitland Formation, San Juan Basin: geologic and hydrologic controls, in W. B. Ayers, Jr., and W. R. Kaiser, eds., Coalbed Methane in the Upper Cretaceous Fruitland Formation, San Juan Basin, New Mexico and Colorado, New Mexico Bureau of Mines and Mineral Resources Bulletin 146, p. 187-207.

Kaiser, W. R., T. E. Swartz, and G. J. Hawkins, 1994, Hydrologic framework of the Fruitland Formation, San Juan Basin, in W. B. Ayers, Jr., and W. R. Kaiser, eds., Coalbed Methane in the Upper Cretaceous Fruitland Formation, San Juan Basin, New Meixco and Colorado, New Mexico Bureau of Mines and Mineral Resources Bulletin 146, p. 133163.

Kernodle, J. M., 1996, Hydrogeology and steady-state simulation of groud-water flow in the San Juan Basin, New Mexico, Colorado, Arizona, and Utah: U.S. Geological Survey WaterResources Investigations Report 95-4187.

Kernodle, J. M., C. R. Thorn, G. W. Levings, S. D. Craigg, and W. L. Dam, 1990, Hydrogeology of the Kirtland Shale and Fruitland Formation in the San Juan Structural Basin, New Mexico, Colorado, Arizona, and Utah: U.S. Geological Survey Hydrologic Investigations Atlas $H A-720-C$, scale 1:1,000,000 and 1:2,000,000, 2 sheets.

Kipfer, R., W. Aeschbach-Hertig, F. Peeters, and M. Stute, 2002, Noble gases in lakes and ground waters, in D. Porcelli, C. J. Ballentine, and R. Wieler, eds., Noble Gases in Geochemistry and Cosmochemistry, v. 47: Washington, D.C., Mineralogical Society of America, Geochemical Society, p. 615-700.

Klute, M. A., 1986, Sedimentology and sandstone petrography of the Upper Kirtland Shale and Ojo Alamo Sandstone, Cretaceous-Tertiary Boundary, western and southern San Juan Basin, New Mexico: American Journal of Science, v. 286, p. 463-488.

Lafortune, S., M. Moreira, P. Agrinier, H. Schneider, and H. Catalette, 2008, Noble gases as precursors of $\mathrm{CO}_{2}$ deep storage leaks towards surface: Geochimica et Cosmochimica Acta, v. 72, p. A510.

Law, B. E., 1992, Thermal maturity patterns of Cretaceous and Tertiary rocks, San Juan Basin, Colorado and New Mexico: Geological Society of America Bulletin, v. 104, p. 192-207. 
Lippmann, J., M. Stute, T. Torgersen, D. P. Moser, J. A. Hall, L. Lin, M. Borcsik, R. E. S. Bellamy, and T. C. Onstott, 2003, Dating ultra-deep mine waters with noble gases and Cl-36, Witwatersrand Basin, South Africa: Geochimica et Cosmochimica Acta, v. 67, p. 4597-4619.

Litynski, J. T., S. Plasynski, H. G. McIlvried, C. Mahoney, and R. D. Srivastava, 2008, The United States Department of Energy's Regional Carbon Sequestration Partnerships Program Validation Phase: Environment International, v. 34, p. 127-138.

Lorenz, J. C., and S. P. Cooper 2003, Tectonic setting and characteristics of natural fractures in Mesaverde and Dakota reservoirs of the San Juan Basin: New Mexico Geology, v. 25, p. $3-14$.

Lorenz, J. C., and R. E. Hill, 1992, Measurement and analysis of fractures in core, in J. W. Schmoker, E. B. Coalson, and C. A. Brown, eds., Geologic Studies Relevant to Horizontal Drilling: Examples from Western North America, Rocky Mountain Association of Geologists, p. 47-59.

Ma, L., M. C. Castro, C. M. Hall, and L. M. Walter, 2005, Cross-formational flow and salinity sources inferred from a combined study of helium concentrations, isotopic ratios, and major elements in the Marshall aquifer, southern Michigan: Geochemistry Geophysics Geosystems, v. 6, p. 21.

Molenaar, C. M., and J. K. Baird, 1992, Regional stratigraphic cross sections of Upper Cretaceous rocks across the San Juan Basin, northwestern New Mexico and southwestern Colorado, U.S. Geological Survey Open-File Report 92-257, sheets 1-3.

Nordbotten, J. M., D. Kavetski, M. A. Celia, and S. Bachu, 2009, Model for $\mathrm{CO}_{2}$ Leakage Including Multiple Geological Layers and Multiple Leaky Wells: Environmental Science \& Technology, v. 43, p. 743-749.

Orr, F. M., 2009, $\mathrm{CO}_{2}$ capture and storage: Are we ready?: Energy \& Environmental Science, v. 2, p. 449-458.

Osenbruck, K., J. Lippmann, and C. Sonntag, 1998, Dating very old pore waters in impermeable rocks by noble gas isotopes: Geochimica et Cosmochimica Acta, v. 62, p. 3041-3045.

Phillips, F. M., M. K. Tansey, L. A. Peeters, S. L. Cheng, and A. Long, 1989, An isotopic investigation of groundwater in the central San Juan Basin, New Mexico: Carbon 14 dating as a basis for numerical flow modeling: Water Resources Research, v. 25, p. 2259-2273.

Pittman, E. D., 1992, Relationship of porosity and permeability to various parameters derived from mercury injection-capillary pressure curves for sandstones: AAPG Bulletin, v. 76, p. 191-198.

PRISM Climate Group, 2009, 103-Year High-Resolution Temperature Climate Data Set for the Conterminous United States, PRISM Climate Group, Oregon State University, Spatial Climate Analysis Service, Oregon, accessed November 12, 2009, http://www.prism.oregonstate.edu/.

Pruess, K., 2008, On $\mathrm{CO}_{2}$ fluid flow and heat transfer behavior in the subsurface, following leakage from a geologic storage reservoir: Environmental Geology, v. 54, p. 1677-1686.

Rohmer, J., and O. Bouc, 2010, A response surface methodology to address uncertainties in cap rock failure assessment for $\mathrm{CO} 2$ geological storage in deep aquifers: International Journal of Greenhouse Gas Control, v. 4, p. 198-208. 
Rubel, A. P., C. Sonntag, J. Lippmann, F. J. Pearson, and A. A. Gautschi, 2002, Solute transport in formations of very low permeability: Profiles of stable isotope and dissolved noble gas contents of pore water in the Opalinus Clay, Mont Terri, Switzerland: Geochimica et Cosmochimica Acta, v. 66, p. 1311-1321.

Sacchi, E., J. L. Michelot, H. Pitsch, P. Lalieux, and J. F. Aranyossy, 2001, Extraction of water and solutes from argillaceous rocks for geochemical characterisation: Methods, processes, and current understanding: Hydrogeology Journal, v. 9, p. 17-33.

Schowalter, T. T., 1979, Mechanics of secondary hydrocarbon migration and entrapment: $A A P G$ Bulletin, v. 63, p. 723-760.

Scott, A. R., W. R. Kaiser, and W. B. Ayers, 1994, Thermogenic and secondary biogenic gases, San Juan Basin, Colorado and New Mexico-Implications for coalbed gas producibility: AAPG Bulletin, v. 78, p. 1186-1209.

Sheldon, A. L., D. K. Solomon, R. J. Poreda, and A. Hunt, 2003, Radiogenic helium in shallow groundwater within a clay till, southwestern Ontario: Water Resources Research, v. 39, p. 12.

Silin, D., T. W. Patzek, and S. M. Benson, 2009, A one-dimensional model of vertical gas plume migration through a heterogeneous porous medium: International Journal of Greenhouse Gas Control, v. 3, p. 300-310.

Snyder, G. T., W. C. Riese, S. Franks, U. Fehn, W. L. Pelzmann, A. W. Gorody, and J. E. Moran, 2003, Origin and history of waters associated with coalbed methane: I-129, Cl36, and stable isotope results from the Fruitland Formation, CO and NM: Geochimica et Cosmochimica Acta, v. 67, p. 4529-4544.

Stone, W. J., F. P. Lyford, P. F. Frenzel, N. H. Nizell, and E. T. Padgett, 1983, Hydrogeology and water resources of San Juan Basin, New Mexico: New Mexico Bureau of Mines and Mineral Resources Hydrologic Report 6, p. 70, 7 sheets.

Stute, M., J. F. Clark, P. Schlosser, W. S. Broecker, and G. Bonani, 1995, A 30,000-yr continental paleotemperature record derived from noble gases dissolved in groundwater from the San Juan Basin, New Mexico: Quaternary Research, v. 43, p. 209-220.

USGS, 2009, National Elevation Dataset (NED) 1 Arc Second, U.S. Geological Survey, accessed November 12, 2009, http://seamless.usgs.gov/products/1arc.php.

Weiss, R.F., 1971, Solubility of helium and neon in water and seawater: Journal of Chemical and Engineering Data, v. 16, p. 235-241.

Wilson, T., A. Wells, D. Peters, A. Mioduchowski, G. Martinez, J. Heath, and G. Koperna, submitted, Fracture evaluation of the Southwest Regional Partnership's San Juan Basin Fruitland coal carbon sequestration pilot site, New Mexico: AAPG Bulletin.

Yang, Y. L., and A. C. Aplin, 2007, Permeability and petrophysical properties of 30 natural mudstones: Journal of Geophysical Research-Solid Earth, v. 112, p. 14.

Yao, N., 2007, Introduction to the focused ion beam system, in N. Yao, ed., Focused ion beam systems: Basics and applications: Cambridge, UK, Cambridge University Press, p. 1-29.

Zhang, Y., C. M. Oldenburg, S. Finsterle, P. Jordan, and K. Zhang, 2008, Probability estimation of $\mathrm{CO}_{2}$ leakage through faults at geologic carbon sequestration sites, 9th International Conference on Greenhouse Gas Control Technologies, November 16-20, Washington D.C.

Zhou, Z., and C. J. Ballentine, 2006, He-4 dating of groundwater associated with hydrocarbon reservoirs: Chemical Geology, v. 226, p. 309-327. 
Zhou, Z., C. J. Ballentine, R. Kipfer, M. Schoell, and S. Thibodeaux, 2005, Noble gas tracing of groundwater/coalbed methane interaction in the San Juan Basin, USA: Geochimica et Cosmochimica Acta, v. 69, p. 5413-5428. 


\section{APPENDICES}

The following appendices document and preserve data and reports generated by the core analysis program of the Pump Canyon Site, NM, which was directed by the Southwest Partnership on Carbon Sequestration (SWP). Some of these appendices were not explicitly described in the above text.

\section{Appendix A. Field Core Handling Report}

Appendix A presents the original core handling report that was developed prior to the execution of the coring program in May 2008. The report was required by ConocoPhillips (the field site operator), Sandia National Laboratories, and the SWP to ensure clear planning of the field activities and to identify potential safety hazards of the field work. 


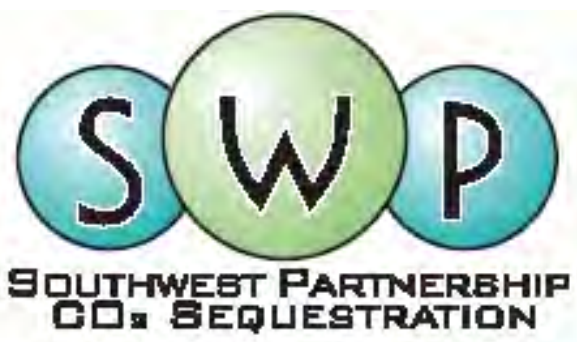

\section{Southwestern Regional Partnership for Carbon Sequestration (Phase 2)}

Procedures for Core Handling at the Pump Canyon $\mathrm{CO}_{2-}$ ECBM/Sequestration Demonstration, San Juan Basin, New Mexico

Prepared by:

Jason Heath and Lee Harris

New Mexico Institute of Mining and Technology

Scott Cooper

Sandia National Laboratories

April 21, 2008 


\section{Introduction}

This report details plans for handling core from the new $\mathrm{CO}_{2}$ injection well that ConocoPhillips will drill as part of the Phase 2 activities of the Southwest Regional Partnership on Carbon Sequestration. The core will be used in studies to further understanding of cap rock sealing behavior with respect to $\mathrm{CO}_{2}$.

The well site is located in Sec. 32, T31N, R8W, which lies east of Aztec, NM (Fig. 1). A total of $120 \mathrm{ft}$ of conventional vertical core will be collected, with approximately $60 \mathrm{ft}$ at both the top and bottom of the Kirtland Shale (Fig. 2).

Subsamples of the core will be preserved in the field for the laboratory analysis of helium concentration and isotopic signatures. We will use the helium data to characterize the transport properties of the shale and infer sealing behavior. The majority of the core will be delivered to TerraTek, Inc., in Salt Lake City, Utah, for petrophysical and petrological analyses, including measurements of gas breakthrough pressure and wettability.

Drilling and coring will most likely begin on April $26^{\text {th }}$.

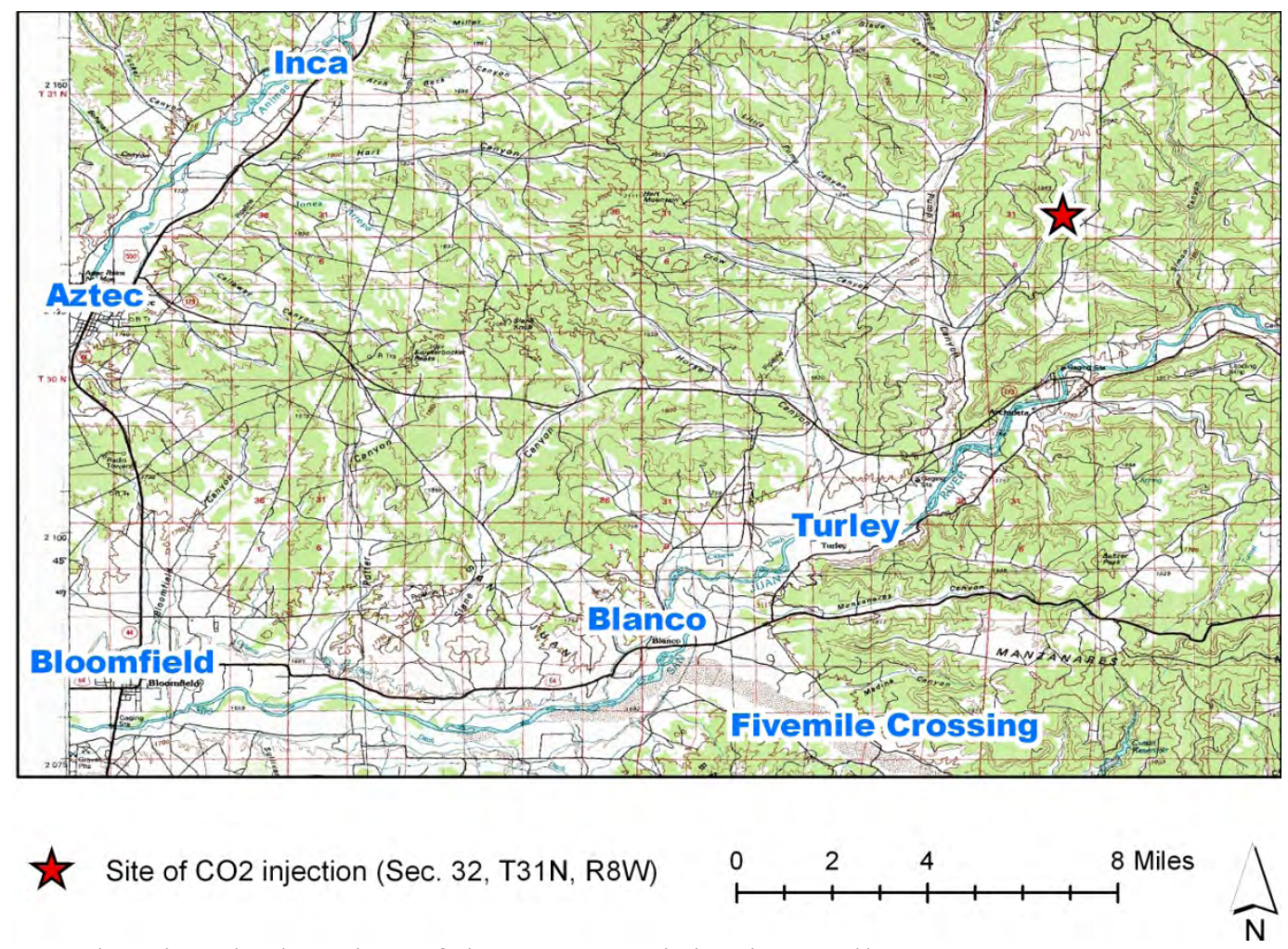

Fig. 1. Map showing the location of the new $\mathrm{CO}_{2}$ injection well. 


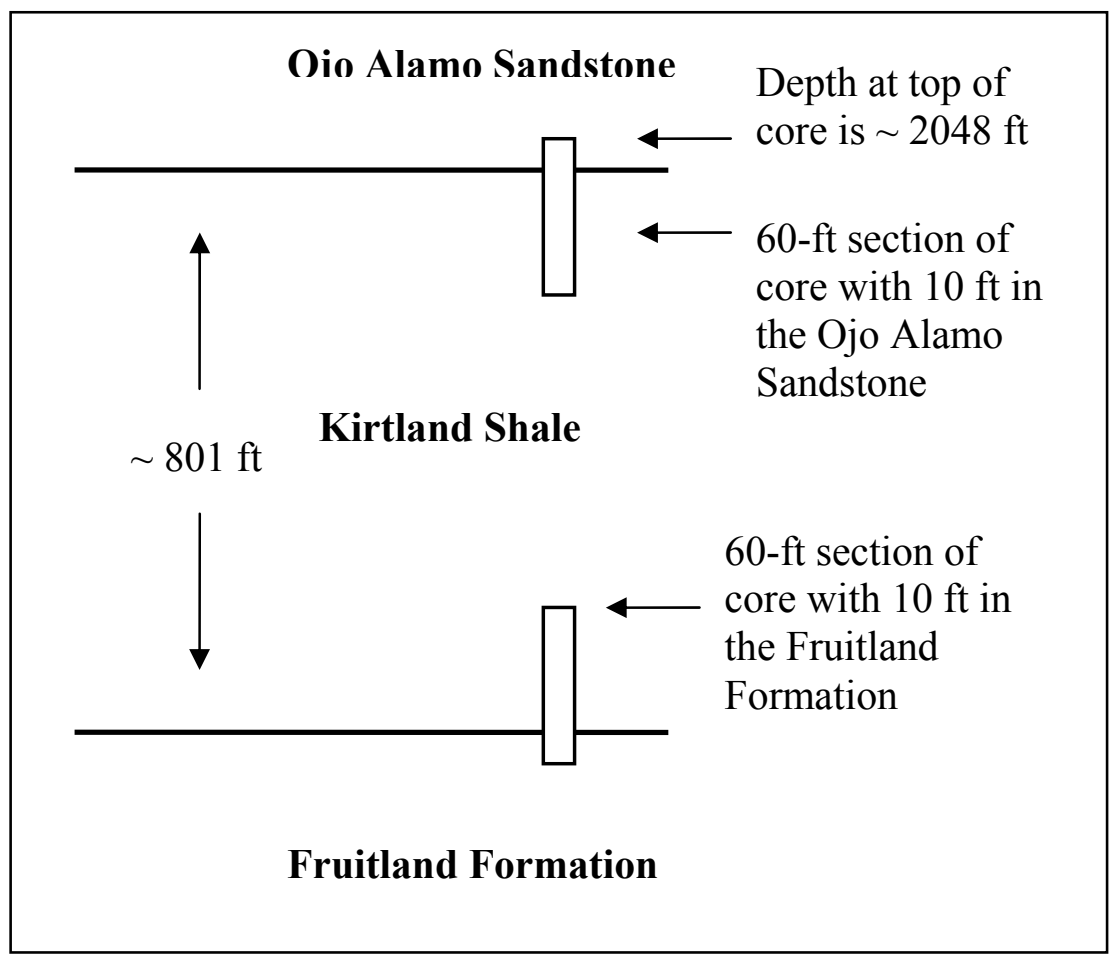

Fig.2. Schematic of the locations of vertical coring.

\section{Description of Core Handling Activities}

\subsection{Team Members and List of Activities}

The core handling team includes, respectively, three members from New Mexico Tech (NMT) and three from Sandia National Laboratories (SNL):

1. Jason Heath

2. Lee Harris

3. Reid Grigg

4. Scott Cooper

5. Randy Everett

6. Bill Holub

Five members of the team will be assigned to specific core handling activities (Table 1), whereas the remaining person, Dr. Grigg, will be available as the "gopher" to help with any unforeseen problems.

The core handling activities are listed in Table 1. ConocoPhillips has contracted Coring Services, Inc., to collect the 4-in diameter vertical core. Coring Services has requested that one member of the core-handling team help mark depths on the aluminum core barrels so that it can be cut into 3-ft sections (see Activity 1 on Table 1). 
Table 1. Major core handling activities associated with team members.

\begin{tabular}{|l|l|}
\hline \multicolumn{1}{|c|}{ Activity } & \multicolumn{1}{|c|}{ Team members } \\
\hline $\begin{array}{l}\text { 1. Mark depths on core barrels, cut core into 3-ft sections, } \\
\text { and place rubber end caps on core barrels. }\end{array}$ & $\begin{array}{l}\text { Coring Services and } \\
\text { Bill Holub }\end{array}$ \\
\hline $\begin{array}{l}\text { 2. Push core out of barrels at specific depth intervals and } \\
\text { choose locations of core subsamples. }\end{array}$ & $\begin{array}{l}\text { Scott Cooper and } \\
\text { Jason Heath }\end{array}$ \\
\hline $\begin{array}{l}\text { 3. Use the drill press to cut 1-in diameter by 3-in long } \\
\text { subsamples of core. }\end{array}$ & Lee Harris \\
\hline 4. Seal subsamples in ultra-tight, high vacuum canisters. & $\begin{array}{l}\text { Jason Heath and } \\
\text { Randy Everett }\end{array}$ \\
\hline 5. Load 3-ft core barrels into the trailer. & Everyone \\
\hline $\begin{array}{l}\text { 6. Transport core to TerraTek and deliver preservation } \\
\text { canisters to Noble Gas Laboratory at University of Utah. }\end{array}$ & $\begin{array}{l}\text { Lee Harris and Jason } \\
\text { Heath }\end{array}$ \\
\hline
\end{tabular}

Activities 2 through 4 relate to the major goal of properly preserving 12 subsamples of core for the laboratory analysis of helium concentration and isotopic signatures in the pore fluids. To prevent loss of helium, 1-in diameter by 3-in long subsamples of core will be placed into canisters with an extremely low leak rate. The canisters have been constructed from parts typically used for vacuum service. The subsamples will be cut using a drill press with cooling fluid that may be tap water, a dilute $\mathrm{KCl}$ solution, or mineral spirits. The cooling fluid chosen will depend on the whether the core samples will disintegrate when exposed to tap water. All fluids will be collected and not allowed to drain onto the ground. We are developing quality control and assurance protocols for drilling the subsamples and sealing them in the preservation canisters.

\subsection{Instructions for Activity 1}

The following is a list of activities, important issues or concerns, and instructions for Activity 1 of Table 1:

1. Pay attention from the dog house to the coring activities on the drill rig. This includes watching for any core that falls out of top or bottom of the core barrels onto the rig floor. Pay close attention to the orientation of any pieces of core that are dropped.

2. Assist Coring Services, if needed, to remove core from the core catcher. Use a hammer or a wrench as necessary.

3. For convenience, use a tape measure labeled in tenths of a foot to mark depths on the aluminum core barrels.

4. Ask the rig operator and mud logger for the depth at which coring began. Sometimes rig operators and loggers may not report the same depth. Ask anyone else involved with the drilling who might know the depth at which coring began.

5. Core will most likely be placed on the catwalk. This is where the core will be marked and cut, using an "island cut", into 3-ft sections. 
6. Use the start-of-coring depth to begin marking depths every foot on the outside of the aluminum core barrel.

7. Assume that any loss of core was at the bottom of the length of the core, not at the top.

8. If the core (i.e., the rock itself) does not lie flush with the top of the core barrel, measure the distance from the core to the top of the core barrel (Fig. 3). Using that measurement, mark a line on the top of the core barrel with the start-of-coring depth. This line will be the datum from which all subsequent marked depths will be based.

1. Measure the distance that the core lies from the top of the core barrel.

2. Draw a line on top and mark the start-of-coring depth.
Measuring tape marked in tenths of a foot
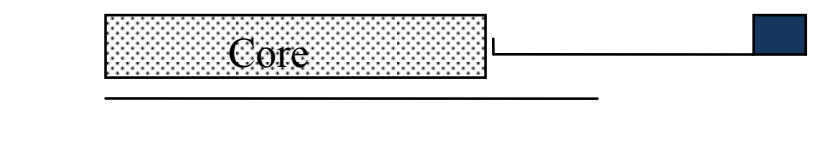
1. Measure the distance that the core lies from the top of the core barrel.
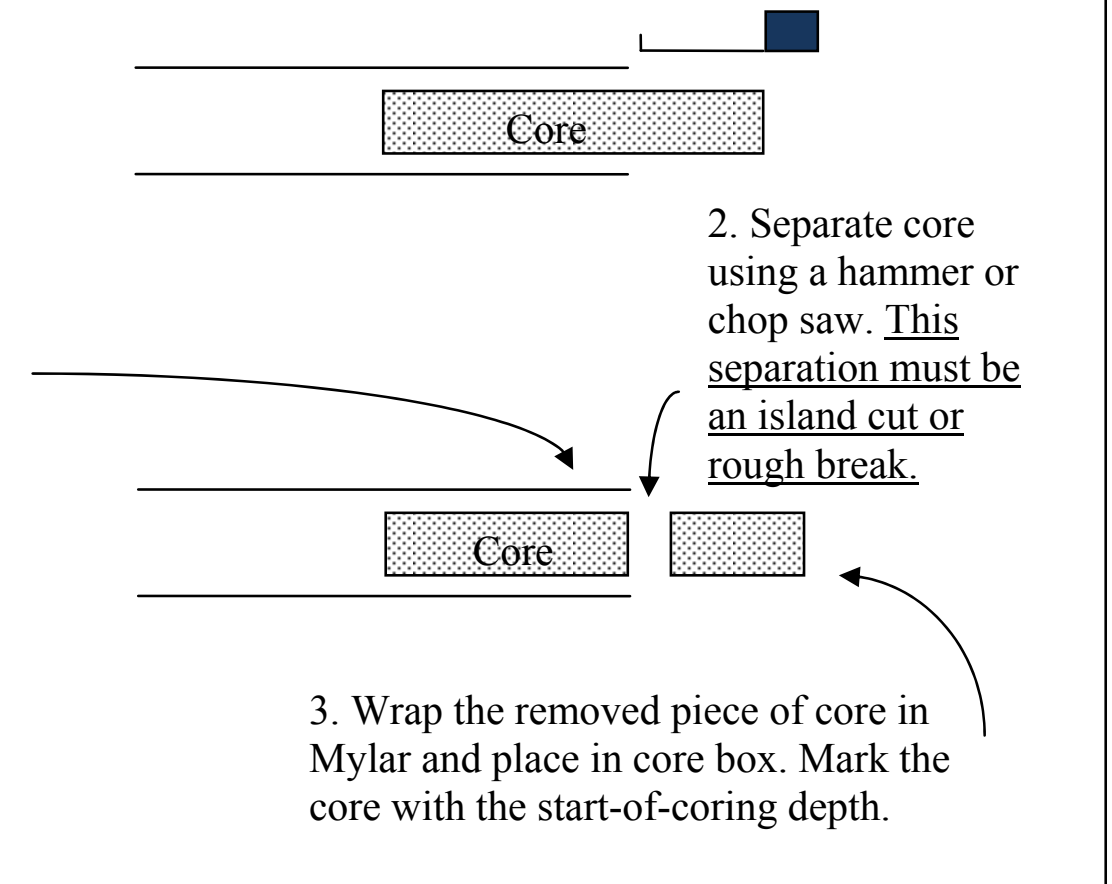

Fig. 4. Schematic cross-section of core barrel with instructions for marking the depth near top of core barrel, if core extends out the top of the barrel

10. Use indelible paint pens for writing on aluminum core barrels.

11. Mark the orientation of the core using black and red paint pens. This is done by placing two stripes of black and red, next to each other, along the entire length of the core. The lines should be such that if a person were to be at the bottom of the barrel looking towards the top (i.e., the bottom of the hole looking up), the red line would be on the right (Fig. 5).

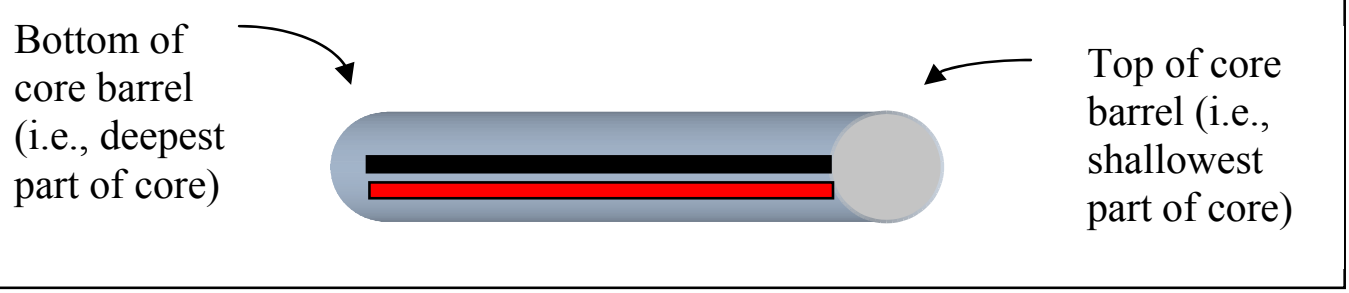

Fig. 5. Schematic of core barrel with red and black lines, which indicate orientation of the core.

12. Depths should be marked every foot along the length of the core barrel.

13. With the assistance of Coring Services, cut through the aluminum core barrel and the core with a chop saw every three feet. Cut on the depth mark. Do not cut straight through with a planar cut; instead, use an island cut. The island cut is made by cutting towards the 
middle of the core, then rotating the core and cutting towards the middle again. This is done until a small neck of rock remains. The neck of rock can then be broken so that the core on either side can be fit together again. Without island cuts, the core can rotate, making it difficult to impossible to properly place the core back together. Improper placement may preclude the interpretation of fractures and other features.

14. The top and bottom of the 3 -ft core-barrel tubes should be labeled (e.g., T1, T2, T3, etc.).

15. The 3-ft core-barrel tubes should be sealed with rubber end caps from Coring Services. Attach the caps with duct tape and/or hose clamps. Clamps are preferable because the tubes will need to be reopened to obtain subsamples of core for preservation for the helium analysis.

16. Coordinate with the rig supervisor on the time needed to properly label and handle the core.

17. Acquire a copy of the core report, which will have information such as weight on bit, core barrel parameters, starting depth, time for cutting, rate of penetration, etc.

18. Any loose pieces of core not in the aluminum barrels should be wrapped in Mylar and placed in core boxes with proper labels.

19. If questions arise while in the field, John Keller at TerraTek can be contacted to give guidance. His office number is: 801-584-2467.

\subsection{Instructions for Activity 2}

The following is a list of activities, important issues or concerns, and instructions for Activity 2:

1. The goal is to determine the locations along the core for 12 subsamples of core for the preservation of helium and other noble gases in the pore fluids.

2. In general, the subsamples should be evenly spaced across the $120 \mathrm{ft}$ of core (i.e., one sample every $10 \mathrm{ft}$ ). However, the exact location will depend on factors discussed below.

3. Using a cart or wheel barrow, carry the labeled 3-ft barrels of core over to the location of the drill press.

4. Using a pole attached to a round piece of wood (or plastic) less than 4-in in diameter, push the core onto a tray made from a 6-in diameter PVC pipe. Remove any jagged metal, if needed, from the ends of the core barrels using a deburring tool.

5. Inspect the core and note lithology, fractures, fissility, etc.

6. For samples within the Kirtland, choose the location for subcoring based on regions with relatively high clay content. Subcoring locations with high clay content adjacent to fractures are preferable.

7. One or two samples will be collected from the Ojo Alamo Sandstone. Regions with relatively low permeabilities, based on clay and silt content opposed to sand, should be chosen.

8. Mark locations for subcoring by placing a thin section of Mylar on top of core.

9. Carefully transfer the core to those in charge of using the drill press.

10. Core should only be examined immediately prior to the using the drill press to minimized disturbance to core before subcoring. Disturbance of core may facilitate loss of helium along microfactures or stress-release fractures. 


\subsection{Instructions for Activity 3}

The following is a list of activities, important issues or concerns, and instructions for Activity 3 :

1. The core will be subsampled with the drill press in the direction perpendicular to the long axis of the core.

2. Place the core onto the wooden tray designed to hold the core below the drill.

3. Use a 1-in drill bit. Use the 1.5-in if the smaller bit does not work. Extra bits will be available.

4. The cooling fluid should be tap water at first. If the core disintegrates, use a dilute $\mathrm{KCl}$ solution or mineral spirits. The cooling fluids will be held in a bucket attached to a tripod. Tubing will allow the fluid to flow to the cutting area.

5. Coring should be started slowing.

6. Use a trim saw to cut off the part of the subsamples that was the original outside surface of the core. The length of the subsample should be approximately 3 in.

7. After subcoring, immediately weigh the subsample and then place it into a preservation canister. Hand the canister over to the person who will seal it.

8. Minimize agitation of the core during subcoring.

9. Use gloves when handling the core.

10. Subcoring should occur immediately prior to placement in the preservation canisters. Subsamples of core should not be left to degas helium into the atmosphere.

11. Subcoring will be done within or over a catch basin. No fluids will contact the ground. We will contact ConocoPhillips for instructions on disposal of fluids.

12. Place the core back into the core barrels and reseal using the rubber end caps and duct tape or hose clamps.

\subsection{Instructions for Activity 4}

The following is a list of activities, important issues or concerns, and instructions for Activity 4:

1. The subsamples of core will be sealed in high-vacuum, low leak-rate canisters (Fig. 6).

2. Receive the canisters with core subsamples from those operating the drill press.

3. Place the large copper gasket onto the canister.

4. Immediately placed the lid onto the canister and the copper gasket. Seal the canister by finger tightening ten bolts with washers.

5. Tighten the bolts in pairs in a cross-hatch pattern as shown on Fig. 7. Go through the pattern tightening the bolts three times until the torque on each bolt is $190 \mathrm{in}-\mathrm{lb}$. Tightening must be done carefully to ensure that the lid closes evenly onto the canister.

6. Connect the valve on the lid into the vacuum line system. Use proper gaskets for the VCR fittings. The fittings should be finger tightened and then tightened to a quarter of a full turn.

7. Place the canister under vacuum and purge using ultra-high purity nitrogen, which should be connected to the vacuum line. The pump down and purging process should follow this process (Shala, pers. com., 2007): 

a. pump for 30 seconds;
b. flush with 5-10 psig nitrogen;
c. pump for 30 seconds;
d. flush with 5-10 psi nitrogen;
e. pump for 45 seconds; and
f. close the valve at top of canister and remove canister from vacuum line.

8. Repeat the closing and sealing process in the same manner for all subsamples. Perform the procedure on an empty canister after sealing all other canisters. The empty canister will serve as a blank.

9. For quality assurance, a sheet listing the steps of the closing and sealing process will be taken to the field. As each step is finished properly, check marks on the sheet besides the steps will be made.

10. The canisters will be delivered to the Noble Gas Laboratory of the University of Utah for analysis of helium and other noble gases.
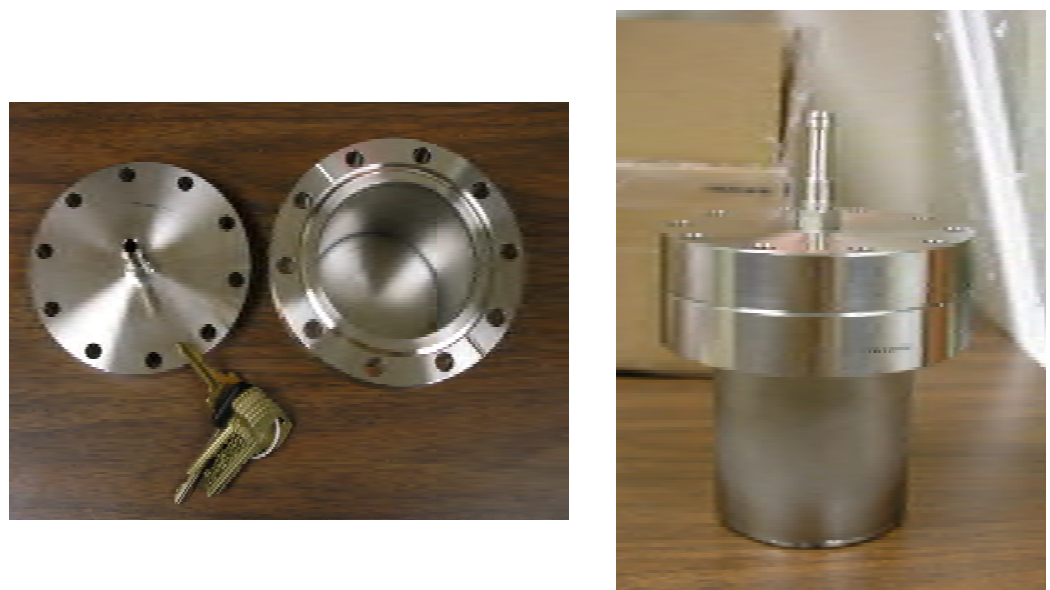

Fig. 6. Photographs of canisters built from high vacuum equipment to preserve noble gases that will degas from pore fluids in core samples. 


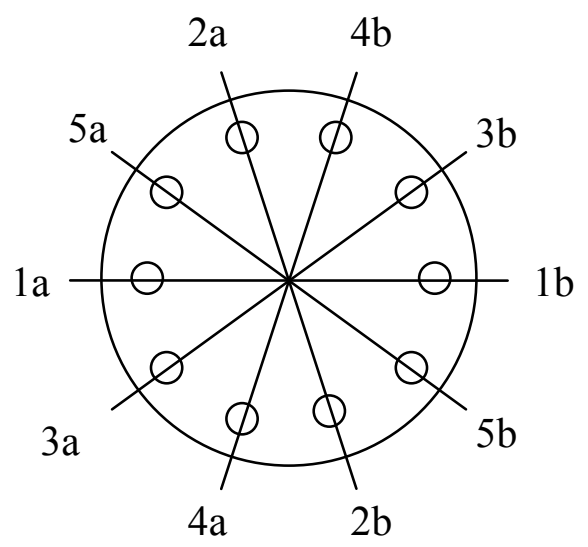

Fig. 7. Plan view schematic of lid of preservation canisters with lines indicating tightening pattern. "1a" stands for the bolt chosen to be tightened first. " $1 b$ " is the corresponding bolt in the pair that lies in line with 1a. "2a" and " $2 \mathrm{~b}$ " comprise the second pair that should be tightened and so on.

\subsection{Instructions for Activities 5 and 6}

The following is a list of activities, important issues or concerns, and instructions for Activity 5:

1. A trailer capable of transporting $\sim 3,000 \mathrm{lbs}$ will be driven to the site.

2. Load the 3 -ft core barrels into the trailers. Use two people, if needed, to avoid straining when picking up the core.

3. Secure the core on the trailer using rope.

4. Two members of the coring team will transport the core to TerraTek in Salt Lake City, Utah. Transport should occur immediately following coring activities.

\section{Equipment needed for Core Handling}

The majority of the equipment in Table 2 has been obtained by New Mexico Tech. Sandia National Laboratories will supply the following:

1. generator;

2. first-aid kit;

3. 305-gallon water tank; and

4. backup drill press.

To be allowed on site by ConocoPhillips, the personal protection equipment of Category 1 in Table 2 has been included.

The list of equipment will be provided to ConocoPhillips prior to coring to make sure that these items can be brought to or near the well site. Items or activities of special concern include: 
1. using a U-Haul truck for shelter in which the subsamples of core will be drilled and preserved;

2. using water, $\mathrm{KCl}$ solutions, or mineral spirits as cooling fluids for the drill press;

3. using electrical equipment such as the vacuum pump and workshop lights;

4. tank of a nitrogen gas.

We do not know what cooling fluid will be best when we drill of subsamples of core. We will most likely use tap water or $\mathrm{KCl}$ solution. We will obtain $\mathrm{KCl}$ solution from the drillers, if possible. We will dispose of cooling fluids ourselves.

\section{National Environmental Policy Act (NEPA)}

The Department of Energy approved the environmental questionnaires that were completed for this project. The NEPA requirements have been met. We have copies of the NEPA paperwork. These will be made available, if needed. 
Table 2. List of equipment for coring handling activities.

\begin{tabular}{|c|c|c|}
\hline Equipment Category & Item \# & Description \\
\hline \multirow{7}{*}{$\begin{array}{l}\text { 1. Personal protection } \\
\text { equipment }\end{array}$} & 1 & Steel-toed boots \\
\hline & 2 & Hard hats \\
\hline & 3 & Safety glasses \\
\hline & 4 & Gloves \\
\hline & 5 & Fire-retardant overalls \\
\hline & 6 & Fire extinguisher \\
\hline & 7 & Fire-aid kit \\
\hline \multirow{12}{*}{$\begin{array}{l}\text { 2. Handling aluminum } \\
\text { core barrels and } \\
\text { preparing core for } \\
\text { transport }\end{array}$} & 8 & Diagraph GP-X paint markers in black, red, and white \\
\hline & 9 & 25 tape measures, engineer's scale (marked in tenths) \\
\hline & 10 & Ratchet straps and rope \\
\hline & 11 & Core packing boxes (for loose pieces of core) \\
\hline & 12 & Utility knife or carpet-hook knife for removing burrs from the core barrel \\
\hline & 13 & Duct tape \\
\hline & 14 & Chop saw with cutting blades (provided by Coring Services) \\
\hline & 15 & Hammer (or wrench) for removing core from the core catcher \\
\hline & 16 & Rags for wiping mud from core \\
\hline & 17 & 1 gallon Ziploc bags \\
\hline & 18 & Roll of mylar (like what the butcher uses) for wrapping core \\
\hline & 19 & Rubber end caps (provided by Coring Services) \\
\hline \multirow{10}{*}{$\begin{array}{l}\text { 3. Cutting subsamples } \\
\text { of core }\end{array}$} & 20 & Pole with round piece of wood on end for pushing core out of barrel \\
\hline & 21 & Scale for weighing subsamples of core \\
\hline & 22 & Drill press with $15 \mathrm{amp}, 120 \mathrm{~V}$ coring motor and drill bits \\
\hline & 23 & Trim saw \\
\hline & 24 & 6" PVC pipe cut in half for holding sections of core \\
\hline & 25 & Wooden frame for holding core during drilling \\
\hline & 26 & Tripod for holding cooling fluid \\
\hline & 27 & 305 gallon water container; water used as cooling fluid for drill press \\
\hline & 28 & Water-catcher oil pan or rubber maid container \\
\hline & 29 & Mineral spirits, cooling fluid (in case water disintegrates samples) \\
\hline
\end{tabular}


Table 2 (continued). List of equipment for coring handling activities

\begin{tabular}{|l|c|l|}
\hline Equipment Category & Item \# & \multicolumn{1}{|c|}{ Description } \\
\hline \multirow{4}{*}{$\begin{array}{l}\text { 4. Preserving subsamples } \\
\text { of core }\end{array}$} & 30 & 13 preservation canisters (see Fig. ) \\
\cline { 2 - 3 } & 31 & Torque wrench for bolting shut the canisters \\
\cline { 2 - 3 } & 32 & Anti-seize for bolts on preservations canisters \\
\cline { 2 - 3 } & 33 & $99.999 \%$ purity nitrogen tank with regulator \\
\cline { 2 - 3 } & 34 & Rotary vane vacuum pump with 115 V, 60 Hz supply voltage \\
\cline { 2 - 3 } & 35 & Vacuum gauge with 115 V power supply \\
\cline { 2 - 3 } & 36 & Assembly support for attaching canisters to nitrogen tank and vacuum gauge \\
\cline { 2 - 3 } & 37 & 1/4" Copper, roll - refrigerator grade soft copper \\
\hline \multirow{4}{*}{ a. Working conditions } & 38 & Flaring tool \\
\cline { 2 - 3 } and miscellaneous items & 39 & Silicon \\
\cline { 2 - 3 } & 40 & Workshop lights \\
\cline { 2 - 3 } & 41 & Generator \\
\cline { 2 - 3 } & 42 & Trailer to transport core to TerraTek in Salt Lake City. UT \\
\cline { 2 - 3 } & 43 & Field notebook \\
\cline { 2 - 3 } & 44 & All weather writing pens and pencils \\
\cline { 2 - 3 } & 46 & Plastic gloves \\
\cline { 2 - 3 } & 47 & Cold weather clothing \\
\cline { 2 - 3 } & 48 & Cart \\
\cline { 2 - 3 } & 49 & Tables \\
\hline 6. Transportation of core & 50 & Large trailer hitched to truck for transporting core \\
\hline
\end{tabular}




\section{Appendix B. Core Handling and Data Collected by TerraTek, a Schlumberger Company}

TerraTek performed petrologic and petrophysical measurements on fresh core samples from the EPNG Com A Inj 1 well, which are given herein. The company also performed handling and preservation procedures, which included wrapping core in Mylar plastic film, aluminum foil, and dipping some core samples in sealant to prevent drying.

\section{B.1 Petrologic Evaluation of Kirtland Shale Core - San Juan BU EPNG Com A Inj \#1 Well, TR08-502488 Report}

TerraTek performed petrologic evaluation of several Kirtland Formation core samples, the locations of which were first identified by Jason Heath and Scott Cooper (formerly of Sandia National Laboratories) during a preliminary examination of the core in May 2008. The depth locations were chosen to characterize major lithostratigraphic units of the Kirtland Formation core and to obtain petrologic data near to locations of plugs for noble gas analysis. TerraTek's petrologic report follows: 


\section{Petrologic Evaluation of Kirtland Shale Core \\ - San Juan BU EPNG Com A Inj \#1 Well -}

Prepared for:
ConocoPhillips
3401 E. 30th Street
Farmington, NM

87402

Attention:

Mr. Ryan Frost

Mr. Jason Heath

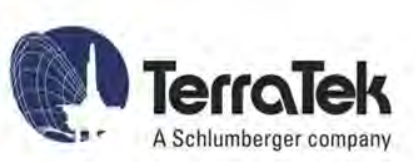

1935 S. Fremont Drive • Salt Lake City, Utah 84104

Telephone (801) 584-2400

FAX (801) 584-2406
TR08-502488

October 2008 


\section{Table of Contents}

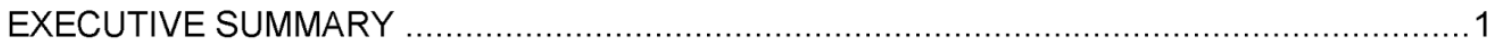

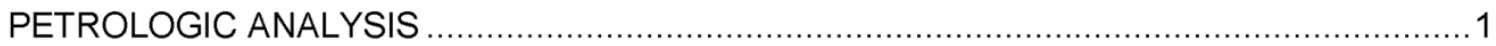

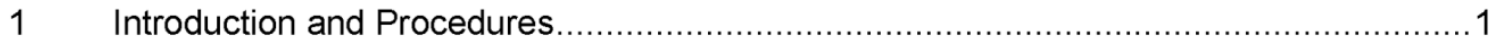

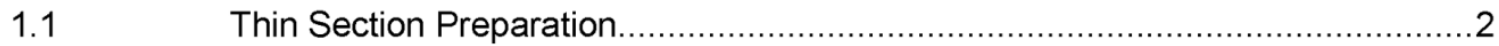

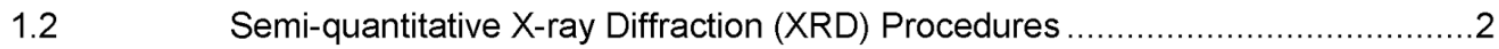

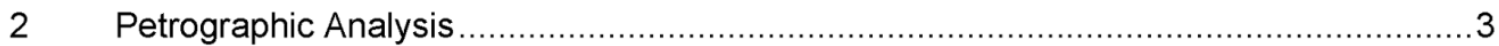

2.1 Argillaceous mudstone and sandy/silty argillaceous mudstone ........................

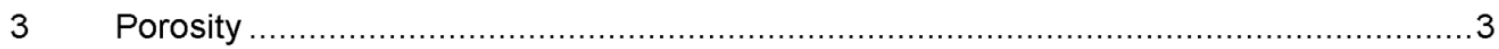

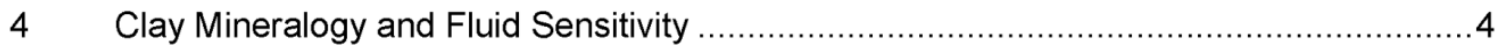

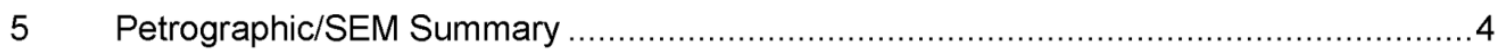

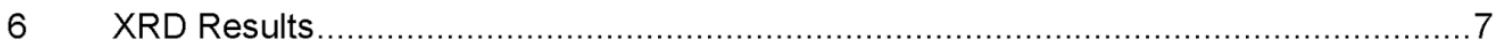




\section{EXECUTIVE SUMMARY}

Core samples of Kirtland Shale recovered from EPNG's Com A Inj \#1 Well in the San Juan Basin consist of poorly laminated to mottled argillaceous mudstones with variable silt and sand content. Both core and petrologic examination reveal evidence of soil-forming processes. Total organic content is negligible, and matrix clays include significant amounts of smectite and highly expandable mixed layer illite-smectite. The rocks are not potential reservoir.

The risk of fresh water sensitivity is high due to large amounts of expandable clays. Smectite and mixed layer illite/smectite with $15-40 \%$ expandability are the predominant clay species. Total expandable clays of $11-23 \%$ are determined by XRD analysis. Expected sensitivity to acid-based fluids is also high, due to the presence of significant amounts of iron-bearing chlorite in most of the samples $(0-13 \%)$.

\section{PETROLOGIC ANALYSIS}

\section{Introduction and Procedures}

At the request of $\mathrm{Mr}$. Ryan Frost of ConocoPhillips, petrologic evaluation was conducted on selected core samples from EPNG's Com A Inj \#1 Well in the San Juan Basin. The following report includes a discussion of composition, texture, cements and porosity based on general thin section examination and scanning electron microscopy (SEM) of 7 samples. Whole-rock Xray diffraction $(\mathrm{XRD})$ analysis was also performed to better constrain mineralogy and potential reservoir sensitivity issues. Descriptions are complimented by digital, annotated photomicrographs presented in the accompanying CD. XRD results are included at the end of this report.

All selected petrographic samples, associated depths, and lithotypes are listed in Table P1. Generalized lithotypes are based on the dominant texture and composition observed in thin section. 
Table P1. Petrologic Testing Matrix

\begin{tabular}{|c|c|c|c|c|c|}
\hline $\begin{array}{c}\text { Sample } \\
\text { No. }\end{array}$ & $\begin{array}{c}\text { Sample } \\
\text { Depth } \\
\text { (ft) }\end{array}$ & Lithotype & TS & SEM & XRD \\
\hline CP-1 & 2048.25 & sandy argillaceous mudstone & $\checkmark$ & $\checkmark$ & $\checkmark$ \\
\hline CP-2 & 2052.06 & sandy argillaceous mudstone & $\checkmark$ & $\checkmark$ & $\checkmark$ \\
\hline CP-3 & 2055.20 & argillaceous mudstone & $\checkmark$ & $\checkmark$ & \\
\hline CP-4 & 2062.30 & sandy argillaceous mudstone & $\checkmark$ & $\checkmark$ & $\checkmark$ \\
\hline CP-5 & 2067.98 & sandy argillaceous mudstone & $\checkmark$ & $\checkmark$ & $\checkmark$ \\
\hline CP-6 & 2692.25 & argillaceous mudstone & $\checkmark$ & $\checkmark$ & $\checkmark$ \\
\hline CP-7 & 2697.15 & silty argillaceous mudstone & $\checkmark$ & $\checkmark$ & $\checkmark$ \\
\hline \multicolumn{2}{|c|}{ Total } & 7 & $\mathbf{7}$ & $\mathbf{7}$ \\
\hline
\end{tabular}

\subsection{Thin Section Preparation}

Core pieces were initially impregnated with a low-viscosity fluorescent red-dye epoxy resin under high vacuum to highlight porosity types. The impregnated samples were surfaced, mounted to standard $(24 \mathrm{~mm} \times 46 \mathrm{~mm})$ thin section slides, and ground to a thickness of approximately 30 microns. The thin sections were then stained with a mixture of potassium ferricyanide and Alizarin Red ' $S$ ' to aid in identification of carbonate minerals. The prepared sections were examined and digitally imaged at various magnifications under plane-polarized, cross-polarized, and reflected UV light using a Nikon polarizing binocular microscope equipped with a Spot Insight digital camera, reflected light source, and various UV filters. At least two images (one at lower magnification, one at higher magnification) were collected for each sample.

\subsection{Semi-quantitative X-ray Diffraction (XRD) Procedures}

Bulk Analysis - Representative splits of the selected bulk samples are ground using a McCrone micronizing mill and loaded into aluminum sample holders. The powdered samples are

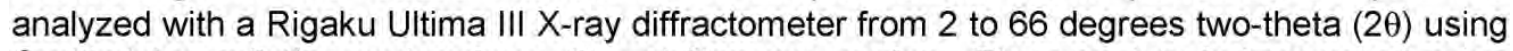
$\mathrm{Cu} \mathrm{K}$-alpha radiation and various slit and filter geometries. The raw data is interpreted using JADE software, which identifies the mineralogy based on peak profile fitting and whole pattern fitting methods. This analysis yields semi-quantitative analysis of the whole rock and best characterizes overall mineralogy and amount of clay in the bulk sample.

The percent expandability is the total amount of swelling clay in the whole rock sample and is determined by adding the amounts of discrete smectite and interlayered smectite in mixed-layer clays in the whole rock sample. For example, a bulk sample with 25 percent mixed-layer illitesmectite that is composed of 20 percent interlayered smectite is approximately 5 percent expandable.

\section{TerraTek}


Clay Analysis - Bulk samples are crushed and disaggregated to obtain a sample less than 4 microns, decanted and centrifuged. Resulting slurries are sedimented on glass slides, and scanned after air-drying and vapor glycolation treatments. Clay minerals are identified and their approximate weight percentages are determined by comparison with mixtures of standard clay minerals in known percentages. XRD analysis of the clay size fraction yields the relative abundance of the clay minerals and determines the amount of expandability (amount of swelling clay) in the mixed-layer clays. The amount of interlayered smectite (swelling clay) in mixedlayer illite/smectite is used to determine the percent expandability of whole rock samples.

\section{Petrographic Analysis}

The seven core samples in the studied interval are classified as argillaceous mudstone, sandy argillaceous mudstone, or silty argillaceous mudstone. Lithotype nomenclature is based on grain-supported vs. matrix-supported texture, and dominant composition of the matrix. The lithotypes are described in the following section.

\subsection{Argillaceous mudstone and sandy/silty argillaceous mudstone}

Samples from the cored interval comprise mudstones with poor lamination or mottled texture. The rocks are entirely matrix-supported, with variable amounts of dispersed detrital silt and sand. The matrix composition is argillaceous, and XRD determines a mixed composition including predominantly mixed layer illite-smectite and smectite, with subordinate amounts of chlorite and locally abundant kaolinite. Mottled color, along with apparent root material, root casts, and illuviation structures observed in thin section and SEM are evidence of soil-forming processes. Total organic content is negligible in the samples, with measured values less than $0.20 \%$ by weight.

Silt to medium sand-sized grains in the samples are composed of quartz, alkaline feldspar, plagioclase, and volcanic rock fragments of both argillaceous and chert-replaced types. A few micas are visible as accessories, particularly chlorite and biotite. No faunal grains are observed.

The most common secondary mineral noted in these mudstones is authigenic quartz, occurring as replacements in volcanic and lithic grains. Small amounts of calcite, ferroan calcite, dolomite, ferroan dolomite and pyrite are also present as crystals within the matrix, or associated with root structures.

\section{Porosity}

Several porosity types are present in the selected samples, the most prominent of which are induced microfractures. Intergranular/intercrystalline micropores and pores associated with decayed organic material are interpreted as natural. Pore types are described below:

$>$ Induced porosity [0.005 to $0.02 \mathrm{~mm} ; 5$ to 20 microns] is pervasive in the suite, and is typical of rocks with significant amounts of expandable clays. Induced pores tend to form lenses between elongate clay ridges, or pock-like cavities in the matrix (SEM

\section{P. TerraTek}


Images 20, 26 and 32). Laminae or parting surfaces are interpreted as induced in some samples (SEM Images 2 and 21). Induced pores are not present in-situ, and may introduce error in porosity and permeability measurements.

$>$ Root and organic particle casts [0.002 to $0.02 \mathrm{~mm} ; 2$ to 20 microns] are observed in both thin section and SEM (SEM Images 4 and 28). These voids are left by organic material which has decayed. Pores tend to be enclosed in envelopes of well-aligned clays (SEM Images 16 and 19), and contribute little to effective porosity.

$>$ Matrix-hosted intercrystalline microporosity $[<0.005 \mathrm{~mm}$; up to 5 microns] is the typical porosity type in most mudstones. It comprises tiny voids between clay flakes and cements, and within porous carbonaceous patches. The pores are tiny and poorly connected. In the case of expandable clays, pores visible under SEM represent a maximum size and dehydrated condition, and therefore are assumed to be smaller or absent in situ.

\section{$4 \quad$ Clay Mineralogy and Fluid Sensitivity}

The clay fractions of argillaceous sandy mudstones, sandy argillaceous mudstones, and silty argillaceous mudstones in this suite consist of mixtures of predominantly expandable clays, of which smectite and illite-smectite are the most abundant. Illite-smectite ranges from $5 \%$ to $40 \%$ expandable interlayers. Chlorite is present in amounts from $0 \%$ to $13 \%$.

Overall matrix expandability is high in the suite (total expandable clays 11-23\%). Reservoir sensitivity related to the water-sensitive clays is considered high.

Iron-bearing minerals in the mudstones include chlorite, minor ferroan calcite and dolomite, and minor pyrite. Reaction of these iron-bearing constituents with acid-based completion fluids could produce ferric iron hydroxide gels, which may act to clog pores and reduce permeability. Reservoir sensitivity to acid based completion fluids should be considered.

\section{Petrographic/SEM Summary}

Tables P2 and P3 below summarize the petrographic characteristics of the selected core sample from the studied well. These tables are also presented in electronic format on the accompanying $C D$.

\section{(1.. Terratek}




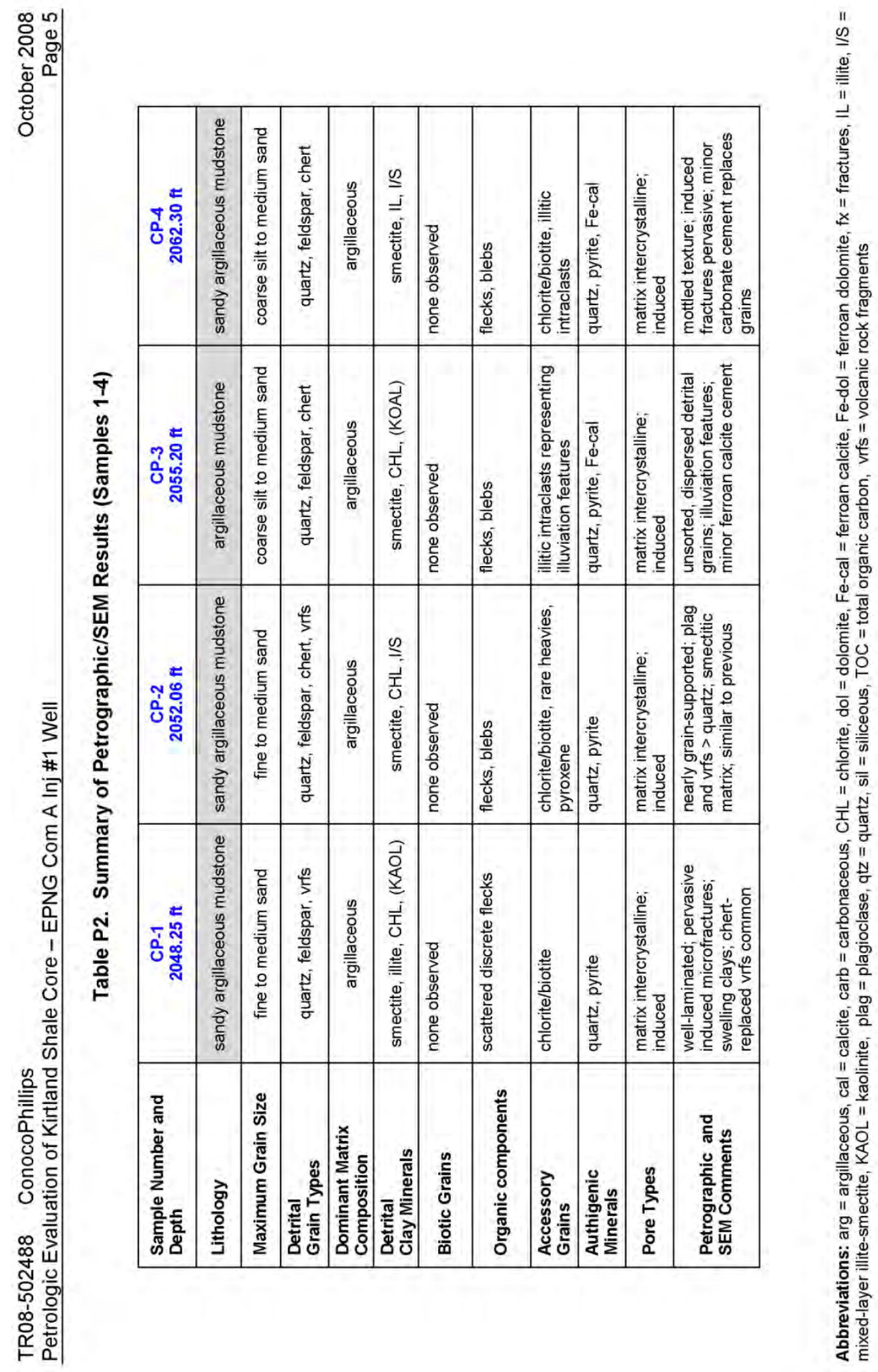




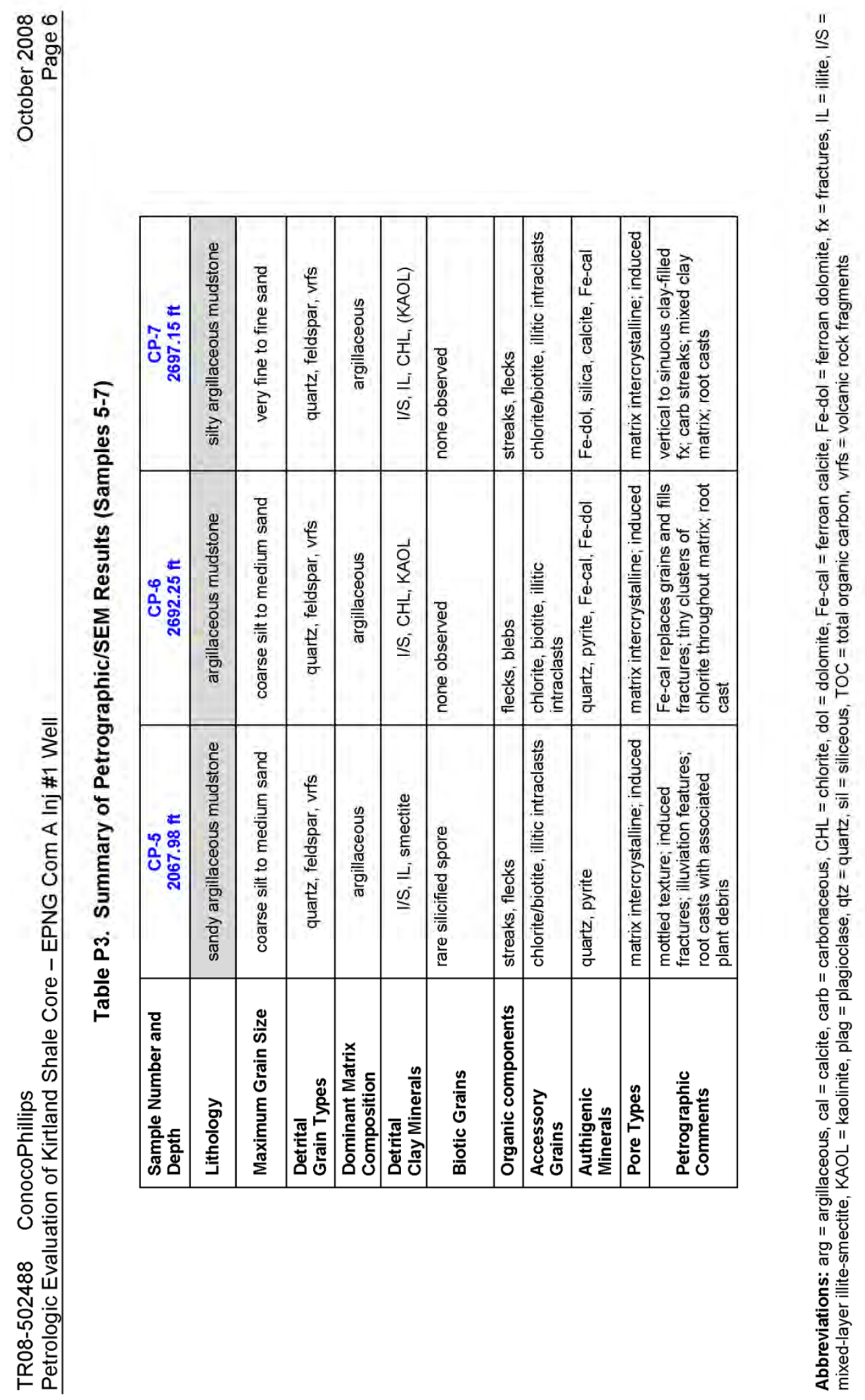




\section{$6 \quad$ XRD Results}

Table P4 presents results of semi-quantitative X-ray diffraction analysis for seven Kirtland Shale core samples. The upper portion of each table lists the whole rock or bulk mineralogy, and relative proportions of the clay minerals in the bulk samples, and the lower portions list the clay mineralogy of the $<4$ micron size fraction. All percentages represent relative abundances of the crystalline phases by weight.

A few additional comments follow:

$\checkmark$ Carbonaceous material cannot be accurately detected by XRD because of typically poor crystallinity.

$\checkmark$ Ferroan composition of calcite and dolomite is confirmed through thin section analyses.

$\checkmark$ Micromicas are recognized by X-ray diffraction as illite and chlorite. Glauconite has an illite crystal structure.

$\checkmark$ Total expandable clay is the sum of the smectite mineral \% and the expandable faction of the illite/smectite \%.

$\checkmark$ Whole rock (bulk) XRD data provides the best representation of reservoir mineralogy. 
TR08-502488 ConocoPhillips

Table P6. Whole Rock and Clay X-Ray Diffraction Data

\begin{tabular}{|c|c|c|c|c|c|c|c|}
\hline \multicolumn{8}{|l|}{$\begin{array}{l}\text { WHOLE ROCK } \\
\text { MINERALOGY }\end{array}$} \\
\hline SAMPLE ID & 1 & 2 & 3 & 4 & 5 & 6 & 7 \\
\hline DEPTH (FT) & 2048.25 & 2052.06 & 2055.20 & 2062.30 & 2067.98 & 2692.25 & 2697.15 \\
\hline QUARTZ & 5 & 11 & 37 & 23 & 12 & 21 & 21 \\
\hline K-FELDSPAR & 11 & 15 & 15 & 9 & 10 & 10 & 6 \\
\hline PLAGIOCLASE & 18 & 26 & 2 & 14 & 12 & 13 & 22 \\
\hline CALCITE & 0 & 1 & 2 & 0 & 1 & 1 & 0 \\
\hline ANKERITE/FE-DOLOMITE & 1 & 3 & 0 & 1 & 1 & 1 & 1 \\
\hline DOLOMITE & 0 & 0 & 0 & 0 & 0 & 0 & 0 \\
\hline PYRITE & 0 & 0 & 2 & 1 & 1 & 1 & 0 \\
\hline TOTAL NON-CLAY & 35 & 56 & 58 & 48 & 38 & 48 & 50 \\
\hline SMECTITE & 23 & 22 & 21 & 19 & 5 & 3 & 4 \\
\hline ILLITE/SMECTITE (I/S) & 4 & 9 & 2 & 11 & 43 & 28 & 20 \\
\hline ILLITE+MICA & 22 & 0 & 0 & 13 & 14 & 0 & 11 \\
\hline KAOLINITE & 5 & 3 & 5 & 1 & 0 & 9 & 5 \\
\hline CHLORITE & 12 & 10 & 13 & 7 & 0 & 12 & 10 \\
\hline TOTAL CLAY & 65 & 43 & 42 & 52 & 62 & 52 & 49 \\
\hline GRAND TOTAL & 100 & 100 & 100 & 100 & 100 & 100 & 100 \\
\hline
\end{tabular}

RELATIVE CLAY ABUNDANCE IN BULK

SAMPLE

\begin{tabular}{|l|r|r|r|r|r|r|r|}
\hline \% I/S Expandability & \multicolumn{1}{|c|}{15} & \multicolumn{1}{|c|}{20} & \multicolumn{1}{|c|}{5} & \multicolumn{1}{l|}{15} & \multicolumn{1}{l|}{35} & \multicolumn{1}{c|}{35} \\
\hline SMECTITE & 35 & 50 & 51 & 38 & 8 & 6 & 8 \\
\hline ILLITE/SMECTITE(I/S) & 6 & 20 & 5 & 22 & 69 & 54 & 40 \\
\hline ILLITE+MICA & 34 & 0 & 0 & 26 & 23 & 0 & 22 \\
\hline KAOLINITE & 7 & 6 & 12 & 1 & 0 & 17 & 10 \\
\hline CHLORITE & 19 & 24 & 32 & 14 & 0 & 23 & 20 \\
\hline \hline TOTAL & 100 & 100 & 100 & 100 & 100 & 100 & 100 \\
\hline \hline $\begin{array}{l}\text { TOTAL EXPANDABLE } \\
\text { CLAY }\end{array}$ & 23 & 23 & 21 & 21 & 20 & 14 & 11 \\
\hline
\end{tabular}

\begin{tabular}{|c|c|c|c|c|c|c|c|}
\hline \multirow{2}{*}{$\begin{array}{l}\text { CLAY MINERALOGY } \\
\text { SAMPLE ID }\end{array}$} & \multicolumn{7}{|c|}{$\begin{array}{l}\text { RELATIVE CLAY ABUNDANCE (LESS THAN } 4 \text { MICRON SIZE } \\
\text { FRACTION) }\end{array}$} \\
\hline & 1 & 2 & 3 & 4 & 5 & 6 & 7 \\
\hline DEPTH (FT) & 2048.25 & 2052.06 & 2055.20 & 2062.30 & 2067.98 & 2692.25 & 2697.15 \\
\hline$\%$ I/S Expandability & 15 & 20 & 5 & 15 & 35 & 40 & 35 \\
\hline SMECTITE & 58 & 38 & 37 & 48 & 9 & 4 & 9 \\
\hline ILLITE/SMECTITE (I/S) & 9 & 15 & 3 & 28 & 75 & 37 & 48 \\
\hline ILLITE & 5 & 4 & 4 & 10 & 13 & 7 & 8 \\
\hline KAOLINITE & 14 & 11 & 11 & 7 & 1 & 8 & 6 \\
\hline CHLORITE & 14 & 32 & 45 & 7 & 2 & 44 & 29 \\
\hline TOTAL & 100 & 100 & 100 & 100 & 100 & 100 & 100 \\
\hline
\end{tabular}




\section{B.2 Photomicrographs from Petrographic and SEM Analysis}

Thin sections and scanning electron microscope (SEM) images taken by TerraTek that are associated with the report of Appendix B.1 are presented here. Methods of image acquisition and interpretation are also given in Appendix B.1. The first line of description of each photo follows this format: name of original jpeg image file, identification number of core sample, depth of core sample, and TS or SEM abbreviation for petrographic thin section image or secondary electron microscope image. 

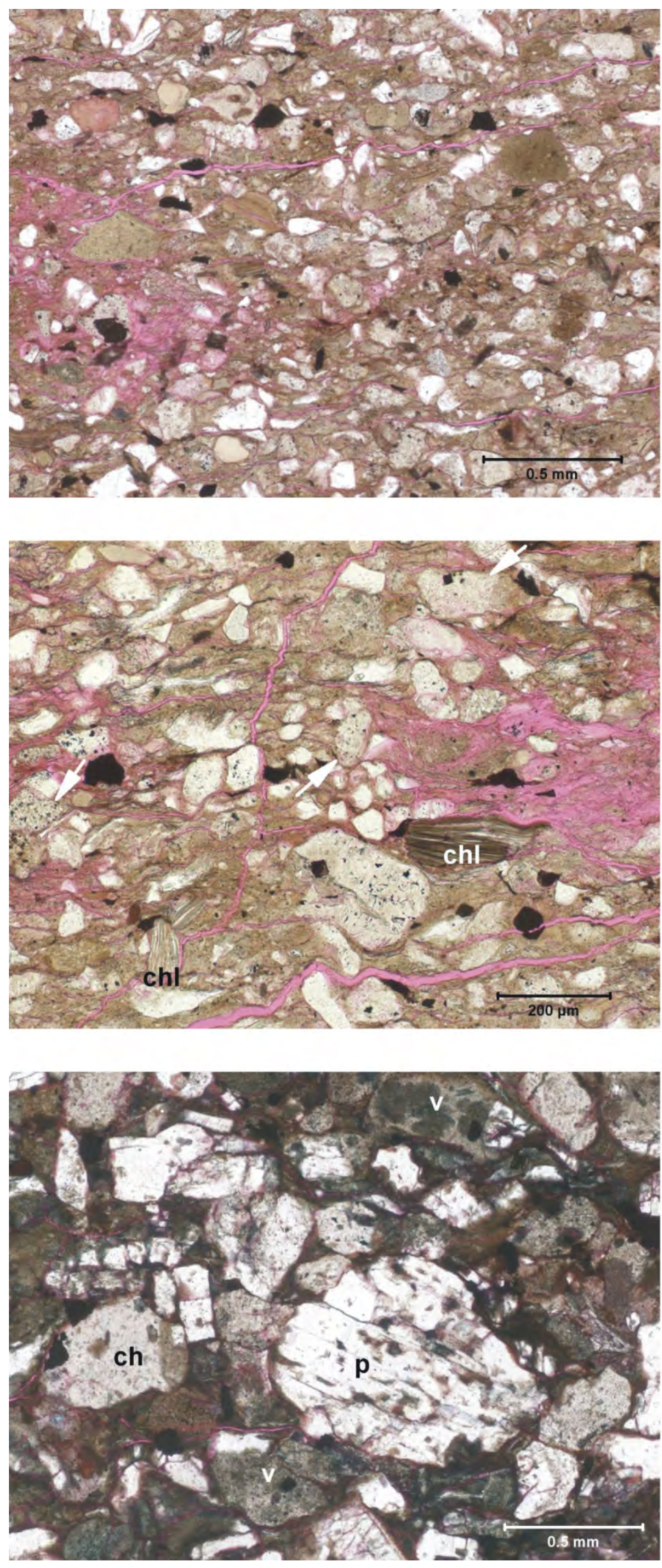

TS_1.jpg, CP-1, 2048.25 ft, TS.

Sandy argillaceous mudstone. The clay matrix is a mixture of illite, smectite, and chlorite, with small amounts of kaolinite and mixed layer illite-smectite (XRD). Detrital grains are sand sized quartz, feldspars and volcanic clasts. Numerous horizontal fissures in this view (stained magenta by dyed epoxy) represent dehydration and pressure-release fractures. (Plane-polarized light. Scale bar $=0.5 \mathrm{~mm}$ )

TS_2.jpg, CP-1, $2048.25 \mathrm{ft}$, TS. Clay minerals in the matrix form layers separated by fractures or wavy planes. A portion of the chlorite noted in XRD $(12 \%)$ is present as detrital kernels (chl). Speckled, rounded grains (arrows) are chert and volcanic fragments; white clasts are quartz and feldspar. Black dots are authigenic pyrite. (Plane-polarized light. Scale bar $=200$ microns)

TS_3.jpg, CP-2, 2052.06 ft, TS. Sandy argillaceous mudstone with smectitic and chloritic matrix. The dark matrix color is due to the response of iron-rich smectite to dual carbonate stain, a reaction commonly noted in smectites. Poorly sorted grains from fine to upper medium sand size comprise plagioclase (p), volcanic quartz, fine-grained volcanic fragments (v), and chert (ch). (Planepolarized light. Scale $\mathrm{bar}=0.5$ $\mathrm{mm}$ ) 

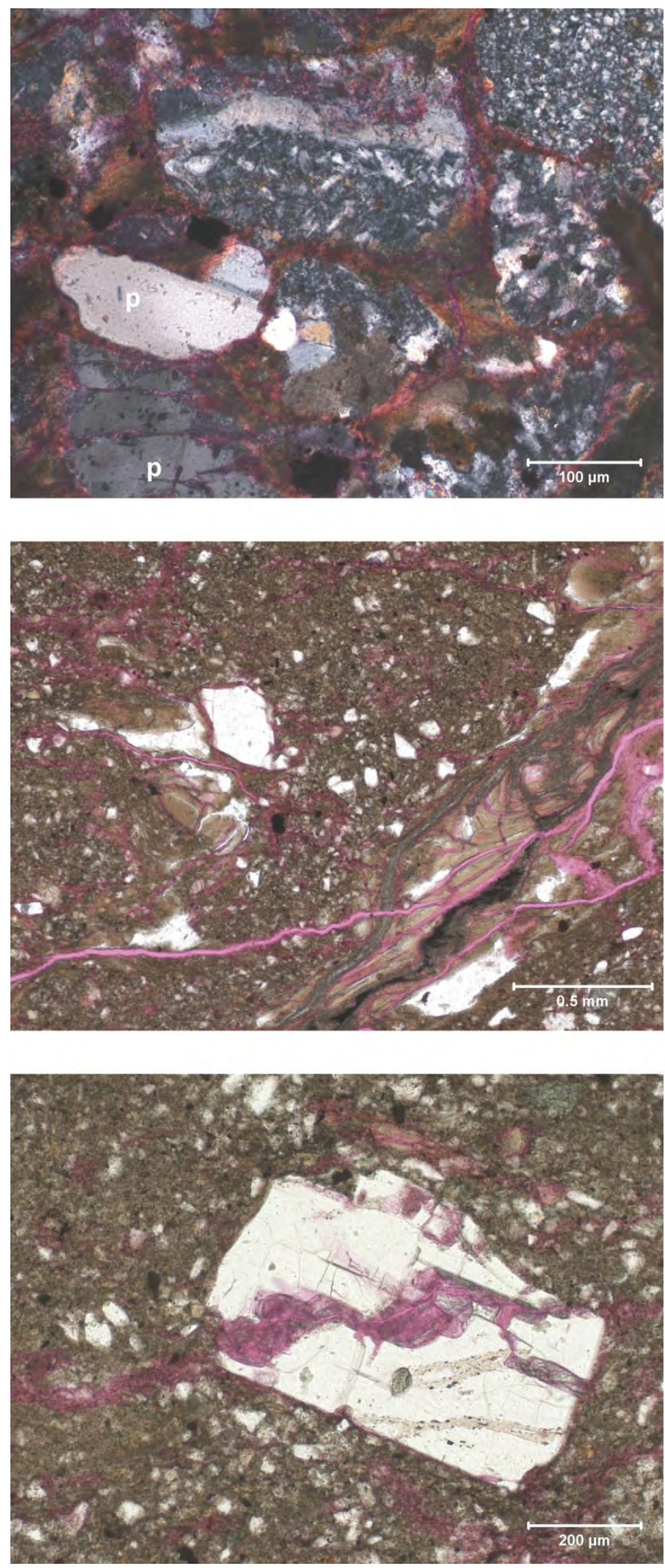

TS_4.jpg, CP-2, $2052.06 \mathrm{ft}$, TS.

Crossed Nichols view of sandyargillaceous mudstone at higher magnification showing chert-replaced volcanic clasts (top right and center), and plagioclase grains (p). Lighter brown material is clay matrix. (Cross-polarized light. Scale bar $=100$ microns)

TS 5.jpg, CP-3, $2055.20 \mathrm{ft}$, TS. Mudstone composed of smectite and chlorite matrix. Poorly sorted detrital grains include medium sand to coarse silt sized material (mainly quartz and feldspar) dispersed in the matrix. The smooth, lighter brown streak at right is interpreted as illuviated clay material resulting as remobilized illite infiltrates soil along root channels and desiccation cracks. (Planepolarized light. Scale $b a r=0.5$ $\mathrm{mm}$ )

TS_6.jpg, CP-3, 2055.20 ft,TS. Feldspar grain fractured diagonally; clay along the fracture suggests movement late in the rock's history. (Plane-polarized light. Scale bar $=200$ microns) 

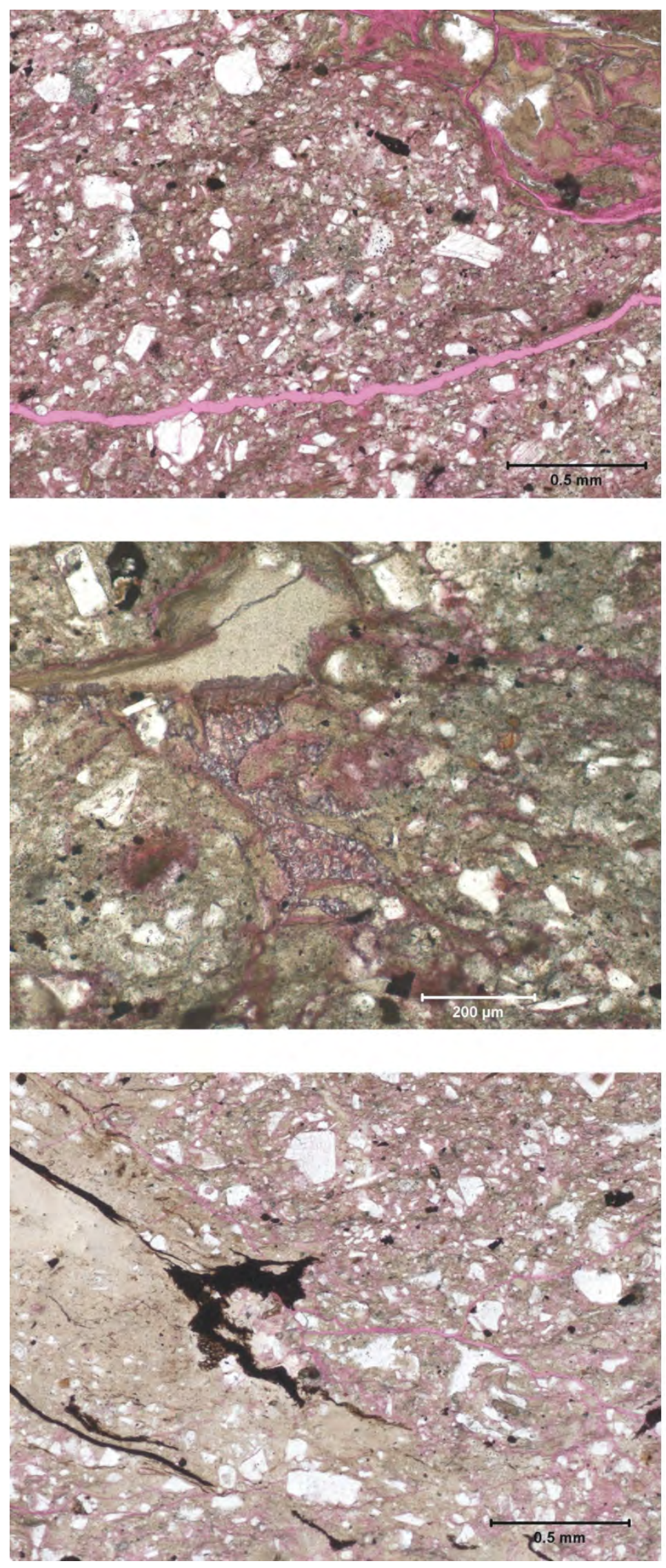

TS_7.jpg, CP-4, $2062.30 \mathrm{ft}$, TS. Sandy argillaceous mudstone, unstained portion of slide. Sharp feldspar and quartz, and rounded chert-replaced volcanic clasts are supported by a mixed smectitic matrix. Induced fractures are pervasive, as represented by the magenta lines (stained epoxy). The fabric exhibits blocky ped structure, especially when viewed under cross-polarized light, and the aligned, curved illite material at upper right is likely a result of illuviation. (Plane-polarized light. Scale bar $=0.5$ microns)

TS_8.jpg, CP-4, $2062.30 \mathrm{ft}$, TS. Detail of mudstone texture showing a fine-grained possible biotic clast at upper left, with associated authigenic ferroan calcite (center; stained purple with dual carbonate stain). Also note lath-shaped plagioclase crystal at upper left. The mottled, disorganized texture evident here is a typical pedogenic feature, along with disruption by roots. (Plane-polarized light. Scale bar $=$ 200 microns)

TS_9.jpg, CP-5, 2067.98 ft, TS. Sandy argillaceous mudstone displaying mottled and blocky ped structure, better visible under cross-polarized light. Dispersed coarse silt to medium sand grains are composed of quartz, feldspar, and subordinate lithic clasts. The tan streak at left cutting the image diagonally consists of well-aligned illite crystals (visible under crossed Nichols) and represents an illuviation layer associated with roots. The stringy black material is an organic remnant of these roots. (Plane-polarized light. Scale bar = $0.5 \mathrm{~mm}$ ) 

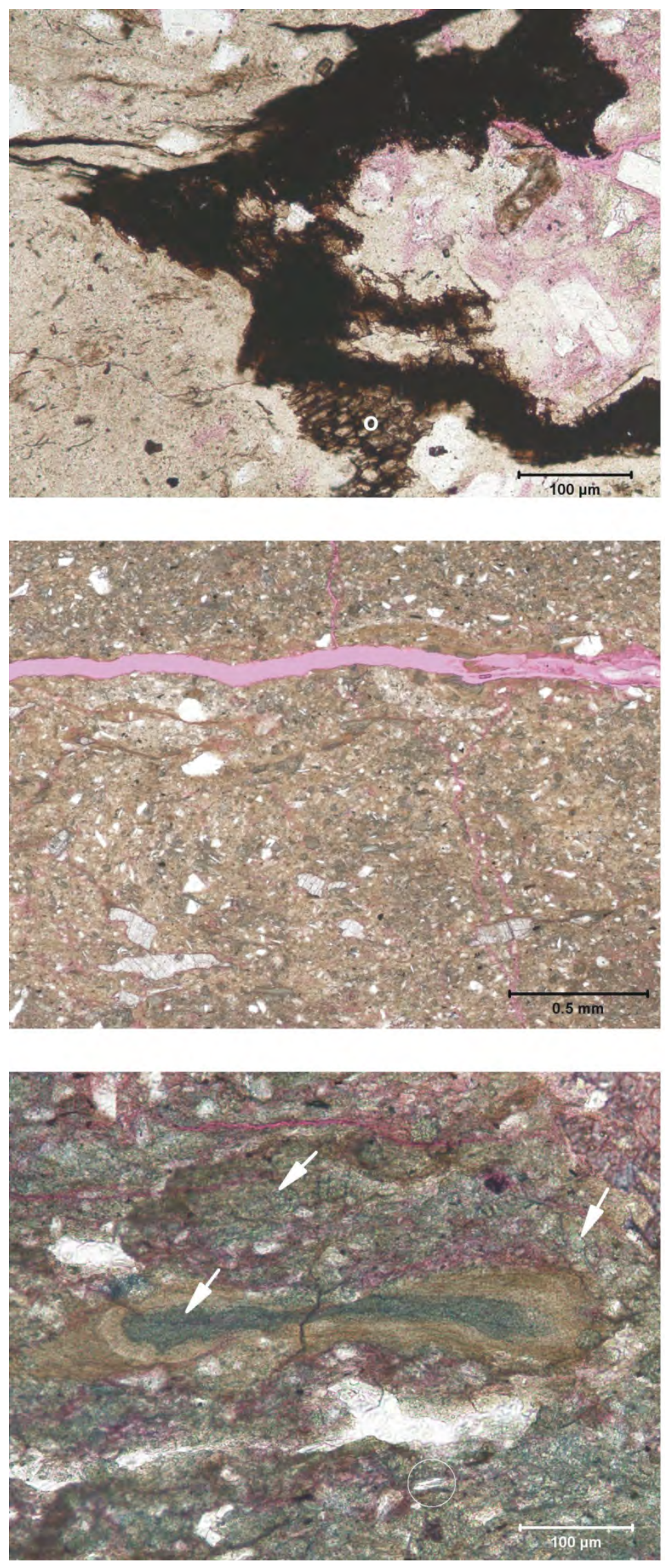

TS_10.jpg, CP-5, 2067.98 ft, TS. Detail of aligned illite and associated carbonaceous material shown in the previous image. The rectilinear, cellular morphology of the dark, carbonaceous particle (o) indicates plant tissues. Feldspars in this sample typically exhibit sharp grain shapes. Subtle pink areas in the clay matrix indicate epoxy-filled microporosity which may be due in part to dehydration of swelling clays. (Plane-polarized light. Scale bar $=100$ microns)

TS_11.jpg, CP-6, 2692.25 ft, TS. Argillaceous mudstone at lower magnification exhibits scattered silt and sand in a mixed clay matrix, with expandable I/S and chlorite as the predominant clay species (XRD). The crystals with cross-hatched cleavage in the lower part of the image are ferroan calcite (unstained). The horizontal fracture (magenta) is interpreted as an induced, stress-release or dehydration feature. (Planepolarized light. Scale bar $=0.5$ $\mathrm{mm}$ )

TS_12.jpg, CP-6, 2692.25 ft, TS. Detail showing chlorite in rounded and scallop-shaped clusters (arrows; pale green) and detrital kernels (circled). The tapered, flattened form at center, possibly representing a compacted biotic particle, root, or envelope around degraded organic material, contains minor replacive ferroan dolomite (stained blue), and an outer rind of illuviated clays. The clay matrix is stained blue in this high magnification view, reflecting ankerite and/or iron-rich expandable I/S. (Plane-polarized light. Scale bar $=100$ microns) 

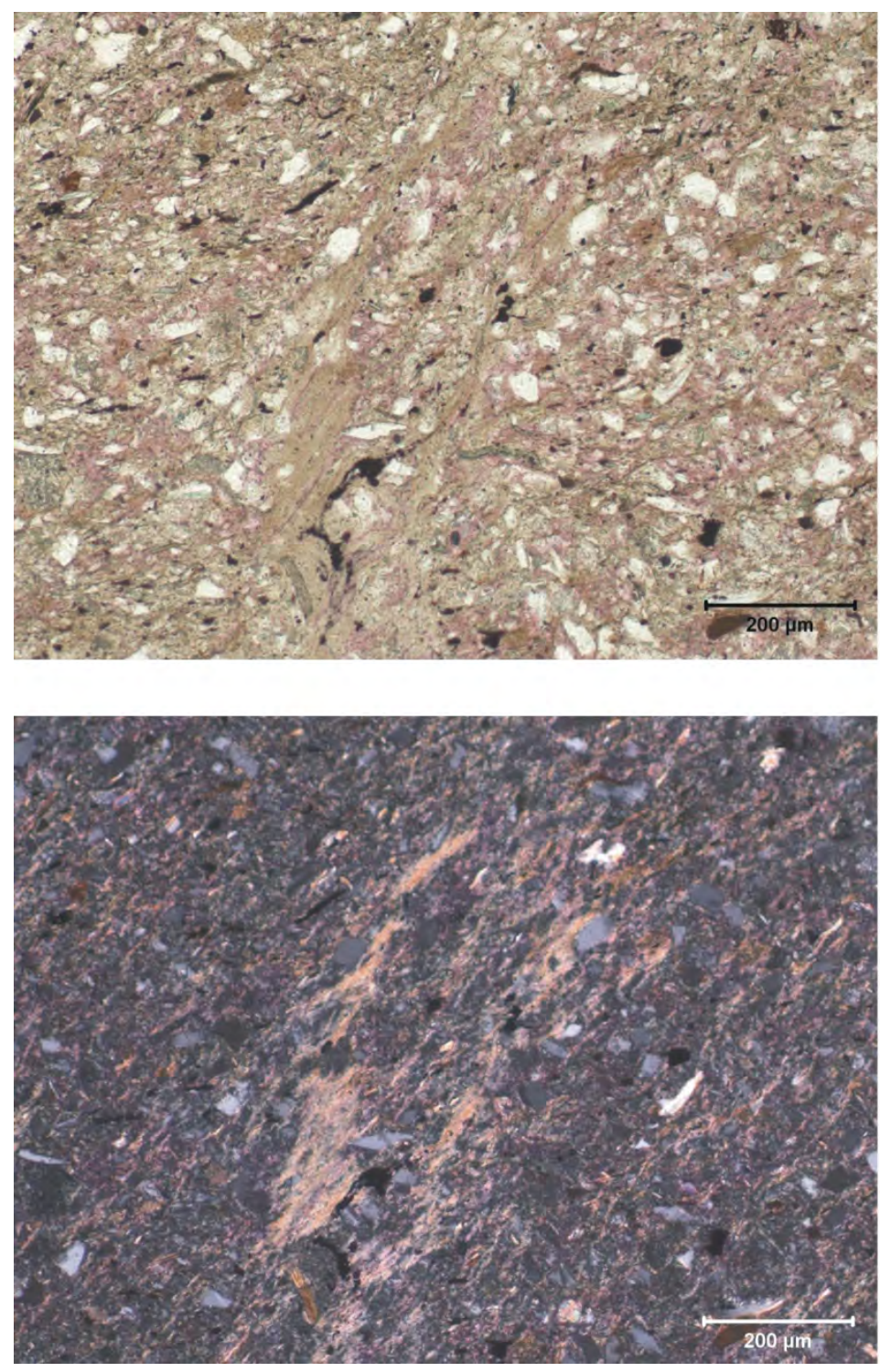

TS_13.jpg, CP-7, 2697.15 ft, TS.

Silty argillaceous mudstone, medium magnification, in the unstained part of the slide. The vertical clay feature at center is likely associated with root formation. The structure shows illuviation along this root cast, typical of soil layers. Clays are mainly I/S, illite and chlorite, with minor smectite and kaolinite. Pink areas reflect dyed epoxy in micropores, which are inferred to be induced dehydration features. (Plane-polarized light. Scale bar $=$ 200 microns)

TS_14.jpg, CP-7, $2697.15 \mathrm{ft}$, TS. Same view as in the previous image except under crosspolarized light. Well-aligned illite streaks appear as brightly birefringent streaks around root casts. The black dots and wisps represent carbonaceous flakes and remnants of root material, and associated replacive pyrite. (Cross -polarized light. Scale bar $=200$ microns) 

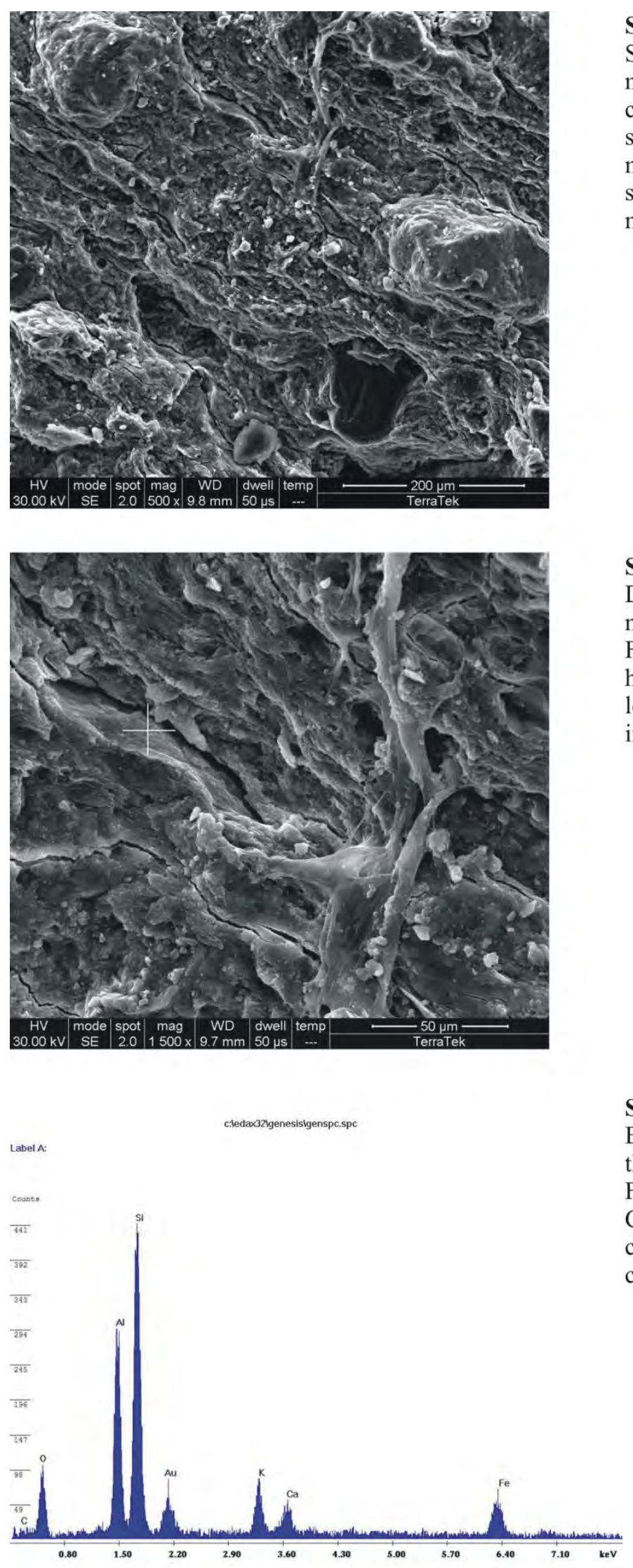

SEM_1.jpg, CP-1, 2048.25 ft, SEM. Sandy argillaceous mudstone, low magnification view. Mottled and disturbed clay-rich matrix hosts quartz and feldspar sand grains. Thin microfractures in the matrix are lined with illite, identified by spot EDX analysis. (Scale bar $=200$ microns)

SEM_2.jpg, CP-1, $2048.25 \mathrm{ft}$, SEM. Detail of microtexture emphasizing the network of illite-lined microfractures. Features visible in thin section are enlarged here. The clay flake visible as a ridge at top left $(+)$ produces the EDX spectrum shown in the next image. (Scale bar $=50$ microns)

SEM_3.jpg, CP-1, 2048.25 ft, SEM. Elemental spectrum for the clay flake in the previous image $(+) . \mathrm{Si}, \mathrm{Al}, \mathrm{O}, \mathrm{K}$, and $\mathrm{Fe}$ are consistent with iron-rich smectite. Ca may reflect the swelling I/S portion of clays. The gold peak reflects sample coating. 

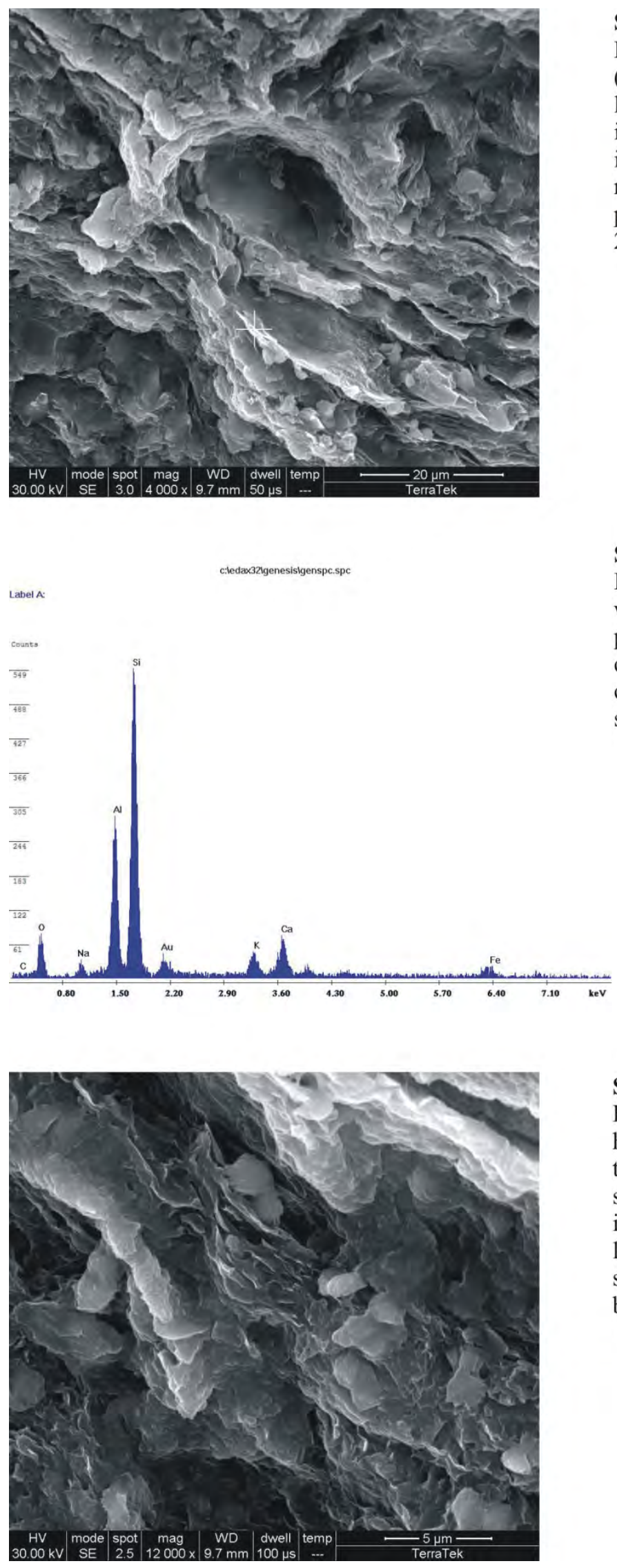

SEM_4.jpg, CP-1, 2048.25 ft, SEM. Detailed view of a possible root cast (center). The adjoining fracture features are lined with delicate illuviated clays identified by spot EDX as mixed layer illite-smectite or smectite. Spot EDX results for the clay ridge at bottom $(+)$ are presented in the next image. (Scale bar $=$ 20 microns)

SEM_5.jpg, CP-1, $2048.25 \mathrm{ft}$, SEM.

Elemental spectrum corresponding to the white ridge of clay at center bottom in the previous image $(+)$. $\mathrm{Si}, \mathrm{Al}$, and $\mathrm{O}$ peaks are common to clays, whereas the array of cations $(\mathrm{K}, \mathrm{Fe}, \mathrm{Na}$, and $\mathrm{Ca}$ ) point to a smectitic or mixed composition.

SEM_6.jpg, CP-1, $2048.25 \mathrm{ft}$, SEM. High magnification view of matrix highlighting expanded, porous texture of the clays. Flakey illite and web-like smectite expand and contract to leave induced fractures. Whole view EDX shows large $\mathrm{Ca}$ and $\mathrm{Fe}$ peaks, suggesting secondary ferroan calcite cement. (Scale bar $=10$ microns) 

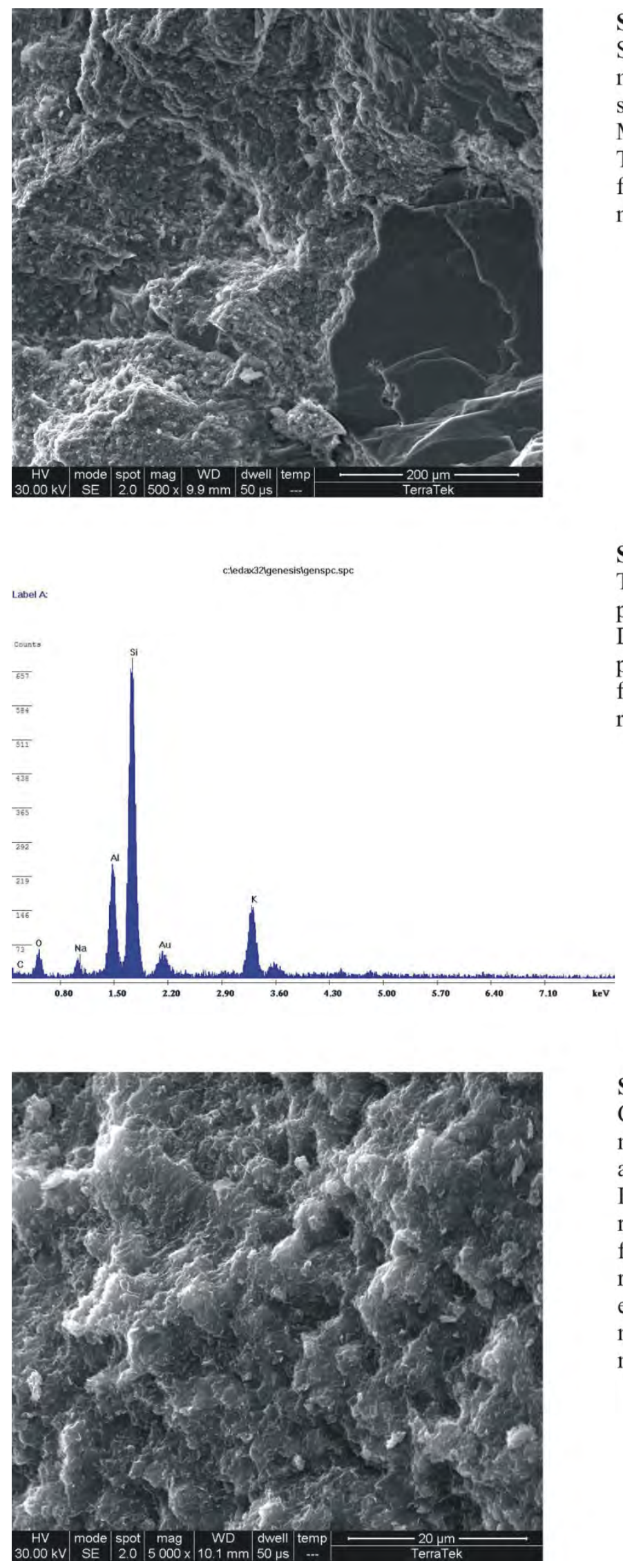

SEM_7.jpg, CP-2, $2052.06 \mathrm{ft}$, SEM. Sandy argillaceous mudstone at low magnification. The sand grains are supported by disorganized clay matrix. Matrix clays form tiny clumps or granules. The dark grain at lower right has a feldspathic composition. (Scale bar $=200$ microns)

SEM_8.jpg, CP-2, $2052.06 \mathrm{ft}$, SEM. The sand grain in the previous image produces this spot EDX spectrum. Dominant $\mathrm{Si}, \mathrm{O}$, and $\mathrm{Al}$ peaks, along with peaks for $\mathrm{K}$ and $\mathrm{Na}$ indicate an alkaline feldspar composition. The gold peak reflects sample coating.

SEM_9.jpg, CP-2, $2052.06 \mathrm{ft}$, SEM. Closer view of the mixed composition clay matrix. XRD analysis determines smectite as the dominant clay species, mixed with I/S and chlorite in approximately $2: 1: 1$ ratio. A small amount of kaolinite is also found by XRD, although discretely not recognizable in SEM. No lamination is evident, and webby to granular clay microcrystals form masses. (Scale bar $=20$ microns) 

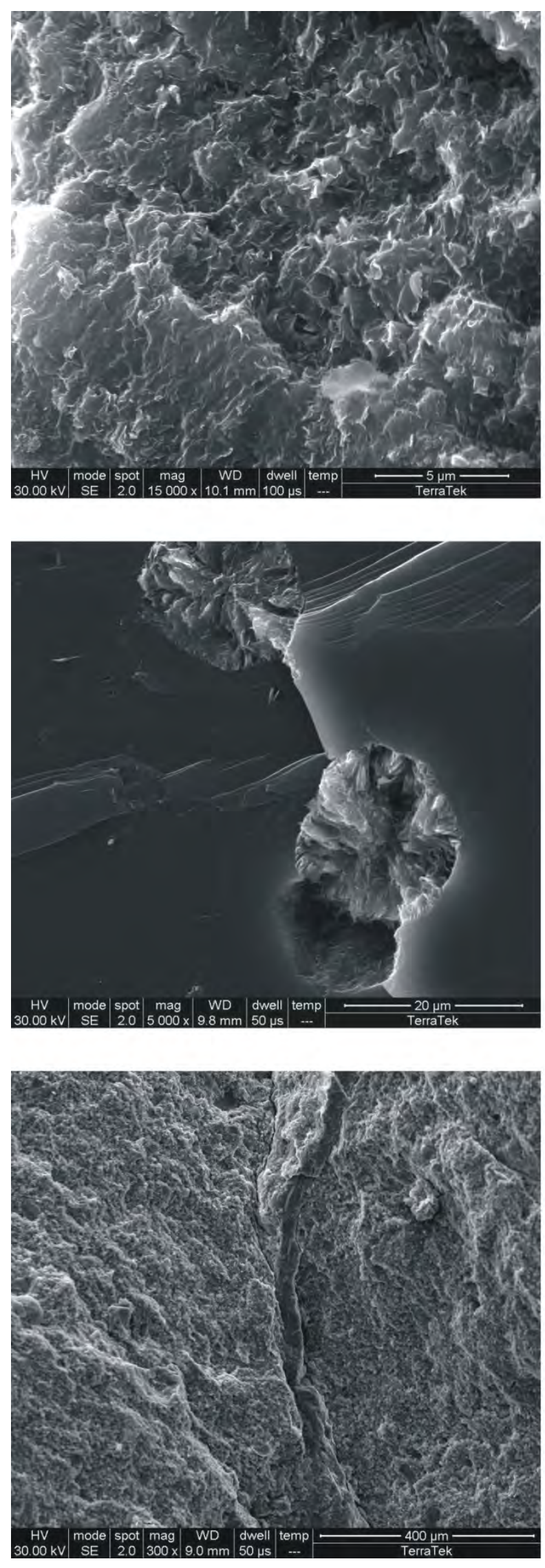

SEM_10.jpg, CP-2, $2052.06 \mathrm{ft}$, SEM.

At high magnification the matrix is seen to be composed of tiny crenulated clay flakes a fraction of a micron in size. The crenulated morphology of flakes supports XRD determination of smectite or expandable I/S composition. (Scale bar $=5$ microns)

SEM_11.jpg, CP-2, 2048.25 ft, SEM. Enlarged view of the feldspar grain shown in SEM Image 7. Tiny round voids in the grain host radially arranged clay crystals; spot EDX shows an iron-rich chlorite composition. (Scale bar $=20$ microns)

SEM_12.jpg, CP-3, $2055.20 \mathrm{ft}$, SEM. Overview of argillaceous mudstone showing a calcite-filled root cavity. Whole view EDX shows an elemental spectrum consistent with variable clay composition and calcite. Spot EDX on the central vertical feature reveals calcite. (Scale bar $=$ 400 microns) 

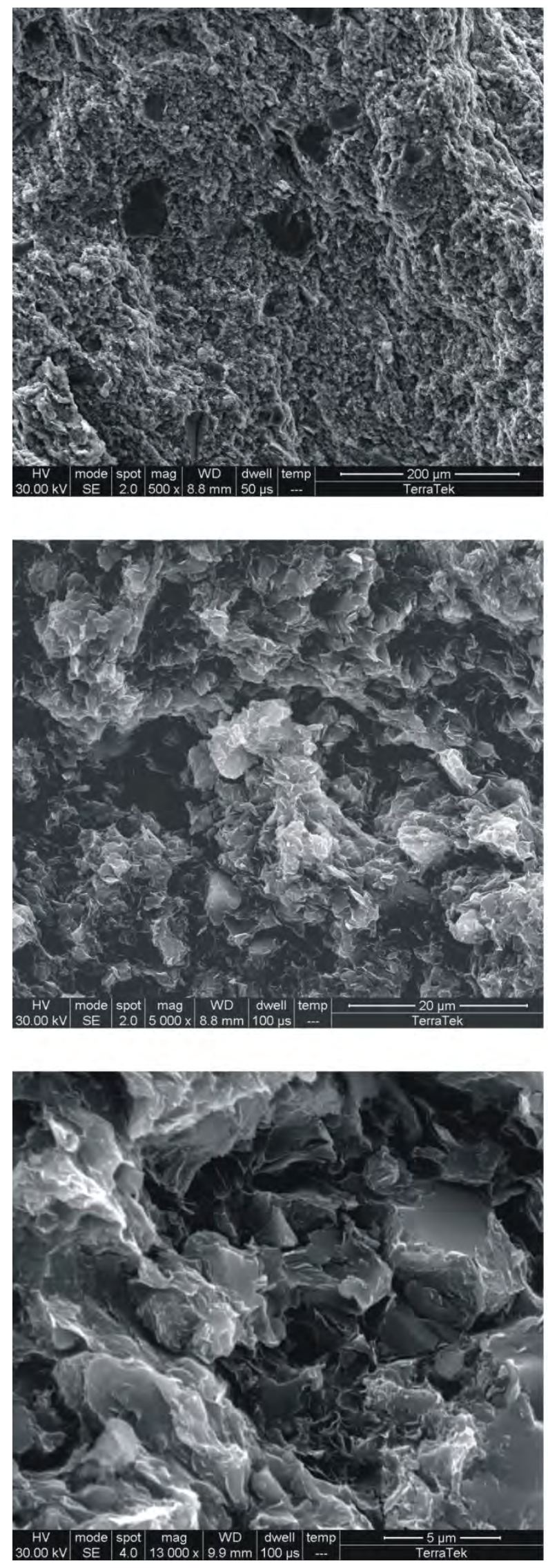

SEM_13.jpg, CP-3, 2055.20 ft, SEM.

Similar overview in another, siltier portion of the sample. The disarranged, lumpy fabric is composed of granules or clumps of mainly expandable smectite $(21 \%$ by weight smectite; XRD). (Scale bar $=200$ microns)

SEM_14.jpg, CP-3, 2055.20 ft, SEM.

Clay granules in the previous image, when viewed at higher magnification, appear as cabbage-shapes and expanded ridges around induced pores, a texture typical of swelling clays. Spot EDX results for the light clump at center contains $\mathrm{Si}, \mathrm{Al}$, and $\mathrm{O}$ peaks accompanied by smaller $\mathrm{Fe}, \mathrm{K}, \mathrm{Ca}$, and $\mathrm{Mg}$ peaks, consistent with expandable clays of variable composition. (Scale bar $=$ 20 microns)

SEM_15.jpg, CP-3, $2055.20 \mathrm{ft}$, SEM. High magnification highlights clays with crenulated to webby flake morphology, most likely smectite. Clays adhere to admixed carbonaceous material as well as chlorite, and authigenic cement crystals. (Scale $b a r=5$ microns) 

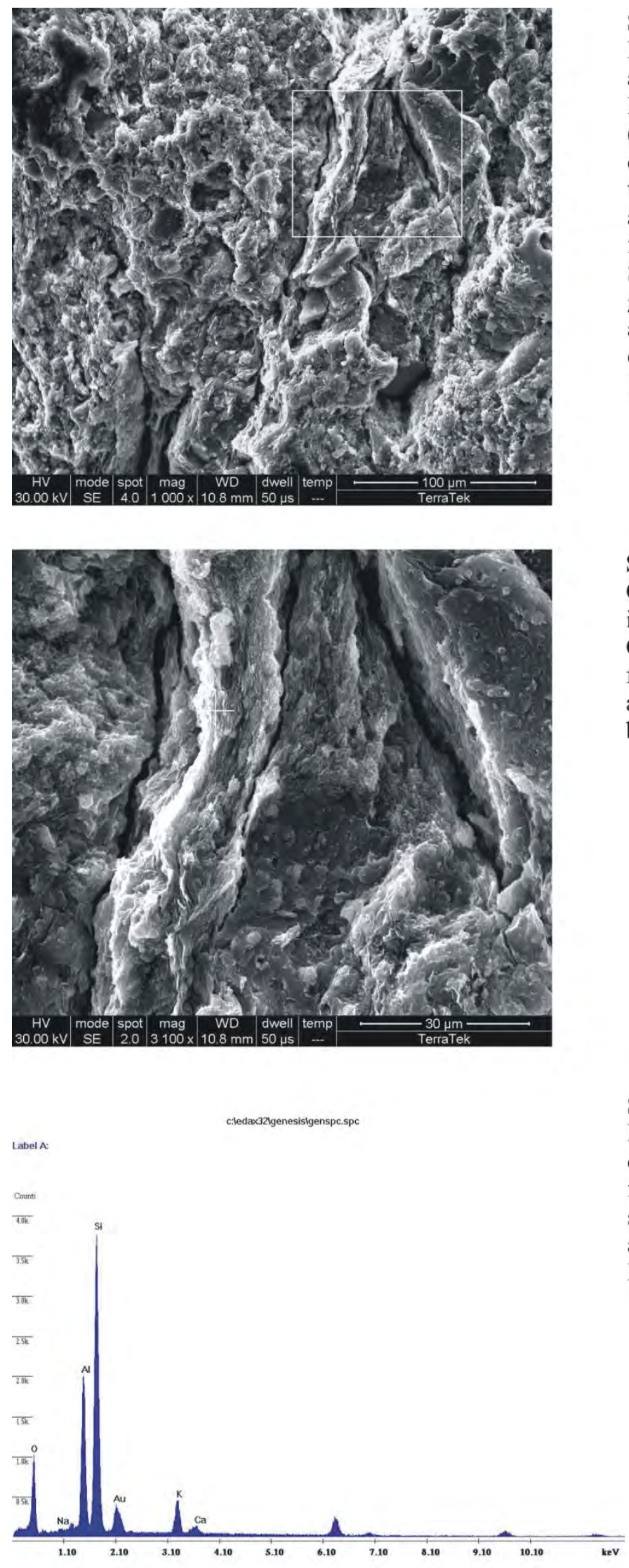

SEM_16.jpg, CP-4, 2062.30 ft, SEM. Medium magnification view of sandy argillaceous mudstone with poorly laminated and mottled, irregular texture (see slab images). Angular to subangular quartz and feldspar sand are scattered throughout the clay matrix, showing approximately vertical microfractures filled with illuvium (see TS Image 7). Spot EDX analysis identifies the dark grains at upper right and center right edge as alkaline feldspars. The boxed area is enlarged in the next image. (Scale bar $=$ 100 microns)

\section{SEM_17.jpg, CP-4, $2062.30 \mathrm{ft}$, SEM.}

Closer view of illuviation envelope shown in the rectangle in the previous image. Clays exhibit web-like morphology, with flake stacks collapsed into thin ridges around inferred root material or cast. (Scale bar $=30$ microns)

SEM_18.jpg, CP-4, $2062.30 \mathrm{ft}$, SEM. Elemental spectrum associated with the clay ridge in the previous image $(+)$. Peaks for $\mathrm{Si}, \mathrm{Al}, \mathrm{O}$ are common to clays; diverse smaller peaks $(\mathrm{K}, \mathrm{Ca}, \mathrm{Na}$, and unlabeled $\mathrm{Fe}$ at $6.2 \mathrm{keV}$ ) are indicative of mixed layer $\mathrm{I} / \mathrm{S}$ and smectite. 

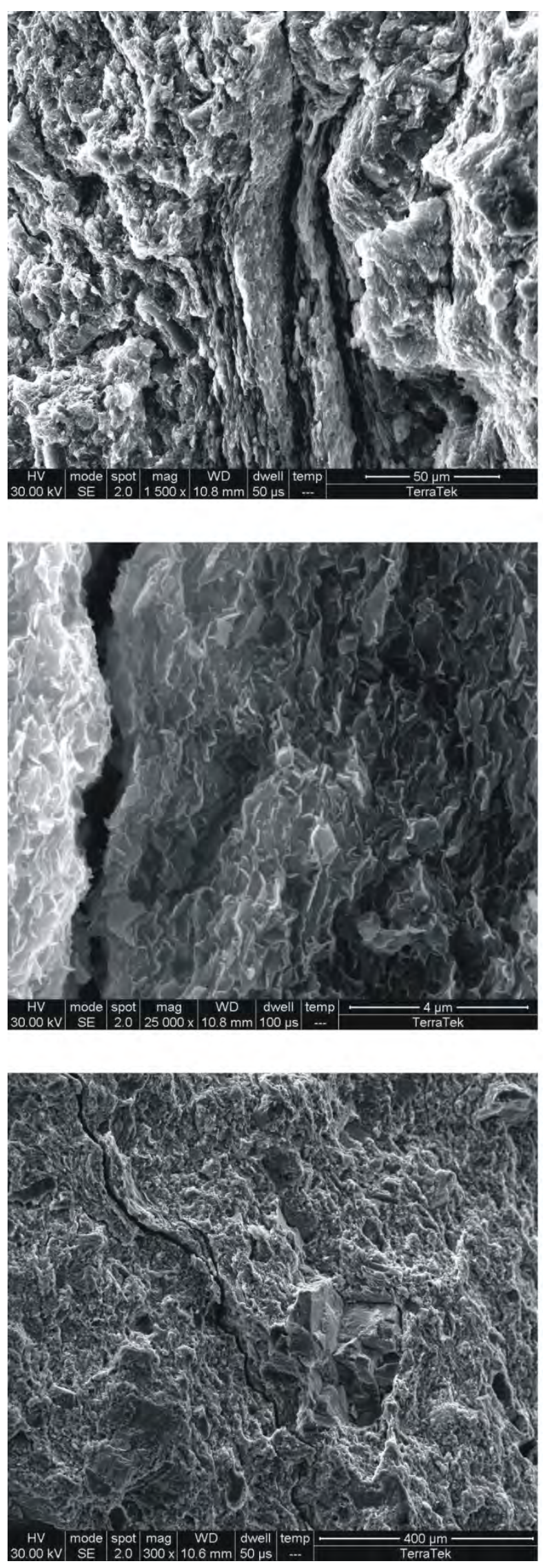

SEM_19.jpg, CP-4, $2062.30 \mathrm{ft}$, SEM.

Detail of possible root cast or illuviation envelope. Note the vertical clay ridges with distinctly aligned crystals compared to disorganized surrounding clay aggregates. (Scale bar $=50$ microns)

SEM_20.jpg, CP-4, $2062.30 \mathrm{ft}$, SEM.

High magnification reveals collapsed networks of swelling clays from the previous image. The tiny flakes are arranged in parallel webs which expand when wet and collapse when dry. The fissure at the left of the screen is interpreted as a dehydration feature. (Scale bar $=4$ microns)

SEM_21.jpg, CP-5, 2067.98 ft, SEM. Textural overview of sandy argillaceous mudstone exhibiting moderate clay orientation and wavy, parted lamination planes, diagonal in this image. Sand grains consisting of detrital quartz and feldspar are widely dispersed in the clay matrix. The diagonal fissure is an induced dehydration fracture. XRD finds $52 \%$ total clay by weight. Clays are predominantly expandable I/S and illite, with a lesser amount $(8 \%)$ of smectite. (Scale bar $=400$ microns) 

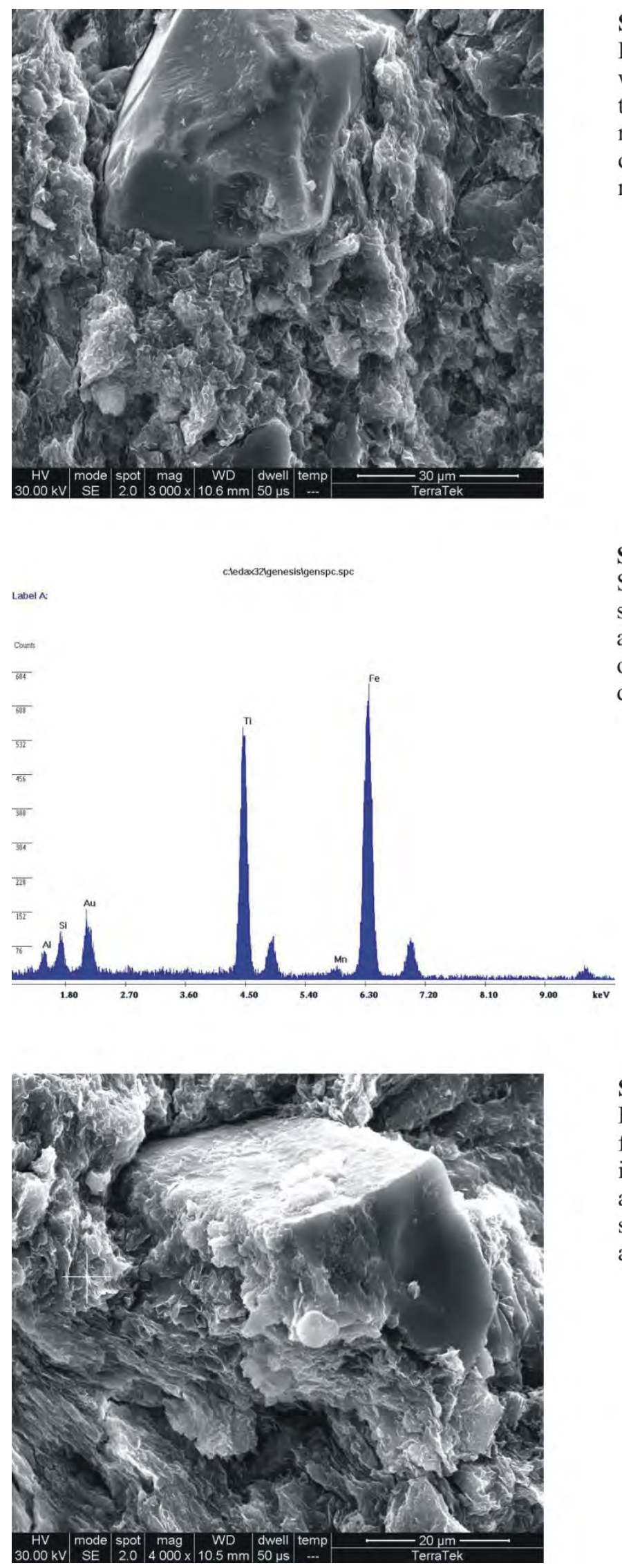

SEM_22.jpg, CP-5, $2067.98 \mathrm{ft}$, SEM. Detrital coarse silt-sized ilmenite grain with smooth, abraded edges indicating transport and recycling. The surrounding matrix is mixed expandable clays showing characteristic crenulated clump morphology. (Scale bar $=30$ microns $)$

SEM_23.jpg, CP-5, $2067.98 \mathrm{ft}$, SEM. Spot EDX spectrum corresponding to the smooth grain in the previous image. Fe, $\mathrm{Ti}$, and $O$ peaks are characteristic of the iron oxide, ilmenite, a relatively common detrital accessory in sands.
SEM_24.jpg, CP-5, $2067.98 \mathrm{ft}$, SEM. Enlarged view of a degraded plagioclase feldspar grain. Spot EDX shows an intermediate composition between albite and anorthite. The left side of the grain shows a reaction front with a skin of authigenic clay. (Scale bar $=20$ microns) 


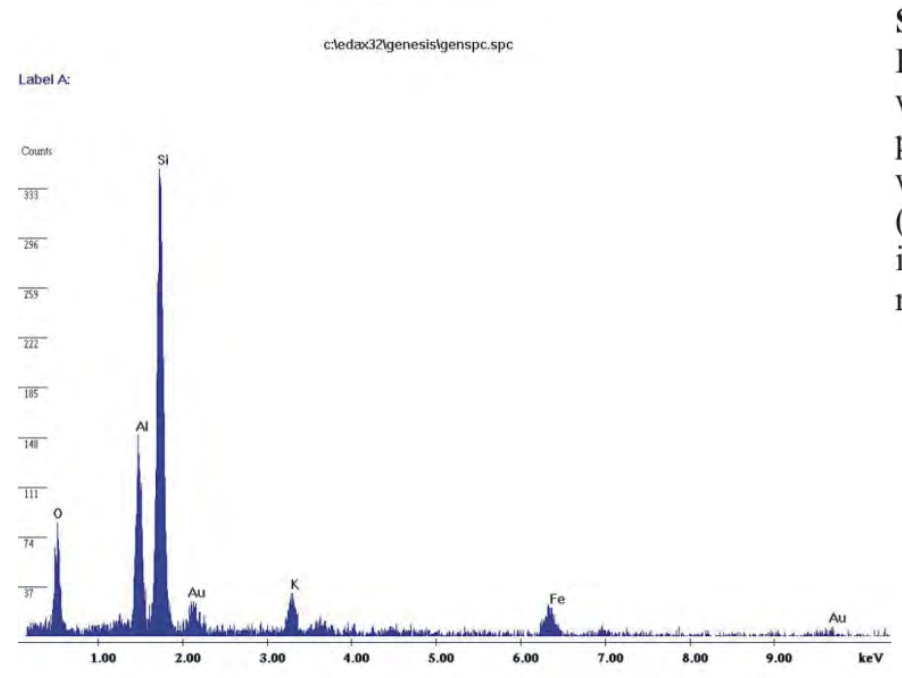

SEM_25.jpg, CP-5, $2067.98 \mathrm{ft}$, SEM.

Elemental spectrum corresponding to the wrinkly packet of clay flakes in the previous image $(+) . \mathrm{Si}, \mathrm{Al}$, and $\mathrm{O}$ peaks with associated $\mathrm{K}, \mathrm{Fe}$, and minor $\mathrm{Ca}$ (unlabeled, approx $3.6 \mathrm{keV}$ ) denote an iron-rich mixed clay composition. Gold reflects sample coating.

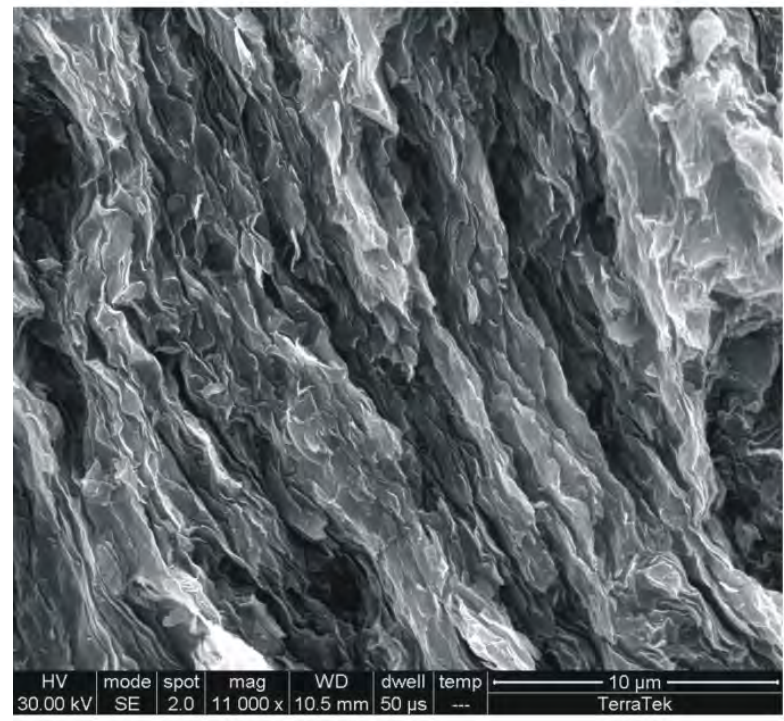

SEM_26.jpg, CP-5, $2067.98 \mathrm{ft}$, SEM.

High magnification detail of well-aligned clays in an illuviation envelope. According to whole view EDX results for the area in the image, the clay composition is a mixture, with the dominant peaks for $\mathrm{Fe}$, $\mathrm{K}$, and $\mathrm{Ca}$ in addition to the $\mathrm{Si}, \mathrm{Al}$, and $\mathrm{O}$ peaks common to clay minerals. (Scale bar $=10$ microns)

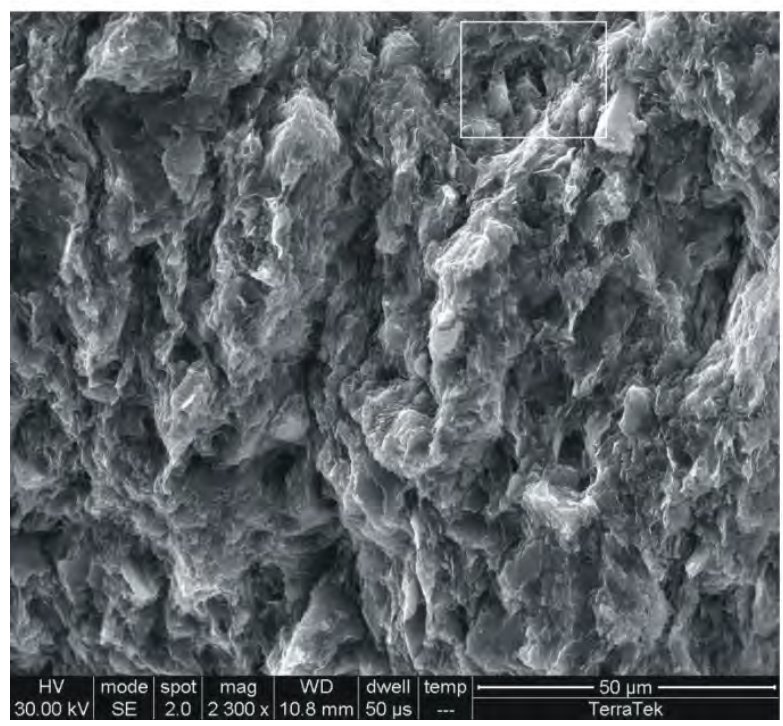

SEM_27.jpg, CP-6, 2692.25 ft, SEM. Argillaceous mudstone displaying moderate lamination, near vertical in this image. Scattered silt and sand are supported in a lumpy, clay-rich matrix. Some of the pores may be real in this sample, as illustrated in the next image, an enlargement of the boxed area at upper right. (Scale bar $=50$ microns) 

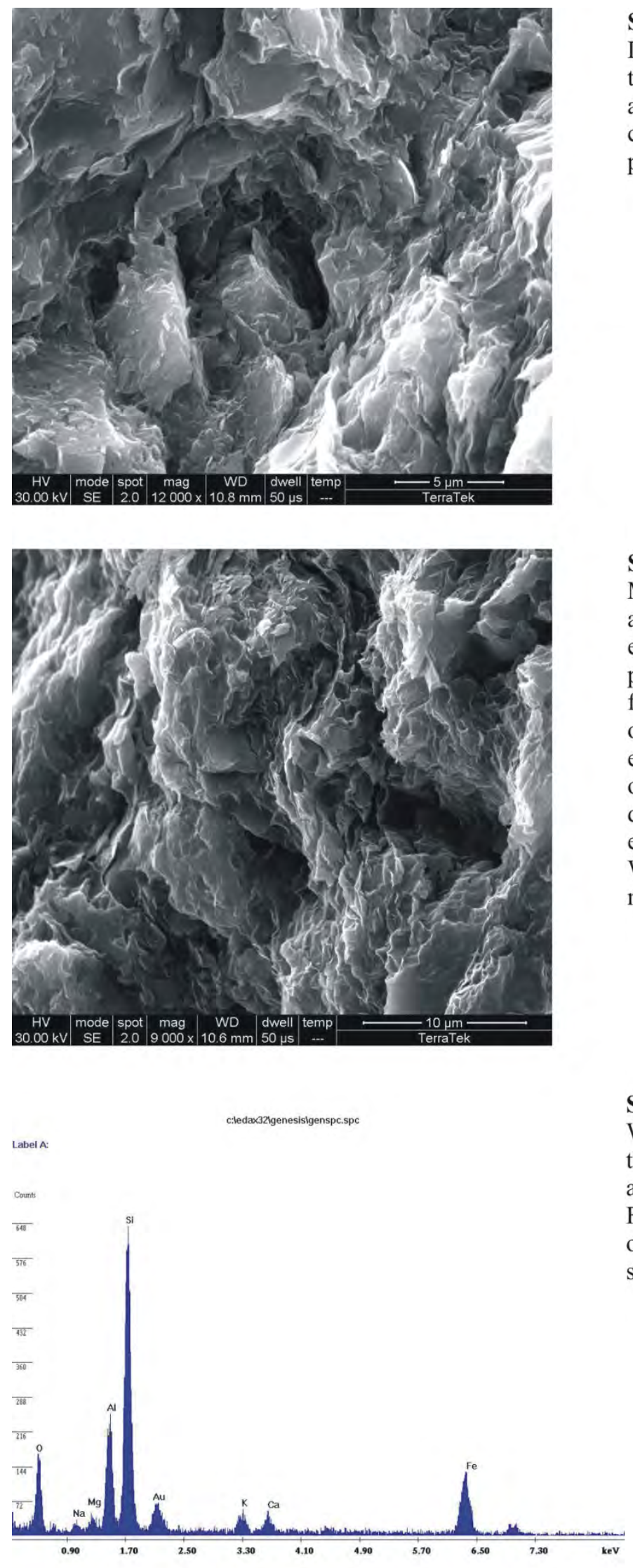

SEM_28.jpg, CP-6, 2692.25 ft, SEM.

Detail of a possible natural pore, center of the image. The irregular, elongate shape and baffled interior suggest a possible root cast. Mixed clays form clumps around the pore. (Scale bar $=5$ microns)

SEM_29.jpg, CP-6, 2692.25 ft, SEM.

Medium magnification view of argillaceous mudstone highlighting webby expandable clay aggregates. The dark pores 5-10 microns across may represent fluid pathways or voids associated with oxidized carbonaceous material. Larger elongate ridges are interpreted as artifacts of swelling clay response to hydration and dehydration. Thin section and core photo evidence suggests features of a paleosol. Whole view EDX results are shown in the next image. (Scale bar $=10$ microns)

SEM_30.jpg, CP-6, 2692.25 ft, SEM. Whole view EDX spectrum for the area in the previous image. Peaks for $\mathrm{Si}, \mathrm{Al}, \mathrm{O}$ and a smaller array including $\mathrm{Fe}>\mathrm{K}=\mathrm{Ca}=\mathrm{Mg}>\mathrm{Na}$ support the mixed suite of mixed layer I/S, chlorite, kaolinite, and smectite determined by XRD analysis. 

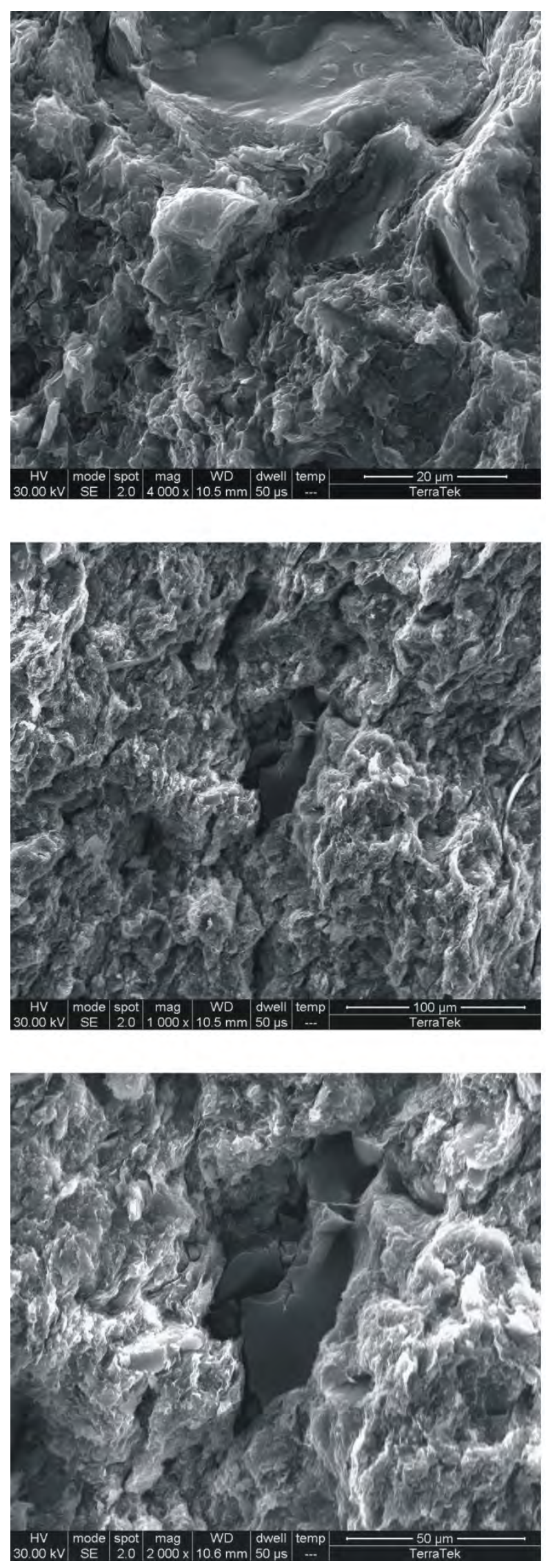

SEM_31.jpg, CP-6, 2692.25 ft, SEM. Medium magnification view showing compaction textures and ped-like structures in clay aggregates. Clumps are bounded by seams or surfaces sometimes hosting disc-shaped or flattened pores. (Scale bar $=20$ microns)

SEM_32.jpg, CP-7, 2697.15 ft, SEM.

Overview of silty argillaceous mudstone with moderate lamination, near vertical in this image. Scattered silt and sand are supported by a mixture of expandable and non-expandable clays. Crenulated clays are arranged in ridges separated by

induced/natural parting surfaces. At center, a carbonaceous particle is visible along one such parting. (Scale bar $=100$ microns)

SEM_33.jpg, CP-7, 2697.15 ft, SEM. Enlarged view of the particle in the previous image. Note the smooth surface and slightly degraded edges of the particle. (Scale bar $=50$ microns) 


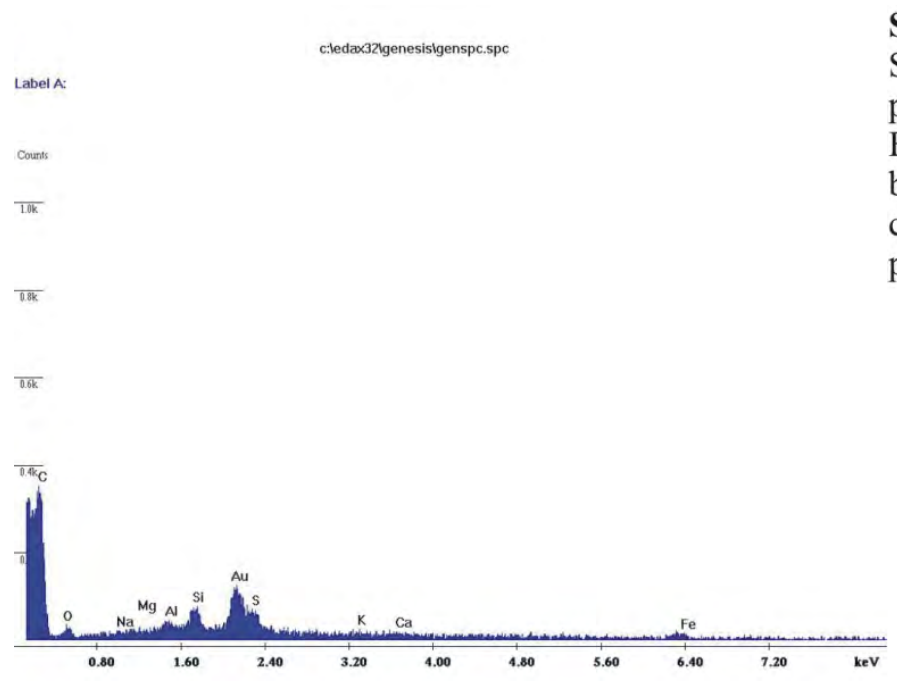

SEM_34.jpg, CP-7, 2697.15 ft, SEM. Spot EDX spectrum produced by the particle in the previous image. Overall low EDX response, and a spectrum dominated by a large $\mathrm{C}$ peak and gold (sample coating) characterize the spectra of organic particles and residue.

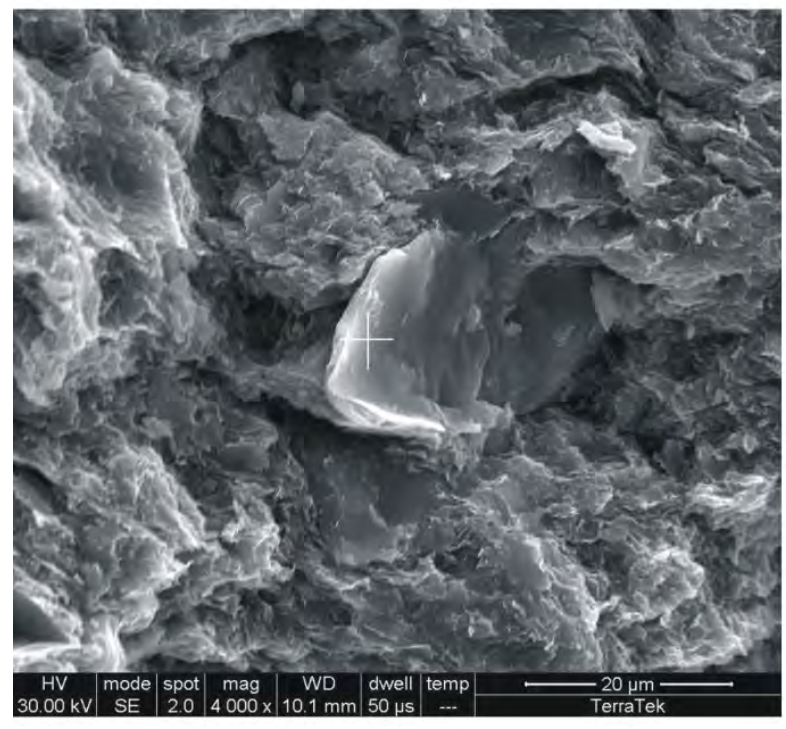

SEM_35.jpg, CP-7, 2697.15 ft, SEM.

A probable detrital chlorite flake at center is surrounded by compacted, crenulated clays including illite, I/S, and kaolinite. Spot EDX results show prominent peaks for $\mathrm{Fe}$ and $\mathrm{Mg}$, in addition to $\mathrm{Si}, \mathrm{Al}$, and $\mathrm{O}$. (Scale bar $=20$ microns)

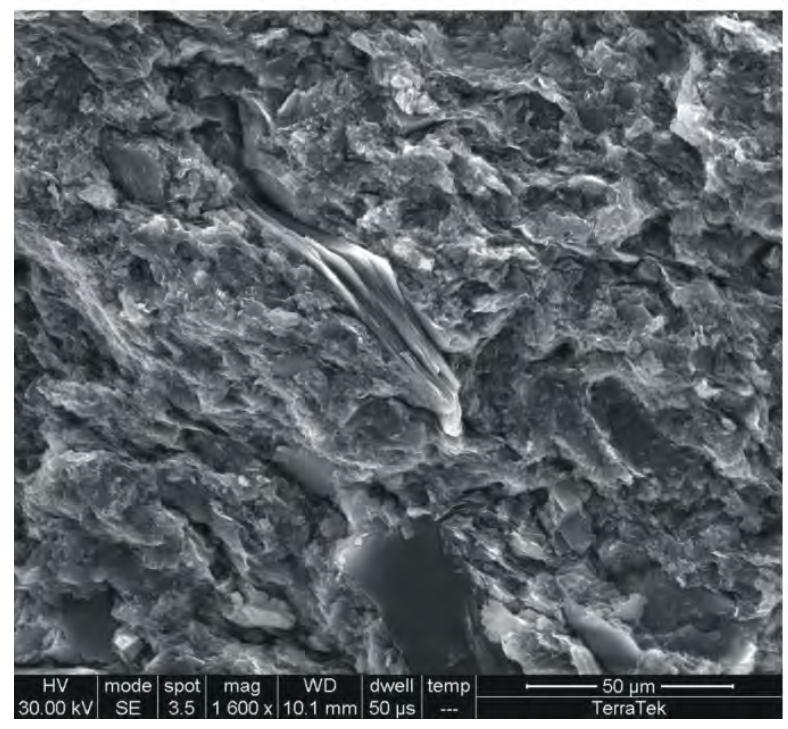

SEM_36.jpg, CP-7, 2697.15 ft, SEM. Medium magnification view showing wavy clay packets and slightly granular texture. The flake at center is biotite; the dark grain at the bottom of the image is potassium feldspar. (Scale bar $=50$ microns) 


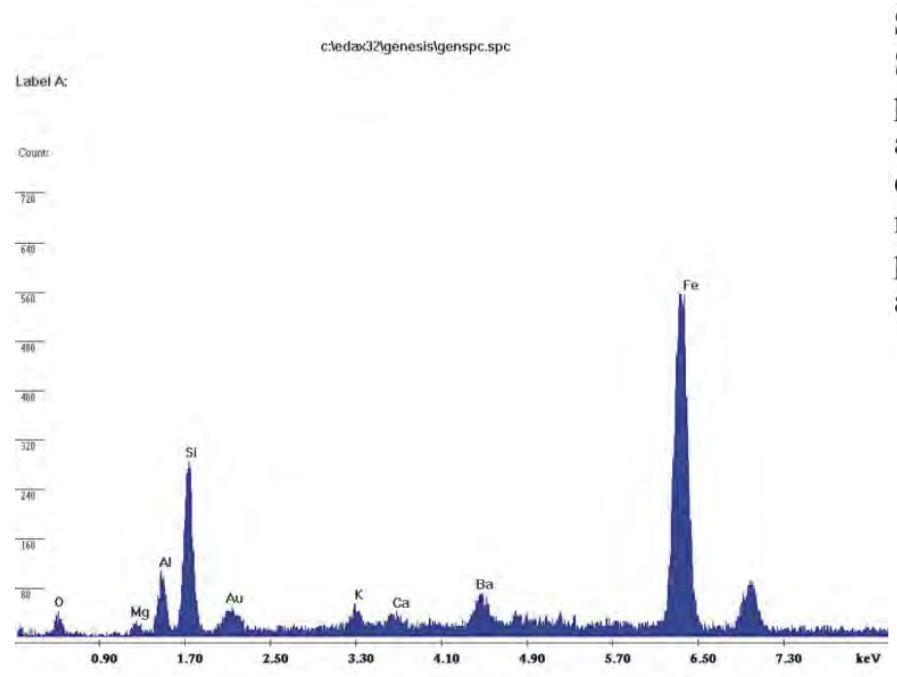

SEM_37.jpg, CP-7, 2697.15 ft, SEM. Spot EDX results for the flake in the previous image. The iron peak, accompanied by $\mathrm{Si}, \mathrm{Al}$, and $\mathrm{O}$ peaks, in combination with the rigid layered morphology indicate the mica biotite. A portion of the chlorite recognized by XRD analysis is likely degraded detrital biotite. 


\section{B.3 Photo Log of Slabbed Core}

After the core was pieced together, preliminary reviewed, and samples chosen and preserved against drying, the core was slabbed and photographed by TerraTek. Slabbing damaged the mudstone sections of the core by inducing fractures. 


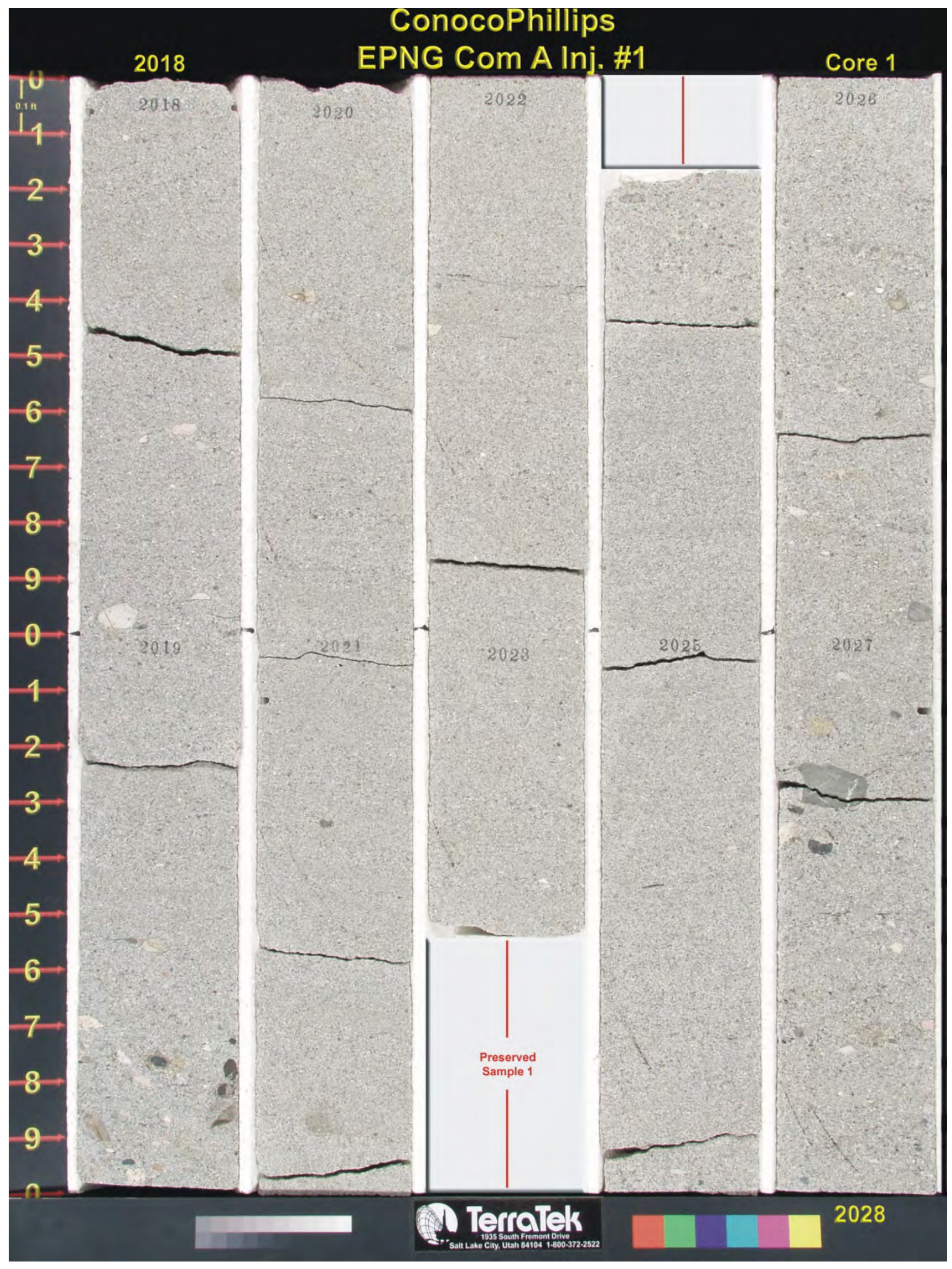




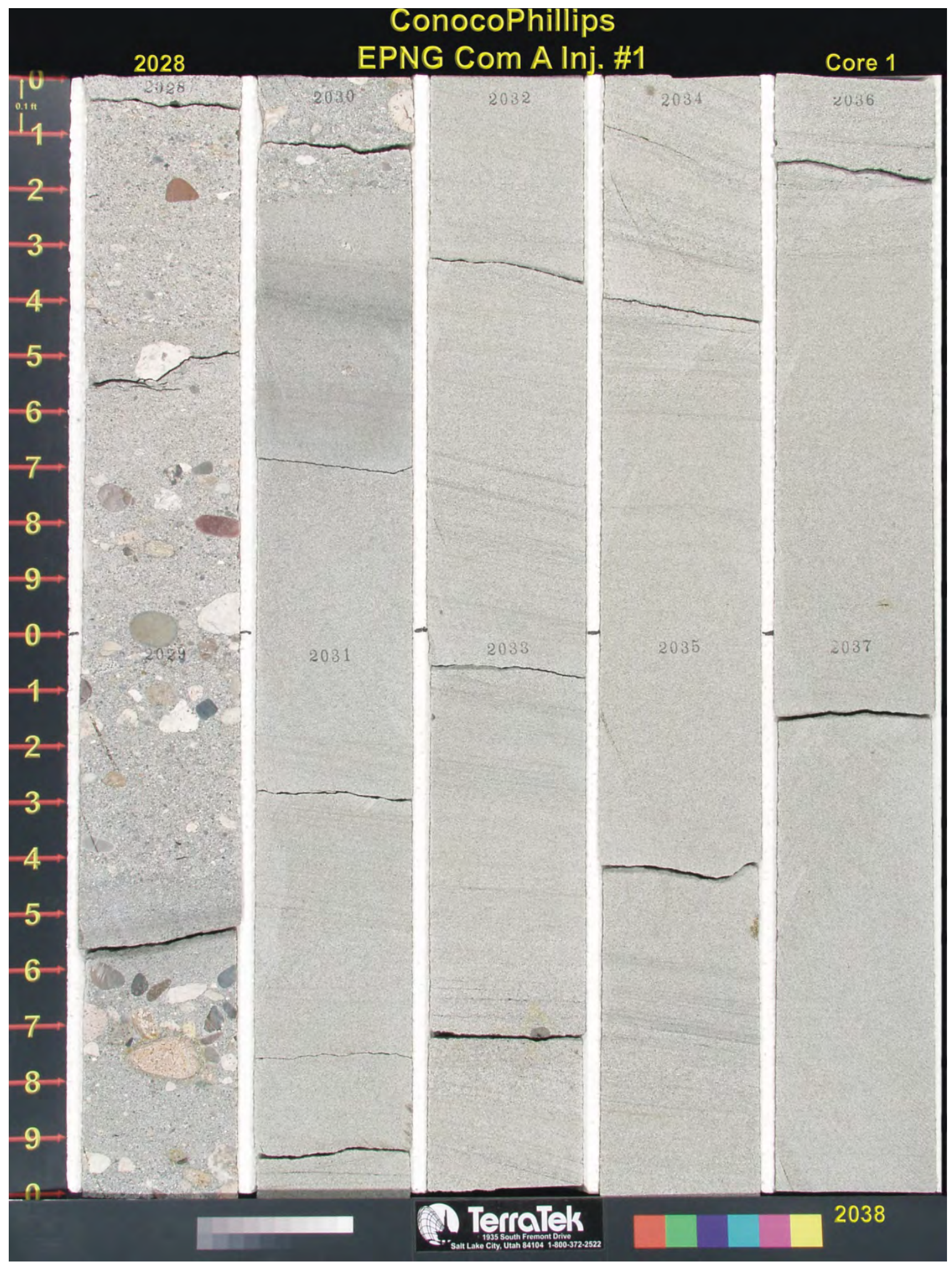




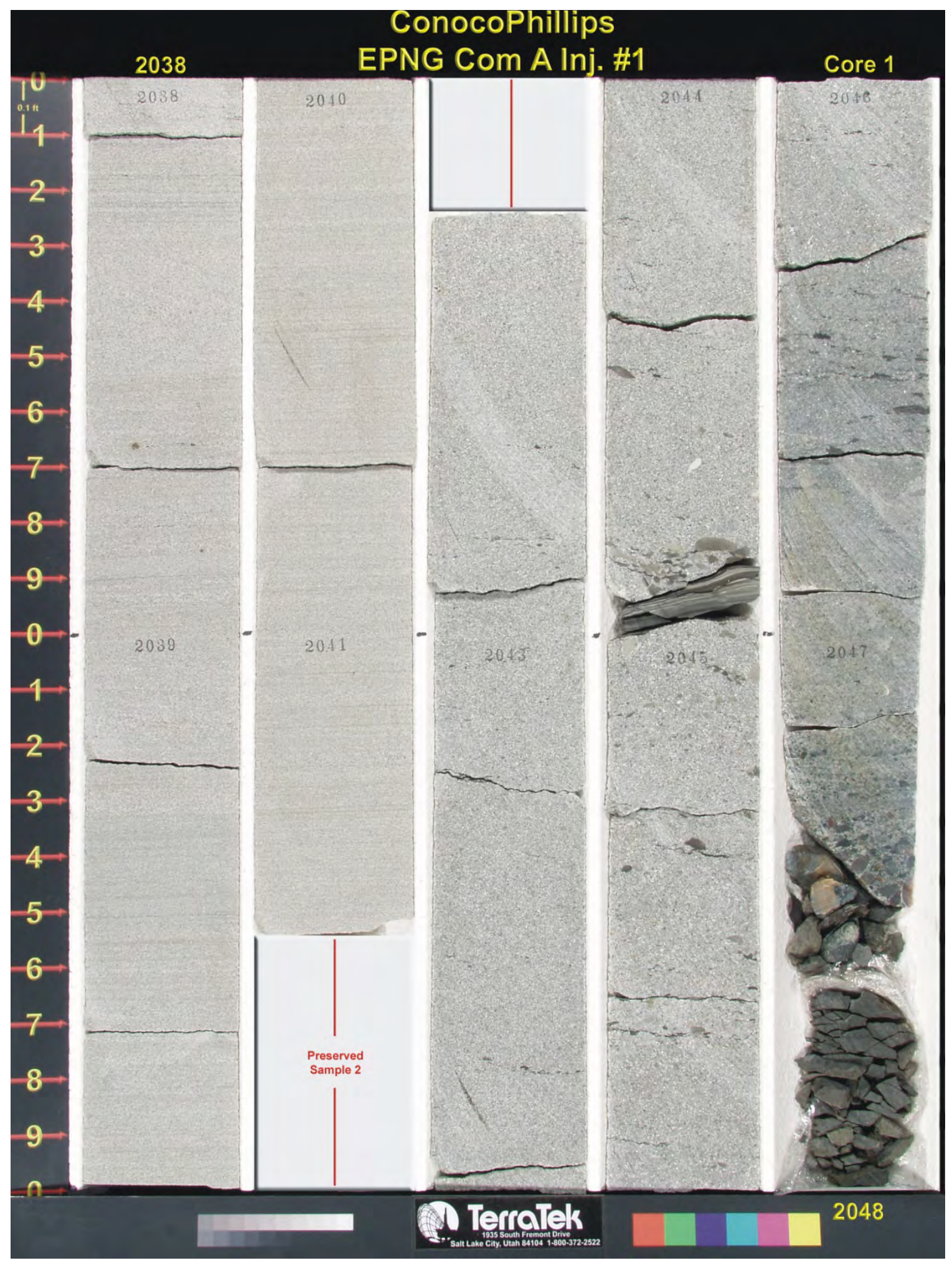




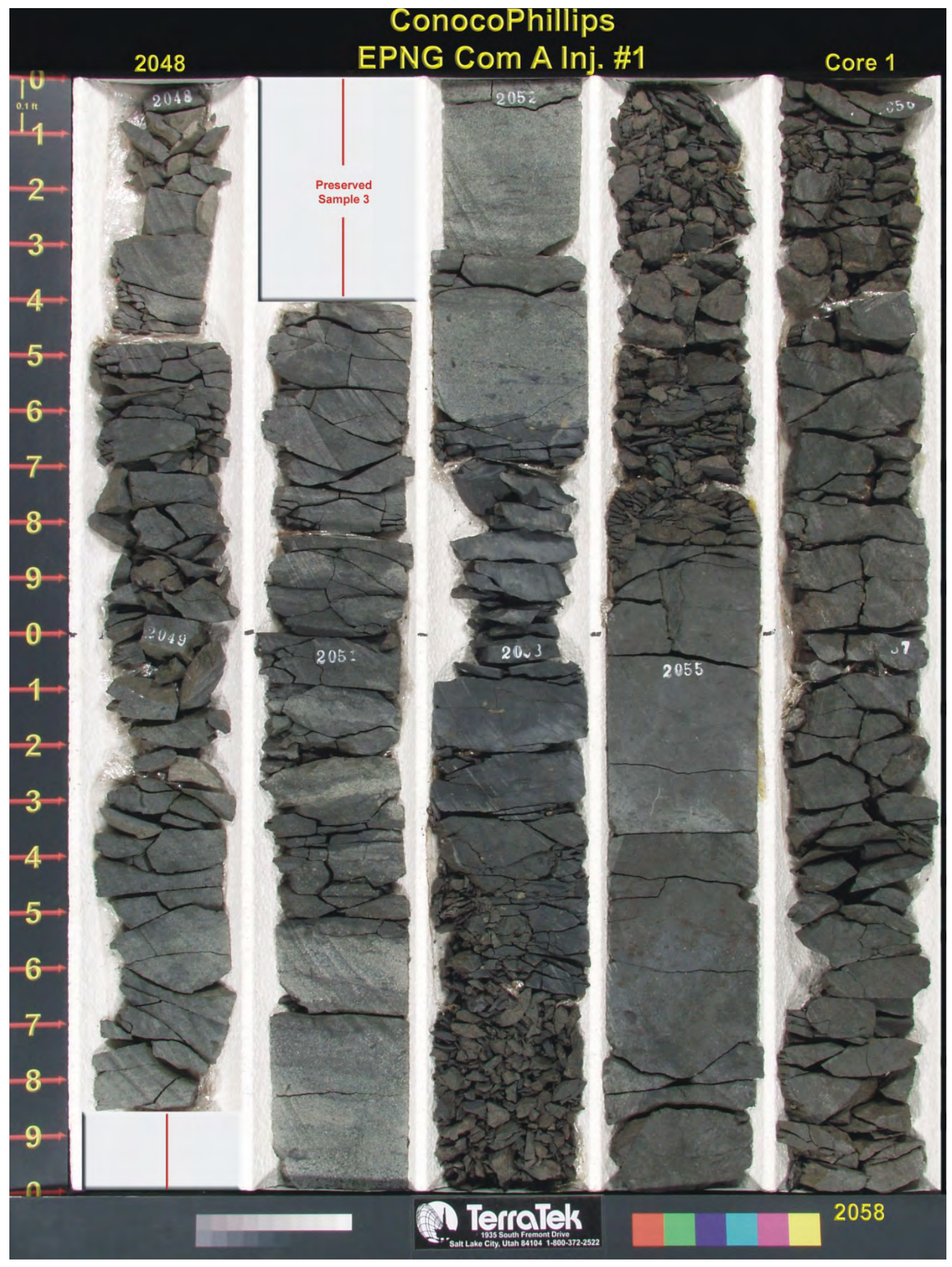




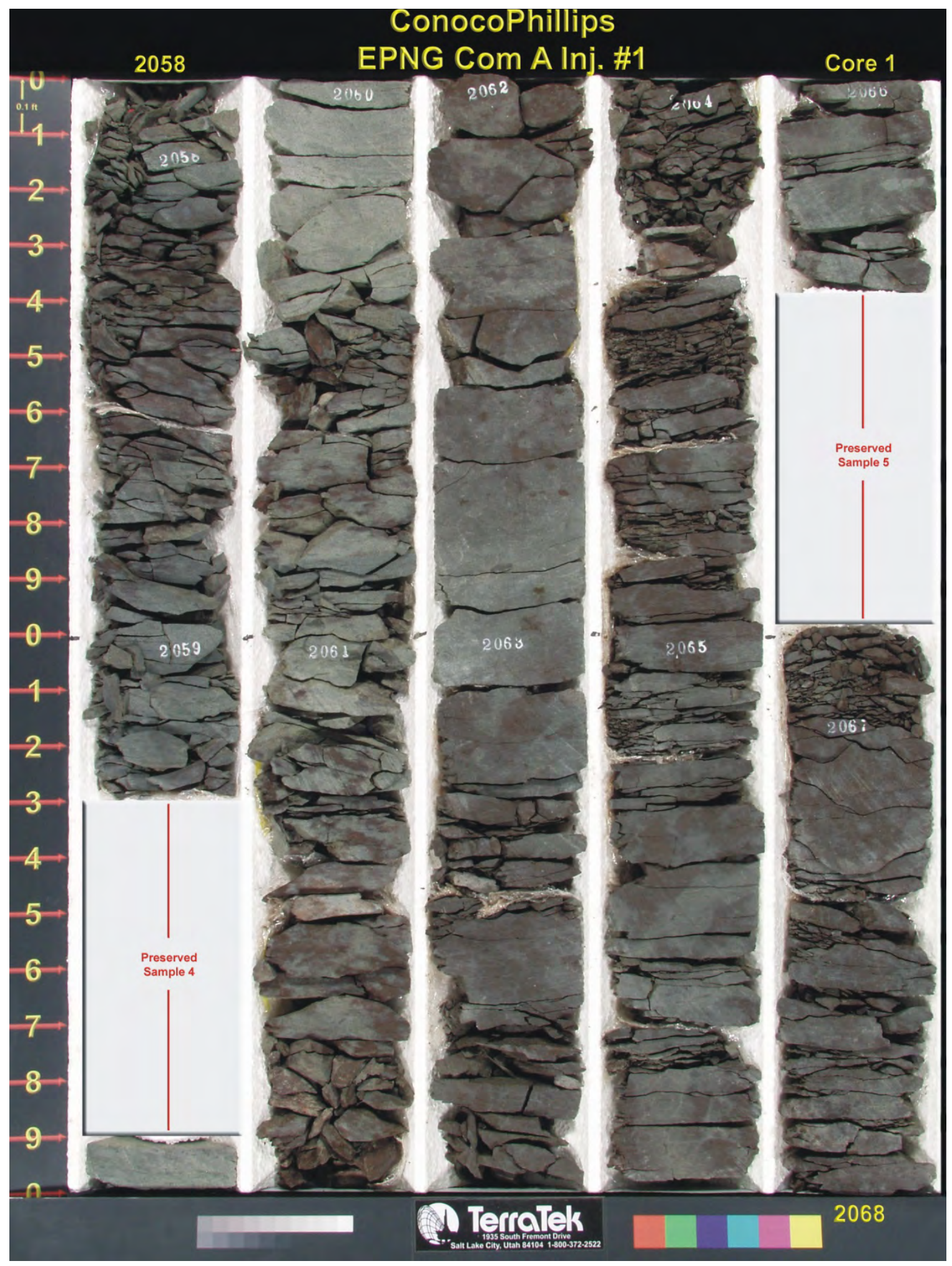




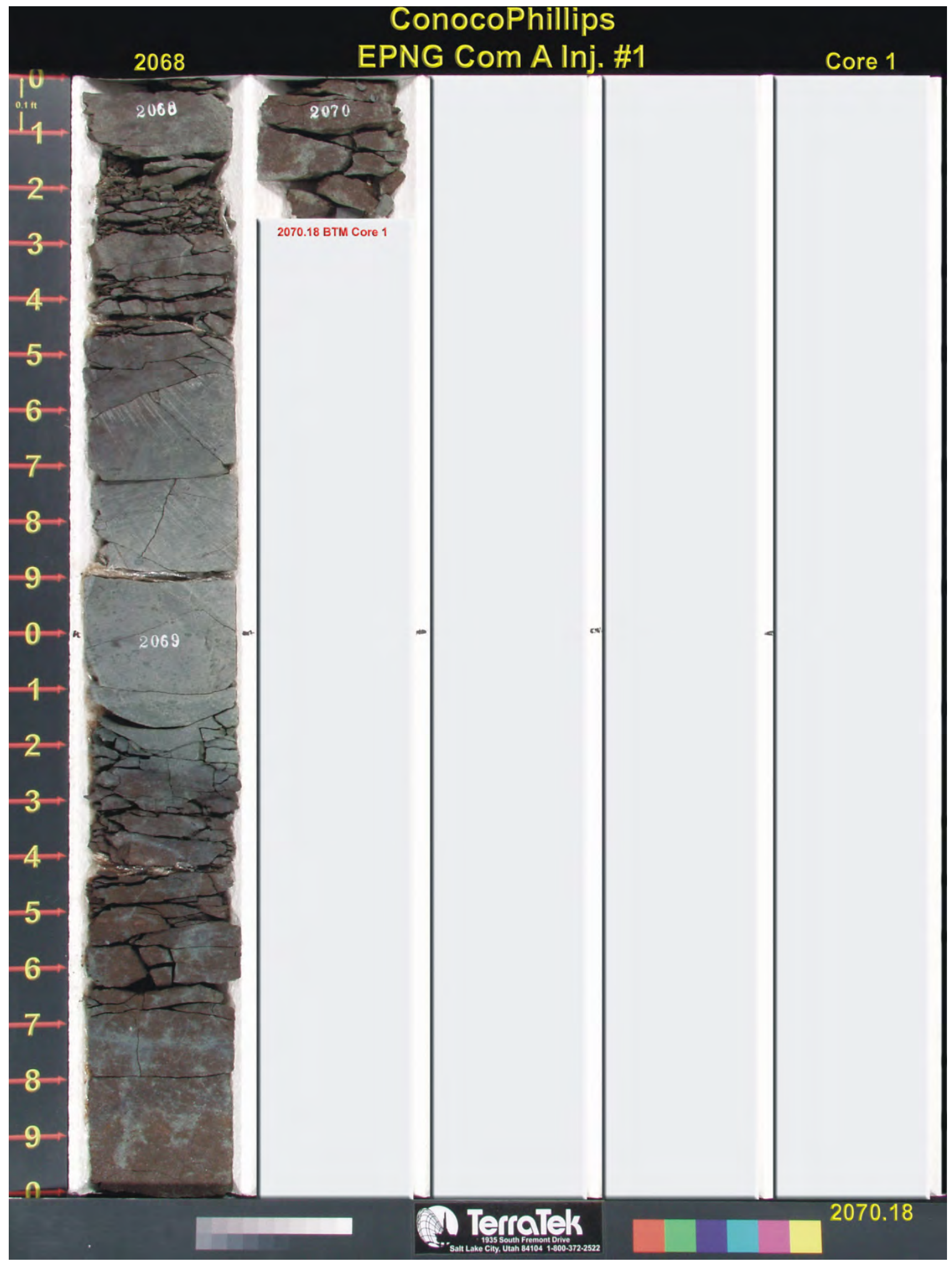




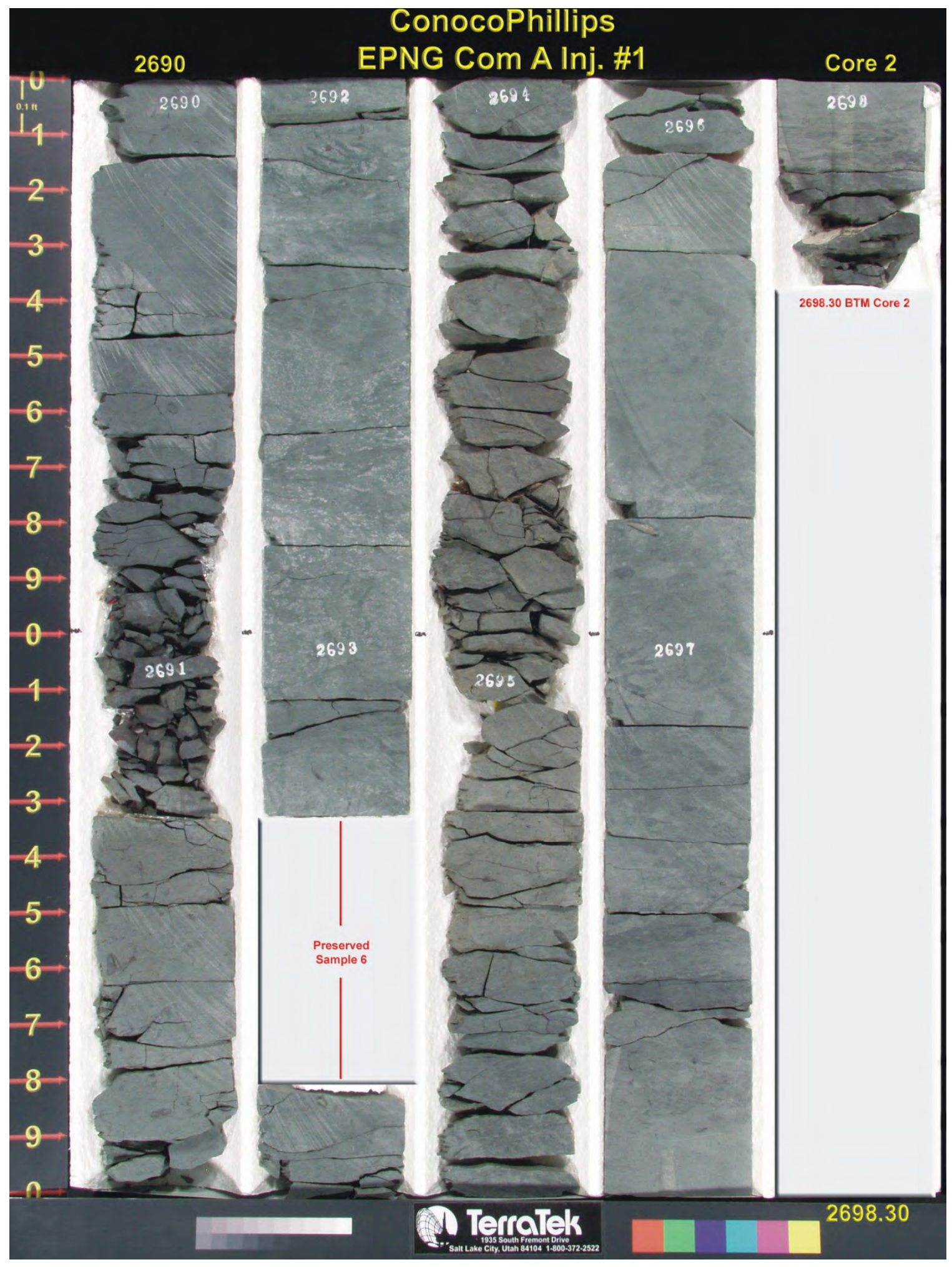




\section{B.4 Gas Breakthrough Experiment Data}

TerraTek performed gas breakthrough pressure measurements on core plugs following guidance from Jason Heath, Brian McPherson, and Thomas Dewers, as described in the following memo of Appendix B.4.1. The results of the measurements are given in Appendix B.4.2. 


\section{B.4.1 Instructions to TerraTek for Gas Breakthrough Pressure Measurements}

\section{Memo}

To: John Keller, TerraTek

From: Jason Heath, Sandia National Laboratories

Date: July 29, 2009

\section{Re: Recommendations for Gas breakthrough Testing}

This memo provides information for the performance of gas breakthrough experiments on preserved core from the Kirtland Formation. Similarly to previous work on Kirtland core, the invoice for these tests should be sent to ConocoPhillips. The total remaining funds for the budget with ConocoPhillips is $\$ 1896.20$. If additional funds are needed for the new tests, please let me know so we could discuss a possible contract with Sandia.

\section{Sample Descriptions}

1. Three "seal peel" samples were sent to TerraTek in the Spring, samples 2A, 3A, and 6A from depths 2042.25-2043.25 ft, 2049.00-2049.89, and 2692.30-2693.30 ft, respectively. Sample $6 \mathrm{~A}$ is the most valuable since it is from the deeper section of core in the lower Kirtland. Sample $3 \mathrm{~A}$ is from the upper Kirtland, and 2A is from the Ojo Alamo.

I recommend using $3 \mathrm{~A}$ first for the gas breakthrough tests to evaluate procedures before using sample 6A. Sample 2A will not be tested at this time.

\section{Two Sets of Tests Based on Saturation}

2. Based on analyses of fresh core, the preserved Kirtland Formation core is not fully saturated with groundwater. Thus, I recommend that two sets of tests be performed. The first should be on preserved samples of core and should not include any further saturation with brine. The second set should be on samples that are fully saturated with brine (information on brine salinity will be given below). At least one measurement at initial conditions of "in situ" saturation and one measurement at the fully saturated conditions are desired. More measurements would be desirable to determine the precision of the experimental methods, but we leave that to you since the budget is limited.

3. Li et al. (2005; page 328) provides guidance for saturating samples.

\section{Sample Evaluation to Avoid Induced Fractures}

4. The effect of induced micro-fractures on the pore structure is a major concern. If costs are not prohibitive, I recommend taking X-ray CT images of the samples prior to removing them 
from the preservation material. Such imaging could help avoid taking plugs at locations of induced fractures. Please let me know if "healed" natural fractures are found.

5. I recommend measurements of absolute permeability prior to the brine-saturated gas breakthrough tests. The measurement of permeability should be in the range of $10^{-8}$ to $10^{-9} \mathrm{~d}$ to correspond with previous measurements made in the summer 2008. For the first set of tests without saturating the samples, permeability measurements after the tests could be performed to check for the possible effects of fractures - again, if costs are not prohibitive.

\section{Drilling of Plugs}

6. Since the samples contain abundant swelling clays, I advise caution in drilling plugs. As the plugs are drilled, please take notes on the methods used, which could include drilling with or without fluid and whether the fluid was aqueous or non-aqueous.

7. Vertical plugs are requested for evaluation of vertical transport properties of the samples.

8. I will not recommend an exact diameter and length for the plugs. Please use what seems best for the size of the flow cells and for optimizing the quality of the results while minimizing the time of the tests. Previous studies by Hildenbrand (2004) used plugs $28.5 \mathrm{~mm}$ in diameter by $30 \mathrm{~mm}$ in length. Perhaps $\sim 1$ inch diameter plus by slightly less than 1 inch long would be suitable for the tests.

\section{Additional Small Plugs for Poro-Technology/MICP}

9. When taking plugs, please core such that a portion of rock, taken as a plug at the same location of the plugs for the breakthrough tests, could be sent off for mercury injection capillary pressure measurements (MICP). Thus, a small disc with dimensions up to approximately 0.85 inch long by 0.90 inch diameter. The drill bit used previously to core the Gothic Shale samples from the UGS worked well for the diameter of Poro-Technology's MICP penetrometer cup, which could possibly be used again for these experiments. Thus, MICP data could be compared to the breakthrough results for approximately the same depth and lithology.

10. These additional samples should be shipped to:

Jason Heath

Sandia National Laboratories

1515 Eubank SE

Bldg 823 Rm 2241 Org 6314

Albuquerque, NM 87123-0750

\section{Hydrostatic Flow Vessel and P\&T Conditions}

11. During the gas breakthrough pressure test, the sample and vessel should be oriented vertically to simulate the vertical transport of $\mathrm{CO}_{2}$ through the Kirtland.

12. We want the initial stress conditions of the test to be similar to the field conditions. The confining pressure will based on estimated in situ field conditions, which will be different for samples $3 \mathrm{~A}$ and $6 \mathrm{~A}$ - the confining pressure will correspond to stress condition at the depths of the two samples. These estimates are based on the "rule-of-thumb" lithostatic pressure gradient of $25 \mathrm{MPa} / \mathrm{km}$ and a hydrostatic gradient of $10 \mathrm{MPa} / \mathrm{km}$. 
The initial confining, pore, and effective $\left(\mathrm{P}_{\mathrm{e}}=\mathrm{P}_{\mathrm{c}}-\mathrm{P}_{\mathrm{f}}\right)$ pressures and temperatures for samples $3 \mathrm{~A}$ and $6 \mathrm{~A}$ should be as follows in the table below. The pressure and temperature conditions will result in gaseous and supercritical $\mathrm{CO}_{2}$ for the two samples - both sets of conditions are very near to the critical point of $\mathrm{CO}_{2}$. The critical point is $31.1^{\circ} \mathrm{C}$ and $7.38 \mathrm{MPa}$. Thus, for sample $3 \mathrm{~A}$, the $\mathrm{CO}_{2}$ should be a vapor with a density of $\sim 184 \mathrm{~kg} / \mathrm{m}^{3}$. The $\mathrm{CO}_{2}$ density for the initial conditions of sample $6 \mathrm{~A}$ should be $\sim 383 \mathrm{~kg} / \mathrm{m}^{3}$.

\begin{tabular}{ccccccccc}
\hline Sample & $\begin{array}{c}\text { Depth } \\
(\mathrm{ft})\end{array}$ & $\begin{array}{c}\text { Confining } \\
\text { Pressure } \\
(\mathrm{MPa})\end{array}$ & $\begin{array}{c}\text { Confining } \\
\text { Pressure } \\
(\mathrm{psi})\end{array}$ & $\begin{array}{c}\text { Pore } \\
\text { Pressure } \\
(\mathrm{MPa})\end{array}$ & $\begin{array}{c}\text { Pore } \\
\text { Pressure } \\
(\mathrm{psi})\end{array}$ & $\begin{array}{c}\text { Effective } \\
\text { Pressure } \\
(\mathrm{MPa})\end{array}$ & $\begin{array}{c}\text { Effective } \\
\text { Pressure } \\
(\mathrm{psi})\end{array}$ & $\begin{array}{c}\text { Temp } \\
\left({ }^{\circ} \mathrm{C}\right)\end{array}$ \\
\hline $3 \mathrm{~A}$ & 2049.5 & 15.6 & 2265.0 & 6.2 & 906.0 & 9.4 & 1359.0 & 30 \\
$6 \mathrm{~A}$ & 2692.8 & 20.5 & 2976.0 & 8.2 & 1190.4 & 12.3 & 1785.6 & 37 \\
\hline
\end{tabular}

13. The general setup is given below. The inlet pressure should vary from the initial back pressure regulator (BRP; or ISCO pump) value up to some fraction of the confining pressure (see below) - for these tests, go up to 0.5 times the confining pressure.

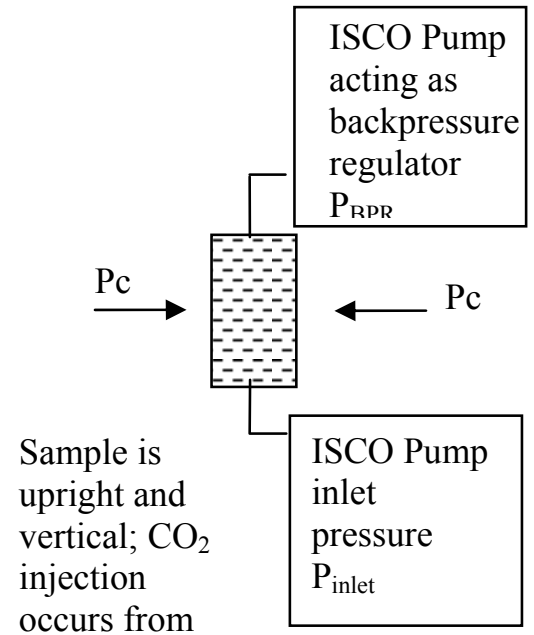

the bottom

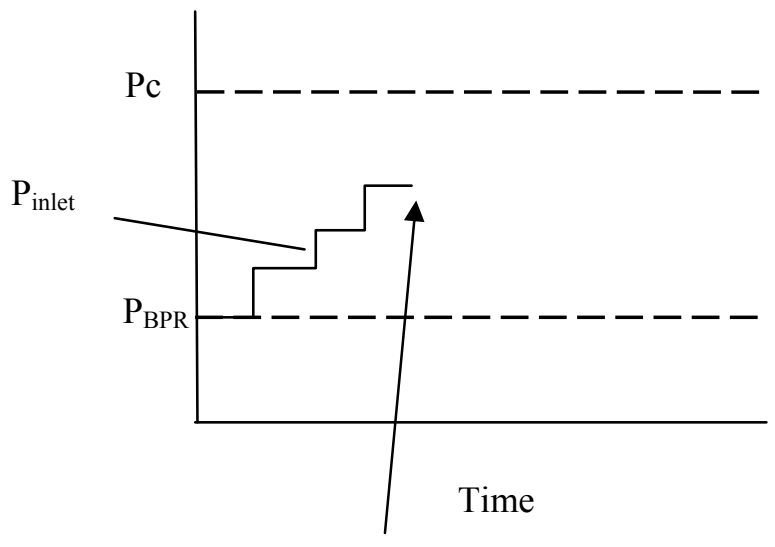

Pressure at which breakthrough occurs or the calculated fracture pressure is reached

14. The brine used in the ISCO pumps should have a salinity of approximately $16,000 \mathrm{mg} / \mathrm{L}$ $\mathrm{NaCl}$ solution. This salinity/ionic strength should avoid shrinkage or swelling of the clays.

15. To check if the $\mathrm{NaCl}$ solution results in significant cation exchange, I recommend doing an XRD test on the samples (or simply review the results from Mary Milner's previous work on the Kirtland core). I then recommend soaking a ground-up sample in the brine solution and then comparing the peaks of the XRD data to see if basal spacing changed.

16. The time for each pressure step should be related to monitoring fluid movement from the sample at the outlet. Once fluid has halted moving for at least 2 hours, proceed to increase the pressure step.

17. Each pressure step should be 0.5 to $1 \mathrm{MPa}$. 
18. The following website has a convenient calculator for determining $\mathrm{CO}_{2}$ densities at various P\&T conditions: http://sequestration.mit.edu/tools/index.html

19. If breakthrough is not reached for the $P_{c}$ and $P_{B P R}$ conditions, then these parameters could be adjusted to higher values while keeping $P_{c}$ minus $P_{B P R}$ constant. The test could then be continued with higher pore pressure values without major damage to the pore structure.

Please contact me with any questions. These instructions are recommendations - please implement the test as seems best suited to the quality of the samples, the apparatus available, and the cost.

Thanks!

Jason

Office: $505-845-1375$

Cell: 801-815-5209

\section{References}

Hildenbrand, A., Schlomer, S., Krooss, B.M., and Littke, R., 2004, Gas breakthrough experiments on pelitic rocks: comparative study with $\mathrm{N}_{2}, \mathrm{CO}_{2}$ and $\mathrm{CH}_{4}$ : Geofluids, v. 4, p. 61-80.

Li, S., Dong, M., Li, Z., Huang, S., Qing, H., and Nickel, E., 2005, Gas breakthrough pressure for hydrocarbon reservoir seal rocks: implications for the security of long-term $\mathrm{CO}_{2}$ storage in the Weyburn field: Geofluids, v. 5, p. 326-334. 


\section{B.4.2 Description of Gas Breakthrough Pressure Measurement Data}

A "seal peel" sample from the upper Kirtland, from the depth interval 2049.00 to 2049.89 $\mathrm{ft}$, was opened and cored for the breakthrough pressure measurement. The first test was performed at the water and gas saturations of the preserved plug. Thus, the test was run without fully saturating the plug with brine (Figure B.4.2.1). The second test included full brine saturation (Figure B.4.2.2). Breakthrough was only seen for the first test. The second test reached the maximum pressure allowable for the experimental system (Figure B.4.2.2). The lower Kirtland gas breakthrough test did not achieve breakthrough before the end of the test for a brine saturated sample (Figure B.4.2.3).

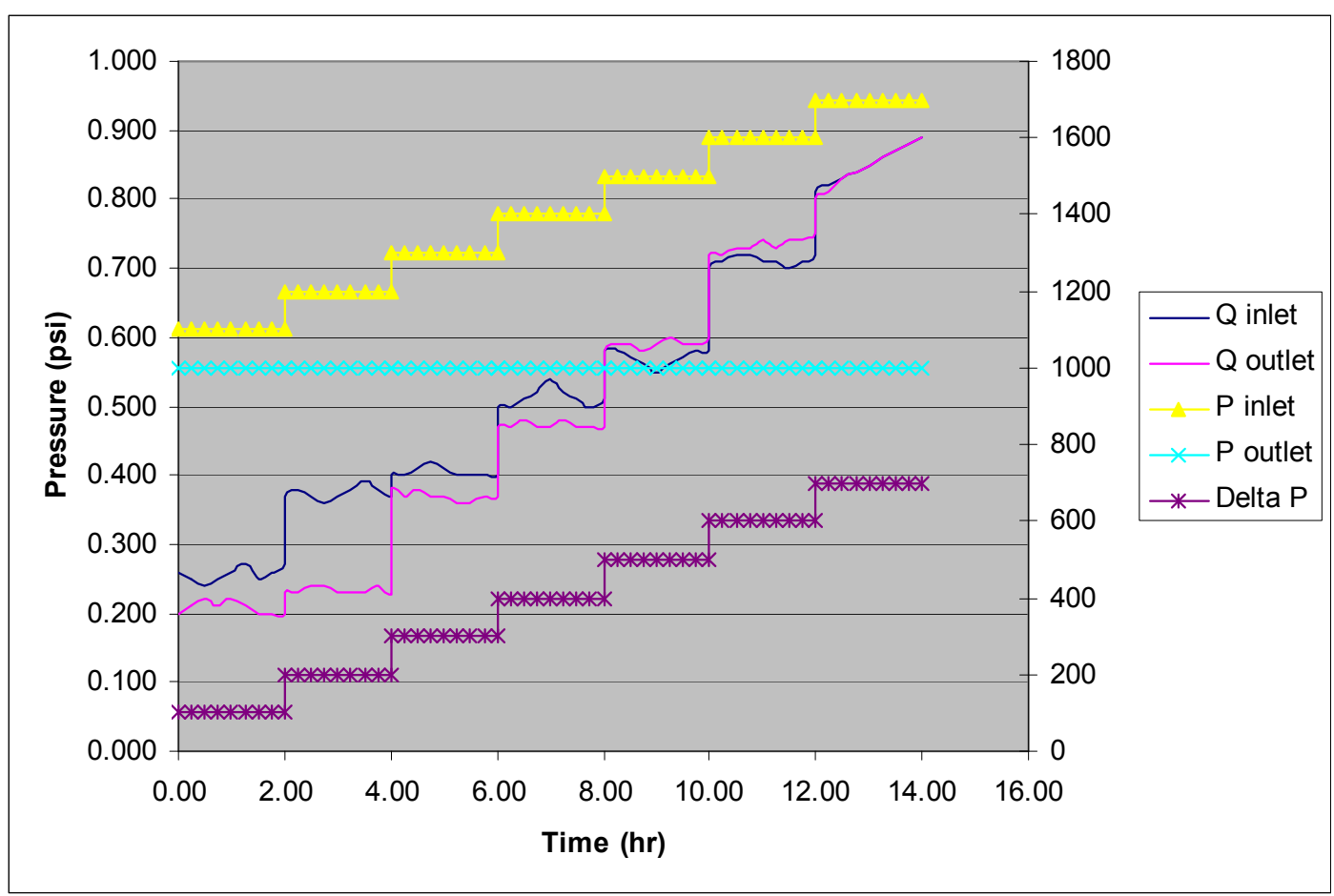

Figure B.4.2.1. Unsaturated, upper Kirtland gas breakthrough pressure test results. 


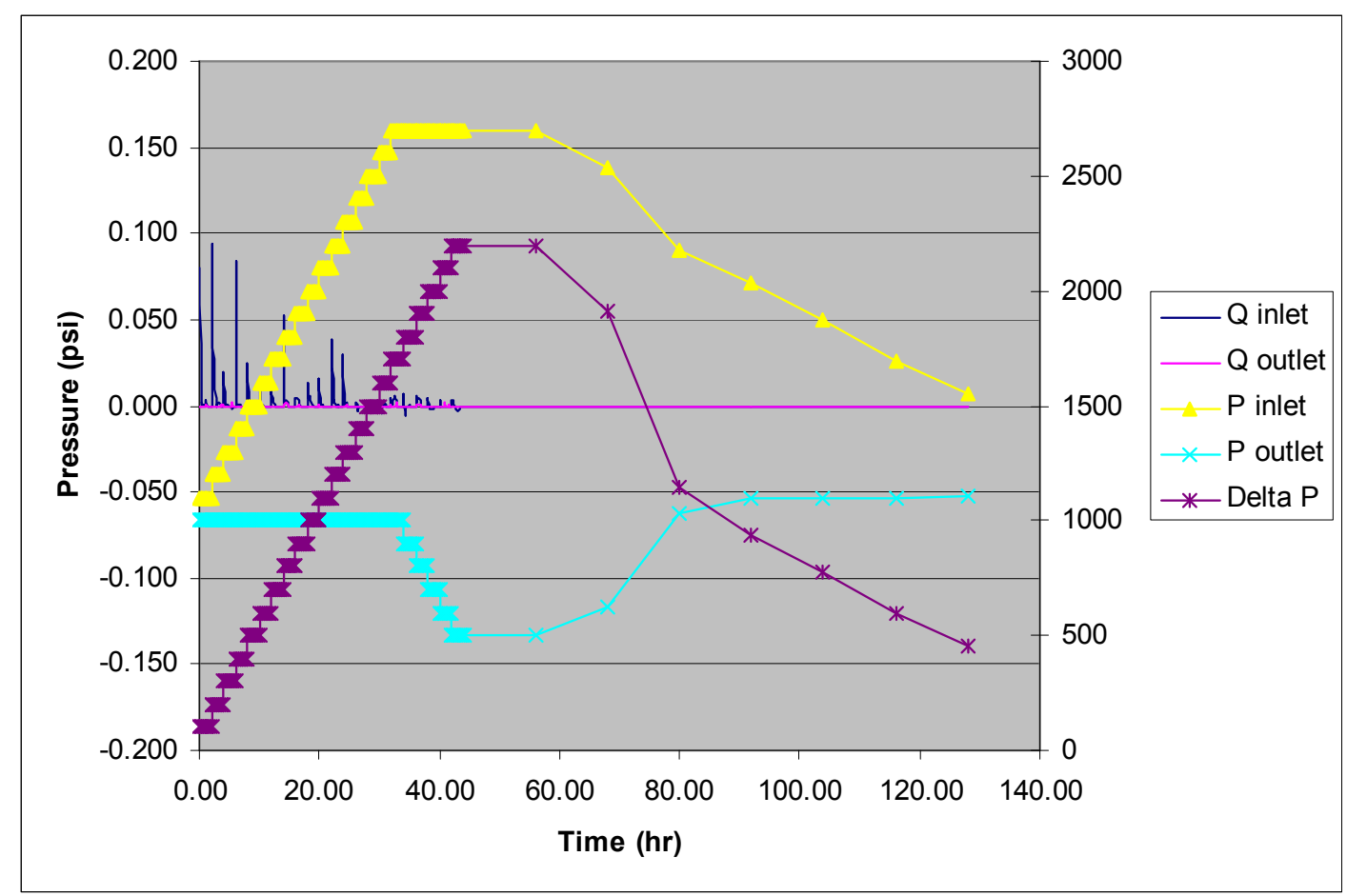

Figure B.4.2.2. Brine saturated, upper Kirtland gas breakthrough pressure test results.

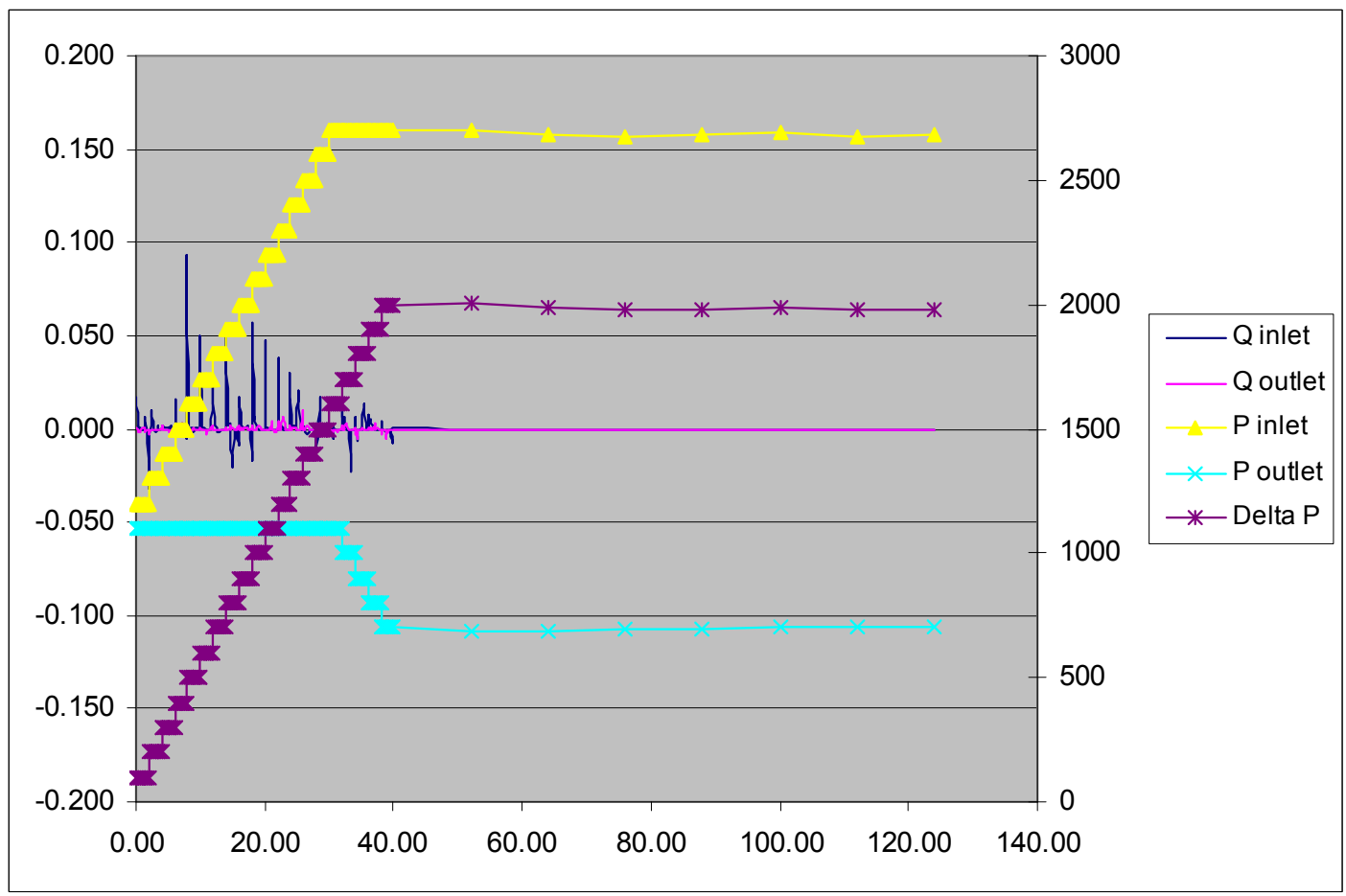

Figure B.4.2.3. Brine saturated lower Kirtland gas breakthrough pressure test results. 


\section{B.4.3 Tables of Gas Breakthrough Pressure Measurement Data}

Table B.4.3.1. Gas breakthrough pressure measurement results for upper Kirtland, brine saturated sample

\begin{tabular}{lr}
\hline Project: & 502488 \\
Depth (ft): & 2049.75 \\
Length (in): & 0.454 \\
Diameter (in): & 1.005 \\
Temp (degC) & 30
\end{tabular}

Brine Saturated Sample

\begin{tabular}{rrrrrrr}
$\begin{array}{c}\text { Time } \\
\text { (hours) }\end{array}$ & $\begin{array}{r}\text { Q inlet } \\
\text { (cc/min) }\end{array}$ & $\begin{array}{c}\text { P inlet } \\
\text { (psi) }\end{array}$ & $\begin{array}{c}\text { P outlet } \\
\text { (psi) }\end{array}$ & $\begin{array}{r}\text { Q outlet } \\
\text { (cc/min) }\end{array}$ & $\begin{array}{c}\text { Delta P } \\
\text { (psi) }\end{array}$ & $\begin{array}{c}\text { P confining } \\
\text { (psi) }\end{array}$ \\
\hline (initial) & 0 & 1000 & 1000 & 0 & 0 & 2265 \\
0.00 & 0.080 & 1100 & 1000 & 0.000 & 100 & 2265 \\
0.25 & 0.002 & 1100 & 1000 & 0.000 & 100 & 2265 \\
0.50 & 0.001 & 1100 & 1000 & 0.000 & 100 & 2265 \\
0.75 & 0.001 & 1100 & 1000 & 0.000 & 100 & 2265 \\
1.00 & 0.001 & 1100 & 1000 & 0.000 & 100 & 2265 \\
1.25 & 0.003 & 1100 & 1000 & 0.001 & 100 & 2265 \\
1.50 & -0.001 & 1100 & 1000 & 0.000 & 100 & 2265 \\
1.75 & 0.000 & 1100 & 1000 & 0.000 & 100 & 2265 \\
2.00 & 0.000 & 1100 & 1000 & 0.000 & 100 & 2265 \\
2.00 & 0.091 & 1200 & 1000 & 0.000 & 200 & 2265 \\
2.25 & 0.061 & 1200 & 1000 & 0.000 & 200 & 2265 \\
2.50 & 0.010 & 1200 & 1000 & 0.000 & 200 & 2265 \\
2.75 & 0.002 & 1200 & 1000 & -0.001 & 200 & 2265 \\
3.00 & 0.000 & 1200 & 1000 & 0.000 & 200 & 2265 \\
3.25 & 0.002 & 1200 & 1000 & 0.000 & 200 & 2265 \\
3.50 & 0.000 & 1200 & 1000 & 0.000 & 200 & 2265 \\
3.75 & 0.000 & 1200 & 1000 & 0.000 & 200 & 2265 \\
4.00 & 0.000 & 1200 & 1000 & 0.001 & 200 & 2265 \\
4.00 & 0.020 & 1300 & 1000 & 0.000 & 300 & 2265 \\
4.25 & 0.005 & 1300 & 1000 & 0.000 & 300 & 2265 \\
4.50 & 0.001 & 1300 & 1000 & 0.000 & 300 & 2265 \\
4.75 & 0.001 & 1300 & 1000 & 0.000 & 300 & 2265 \\
5.00 & 0.000 & 1300 & 1000 & 0.000 & 300 & 2265 \\
5.25 & 0.000 & 1300 & 1000 & 0.000 & 300 & 2265 \\
5.50 & -0.002 & 1300 & 1000 & 0.002 & 300 & 2265 \\
5.75 & 0.000 & 1300 & 1000 & 0.000 & 300 & 2265 \\
6.00 & 0.000 & 1300 & 1000 & 0.000 & 300 & 2265 \\
6.00 & 0.084 & 1400 & 1000 & 0.000 & 400 & 2265 \\
6.25 & 0.001 & 1400 & 1000 & 0.000 & 400 & 2265 \\
6.50 & 0.001 & 1400 & 1000 & 0.000 & 400 & 2265 \\
6.75 & 0.000 & 1400 & 1000 & 0.000 & 400 & 2265 \\
7.00 & 0.000 & 1400 & 1000 & 0.000 & 400 & 2265 \\
7.25 & 0.000 & 1400 & 1000 & 0.000 & 400 & 2265 \\
7.50 & 0.000 & 1400 & 1000 & 0.000 & 400 & 2265 \\
& & & & & 106 & \\
& & & & & &
\end{tabular}




\begin{tabular}{|c|c|c|c|c|c|c|}
\hline $\begin{array}{l}\text { Time } \\
\text { (hours) }\end{array}$ & $\begin{array}{l}\text { Q inlet } \\
\text { (cc/min) }\end{array}$ & $\begin{array}{l}P \text { inlet } \\
\text { (psi) }\end{array}$ & $\begin{array}{l}\text { P outlet } \\
\text { (psi) }\end{array}$ & $\begin{array}{l}\text { Q outlet } \\
\text { (cc/min) }\end{array}$ & $\begin{array}{c}\text { Delta P } \\
\text { (psi) }\end{array}$ & $\begin{array}{c}\text { P confining } \\
(p s i)\end{array}$ \\
\hline 7.75 & 0.000 & 1400 & 1000 & 0.000 & 400 & 2265 \\
\hline 8.00 & 0.000 & 1400 & 1000 & -0.001 & 400 & 2265 \\
\hline 8.00 & 0.025 & 1500 & 1000 & 0.000 & 500 & 2265 \\
\hline 8.25 & 0.003 & 1500 & 1000 & 0.000 & 500 & 2265 \\
\hline 8.50 & 0.001 & 1500 & 1000 & 0.000 & 500 & 2265 \\
\hline 8.75 & 0.000 & 1500 & 1000 & 0.000 & 500 & 2265 \\
\hline 9.00 & 0.000 & 1500 & 1000 & 0.000 & 500 & 2265 \\
\hline 9.25 & 0.000 & 1500 & 1000 & 0.000 & 500 & 2265 \\
\hline 9.50 & 0.000 & 1500 & 1000 & 0.000 & 500 & 2265 \\
\hline 9.75 & 0.000 & 1500 & 1000 & 0.000 & 500 & 2265 \\
\hline 10.00 & 0.000 & 1500 & 1000 & 0.000 & 500 & 2265 \\
\hline 10.00 & 0.009 & 1600 & 1000 & 0.001 & 600 & 2265 \\
\hline 10.25 & 0.002 & 1600 & 1000 & 0.000 & 600 & 2265 \\
\hline 10.50 & 0.001 & 1600 & 1000 & 0.000 & 600 & 2265 \\
\hline 10.75 & 0.000 & 1600 & 1000 & 0.000 & 600 & 2265 \\
\hline 11.00 & 0.000 & 1600 & 1000 & 0.000 & 600 & 2265 \\
\hline 11.25 & 0.000 & 1600 & 1000 & 0.000 & 600 & 2265 \\
\hline 11.50 & 0.000 & 1600 & 1000 & 0.000 & 600 & 2265 \\
\hline 11.75 & -0.001 & 1600 & 1000 & 0.000 & 600 & 2265 \\
\hline 12.00 & 0.000 & 1600 & 1000 & 0.000 & 600 & 2265 \\
\hline 12.00 & 0.010 & 1700 & 1000 & 0.000 & 700 & 2265 \\
\hline 12.25 & 0.002 & 1700 & 1000 & 0.000 & 700 & 2265 \\
\hline 12.50 & 0.000 & 1700 & 1000 & 0.000 & 700 & 2265 \\
\hline 12.75 & 0.000 & 1700 & 1000 & 0.000 & 700 & 2265 \\
\hline 13.00 & 0.000 & 1700 & 1000 & 0.000 & 700 & 2265 \\
\hline 13.25 & 0.000 & 1700 & 1000 & 0.000 & 700 & 2265 \\
\hline 13.50 & 0.000 & 1700 & 1000 & -0.001 & 700 & 2265 \\
\hline 13.75 & 0.000 & 1700 & 1000 & 0.000 & 700 & 2265 \\
\hline 14.00 & 0.000 & 1700 & 1000 & 0.000 & 700 & 2265 \\
\hline 14.00 & 0.052 & 1800 & 1000 & 0.000 & 800 & 2265 \\
\hline 14.25 & 0.002 & 1800 & 1000 & 0.000 & 800 & 2265 \\
\hline 14.50 & 0.003 & 1800 & 1000 & 0.002 & 800 & 2265 \\
\hline 14.75 & 0.001 & 1800 & 1000 & 0.000 & 800 & 2265 \\
\hline 15.00 & 0.000 & 1800 & 1000 & 0.000 & 800 & 2265 \\
\hline 15.25 & -0.001 & 1800 & 1000 & 0.000 & 800 & 2265 \\
\hline 15.50 & -0.001 & 1800 & 1000 & 0.000 & 800 & 2265 \\
\hline 15.75 & 0.000 & 1800 & 1000 & 0.000 & 800 & 2265 \\
\hline 16.00 & 0.000 & 1800 & 1000 & 0.000 & 800 & 2265 \\
\hline 16.00 & 0.004 & 1900 & 1000 & 0.000 & 900 & 2365 \\
\hline 16.25 & 0.005 & 1900 & 1000 & 0.000 & 900 & 2365 \\
\hline 16.50 & 0.002 & 1900 & 1000 & 0.001 & 900 & 2365 \\
\hline 16.75 & 0.001 & 1900 & 1000 & 0.000 & 900 & 2365 \\
\hline 17.00 & 0.000 & 1900 & 1000 & 0.000 & 900 & 2365 \\
\hline 17.25 & 0.000 & 1900 & 1000 & 0.000 & 900 & 2365 \\
\hline 17.50 & 0.000 & 1900 & 1000 & 0.000 & 900 & 2365 \\
\hline 17.75 & 0.000 & 1900 & 1000 & 0.000 & 900 & 2365 \\
\hline 18.00 & 0.000 & 1900 & 1000 & 0.000 & 900 & 2365 \\
\hline
\end{tabular}




\begin{tabular}{|c|c|c|c|c|c|c|}
\hline $\begin{array}{l}\text { Time } \\
\text { (hours) }\end{array}$ & $\begin{array}{c}Q \text { inlet } \\
\text { (cc/min) }\end{array}$ & $\begin{array}{l}P \text { inlet } \\
\text { (psi) }\end{array}$ & $\begin{array}{c}\text { P outlet } \\
\text { (psi) }\end{array}$ & $\begin{array}{l}\text { Q outlet } \\
\text { (cc/min) }\end{array}$ & $\begin{array}{c}\text { Delta P } \\
\text { (psi) }\end{array}$ & $\begin{array}{l}\text { P confining } \\
(p s i)\end{array}$ \\
\hline 18.00 & 0.013 & 2000 & 1000 & 0.000 & 1000 & 2465 \\
\hline 18.25 & 0.005 & 2000 & 1000 & 0.000 & 1000 & 2465 \\
\hline 18.50 & 0.006 & 2000 & 1000 & 0.000 & 1000 & 2465 \\
\hline 18.75 & 0.001 & 2000 & 1000 & 0.000 & 1000 & 2465 \\
\hline 19.00 & 0.000 & 2000 & 1000 & 0.000 & 1000 & 2465 \\
\hline 19.25 & 0.000 & 2000 & 1000 & 0.000 & 1000 & 2465 \\
\hline 19.50 & 0.000 & 2000 & 1000 & 0.000 & 1000 & 2465 \\
\hline 19.75 & 0.000 & 2000 & 1000 & 0.000 & 1000 & 2465 \\
\hline 20.00 & 0.000 & 2000 & 1000 & 0.001 & 1000 & 2465 \\
\hline 20.00 & 0.016 & 2100 & 1000 & 0.000 & 1100 & 2565 \\
\hline 20.25 & 0.001 & 2100 & 1000 & 0.000 & 1100 & 2565 \\
\hline 20.50 & 0.001 & 2100 & 1000 & 0.000 & 1100 & 2565 \\
\hline 20.75 & -0.001 & 2100 & 1000 & 0.000 & 1100 & 2565 \\
\hline 21.00 & 0.000 & 2100 & 1000 & 0.000 & 1100 & 2565 \\
\hline 21.25 & 0.000 & 2100 & 1000 & 0.000 & 1100 & 2565 \\
\hline 21.50 & 0.000 & 2100 & 1000 & 0.000 & 1100 & 2565 \\
\hline 21.75 & 0.000 & 2100 & 1000 & 0.000 & 1100 & 2565 \\
\hline 22.00 & 0.000 & 2100 & 1000 & 0.000 & 1100 & 2565 \\
\hline 22.00 & 0.038 & 2200 & 1000 & 0.000 & 1200 & 2665 \\
\hline 22.25 & 0.002 & 2200 & 1000 & 0.000 & 1200 & 2665 \\
\hline 22.50 & 0.003 & 2200 & 1000 & 0.000 & 1200 & 2665 \\
\hline 22.75 & 0.000 & 2200 & 1000 & 0.000 & 1200 & 2665 \\
\hline 23.00 & 0.001 & 2200 & 1000 & 0.000 & 1200 & 2665 \\
\hline 23.25 & 0.000 & 2200 & 1000 & 0.000 & 1200 & 2665 \\
\hline 23.50 & 0.000 & 2200 & 1000 & -0.001 & 1200 & 2665 \\
\hline 23.75 & 0.000 & 2200 & 1000 & 0.000 & 1200 & 2665 \\
\hline 24.00 & 0.000 & 2200 & 1000 & 0.000 & 1200 & 2665 \\
\hline 24.00 & 0.030 & 2300 & 1000 & 0.000 & 1300 & 2765 \\
\hline 24.25 & 0.001 & 2300 & 1000 & 0.000 & 1300 & 2765 \\
\hline 24.50 & 0.002 & 2300 & 1000 & 0.001 & 1300 & 2765 \\
\hline 24.75 & 0.000 & 2300 & 1000 & 0.000 & 1300 & 2765 \\
\hline 25.00 & 0.000 & 2300 & 1000 & 0.000 & 1300 & 2765 \\
\hline 25.25 & 0.000 & 2300 & 1000 & 0.000 & 1300 & 2765 \\
\hline 25.50 & 0.000 & 2300 & 1000 & 0.000 & 1300 & 2765 \\
\hline 25.75 & 0.000 & 2300 & 1000 & 0.000 & 1300 & 2765 \\
\hline 26.00 & 0.000 & 2300 & 1000 & 0.000 & 1300 & 2765 \\
\hline 26.00 & 0.002 & 2400 & 1000 & 0.000 & 1400 & 2865 \\
\hline 26.25 & 0.001 & 2400 & 1000 & 0.000 & 1400 & 2865 \\
\hline 26.50 & -0.003 & 2400 & 1000 & 0.000 & 1400 & 2865 \\
\hline 26.75 & 0.000 & 2400 & 1000 & 0.000 & 1400 & 2865 \\
\hline 27.00 & 0.000 & 2400 & 1000 & 0.000 & 1400 & 2865 \\
\hline 27.25 & 0.000 & 2400 & 1000 & 0.000 & 1400 & 2865 \\
\hline 27.50 & 0.000 & 2400 & 1000 & 0.000 & 1400 & 2865 \\
\hline 27.75 & 0.000 & 2400 & 1000 & 0.002 & 1400 & 2865 \\
\hline 28.00 & 0.000 & 2400 & 1000 & 0.000 & 1400 & 2865 \\
\hline 28.00 & 0.002 & 2500 & 1000 & 0.000 & 1500 & 2965 \\
\hline 28.25 & 0.000 & 2500 & 1000 & 0.000 & 1500 & 2965 \\
\hline
\end{tabular}




\begin{tabular}{|c|c|c|c|c|c|c|}
\hline $\begin{array}{l}\text { Time } \\
\text { (hours) }\end{array}$ & $\begin{array}{l}\text { Q inlet } \\
\text { (cc/min) }\end{array}$ & $\begin{array}{l}P \text { inlet } \\
\text { (psi) }\end{array}$ & $\begin{array}{l}\text { P outlet } \\
\text { (psi) }\end{array}$ & $\begin{array}{l}\text { Q outlet } \\
\text { (cc/min) }\end{array}$ & $\begin{array}{c}\text { Delta P } \\
\text { (psi) }\end{array}$ & $\begin{array}{c}\text { P confining } \\
(p s i)\end{array}$ \\
\hline 28.50 & 0.000 & 2500 & 1000 & 0.000 & 1500 & 2965 \\
\hline 28.75 & 0.000 & 2500 & 1000 & 0.000 & 1500 & 2965 \\
\hline 29.00 & 0.000 & 2500 & 1000 & 0.000 & 1500 & 2965 \\
\hline 29.25 & 0.000 & 2500 & 1000 & 0.000 & 1500 & 2965 \\
\hline 29.50 & 0.000 & 2500 & 1000 & -0.001 & 1500 & 2965 \\
\hline 29.75 & 0.000 & 2500 & 1000 & 0.000 & 1500 & 2965 \\
\hline 30.00 & 0.000 & 2500 & 1000 & 0.000 & 1500 & 2965 \\
\hline 30.00 & 0.003 & 2600 & 1000 & 0.000 & 1600 & 3065 \\
\hline 30.25 & 0.001 & 2600 & 1000 & 0.000 & 1600 & 3065 \\
\hline 30.50 & -0.005 & 2600 & 1000 & 0.000 & 1600 & 3065 \\
\hline 30.75 & 0.002 & 2600 & 1000 & 0.000 & 1600 & 3065 \\
\hline 31.00 & 0.000 & 2600 & 1000 & 0.000 & 1600 & 3065 \\
\hline 31.25 & 0.000 & 2600 & 1000 & 0.000 & 1600 & 3065 \\
\hline 31.50 & 0.000 & 2600 & 1000 & 0.000 & 1600 & 3065 \\
\hline 31.75 & 0.000 & 2600 & 1000 & 0.000 & 1600 & 3065 \\
\hline 32.00 & 0.000 & 2600 & 1000 & 0.001 & 1600 & 3065 \\
\hline 32.00 & 0.005 & 2700 & 1000 & 0.000 & 1700 & 3165 \\
\hline 32.25 & 0.001 & 2700 & 1000 & 0.000 & 1700 & 3165 \\
\hline 32.50 & 0.006 & 2700 & 1000 & 0.000 & 1700 & 3165 \\
\hline 32.75 & 0.000 & 2700 & 1000 & 0.002 & 1700 & 3165 \\
\hline 33.00 & 0.000 & 2700 & 1000 & 0.000 & 1700 & 3165 \\
\hline 33.25 & 0.000 & 2700 & 1000 & 0.000 & 1700 & 3165 \\
\hline 33.50 & 0.000 & 2700 & 1000 & 0.000 & 1700 & 3165 \\
\hline 33.75 & 0.000 & 2700 & 1000 & 0.000 & 1700 & 3165 \\
\hline 34.00 & 0.000 & 2700 & 1000 & 0.000 & 1700 & 3165 \\
\hline 34.00 & 0.007 & 2700 & 900 & 0.000 & 1800 & 3165 \\
\hline 34.25 & -0.006 & 2700 & 900 & 0.000 & 1800 & 3165 \\
\hline 34.50 & 0.000 & 2700 & 900 & 0.000 & 1800 & 3165 \\
\hline 34.75 & 0.000 & 2700 & 900 & 0.000 & 1800 & 3165 \\
\hline 35.00 & 0.001 & 2700 & 900 & 0.000 & 1800 & 3165 \\
\hline 35.25 & 0.000 & 2700 & 900 & 0.000 & 1800 & 3165 \\
\hline 35.50 & 0.000 & 2700 & 900 & 0.000 & 1800 & 3165 \\
\hline 35.75 & 0.000 & 2700 & 900 & 0.000 & 1800 & 3165 \\
\hline 36.00 & 0.000 & 2700 & 900 & 0.000 & 1800 & 3165 \\
\hline 36.00 & 0.006 & 2700 & 800 & 0.000 & 1900 & 3165 \\
\hline 36.25 & 0.002 & 2700 & 800 & 0.000 & 1900 & 3165 \\
\hline 36.50 & 0.005 & 2700 & 800 & 0.001 & 1900 & 3165 \\
\hline 36.75 & 0.001 & 2700 & 800 & 0.000 & 1900 & 3165 \\
\hline 37.00 & 0.000 & 2700 & 800 & 0.000 & 1900 & 3165 \\
\hline 37.25 & 0.000 & 2700 & 800 & 0.000 & 1900 & 3165 \\
\hline 37.50 & 0.000 & 2700 & 800 & -0.001 & 1900 & 3165 \\
\hline 37.75 & 0.000 & 2700 & 800 & 0.000 & 1900 & 3165 \\
\hline 38.00 & 0.000 & 2700 & 800 & 0.000 & 1900 & 3165 \\
\hline 38.00 & 0.004 & 2700 & 700 & 0.000 & 2000 & 3165 \\
\hline 38.25 & 0.001 & 2700 & 700 & 0.000 & 2000 & 3165 \\
\hline 38.50 & 0.000 & 2700 & 700 & 0.000 & 2000 & 3165 \\
\hline 38.75 & -0.002 & 2700 & 700 & 0.000 & 2000 & 3165 \\
\hline
\end{tabular}




\begin{tabular}{|c|c|c|c|c|c|c|}
\hline $\begin{array}{l}\text { Time } \\
\text { (hours) }\end{array}$ & $\begin{array}{l}\text { Q inlet } \\
\text { (cc/min) }\end{array}$ & $\begin{array}{l}P \text { inlet } \\
\text { (psi) }\end{array}$ & $\begin{array}{l}\text { P outlet } \\
\text { (psi) }\end{array}$ & $\begin{array}{l}\text { Q outlet } \\
\text { (cc/min) }\end{array}$ & $\begin{array}{l}\text { Delta P } \\
\text { (psi) }\end{array}$ & $\begin{array}{l}\text { P confining } \\
\text { (psi) }\end{array}$ \\
\hline 39.00 & 0.000 & 2700 & 700 & 0.000 & 2000 & 3165 \\
\hline 39.25 & 0.000 & 2700 & 700 & 0.000 & 2000 & 3165 \\
\hline 39.50 & 0.000 & 2700 & 700 & 0.000 & 2000 & 3165 \\
\hline 39.75 & 0.000 & 2700 & 700 & 0.000 & 2000 & 3165 \\
\hline 40.00 & 0.000 & 2700 & 700 & 0.000 & 2000 & 3165 \\
\hline 40.00 & 0.003 & 2700 & 600 & 0.000 & 2100 & 3165 \\
\hline 40.25 & 0.000 & 2700 & 600 & 0.000 & 2100 & 3165 \\
\hline 40.50 & 0.000 & 2700 & 600 & 0.000 & 2100 & 3165 \\
\hline 40.75 & 0.000 & 2700 & 600 & 0.000 & 2100 & 3165 \\
\hline 41.00 & -0.001 & 2700 & 600 & 0.002 & 2100 & 3165 \\
\hline 41.25 & 0.000 & 2700 & 600 & 0.000 & 2100 & 3165 \\
\hline 41.50 & 0.000 & 2700 & 600 & 0.001 & 2100 & 3165 \\
\hline 41.75 & 0.000 & 2700 & 600 & 0.000 & 2100 & 3165 \\
\hline 42.00 & 0.000 & 2700 & 600 & 0.000 & 2100 & 3165 \\
\hline 42.00 & 0.002 & 2700 & 500 & -0.001 & 2200 & 3165 \\
\hline 42.25 & 0.003 & 2700 & 500 & 0.000 & 2200 & 3165 \\
\hline 42.50 & 0.001 & 2700 & 500 & 0.000 & 2200 & 3165 \\
\hline 42.75 & 0.000 & 2700 & 500 & 0.000 & 2200 & 3165 \\
\hline 43.00 & -0.003 & 2700 & 500 & 0.000 & 2200 & 3165 \\
\hline 43.25 & 0.000 & 2700 & 500 & 0.000 & 2200 & 3165 \\
\hline 43.50 & 0.000 & 2700 & 500 & 0.000 & 2200 & 3165 \\
\hline 43.75 & 0.000 & 2700 & 500 & 0.000 & 2200 & 3165 \\
\hline \multicolumn{7}{|c|}{ **Stop Constant Pressure Pump Mode } \\
\hline 44.00 & 0.000 & 2700 & 500 & 0.000 & 2200 & 3165 \\
\hline 56.00 & 0.000 & 2700 & 500 & 0.000 & 2200 & 3165 \\
\hline 68.00 & 0.000 & 2534 & 625 & 0.000 & 1909 & 3165 \\
\hline 80.00 & 0.000 & 2172 & 1027 & 0.000 & 1145 & 3165 \\
\hline 92.00 & 0.000 & 2030 & 1095 & 0.000 & 935 & 3165 \\
\hline 104.00 & 0.000 & 1872 & 1099 & 0.000 & 773 & 3165 \\
\hline 116.00 & 0.000 & 1698 & 1102 & 0.000 & 596 & 3165 \\
\hline 128.00 & 0.000 & 1555 & 1104 & 0.000 & 451 & 3165 \\
\hline
\end{tabular}


Table B.4.3.2. Gas breakthrough pressure measurement results for upper Kirtland, non-saturated sample

\begin{tabular}{lr}
\hline Project: & 502488 \\
Depth (ft): & 2049.75 \\
Length (in): & 0.454 \\
Diameter (in): & 1.005 \\
Temp (degC) & 30
\end{tabular}

Non-Saturated Sample

\begin{tabular}{crrrrrr}
$\begin{array}{c}\text { Time } \\
\text { (hours) }\end{array}$ & $\begin{array}{c}\text { Q inlet } \\
\text { (cc/min) }\end{array}$ & $\begin{array}{c}\text { P inlet } \\
\text { (psi) }\end{array}$ & $\begin{array}{c}\text { P outlet } \\
\text { (psi) }\end{array}$ & $\begin{array}{r}\text { Q outlet } \\
\text { (cc/min) }\end{array}$ & $\begin{array}{c}\text { Delta P } \\
\text { (psi) }\end{array}$ & $\begin{array}{r}\text { P confining } \\
\text { (psi) }\end{array}$ \\
\hline (initial) & 0 & 1000 & 1000 & 0 & 0 & 2265 \\
0.00 & 0.260 & 1100 & 1000 & 0.200 & 100 & 2265 \\
0.25 & 0.250 & 1100 & 1000 & 0.210 & 100 & 2265 \\
0.50 & 0.240 & 1100 & 1000 & 0.220 & 100 & 2265 \\
0.75 & 0.250 & 1100 & 1000 & 0.210 & 100 & 2265 \\
1.00 & 0.260 & 1100 & 1000 & 0.220 & 100 & 2265 \\
1.25 & 0.270 & 1100 & 1000 & 0.210 & 100 & 2265 \\
1.50 & 0.250 & 1100 & 1000 & 0.200 & 100 & 2265 \\
1.75 & 0.260 & 1100 & 1000 & 0.200 & 100 & 2265 \\
2.00 & 0.270 & 1100 & 1000 & 0.200 & 100 & 2265 \\
2.00 & 0.370 & 1200 & 1000 & 0.230 & 200 & 2265 \\
2.25 & 0.380 & 1200 & 1000 & 0.230 & 200 & 2265 \\
2.50 & 0.370 & 1200 & 1000 & 0.240 & 200 & 2265 \\
2.75 & 0.360 & 1200 & 1000 & 0.240 & 200 & 2265 \\
3.00 & 0.370 & 1200 & 1000 & 0.230 & 200 & 2265 \\
3.25 & 0.380 & 1200 & 1000 & 0.230 & 200 & 2265 \\
3.50 & 0.390 & 1200 & 1000 & 0.230 & 200 & 2265 \\
3.75 & 0.380 & 1200 & 1000 & 0.240 & 200 & 2265 \\
4.00 & 0.370 & 1200 & 1000 & 0.230 & 200 & 2265 \\
4.00 & 0.400 & 1300 & 1000 & 0.380 & 300 & 2265 \\
4.25 & 0.400 & 1300 & 1000 & 0.370 & 300 & 2265 \\
4.50 & 0.410 & 1300 & 1000 & 0.380 & 300 & 2265 \\
4.75 & 0.420 & 1300 & 1000 & 0.370 & 300 & 2265 \\
5.00 & 0.410 & 1300 & 1000 & 0.370 & 300 & 2265 \\
5.25 & 0.400 & 1300 & 1000 & 0.360 & 300 & 2265 \\
5.50 & 0.400 & 1300 & 1000 & 0.360 & 300 & 2265 \\
5.75 & 0.400 & 1300 & 1000 & 0.370 & 300 & 2265 \\
6.00 & 0.400 & 1300 & 1000 & 0.370 & 300 & 2265 \\
6.00 & 0.500 & 1400 & 1000 & 0.470 & 400 & 2265 \\
6.25 & 0.500 & 1400 & 1000 & 0.470 & 400 & 2265 \\
6.50 & 0.510 & 1400 & 1000 & 0.480 & 400 & 2265 \\
6.75 & 0.520 & 1400 & 1000 & 0.470 & 400 & 2265 \\
7.00 & 0.540 & 1400 & 1000 & 0.470 & 400 & 2265 \\
7.25 & 0.520 & 1400 & 1000 & 0.480 & 400 & 2265 \\
7.50 & 0.510 & 1400 & 1000 & 0.470 & 400 & 2265 \\
7.75 & 0.500 & 1400 & 1000 & 0.470 & 400 & 2265 \\
8.00 & 0.510 & 1400 & 1000 & 0.470 & 400 & 2265 \\
& & & & & & \\
& & & & & 111 &
\end{tabular}




\begin{tabular}{crrrrrr}
$\begin{array}{c}\text { Time } \\
\text { (hours) }\end{array}$ & $\begin{array}{c}\text { Q inlet } \\
(\mathrm{cc} / \mathrm{min})\end{array}$ & $\begin{array}{c}\mathrm{P} \text { inlet } \\
\text { (psi) }\end{array}$ & $\begin{array}{c}\text { P outlet } \\
\text { (psi) }\end{array}$ & $\begin{array}{c}\text { Q outlet } \\
\text { (cc/min) }\end{array}$ & $\begin{array}{c}\text { Delta } P \\
\text { (psi) }\end{array}$ & $\begin{array}{c}\text { P confining } \\
\text { (psi) }\end{array}$ \\
\hline 8.00 & 0.580 & 1500 & 1000 & 0.580 & 500 & 2265 \\
8.25 & 0.580 & 1500 & 1000 & 0.590 & 500 & 2265 \\
8.50 & 0.570 & 1500 & 1000 & 0.590 & 500 & 2265 \\
8.75 & 0.560 & 1500 & 1000 & 0.580 & 500 & 2265 \\
9.00 & 0.550 & 1500 & 1000 & 0.590 & 500 & 2265 \\
9.25 & 0.560 & 1500 & 1000 & 0.600 & 500 & 2265 \\
9.50 & 0.570 & 1500 & 1000 & 0.590 & 500 & 2265 \\
9.75 & 0.580 & 1500 & 1000 & 0.590 & 500 & 2265 \\
10.00 & 0.580 & 1500 & 1000 & 0.600 & 500 & 2265 \\
10.00 & 0.700 & 1600 & 1000 & 0.720 & 600 & 2265 \\
10.25 & 0.710 & 1600 & 1000 & 0.720 & 600 & 2265 \\
10.50 & 0.720 & 1600 & 1000 & 0.730 & 600 & 2265 \\
10.75 & 0.720 & 1600 & 1000 & 0.730 & 600 & 2265 \\
11.00 & 0.710 & 1600 & 1000 & 0.740 & 600 & 2265 \\
11.25 & 0.710 & 1600 & 1000 & 0.730 & 600 & 2265 \\
11.50 & 0.700 & 1600 & 1000 & 0.740 & 600 & 2265 \\
11.75 & 0.710 & 1600 & 1000 & 0.740 & 600 & 2265 \\
12.00 & 0.720 & 1600 & 1000 & 0.750 & 600 & 2265 \\
12.00 & 0.810 & 1700 & 1000 & 0.800 & 700 & 2265 \\
12.25 & 0.820 & 1700 & 1000 & 0.810 & 700 & 2265 \\
12.50 & 0.830 & 1700 & 1000 & 0.830 & 700 & 2265 \\
12.75 & 0.840 & 1700 & 1000 & 0.840 & 700 & 2265 \\
13.00 & 0.850 & 1700 & 1000 & 0.850 & 700 & 2265 \\
13.25 & 0.860 & 1700 & 1000 & 0.860 & 700 & 2265 \\
13.50 & 0.870 & 1700 & 1000 & 0.870 & 700 & 2265 \\
13.75 & 0.880 & 1700 & 1000 & 0.880 & 700 & 2265 \\
14.00 & 0.890 & 1700 & 1000 & 0.890 & 700 & 2265 \\
\hline & & & & & &
\end{tabular}


Table B.4.3.3. Gas breakthrough pressure measurement results for lower Kirtland, brine saturated sample

\begin{tabular}{lr}
\hline Project: & 502488 \\
Depth (ft): & 2692.98 \\
Length (in): & 0.699 \\
Diameter (in): & 0.999 \\
Temp (degC) & 30
\end{tabular}

Brine Saturated Sample

\begin{tabular}{rrrrrrr}
$\begin{array}{c}\text { Time } \\
\text { (hours) }\end{array}$ & $\begin{array}{r}\text { Q inlet } \\
\text { (cc/min) }\end{array}$ & $\begin{array}{c}\text { P inlet } \\
\text { (psi) }\end{array}$ & $\begin{array}{c}\text { P outlet } \\
\text { (psi) }\end{array}$ & $\begin{array}{r}\text { Q outlet } \\
\text { (cc/min) }\end{array}$ & $\begin{array}{c}\text { Delta } P \\
\text { (psi) }\end{array}$ & $\begin{array}{c}\text { P confining } \\
\text { (psi) }\end{array}$ \\
\hline (initial) & 0 & 1100 & 1100 & 0 & 0 & 2976 \\
0.00 & 0.017 & 1200 & 1100 & 0.000 & 100 & 2976 \\
0.25 & 0.002 & 1200 & 1100 & 0.000 & 100 & 2976 \\
0.50 & 0.001 & 1200 & 1100 & 0.000 & 100 & 2976 \\
0.75 & 0.001 & 1200 & 1100 & -0.002 & 100 & 2976 \\
1.00 & 0.000 & 1200 & 1100 & 0.001 & 100 & 2976 \\
1.25 & 0.001 & 1200 & 1100 & 0.001 & 100 & 2976 \\
1.50 & 0.006 & 1200 & 1100 & -0.001 & 100 & 2976 \\
1.75 & 0.000 & 1200 & 1100 & 0.000 & 100 & 2976 \\
2.00 & -0.033 & 1200 & 1100 & -0.001 & 100 & 2976 \\
2.00 & -0.013 & 1300 & 1100 & -0.003 & 200 & 2976 \\
2.25 & 0.005 & 1300 & 1100 & 0.000 & 200 & 2976 \\
2.50 & 0.010 & 1300 & 1100 & 0.000 & 200 & 2976 \\
2.75 & 0.002 & 1300 & 1100 & -0.001 & 200 & 2976 \\
3.00 & -0.001 & 1300 & 1100 & -0.001 & 200 & 2976 \\
3.25 & 0.002 & 1300 & 1100 & 0.000 & 200 & 2976 \\
3.50 & 0.000 & 1300 & 1100 & 0.000 & 200 & 2976 \\
3.75 & 0.000 & 1300 & 1100 & 0.000 & 200 & 2976 \\
4.00 & 0.001 & 1300 & 1100 & 0.002 & 200 & 2976 \\
4.00 & 0.001 & 1400 & 1100 & 0.002 & 300 & 2976 \\
4.25 & 0.002 & 1400 & 1100 & 0.000 & 300 & 2976 \\
4.50 & 0.001 & 1400 & 1100 & 0.000 & 300 & 2976 \\
4.75 & 0.001 & 1400 & 1100 & 0.000 & 300 & 2976 \\
5.00 & 0.000 & 1400 & 1100 & 0.000 & 300 & 2976 \\
5.25 & 0.000 & 1400 & 1100 & 0.000 & 300 & 2976 \\
5.50 & 0.001 & 1400 & 1100 & -0.002 & 300 & 2976 \\
5.75 & 0.000 & 1400 & 1100 & 0.000 & 300 & 2976 \\
6.00 & 0.003 & 1400 & 1100 & -0.003 & 300 & 2976 \\
6.00 & 0.015 & 1500 & 1100 & -0.002 & 400 & 2976 \\
6.25 & -0.001 & 1500 & 1100 & 0.000 & 400 & 2976 \\
6.50 & 0.001 & 1500 & 1100 & 0.000 & 400 & 2976 \\
6.75 & -0.003 & 1500 & 1100 & 0.000 & 400 & 2976 \\
7.00 & 0.003 & 1500 & 1100 & 0.003 & 400 & 2976 \\
7.25 & 0.000 & 1500 & 1100 & 0.000 & 400 & 2976 \\
7.50 & 0.000 & 1500 & 1100 & 0.000 & 400 & 2976 \\
7.75 & 0.000 & 1500 & 1100 & 0.000 & 400 & 2976 \\
8.00 & -0.005 & 1500 & 1100 & -0.002 & 400 & 2976 \\
& & & & & & \\
& & & & & 113 & \\
\hline
\end{tabular}




\begin{tabular}{|c|c|c|c|c|c|c|}
\hline $\begin{array}{l}\text { Time } \\
\text { (hours) }\end{array}$ & $\begin{array}{c}Q \text { inlet } \\
\text { (cc/min) }\end{array}$ & $\begin{array}{l}P \text { inlet } \\
\text { (psi) }\end{array}$ & $\begin{array}{c}\text { P outlet } \\
\text { (psi) }\end{array}$ & $\begin{array}{l}\text { Q outlet } \\
\text { (cc/min) }\end{array}$ & $\begin{array}{c}\text { Delta } P \\
\text { (psi) }\end{array}$ & $\begin{array}{l}\text { P confining } \\
(p s i)\end{array}$ \\
\hline 8.00 & 0.093 & 1600 & 1100 & -0.001 & 500 & 2976 \\
\hline 8.25 & -0.003 & 1600 & 1100 & 0.000 & 500 & 2976 \\
\hline 8.50 & 0.001 & 1600 & 1100 & 0.000 & 500 & 2976 \\
\hline 8.75 & 0.000 & 1600 & 1100 & 0.000 & 500 & 2976 \\
\hline 9.00 & -0.001 & 1600 & 1100 & 0.001 & 500 & 2976 \\
\hline 9.25 & 0.000 & 1600 & 1100 & 0.000 & 500 & 2976 \\
\hline 9.50 & 0.001 & 1600 & 1100 & 0.000 & 500 & 2976 \\
\hline 9.75 & 0.000 & 1600 & 1100 & 0.000 & 500 & 2976 \\
\hline 10.00 & 0.003 & 1600 & 1100 & 0.001 & 500 & 2976 \\
\hline 10.00 & 0.050 & 1700 & 1100 & 0.000 & 600 & 2976 \\
\hline 10.25 & 0.002 & 1700 & 1100 & 0.000 & 600 & 2976 \\
\hline 10.50 & 0.001 & 1700 & 1100 & 0.000 & 600 & 2976 \\
\hline 10.75 & 0.000 & 1700 & 1100 & 0.000 & 600 & 2976 \\
\hline 11.00 & 0.000 & 1700 & 1100 & -0.003 & 600 & 2976 \\
\hline 11.25 & 0.000 & 1700 & 1100 & 0.000 & 600 & 2976 \\
\hline 11.50 & 0.000 & 1700 & 1100 & 0.000 & 600 & 2976 \\
\hline 11.75 & -0.001 & 1700 & 1100 & 0.000 & 600 & 2976 \\
\hline 12.00 & 0.014 & 1700 & 1100 & 0.001 & 600 & 2976 \\
\hline 12.00 & 0.024 & 1800 & 1100 & 0.000 & 700 & 2976 \\
\hline 12.25 & 0.002 & 1800 & 1100 & 0.000 & 700 & 2976 \\
\hline 12.50 & 0.000 & 1800 & 1100 & 0.000 & 700 & 2976 \\
\hline 12.75 & 0.000 & 1800 & 1100 & 0.000 & 700 & 2976 \\
\hline 13.00 & -0.001 & 1800 & 1100 & 0.000 & 700 & 2976 \\
\hline 13.25 & 0.000 & 1800 & 1100 & 0.000 & 700 & 2976 \\
\hline 13.50 & 0.000 & 1800 & 1100 & -0.001 & 700 & 2976 \\
\hline 13.75 & 0.000 & 1800 & 1100 & 0.000 & 700 & 2976 \\
\hline 14.00 & 0.000 & 1800 & 1100 & 0.000 & 700 & 2976 \\
\hline 14.00 & 0.052 & 1900 & 1100 & 0.001 & 800 & 2976 \\
\hline 14.25 & 0.002 & 1900 & 1100 & 0.000 & 800 & 2976 \\
\hline 14.50 & 0.003 & 1900 & 1100 & 0.002 & 800 & 2976 \\
\hline 14.75 & 0.001 & 1900 & 1100 & 0.000 & 800 & 2976 \\
\hline 15.00 & -0.021 & 1900 & 1100 & 0.000 & 800 & 2976 \\
\hline 15.25 & -0.001 & 1900 & 1100 & 0.000 & 800 & 2976 \\
\hline 15.50 & -0.001 & 1900 & 1100 & 0.000 & 800 & 2976 \\
\hline 15.75 & 0.000 & 1900 & 1100 & 0.000 & 800 & 2976 \\
\hline 16.00 & -0.008 & 1900 & 1100 & 0.002 & 800 & 2976 \\
\hline 16.00 & 0.017 & 2000 & 1100 & 0.000 & 900 & 2976 \\
\hline 16.25 & 0.005 & 2000 & 1100 & 0.000 & 900 & 2976 \\
\hline 16.50 & 0.002 & 2000 & 1100 & 0.001 & 900 & 2976 \\
\hline 16.75 & 0.001 & 2000 & 1100 & 0.000 & 900 & 2976 \\
\hline 17.00 & 0.000 & 2000 & 1100 & 0.001 & 900 & 2976 \\
\hline 17.25 & 0.002 & 2000 & 1100 & 0.000 & 900 & 2976 \\
\hline 17.50 & 0.000 & 2000 & 1100 & 0.000 & 900 & 2976 \\
\hline 17.75 & 0.000 & 2000 & 1100 & 0.000 & 900 & 2976 \\
\hline 18.00 & -0.015 & 2000 & 1100 & 0.002 & 900 & 2976 \\
\hline 18.00 & 0.057 & 2100 & 1100 & -0.001 & 1000 & 2976 \\
\hline 18.25 & 0.005 & 2100 & 1100 & 0.000 & 1000 & 2976 \\
\hline
\end{tabular}




\begin{tabular}{|c|c|c|c|c|c|c|}
\hline $\begin{array}{l}\text { Time } \\
\text { (hours) }\end{array}$ & $\begin{array}{c}Q \text { inlet } \\
\text { (cc/min) }\end{array}$ & $\begin{array}{l}P \text { inlet } \\
\text { (psi) }\end{array}$ & $\begin{array}{c}\text { P outlet } \\
\text { (psi) }\end{array}$ & $\begin{array}{l}\text { Q outlet } \\
\text { (cc/min) }\end{array}$ & $\begin{array}{c}\text { Delta P } \\
\text { (psi) }\end{array}$ & $\begin{array}{l}\text { P confining } \\
(p s i)\end{array}$ \\
\hline 18.50 & 0.006 & 2100 & 1100 & 0.000 & 1000 & 2976 \\
\hline 18.75 & 0.001 & 2100 & 1100 & 0.000 & 1000 & 2976 \\
\hline 19.00 & 0.000 & 2100 & 1100 & 0.002 & 1000 & 2976 \\
\hline 19.25 & 0.000 & 2100 & 1100 & 0.000 & 1000 & 2976 \\
\hline 19.50 & 0.000 & 2100 & 1100 & -0.001 & 1000 & 2976 \\
\hline 19.75 & 0.000 & 2100 & 1100 & 0.000 & 1000 & 2976 \\
\hline 20.00 & -0.001 & 2100 & 1100 & -0.001 & 1000 & 2976 \\
\hline 20.00 & 0.048 & 2200 & 1100 & -0.001 & 1100 & 2976 \\
\hline 20.25 & 0.001 & 2200 & 1100 & 0.000 & 1100 & 2976 \\
\hline 20.50 & 0.001 & 2200 & 1100 & 0.000 & 1100 & 2976 \\
\hline 20.75 & -0.001 & 2200 & 1100 & 0.000 & 1100 & 2976 \\
\hline 21.00 & 0.000 & 2200 & 1100 & 0.004 & 1100 & 2976 \\
\hline 21.25 & 0.000 & 2200 & 1100 & 0.000 & 1100 & 2976 \\
\hline 21.50 & 0.000 & 2200 & 1100 & 0.000 & 1100 & 2976 \\
\hline 21.75 & 0.000 & 2200 & 1100 & -0.002 & 1100 & 2976 \\
\hline 22.00 & -0.001 & 2200 & 1100 & 0.004 & 1100 & 2976 \\
\hline 22.00 & 0.038 & 2300 & 1100 & 0.000 & 1200 & 2976 \\
\hline 22.25 & 0.002 & 2300 & 1100 & 0.000 & 1200 & 2976 \\
\hline 22.50 & 0.003 & 2300 & 1100 & 0.000 & 1200 & 2976 \\
\hline 22.75 & 0.000 & 2300 & 1100 & 0.006 & 1200 & 2976 \\
\hline 23.00 & 0.001 & 2300 & 1100 & 0.000 & 1200 & 2976 \\
\hline 23.25 & 0.000 & 2300 & 1100 & 0.000 & 1200 & 2976 \\
\hline 23.50 & 0.000 & 2300 & 1100 & -0.001 & 1200 & 2976 \\
\hline 23.75 & 0.000 & 2300 & 1100 & 0.000 & 1200 & 2976 \\
\hline 24.00 & -0.001 & 2300 & 1100 & 0.002 & 1200 & 2976 \\
\hline 24.00 & 0.030 & 2400 & 1100 & 0.000 & 1300 & 2976 \\
\hline 24.25 & 0.001 & 2400 & 1100 & 0.000 & 1300 & 2976 \\
\hline 24.50 & 0.002 & 2400 & 1100 & 0.001 & 1300 & 2976 \\
\hline 24.75 & 0.000 & 2400 & 1100 & 0.000 & 1300 & 2976 \\
\hline 25.00 & 0.000 & 2400 & 1100 & 0.000 & 1300 & 2976 \\
\hline 25.25 & 0.021 & 2400 & 1100 & 0.000 & 1300 & 2976 \\
\hline 25.50 & 0.000 & 2400 & 1100 & 0.000 & 1300 & 2976 \\
\hline 25.75 & 0.000 & 2400 & 1100 & 0.010 & 1300 & 2976 \\
\hline 26.00 & -0.001 & 2400 & 1100 & 0.000 & 1300 & 2976 \\
\hline 26.00 & 0.002 & 2500 & 1100 & 0.000 & 1400 & 2976 \\
\hline 26.25 & 0.001 & 2500 & 1100 & 0.000 & 1400 & 2976 \\
\hline 26.50 & -0.003 & 2500 & 1100 & 0.002 & 1400 & 2976 \\
\hline 26.75 & 0.000 & 2500 & 1100 & -0.001 & 1400 & 2976 \\
\hline 27.00 & 0.000 & 2500 & 1100 & 0.000 & 1400 & 2976 \\
\hline 27.25 & 0.000 & 2500 & 1100 & 0.000 & 1400 & 2976 \\
\hline 27.50 & 0.000 & 2500 & 1100 & 0.000 & 1400 & 2976 \\
\hline 27.75 & -0.002 & 2500 & 1100 & 0.002 & 1400 & 2976 \\
\hline 28.00 & 0.000 & 2500 & 1100 & 0.001 & 1400 & 2976 \\
\hline 28.00 & -0.015 & 2600 & 1100 & -0.001 & 1500 & 2976 \\
\hline 28.25 & 0.000 & 2600 & 1100 & 0.000 & 1500 & 2976 \\
\hline 28.50 & 0.017 & 2600 & 1100 & 0.000 & 1500 & 2976 \\
\hline 28.75 & 0.000 & 2600 & 1100 & 0.003 & 1500 & 2976 \\
\hline
\end{tabular}




\begin{tabular}{|c|c|c|c|c|c|c|}
\hline $\begin{array}{l}\text { Time } \\
\text { (hours) }\end{array}$ & $\begin{array}{l}Q \text { inlet } \\
\text { (cc/min) }\end{array}$ & $\begin{array}{l}P \text { inlet } \\
\text { (psi) }\end{array}$ & $\begin{array}{c}\text { P outlet } \\
\text { (psi) }\end{array}$ & $\begin{array}{l}\text { Q outlet } \\
\text { (cc/min) }\end{array}$ & $\begin{array}{c}\text { Delta P } \\
\text { (psi) }\end{array}$ & $\begin{array}{l}\text { P confining } \\
(p s i)\end{array}$ \\
\hline 29.00 & 0.000 & 2600 & 1100 & 0.001 & 1500 & 2976 \\
\hline 29.25 & 0.000 & 2600 & 1100 & 0.000 & 1500 & 2976 \\
\hline 29.50 & 0.000 & 2600 & 1100 & -0.001 & 1500 & 2976 \\
\hline 29.75 & 0.002 & 2600 & 1100 & 0.000 & 1500 & 2976 \\
\hline 30.00 & 0.000 & 2600 & 1100 & -0.002 & 1500 & 2976 \\
\hline 30.00 & 0.003 & 2700 & 1100 & 0.000 & 1600 & 2976 \\
\hline 30.25 & 0.001 & 2700 & 1100 & 0.000 & 1600 & 2976 \\
\hline 30.50 & -0.005 & 2700 & 1100 & -0.002 & 1600 & 2976 \\
\hline 30.75 & 0.002 & 2700 & 1100 & 0.000 & 1600 & 2976 \\
\hline 31.00 & 0.000 & 2700 & 1100 & 0.000 & 1600 & 2976 \\
\hline 31.25 & 0.000 & 2700 & 1100 & -0.002 & 1600 & 2976 \\
\hline 31.50 & 0.000 & 2700 & 1100 & 0.000 & 1600 & 2976 \\
\hline 31.75 & 0.000 & 2700 & 1100 & 0.000 & 1600 & 2976 \\
\hline 32.00 & 0.000 & 2700 & 1100 & 0.002 & 1600 & 2976 \\
\hline 32.00 & 0.013 & 2700 & 1000 & 0.000 & 1700 & 2976 \\
\hline 32.25 & 0.001 & 2700 & 1000 & 0.000 & 1700 & 2976 \\
\hline 32.50 & 0.006 & 2700 & 1000 & 0.000 & 1700 & 2976 \\
\hline 32.75 & 0.000 & 2700 & 1000 & 0.003 & 1700 & 2976 \\
\hline 33.00 & 0.000 & 2700 & 1000 & 0.000 & 1700 & 2976 \\
\hline 33.25 & -0.023 & 2700 & 1000 & 0.000 & 1700 & 2976 \\
\hline 33.50 & 0.000 & 2700 & 1000 & 0.000 & 1700 & 2976 \\
\hline 33.75 & 0.000 & 2700 & 1000 & 0.000 & 1700 & 2976 \\
\hline 34.00 & 0.000 & 2700 & 1000 & 0.001 & 1700 & 2976 \\
\hline 34.00 & 0.007 & 2700 & 900 & 0.000 & 1800 & 2976 \\
\hline 34.25 & -0.006 & 2700 & 900 & -0.005 & 1800 & 2976 \\
\hline 34.50 & 0.000 & 2700 & 900 & 0.000 & 1800 & 2976 \\
\hline 34.75 & 0.000 & 2700 & 900 & 0.000 & 1800 & 2976 \\
\hline 35.00 & 0.001 & 2700 & 900 & 0.000 & 1800 & 2976 \\
\hline 35.25 & 0.000 & 2700 & 900 & 0.001 & 1800 & 2976 \\
\hline 35.50 & 0.014 & 2700 & 900 & 0.000 & 1800 & 2976 \\
\hline 35.75 & 0.000 & 2700 & 900 & 0.000 & 1800 & 2976 \\
\hline 36.00 & 0.000 & 2700 & 900 & 0.000 & 1800 & 2976 \\
\hline 36.00 & 0.008 & 2700 & 800 & 0.000 & 1900 & 2976 \\
\hline 36.25 & 0.002 & 2700 & 800 & 0.000 & 1900 & 2976 \\
\hline 36.50 & 0.005 & 2700 & 800 & 0.001 & 1900 & 2976 \\
\hline 36.75 & 0.001 & 2700 & 800 & 0.000 & 1900 & 2976 \\
\hline 37.00 & 0.000 & 2700 & 800 & 0.003 & 1900 & 2976 \\
\hline 37.25 & 0.000 & 2700 & 800 & 0.000 & 1900 & 2976 \\
\hline 37.50 & 0.000 & 2700 & 800 & 0.001 & 1900 & 2976 \\
\hline 37.75 & 0.000 & 2700 & 800 & 0.000 & 1900 & 2976 \\
\hline 38.00 & 0.000 & 2700 & 800 & 0.000 & 1900 & 2976 \\
\hline 38.00 & 0.004 & 2700 & 700 & -0.003 & 2000 & 2976 \\
\hline 38.25 & 0.001 & 2700 & 700 & 0.000 & 2000 & 2976 \\
\hline 38.50 & 0.000 & 2700 & 700 & 0.000 & 2000 & 2976 \\
\hline 38.75 & -0.002 & 2700 & 700 & 0.000 & 2000 & 2976 \\
\hline 39.00 & 0.000 & 2700 & 700 & -0.005 & 2000 & 2976 \\
\hline 39.25 & 0.000 & 2700 & 700 & 0.000 & 2000 & 2976 \\
\hline
\end{tabular}




\begin{tabular}{rcccccr}
$\begin{array}{c}\text { Time } \\
\text { (hours) }\end{array}$ & $\begin{array}{c}\text { Q inlet } \\
(\mathrm{cc} / \mathrm{min})\end{array}$ & $\begin{array}{c}\text { P inlet } \\
(\mathrm{psi})\end{array}$ & $\begin{array}{c}\text { P outlet } \\
(\mathrm{psi})\end{array}$ & $\begin{array}{c}\text { Q outlet } \\
(\mathrm{cc} / \mathrm{min})\end{array}$ & $\begin{array}{c}\text { Delta } P \\
(\mathrm{psi})\end{array}$ & $\begin{array}{c}\text { P confining } \\
(\mathrm{psi})\end{array}$ \\
\hline 39.50 & 0.000 & 2700 & 700 & 0.000 & 2000 & 2976 \\
39.75 & -0.008 & 2700 & 700 & 0.000 & 2000 & 2976 \\
40.00 & 0.001 & 2700 & 700 & 0.000 & 2000 & 2976 \\
52.00 & 0.000 & 2700 & 690 & 0.000 & 2010 & 2976 \\
64.00 & 0.000 & 2680 & 688 & 0.000 & 1992 & 2976 \\
76.00 & 0.000 & 2672 & 694 & 0.000 & 1978 & 2976 \\
88.00 & 0.000 & 2679 & 699 & 0.000 & 1980 & 2976 \\
100.00 & 0.000 & 2689 & 705 & 0.000 & 1984 & 2976 \\
112.00 & 0.000 & 2678 & 700 & 0.000 & 1978 & 2976 \\
124.00 & 0.000 & 2684 & 702 & 0.000 & 1982 & 2976
\end{tabular}




\section{B.5 Routine Core Analysis}

TerraTek performed "routine core analysis" on three, fresh core samples from the Ojo Alamo Sandstone. The analysis was suited to non-mudstone lithologies and thus chosen for the Ojo Alamo Sandstone.

\section{Conoco/Phillips}

EPNG Com A Inj. \#1

Routine Core Analysis Test Results

Project No: 502488

June 18, 2008

\begin{tabular}{|c|c|c|c|c|c|c|c|c|c|}
\hline \multirow[b]{2}{*}{$\begin{array}{l}\text { Sample } \\
\text { Number }\end{array}$} & \multirow{2}{*}{$\begin{array}{l}\text { Sample } \\
\text { Dep th } \\
\text { (ft) }\end{array}$} & \multirow{2}{*}{$\begin{array}{l}\text { Sample } \\
\text { Length } \\
\text { (in) }\end{array}$} & \multirow{2}{*}{$\begin{array}{c}\text { Sample } \\
\text { Diameter } \\
\text { (in) }\end{array}$} & \multirow{2}{*}{$\begin{array}{c}\text { Ambient } \\
\text { Porosity } \\
(\%) \\
\end{array}$} & \multirow{2}{*}{$\begin{array}{l}\text { Dry Bulk } \\
\text { Density } \\
\text { (g/cc) } \\
\end{array}$} & \multirow{2}{*}{$\begin{array}{l}\text { Grain } \\
\text { Density } \\
\text { (g/cc) }\end{array}$} & \multirow{2}{*}{$\begin{array}{c}\text { Gas } \\
\text { Permeability } \\
\text { (md) }\end{array}$} & \multicolumn{2}{|c|}{ Saturation } \\
\hline & & & & & & & & $\begin{array}{l}\text { Water } \\
(\%)\end{array}$ & $\begin{array}{r}\text { Oil } \\
(\%) \\
\end{array}$ \\
\hline 1 & 2022.10 & 2.290 & 1.473 & 12.41 & 2.329 & 2.659 & 5.182 & 54.59 & $\mathrm{~N} / \mathrm{A}$ \\
\hline 2 & 2034.50 & 2.271 & 1.475 & 9.44 & 2.418 & 2.670 & 0.058 & 61.10 & $\mathrm{~N} / \mathrm{A}$ \\
\hline 3 & 2047.10 & 2.527 & 1.474 & 1.62 & 2.683 & 2.727 & 0.001 & 44.87 & $\mathrm{~N} / \mathrm{A}$ \\
\hline & & $\begin{array}{c}+/-0.0005 \\
\text { (in) }\end{array}$ & $\begin{array}{c}+1-0.0005 \\
\text { (in) }\end{array}$ & $\begin{array}{c}+/-0.5 \\
(\%)\end{array}$ & $\begin{array}{c}+/-0.005 \\
(\mathrm{~g} / \mathrm{cc})\end{array}$ & $\begin{array}{c}+/-0.005 \\
(\mathrm{~g} / \mathrm{cc})\end{array}$ & $\begin{array}{l}+/-0.1 \\
(\mathrm{md})\end{array}$ & $\begin{array}{c}+/-0.5 \\
\text { (\%of PV) }\end{array}$ & $\begin{array}{c}+1-0.5 \\
(\% \text { of PV) }\end{array}$ \\
\hline \multicolumn{10}{|c|}{$\%=$ Percent } \\
\hline \multicolumn{10}{|c|}{ g/cc $=$ Grams per cubic cen timeter } \\
\hline \multicolumn{10}{|c|}{ md = Millid arcy } \\
\hline
\end{tabular}




\section{B.6 Tight Rock Analysis Results}

TerraTek performed analysis of upper and lower Kirtland Formation samples using their "Tight Rock Analysis" methods, which are suited for mudstone lithologies. The methods are designed to measure matrix properties and not the effect of pressurerelease due to drilling, coring, and core handling activities.

\section{Conoco/Phillips EPNG Com A Inj. \#1 Tight Rock Analysis Project No: 502488 June 18, 2008}

\begin{tabular}{|c|c|c|c|c|c|c|c|c|c|c|c|c|}
\hline $\begin{array}{l}\text { Sample } \\
\text { ID }\end{array}$ & $\begin{array}{l}\text { Depth } \\
\text { (ft) }\end{array}$ & $\begin{array}{c}\text { As } \\
\text { Rece ived } \\
\text { Bulk } \\
\text { Density } \\
\left({ }^{9} / \mathrm{cc}\right)\end{array}$ & $\begin{array}{c}\text { As } \\
\text { Received } \\
\text { Grain } \\
\text { Density } \\
\left({ }^{9} / \text { cc }\right)\end{array}$ & $\begin{array}{c}\text { Dry Grain } \\
\text { Density } \\
(\% / c c)\end{array}$ & $\begin{array}{c}\text { Porosity } \\
\text { (\% of BV) }\end{array}$ & $\begin{array}{c}\text { Water } \\
\text { Saturation } \\
\text { (\% of PV) }\end{array}$ & $\begin{array}{c}\text { Gas } \\
\text { Saturation } \\
(\% \text { of PV) }\end{array}$ & $\begin{array}{l}\text { Mobile Oil } \\
\text { Saturation } \\
\text { (\% of PV) }\end{array}$ & $\begin{array}{l}\text { Gas Filled } \\
\text { Porosity } \\
\text { (\% of BV) }\end{array}$ & $\begin{array}{l}\text { Bound } \\
\text { Hydrocarbon } \\
\text { Saturation } \\
\text { (\% of BV) }\end{array}$ & $\begin{array}{l}\text { Bound Clay } \\
\text { Water } \\
\text { (\% of BV) }\end{array}$ & $\begin{array}{l}\text { Pressure-Decay } \\
\text { Permeability } \\
\text { (md) }\end{array}$ \\
\hline 1 & 2048.25 & 2.353 & 2.394 & 2.521 & 9.88 & 81.99 & 17.22 & 0.79 & 1.70 & 0.51 & 20.71 & 0.000073 \\
\hline 2 & 2052.06 & 2.493 & 2.523 & 2.607 & 6.33 & 79.95 & 18.74 & 1.31 & 1.19 & 0.24 & 13.70 & 0.000097 \\
\hline 3 & 2055.20 & 2.515 & 2.537 & 2.651 & 7.66 & 87.56 & 11.35 & 1.09 & 0.87 & 0.49 & 14.75 & 0.000069 \\
\hline 4 & 2062.30 & 2.474 & 2.515 & 2.645 & 9.40 & 80.95 & 17.30 & 1.75 & 1.63 & 0.18 & 13.08 & 0.000090 \\
\hline 5 & 2067.98 & 2.482 & 2.516 & 2.629 & 8.17 & 80.80 & 16.39 & 2.81 & 1.34 & 0.33 & 14.79 & 0.000093 \\
\hline 6 & 2692.25 & 2.550 & 2.590 & 2.677 & 6.65 & 75.39 & 23.34 & 1.27 & 1.55 & 0.22 & 14.76 & 0.000080 \\
\hline 7 & 2697.15 & 2.526 & 2.565 & 2.649 & 6.46 & 73.89 & 23.53 & 2.58 & 1.52 & 0.14 & 13.35 & 0.000085 \\
\hline \multicolumn{2}{|c|}{ Error } & $\begin{array}{c}+/-0.005 \\
(\mathrm{~g} / \mathrm{cc})\end{array}$ & $\begin{array}{c}+1-0.005 \\
(\mathrm{~g} / \mathrm{cc})\end{array}$ & $\begin{array}{c}+/-0.005 \\
(\mathrm{~g} / \mathrm{cc})\end{array}$ & $\begin{array}{c}+1-0.02 \\
(\% \text { of BV) }\end{array}$ & $\begin{array}{c}+1-0.5 \\
(\% \circ f \text { PV })\end{array}$ & $\begin{array}{l}+1-0.5 \\
(\% \text { of PV) }\end{array}$ & $\begin{array}{l}+l-0.5 \\
\text { (\%of PV) }\end{array}$ & $\begin{array}{l}+1-0.02 \\
\text { (\%of BV) }\end{array}$ & $\begin{array}{l}+/-0.5 \\
\text { (\%of BV) }\end{array}$ & $\begin{array}{l}+/-0.5 \\
\text { (\%of BV) }\end{array}$ & $+/-0.000010$ \\
\hline \multicolumn{13}{|c|}{$\begin{array}{l}\% \text { of PV }=\text { Percent of Pore Volume } \\
\% \text { of BV }=\text { Percent of Bulk Volume }\end{array}$} \\
\hline \multicolumn{10}{|c|}{$\%$ of BV = Percent of Bulk Volume } & & & \\
\hline \multicolumn{13}{|c|}{ md = millidarcy } \\
\hline
\end{tabular}




\section{B.7 Gamma Ray on Core}

TerraTek ran a component core gamma ray log to facilitate correlation between the core and the field well logs and to obtain information on $\mathrm{U}$, Th, and $\mathrm{K}$ content. The $\mathrm{U}$ and Th concentrations were needed for assessing in situ production of helium. Herein are presented graphs of the data, plotted by TerraTek, and the raw data as given in a ".las" file. Note that from depths 2072.45 to $2690.45 \mathrm{ft}$, "no data" entries were removed for presentation here. 

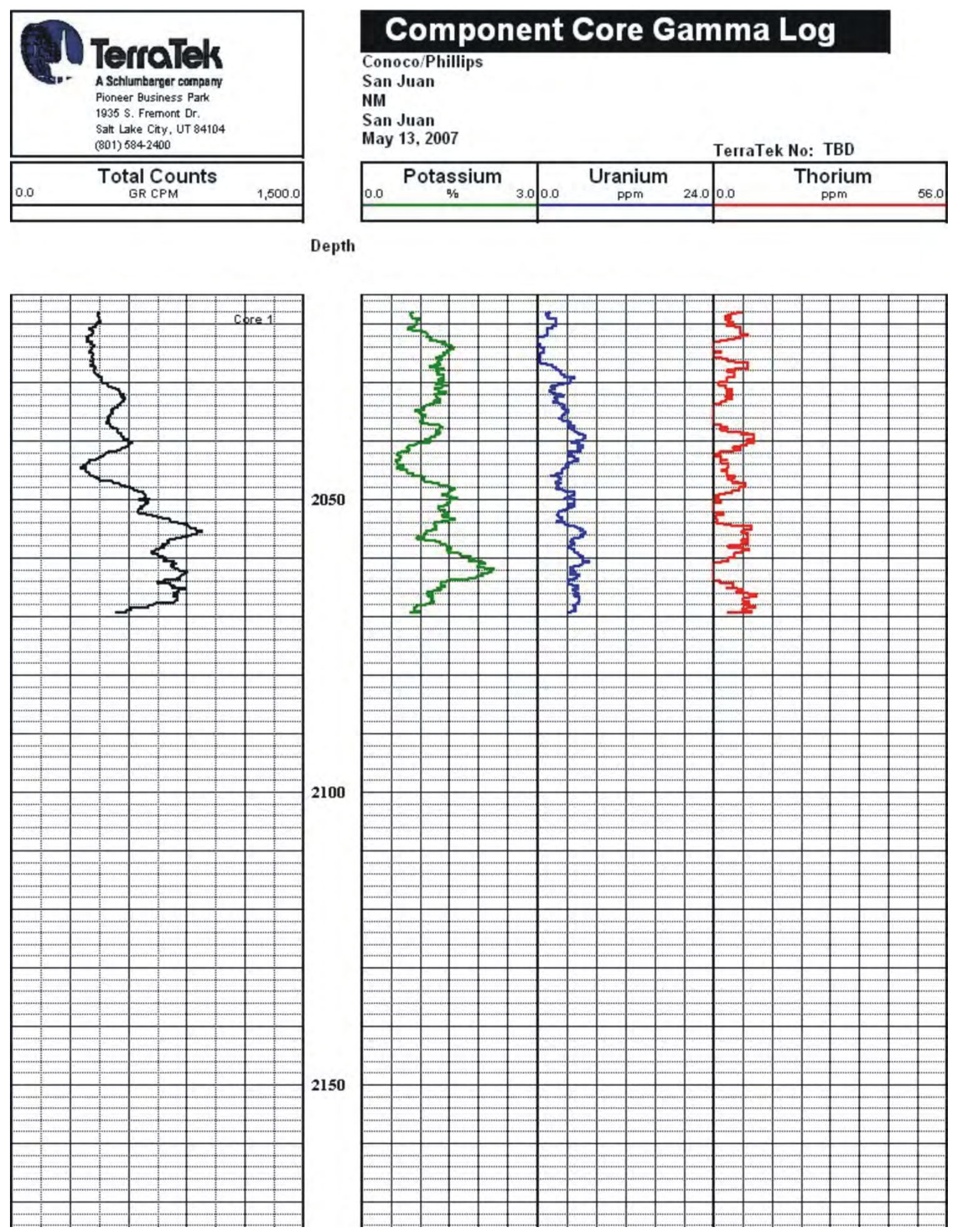


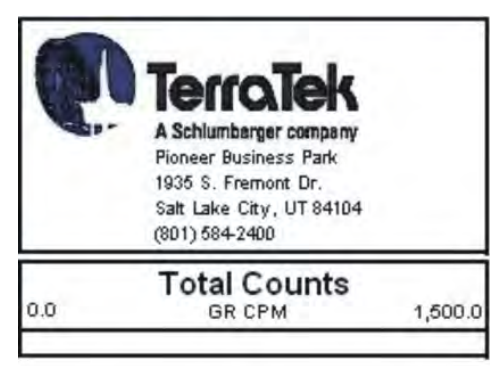

\section{Component Core Gamma Log}

Conoco/Phillips

San Juan

NM

San Juan

May 13, 2007

TerraTek No: TBD

\begin{tabular}{|c|c|c|c|c|c|c|c|}
\hline \multirow{2}{*}{\multicolumn{2}{|c|}{ Potassium }} & \multirow{2}{*}{\multicolumn{3}{|c|}{ Uranium }} & \multicolumn{3}{|c|}{ Thorium } \\
\hline & & 0.0 & & 24.0 & 0.0 & & 56.0 \\
\hline
\end{tabular}

Depth
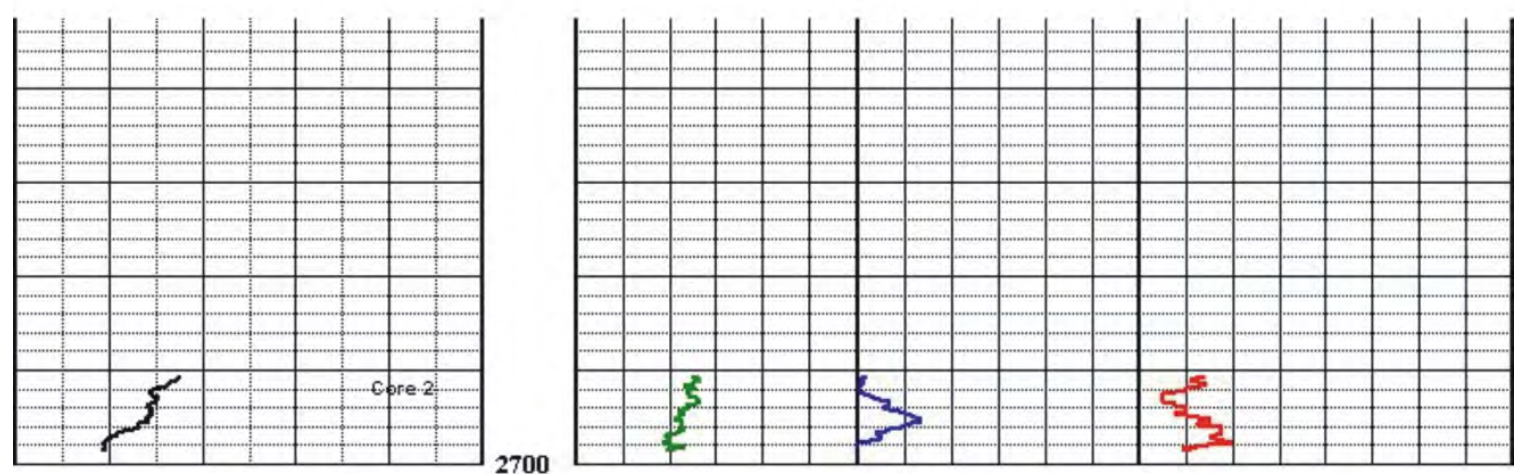

\#Do NOT edit this file. Doing so will render it un-usable $\sim$ VERSION INFORMATION

VERS. $\quad 2.0$

WRAP. NO

$\sim$ WELL INFORMATION

STRT.FT $\quad-2018$

STOP.FT $\quad-2698.5$

STEP.FT 3

COMP. EPNG

WELL. San Juan

LOC . NM

DATE. May 132008

CURVE INFORMATION

DEPT.FT MD

GAMMA. CPM

K. 응

UR. PPM

$\mathrm{TH}$. P PM

PARAMETER INFORMATION

DREF .

EREF.FT

DEX.

DEY .

CALM. TEQ1

\section{$\sim$ ASCII}

\# DEPT

$-2018$

$-2018.18$

$-2018.36$

GAMMA

453.5389

447.6420

437.4973
:LOG ASCII STANDARD - VERSION 2.0

:One line per Depth Step

:START DEPTH

:STOP DEPTH

:STEP

: COMPANY

:WELL

: LOCATION

:DATE

:DEPTH IN FEET

:TOTAL GAMMA

:POTASSIUM

: URANIUM

:THORIUM

: Depth Reference

:ELEVATION OF DEPTH REFERENCE

:DELTA EPISON $\mathrm{X}$

:DELTA EPISON Y

:CALIBRATION METHOD
$\mathrm{K}$

0.8902

0.8353

0.8394
UR

1.6696

1.3360

1.0630

122
$\mathrm{TH}$

6.6282

5. 2999

4. 2132 


\begin{tabular}{|c|c|c|c|c|}
\hline$\# \quad$ DEPT & GAMMA & K & UR & $\mathrm{TH}$ \\
\hline-2018.54 & 445.6633 & 0.8356 & 1.4515 & 3.3076 \\
\hline-2018.73 & 447.1208 & 0.8595 & 1.2116 & 2.5413 \\
\hline-2018.91 & 450.8464 & 0.8584 & 1.5549 & 4.0759 \\
\hline-2019.1 & 454.4920 & 0.9668 & 1.3402 & 3.3605 \\
\hline-2019.27 & 454.5112 & 0.9830 & 2.5502 & 2.7346 \\
\hline-2019.46 & 447.7435 & 0.9461 & 2.3022 & 3.8729 \\
\hline-2019.64 & 455.9683 & 0.9372 & 2.5021 & 3.2091 \\
\hline-2019.83 & 438.4922 & 0.9134 & 2.5021 & 4.8058 \\
\hline-2020 & 439.7567 & 0.9373 & 2.5021 & 3.1664 \\
\hline-2020.18 & 431.2189 & 0.8897 & 2.5021 & 3.0559 \\
\hline-2020.37 & 432.9244 & 0.8991 & 2.0828 & 4.9516 \\
\hline-2020.55 & 416.2133 & 0.7918 & 2.0828 & 6.5761 \\
\hline-2020.73 & 402.7250 & 0.8079 & 1.6396 & 6.5761 \\
\hline-2020.91 & 396.9161 & 0.7856 & 1.2362 & 6.5761 \\
\hline-2021.1 & 405.5178 & 0.8605 & 1.2594 & 6.5761 \\
\hline-2021.28 & 421.1161 & 1.0214 & 1.2594 & 6.5761 \\
\hline-2021.46 & 421.2767 & 1.0892 & 1.2594 & 6.5761 \\
\hline-2021.65 & 415.8050 & 1.1132 & 1.2629 & 6.5761 \\
\hline-2021.83 & 410.1717 & 1.1381 & 1.2629 & 8.1867 \\
\hline-2022.01 & 393.8528 & 1.1360 & 0.8360 & 6.4823 \\
\hline-2022.19 & 387.3661 & 1.0852 & 0.8360 & 6.4823 \\
\hline-2022.37 & 381.4312 & 1.1555 & 0.0000 & 6.4823 \\
\hline-2022.55 & 393.6156 & 1.2037 & 0.0000 & 4.8857 \\
\hline-2022.73 & 388.0584 & 1.1545 & 0.0000 & 3.2073 \\
\hline-2022.91 & 385.2784 & 1.2698 & 0.0000 & 1.5874 \\
\hline-2023.09 & 415.8423 & 1.4282 & 0.0000 & 0.0000 \\
\hline-2023.27 & 403.3401 & 1.3585 & 0.0000 & 0.0000 \\
\hline-2023.45 & 408.1184 & 1.4552 & 0.3976 & 0.0000 \\
\hline-2023.63 & 412.1517 & 1.4210 & 0.3976 & 0.0000 \\
\hline-2023.81 & 429.5728 & 1.5381 & 0.3976 & 0.0000 \\
\hline-2024 & 416.0905 & 1.5542 & 0.3976 & 0.0000 \\
\hline-2024.19 & 416.5373 & 1.5805 & 0.8367 & 0.0000 \\
\hline-2024.37 & 410.9506 & 1.5058 & 0.8146 & 0.0000 \\
\hline-2024.55 & 404.1151 & 1.4422 & 0.8146 & 0.0000 \\
\hline-2024.74 & 403.8485 & 1.4931 & 0.8146 & 1.6347 \\
\hline-2024.92 & 401.6757 & 1.4679 & 0.4004 & 1.6347 \\
\hline-2025.1 & 411.2741 & 1.3779 & 0.4004 & 0.0241 \\
\hline-2025.28 & 422.3474 & 1.4227 & 0.4004 & 0.0241 \\
\hline-2025.46 & 413.6256 & 1.3792 & 0.4004 & 0.0241 \\
\hline-2025.64 & 417.3501 & 1.3126 & 0.4004 & 0.0241 \\
\hline-2025.82 & 413.6584 & 1.2652 & 0.4004 & 1.6487 \\
\hline-2026 & 418.6418 & 1.3633 & 0.4004 & 3.3429 \\
\hline-2026.19 & 421.5573 & 1.3173 & 0.4004 & 3.3429 \\
\hline-2026.36 & 402.8195 & 1.2960 & 0.0005 & 4.9535 \\
\hline-2026.54 & 419.5234 & 1.2967 & 0.0005 & 4.9535 \\
\hline-2026.72 & 420.8719 & 1.2717 & 0.4062 & 8.2415 \\
\hline-2026.9 & 411.4785 & 1.3422 & 1.2322 & 8.2415 \\
\hline-2027.08 & 400.7419 & 1.2480 & 2.0437 & 8.2415 \\
\hline-2027.26 & 428.0113 & 1.1588 & 2.0437 & 8.2415 \\
\hline-2027.44 & 431.2485 & 1.2949 & 2.4258 & 8.1282 \\
\hline-2027.62 & 424.3318 & 1.3602 & 2.4144 & 4.9070 \\
\hline-2027.81 & 420.8934 & 1.4058 & 2.4144 & 4.9070 \\
\hline-2027.99 & 424.8951 & 1.2597 & 2.8311 & 3.2026 \\
\hline-2028.17 & 425.6768 & 1.3074 & 3.2417 & 3.2026 \\
\hline
\end{tabular}




\begin{tabular}{|c|c|c|c|c|}
\hline \# $\quad$ DEPT & GAMMA & K & UR & $\mathrm{TH}$ \\
\hline-2028.35 & 426.9017 & 1.3308 & 3.2417 & 4.8810 \\
\hline-2028.53 & 429.9540 & 1.2836 & 3.2417 & 4.8810 \\
\hline-2028.71 & 444.6174 & 1.4029 & 3.6585 & 4.8810 \\
\hline-2028.9 & 443.9297 & 1.3774 & 3.6585 & 4.8810 \\
\hline-2029.08 & 458.7842 & 1.4040 & 3.6585 & 4.9655 \\
\hline-2029.27 & 466.5531 & 1.4032 & 4.9237 & 3.2714 \\
\hline-2029.46 & 456.7220 & 1.3352 & 4.5168 & 3.2714 \\
\hline-2029.64 & 466.7559 & 1.2926 & 4.5168 & 3.3141 \\
\hline-2029.82 & 458.7414 & 1.4088 & 4.5168 & 3.3141 \\
\hline-2030 & 461.6747 & 1.3829 & 4.2885 & 1.2140 \\
\hline-2030.18 & 487.9113 & 1.2661 & 3.4625 & 1.2140 \\
\hline-2030.36 & 496.3463 & 1.3801 & 2.6510 & 1.2140 \\
\hline-2030.54 & 488.6615 & 1.4711 & 2.6510 & 2.8199 \\
\hline-2030.72 & 498.7843 & 1.3788 & 1.8299 & 2.8292 \\
\hline-2030.9 & 515.3527 & 1.3642 & 1.8634 & 2.8292 \\
\hline-2031.07 & 532.7571 & 1.2456 & 2.2692 & 2.8292 \\
\hline-2031.25 & 552.0450 & 1.3170 & 1.8525 & 4.5030 \\
\hline-2031.43 & 551.7089 & 1.2911 & 1.4418 & 4.5030 \\
\hline-2031.61 & 559.5573 & 1.4570 & 1.8611 & 2.8246 \\
\hline-2031.8 & 555.8455 & 1.4128 & 2.2804 & 4.4983 \\
\hline-2031.99 & 561.3271 & 1.2472 & 2.2694 & 4.4983 \\
\hline-2032.17 & 575.6298 & 1.2698 & 3.1054 & 4.4983 \\
\hline-2032.35 & 566.4392 & 1.2672 & 3.5184 & 2.7893 \\
\hline-2032.53 & 566.9399 & 1.2896 & 2.2531 & 2.7893 \\
\hline-2032.71 & 580.6287 & 1.2903 & 2.2531 & 4.4779 \\
\hline-2032.9 & 573.4364 & 1.3362 & 2.6650 & 2.8246 \\
\hline-2033.08 & 574.2908 & 1.2422 & 2.6650 & 2.8246 \\
\hline-2033.26 & 566.8992 & 1.2456 & 2.0696 & 1.6366 \\
\hline-2033.45 & 559.8309 & 1.3382 & 2.4791 & 1.6366 \\
\hline-2033.62 & 560.6504 & 1.2468 & 2.8813 & 1.6366 \\
\hline-2033.8 & 558.2331 & 1.1578 & 3.2955 & 0.0307 \\
\hline-2033.98 & 539.9496 & 1.0873 & 3.7024 & 0.0000 \\
\hline-2034.17 & 548.5712 & 1.0605 & 3.2769 & 0.0000 \\
\hline-2034.34 & 526.9417 & 1.0382 & 3.2829 & 0.0260 \\
\hline-2034.52 & 512.3726 & 1.0393 & 3.7059 & 0.0000 \\
\hline-2034.7 & 519.5070 & 1.0673 & 4.1238 & 0.0204 \\
\hline-2034.88 & 509.5059 & 0.8995 & 3.7045 & 0.0204 \\
\hline-2035.06 & 518.7166 & 0.9692 & 4.1112 & 0.0000 \\
\hline-2035.25 & 522.8309 & 0.9932 & 3.7055 & 0.0000 \\
\hline-2035.43 & 508.5228 & 1.0363 & 3.6810 & 0.0000 \\
\hline-2035.62 & 506.7083 & 1.0834 & 3.2680 & 0.0000 \\
\hline-2035.8 & 495.7854 & 1.0337 & 3.2680 & 0.0000 \\
\hline-2035.98 & 496.9371 & 1.0320 & 3.2680 & 0.0000 \\
\hline-2036.16 & 494.2183 & 1.0063 & 2.8562 & 0.0000 \\
\hline-2036.34 & 503.2339 & 1.0078 & 3.2780 & 0.0000 \\
\hline-2036.52 & 501.6884 & 1.0563 & 3.2780 & 0.0000 \\
\hline-2036.7 & 488.0295 & 0.9873 & 4.1224 & 0.0000 \\
\hline-2036.89 & 485.5551 & 1.0356 & 4.5486 & 0.0000 \\
\hline-2037.07 & 499.4030 & 1.1293 & 4.1345 & 0.0000 \\
\hline-2037.25 & 510.2296 & 1.3141 & 4.1357 & 1.6245 \\
\hline-2037.43 & 509.0176 & 1.3383 & 4.9642 & 1.6245 \\
\hline-2037.61 & 516.6536 & 1.3767 & 4.5524 & 1.4787 \\
\hline-2037.79 & 523.2643 & 1.3352 & 4.1294 & 3.3178 \\
\hline-2037.98 & 539.1810 & 1.3301 & 4.5114 & 1.6496 \\
\hline
\end{tabular}




\begin{tabular}{|c|c|c|c|c|}
\hline$\# \quad$ DEPT & GAMMA & K & UR & $\mathrm{TH}$ \\
\hline-2038.16 & 547.7493 & 1.3308 & 4.9209 & 1.6496 \\
\hline-2038.34 & 548.8965 & 1.2608 & 4.9235 & 3.3029 \\
\hline-2038.52 & 548.2005 & 1.3528 & 5.3330 & 6.5715 \\
\hline-2038.69 & 566.2472 & 1.3292 & 5.7317 & 8.1821 \\
\hline-2038.87 & 562.9915 & 1.3111 & 5.7317 & 6.5288 \\
\hline-2039.06 & 560.6189 & 1.2611 & 6.1196 & 9.6246 \\
\hline-2039.24 & 562.3329 & 1.2593 & 6.5116 & 9.6246 \\
\hline-2039.43 & 575.5484 & 1.1709 & 6.5116 & 9.6246 \\
\hline-2039.61 & 574.2205 & 1.1467 & 6.0898 & 9.6246 \\
\hline-2039.79 & 596.0833 & 1.0757 & 6.0898 & 7.9406 \\
\hline-2039.97 & 597.4772 & 1.1689 & 5.2490 & 7.9406 \\
\hline-2040.15 & 620.5876 & 1.1449 & 4.4204 & 9.5800 \\
\hline-2040.34 & 605.1882 & 1.0990 & 5.2564 & 9.5800 \\
\hline-2040.52 & 611.4570 & 0.9387 & 5.6868 & 7.9508 \\
\hline-2040.7 & 599.2042 & 0.8924 & 5.2776 & 7.9508 \\
\hline-2040.88 & 599.7491 & 0.8075 & 6.1061 & 6.4526 \\
\hline-2041.07 & 582.9744 & 0.7759 & 6.1061 & 4.6135 \\
\hline-2041.25 & 567.3932 & 0.7752 & 5.3062 & 4.6135 \\
\hline-2041.43 & 559.0471 & 0.8261 & 5.7557 & 6.3281 \\
\hline-2041.6 & 539.7858 & 0.8027 & 5.7680 & 4.6748 \\
\hline-2041.79 & 517.4091 & 0.6637 & 5.3585 & 3.0456 \\
\hline-2041.96 & 497.3207 & 0.6668 & 4.1482 & 1.4350 \\
\hline-2042.14 & 484.3097 & 0.6141 & 4.1482 & 1.4350 \\
\hline-2042.33 & 479.4154 & 0.5953 & 4.5912 & 0.0000 \\
\hline-2042.5 & 470.4894 & 0.6227 & 4.1992 & 0.0279 \\
\hline-2042.68 & 458.2826 & 0.6675 & 5.0277 & 1.6812 \\
\hline-2042.87 & 444.4453 & 0.6433 & 5.0277 & 1.6812 \\
\hline-2043.05 & 432.3806 & 0.6415 & 5.4384 & 1.6812 \\
\hline-2043.23 & 429.4219 & 0.5947 & 5.0254 & 3.3299 \\
\hline-2043.41 & 398.1645 & 0.5716 & 5.4372 & 1.6905 \\
\hline-2043.59 & 399.9677 & 0.5920 & 4.6012 & 1.6905 \\
\hline-2043.77 & 390.8270 & 0.6155 & 4.1806 & 1.6905 \\
\hline-2043.95 & 384.5677 & 0.6174 & 3.7613 & 3.4320 \\
\hline-2044.13 & 363.7439 & 0.6835 & 3.7127 & 3.4320 \\
\hline-2044.31 & 380.3012 & 0.7079 & 4.1305 & 3.4320 \\
\hline-2044.49 & 363.5308 & 0.5954 & 4.1305 & 3.4320 \\
\hline-2044.67 & 354.4054 & 0.5911 & 3.6822 & 3.3568 \\
\hline-2044.85 & 374.1671 & 0.6608 & 3.2520 & 3.3568 \\
\hline-2045.04 & 381.4588 & 0.7808 & 3.2520 & 1.7174 \\
\hline-2045.21 & 381.6866 & 0.7787 & 3.2520 & 3.3419 \\
\hline-2045.4 & 395.3537 & 0.7806 & 3.2520 & 3.3419 \\
\hline-2045.58 & 401.6437 & 0.8725 & 2.4211 & 3.3419 \\
\hline-2045.76 & 402.2969 & 0.8704 & 2.4211 & 3.2927 \\
\hline-2045.94 & 407.6779 & 0.9658 & 1.5926 & 3.3076 \\
\hline-2046.12 & 419.8190 & 1.0344 & 2.8102 & 4.9275 \\
\hline-2046.3 & 432.1762 & 1.0595 & 2.8213 & 4.9275 \\
\hline-2046.48 & 447.5256 & 1.0366 & 3.2380 & 3.2788 \\
\hline-2046.66 & 448.7969 & 1.0676 & 2.8262 & 4.3739 \\
\hline-2046.84 & 515.3680 & 1.0668 & 2.8262 & 4.3739 \\
\hline-2047.02 & 518.2400 & 1.2037 & 2.4083 & 6.0030 \\
\hline-2047.2 & 525.4089 & 1.2704 & 3.2294 & 4.2615 \\
\hline-2047.38 & 552.1250 & 1.3254 & 2.4495 & 7.6805 \\
\hline-2047.56 & 558.0013 & 1.3241 & 2.8527 & 7.6805 \\
\hline-2047.74 & 581.7773 & 1.4906 & 2.8527 & 7.6805 \\
\hline
\end{tabular}




\begin{tabular}{|c|c|c|c|c|}
\hline$\# \quad$ DEPT & GAMMA & K & UR & $\mathrm{TH}$ \\
\hline-2047.92 & 608.6892 & 1.5163 & 2.4421 & 6.0411 \\
\hline-2048.1 & 619.8871 & 1.6032 & 2.4270 & 6.0411 \\
\hline-2048.29 & 625.6306 & 1.5533 & 3.2529 & 6.0411 \\
\hline-2048.47 & 647.9110 & 1.5104 & 3.6785 & 4.4166 \\
\hline-2048.65 & 655.3312 & 1.5098 & 4.0989 & 4.4166 \\
\hline-2048.83 & 674.7864 & 1.4901 & 4.9423 & 4.4166 \\
\hline-2049.01 & 679.5886 & 1.4914 & 4.9423 & 2.7772 \\
\hline-2049.19 & 687.1996 & 1.3703 & 4.9423 & 1.1090 \\
\hline-2049.37 & 687.5148 & 1.4465 & 4.5733 & 0.0000 \\
\hline-2049.54 & 684.8156 & 1.5399 & 4.1515 & 1.1527 \\
\hline-2049.73 & 683.6081 & 1.6293 & 3.7348 & 1.1527 \\
\hline-2049.91 & 711.8680 & 1.6227 & 3.7348 & 0.0576 \\
\hline-2050.1 & 654.6975 & 1.5079 & 4.9523 & 0.0576 \\
\hline-2050.27 & 681.4427 & 1.4859 & 4.9523 & 0.0678 \\
\hline-2050.45 & 704.3325 & 1.5116 & 4.9672 & 1.7360 \\
\hline-2050.63 & 698.4019 & 1.4382 & 4.9672 & 0.0000 \\
\hline-2050.81 & 687.0825 & 1.4857 & 4.1461 & 0.0000 \\
\hline-2050.99 & 679.6749 & 1.4155 & 4.5717 & 0.0000 \\
\hline-2051.17 & 658.9297 & 1.3437 & 4.9847 & 0.0000 \\
\hline-2051.35 & 657.0495 & 1.3078 & 4.5891 & 0.0000 \\
\hline-2051.54 & 672.4167 & 1.3320 & 4.1799 & 0.0000 \\
\hline-2051.72 & 650.2903 & 1.3307 & 3.7543 & 0.0000 \\
\hline-2051.9 & 653.3832 & 1.4237 & 3.3339 & 0.0000 \\
\hline-2052.08 & 648.7036 & 1.4005 & 2.9149 & 0.0000 \\
\hline-2052.26 & 651.0208 & 1.4482 & 2.9149 & 2.3620 \\
\hline-2052.44 & 692.9926 & 1.4878 & 2.9149 & 2.3620 \\
\hline-2052.62 & 701.0612 & 1.3813 & 2.4288 & 2.3620 \\
\hline-2052.8 & 722.7109 & 1.3732 & 2.8911 & 0.6985 \\
\hline-2052.98 & 749.5504 & 1.3941 & 2.8911 & 0.6985 \\
\hline-2053.15 & 774.3099 & 1.4938 & 3.3220 & 0.6985 \\
\hline-2053.33 & 810.2995 & 1.5870 & 2.9256 & 0.6985 \\
\hline-2053.51 & 813.3060 & 1.4966 & 3.3474 & 0.7431 \\
\hline-2053.69 & 812.9657 & 1.3548 & 2.5114 & 0.7143 \\
\hline-2053.87 & 844.1541 & 1.3304 & 3.3351 & 0.7143 \\
\hline-2054.06 & 853.0087 & 1.2345 & 3.7113 & 0.7143 \\
\hline-2054.24 & 884.2496 & 1.2378 & 3.7262 & 2.4725 \\
\hline-2054.42 & 901.4202 & 1.2606 & 4.1319 & 4.1073 \\
\hline-2054.6 & 912.3737 & 1.2804 & 4.9605 & 9.0682 \\
\hline-2054.78 & 917.3485 & 1.2333 & 5.3772 & 9.0682 \\
\hline-2054.97 & 947.1970 & 1.2788 & 5.7890 & 9.0682 \\
\hline-2055.15 & 946.0690 & 1.2021 & 6.1652 & 7.4149 \\
\hline-2055.33 & 965.3429 & 1.1853 & 5.7408 & 7.4149 \\
\hline-2055.51 & 979.2005 & 1.0901 & 6.1538 & 6.6718 \\
\hline-2055.69 & 954.4527 & 1.1020 & 6.5768 & 6.6718 \\
\hline-2055.87 & 946.9809 & 1.0639 & 6.2143 & 8.3205 \\
\hline-2056.06 & 921.5555 & 1.0463 & 5.7520 & 8.3205 \\
\hline-2056.24 & 905.9114 & 1.0725 & 6.1578 & 8.3205 \\
\hline-2056.42 & 873.1680 & 0.9491 & 5.7269 & 8.3205 \\
\hline-2056.6 & 840.3845 & 0.9502 & 4.9058 & 8.3205 \\
\hline-2056.78 & 832.0525 & 0.9913 & 4.4839 & 8.2425 \\
\hline-2056.96 & 810.9922 & 1.0604 & 4.8909 & 6.6031 \\
\hline-2057.14 & 796.5521 & 1.2537 & 4.4928 & 6.6031 \\
\hline-2057.32 & 812.2765 & 1.3449 & 4.5142 & 8.1904 \\
\hline-2057.5 & 797.5820 & 1.3465 & 4.9686 & 8.2183 \\
\hline
\end{tabular}




\begin{tabular}{|c|c|c|c|c|}
\hline \# $\quad$ DEPT & GAMMA & K & UR & $\mathrm{TH}$ \\
\hline-2057.68 & 773.7548 & 1.4210 & 4.5135 & 6.5836 \\
\hline-2057.87 & 782.4388 & 1.4543 & 4.5631 & 3.3754 \\
\hline-2058.05 & 781.5855 & 1.4989 & 4.1354 & 3.3754 \\
\hline-2058.23 & 767.4739 & 1.5214 & 4.5424 & 6.6439 \\
\hline-2058.41 & 758.9332 & 1.5268 & 4.5742 & 6.6439 \\
\hline-2058.6 & 741.4080 & 1.4476 & 5.0037 & 8.3586 \\
\hline-2058.78 & 734.2765 & 1.5205 & 5.0163 & 6.7099 \\
\hline-2058.96 & 715.1532 & 1.4678 & 4.9877 & 6.7099 \\
\hline-2059.13 & 720.4978 & 1.6638 & 5.4186 & 5.0612 \\
\hline-2059.31 & 747.1593 & 1.6894 & 5.4186 & 5.0612 \\
\hline-2059.5 & 753.9423 & 1.6894 & 5.8243 & 5.0612 \\
\hline-2059.69 & 769.0876 & 1.7807 & 5.8243 & 5.0612 \\
\hline-2059.87 & 780.2352 & 1.8593 & 6.2089 & 5.0612 \\
\hline-2060.06 & 789.6714 & 1.8454 & 6.2089 & 3.4553 \\
\hline-2060.24 & 800.1749 & 1.9370 & 6.2078 & 3.4553 \\
\hline-2060.41 & 779.1146 & 1.8229 & 6.0845 & 3.4553 \\
\hline-2060.59 & 835.0430 & 2.0629 & 6.9332 & 1.8679 \\
\hline-2060.77 & 824.0360 & 2.1023 & 6.0384 & 0.0817 \\
\hline-2060.95 & 850.4163 & 2.1219 & 6.0877 & 0.0817 \\
\hline-2061.13 & 831.6702 & 2.0171 & 6.0237 & 0.0000 \\
\hline-2061.31 & 816.5699 & 2.0213 & 5.6180 & 0.0000 \\
\hline-2061.5 & 824.5855 & 1.9781 & 4.7992 & 0.0000 \\
\hline-2061.69 & 837.1484 & 2.1020 & 4.3911 & 0.0000 \\
\hline-2061.87 & 854.1081 & 2.2710 & 4.8155 & 0.0000 \\
\hline-2062.05 & 858.6085 & 2.1986 & 4.3900 & 0.0000 \\
\hline-2062.24 & 888.0695 & 2.2254 & 4.8241 & 0.0000 \\
\hline-2062.42 & 902.4262 & 2.2079 & 4.3932 & 0.0000 \\
\hline-2062.6 & 894.4653 & 2.1608 & 5.2266 & 0.0000 \\
\hline-2062.78 & 884.1129 & 2.0253 & 4.4151 & 0.0000 \\
\hline-2062.96 & 870.8342 & 2.0726 & 5.6468 & 0.0000 \\
\hline-2063.14 & 868.7309 & 1.9694 & 5.2622 & 0.0000 \\
\hline-2063.32 & 857.1571 & 1.9417 & 5.2622 & 0.0000 \\
\hline-2063.49 & 846.4167 & 1.8286 & 4.8565 & 0.0000 \\
\hline-2063.67 & 863.2578 & 1.7712 & 4.9542 & 0.0000 \\
\hline-2063.85 & 785.0356 & 1.4856 & 4.1021 & 0.0000 \\
\hline-2064.03 & 778.1111 & 1.4388 & 4.1021 & 1.5623 \\
\hline-2064.21 & 746.2249 & 1.3375 & 4.2399 & 1.5623 \\
\hline-2064.39 & 818.1511 & 1.3562 & 4.2013 & 4.6581 \\
\hline-2064.57 & 818.3455 & 1.3548 & 4.6191 & 4.6581 \\
\hline-2064.75 & 831.9626 & 1.4276 & 5.4705 & 4.6581 \\
\hline-2064.93 & 838.3898 & 1.3523 & 5.4705 & 4.6581 \\
\hline-2065.11 & 821.0625 & 1.2862 & 4.9200 & 2.9537 \\
\hline-2065.29 & 893.9827 & 1.3700 & 5.5545 & 5.4866 \\
\hline-2065.48 & 860.4132 & 1.3416 & 4.7259 & 7.0220 \\
\hline-2065.66 & 858.7804 & 1.2121 & 5.1529 & 5.4383 \\
\hline-2065.85 & 848.2830 & 1.1176 & 5.1454 & 5.4383 \\
\hline-2066.04 & 831.1580 & 1.2258 & 5.4909 & 8.1970 \\
\hline-2066.22 & 850.8238 & 1.1274 & 4.7743 & 10.2534 \\
\hline-2066.4 & 836.7422 & 1.1238 & 5.1675 & 10.2534 \\
\hline-2066.57 & 835.1267 & 1.1721 & 5.1675 & 10.2534 \\
\hline-2066.75 & 853.8489 & 1.2205 & 5.5919 & 8.5750 \\
\hline-2066.94 & 851.6719 & 1.2217 & 5.6026 & 6.9783 \\
\hline-2067.12 & 850.7708 & 1.1789 & 5.6338 & 6.9783 \\
\hline-2067.3 & 842.1172 & 1.2030 & 5.6338 & 6.9886 \\
\hline
\end{tabular}




\begin{tabular}{|c|c|c|c|c|}
\hline$\# \quad$ DEPT & GAMMA & K & UR & $\mathrm{TH}$ \\
\hline-2067.49 & 834.5017 & 1.2280 & 5.4686 & 8.5276 \\
\hline-2067.67 & 740.6371 & 1.1640 & 5.5340 & 7.1102 \\
\hline-2067.85 & 730.3950 & 1.0826 & 5.1161 & 7.1102 \\
\hline-2068.04 & 711.8704 & 0.9949 & 4.6137 & 7.9199 \\
\hline-2068.22 & 701.8721 & 0.9532 & 5.0062 & 8.8308 \\
\hline-2068.4 & 703.1427 & 0.9238 & 5.0870 & 9.8631 \\
\hline-2068.58 & 606.5993 & 0.8842 & 4.7537 & 7.7863 \\
\hline-2068.76 & 614.0841 & 0.8973 & 5.2476 & 6.7712 \\
\hline-2068.93 & 593.0690 & 0.9017 & 5.1833 & 7.8900 \\
\hline-2069.11 & 583.2756 & 0.9873 & 4.4545 & 9.2122 \\
\hline-2069.3 & 588.0187 & 0.8506 & 4.4447 & 5.8333 \\
\hline-2069.45 & 532.9548 & 0.8214 & 4.0935 & 3.1079 \\
\hline-2690.6 & 524.9428 & 1.2420 & 0.6533 & 9.5845 \\
\hline-2690.8 & 519.3751 & 1.2981 & 0.3909 & 8.5086 \\
\hline-2690.99 & 515.6177 & 1.3124 & 0.1688 & 7.5981 \\
\hline-2691.19 & 494.1300 & 1.2638 & 0.4972 & 8.8885 \\
\hline-2691.39 & 488.0267 & 1.2510 & 0.2976 & 10.0414 \\
\hline-2691.58 & 481.2869 & 1.1613 & 0.1230 & 9.2059 \\
\hline-2691.79 & 455.9489 & 1.2636 & 0.1158 & 6.9836 \\
\hline-2691.98 & 440.2959 & 1.2893 & 0.0000 & 6.9836 \\
\hline-2692.18 & 440.7412 & 1.1860 & 0.0697 & 6.9079 \\
\hline-2692.38 & 428.9995 & 1.1675 & 0.0919 & 5.2458 \\
\hline-2692.58 & 435.5718 & 1.2177 & 0.5292 & 3.5100 \\
\hline-2692.78 & 441.8771 & 1.1902 & 0.9418 & 3.5100 \\
\hline-2692.98 & 456.3618 & 1.2868 & 1.3678 & 3.5100 \\
\hline-2693.17 & 454.4783 & 1.3006 & 1.7750 & 3.5100 \\
\hline-2693.38 & 452.6400 & 1.3273 & 2.6471 & 3.5454 \\
\hline-2693.57 & 431.9500 & 1.2808 & 2.6471 & 5.2911 \\
\hline-2693.77 & 422.9018 & 1.1799 & 2.6471 & 5.2911 \\
\hline-2693.97 & 432.5882 & 1.2048 & 2.2211 & 7.0062 \\
\hline-2694.17 & 436.5871 & 1.1306 & 2.6559 & 7.0062 \\
\hline-2694.36 & 427.4000 & 1.0818 & 3.5253 & 7.0062 \\
\hline-2694.56 & 437.7859 & 1.1613 & 3.9939 & 5.3009 \\
\hline-2694.76 & 432.7335 & 1.1112 & 4.4198 & 6.9659 \\
\hline-2694.97 & 422.0265 & 1.0867 & 4.8598 & 8.7224 \\
\hline-2695.17 & 415.6429 & 1.0448 & 5.3092 & 10.5163 \\
\hline-2695.37 & 426.6976 & 1.1351 & 5.3092 & 10.5163 \\
\hline-2695.56 & 392.4376 & 1.1383 & 4.4622 & 8.8257 \\
\hline-2695.76 & 394.1476 & 1.1398 & 4.0237 & 8.8257 \\
\hline-2695.96 & 392.5641 & 1.1164 & 3.5864 & 12.348 \\
\hline-2696.16 & 377.8194 & 1.1643 & 2.7244 & 12.348 \\
\hline-2696.36 & 360.1911 & 1.0933 & 2.7321 & 12.3485 \\
\hline-2696.56 & 342.7811 & 1.1218 & 2.3248 & 12.348 \\
\hline-2696.75 & 325.6335 & 1.0700 & 1.4527 & 12.2885 \\
\hline-2696.95 & 328.2143 & 0.9645 & 1.6995 & 11.4097 \\
\hline-2697.15 & 308.7833 & 0.9587 & 1.9792 & 10.448 \\
\hline-2697.34 & 293.2599 & 0.9804 & 1.7709 & 11.4322 \\
\hline-2697.54 & 291.6376 & 1.0056 & 0.9623 & 12.5675 \\
\hline-2697.74 & 283.3283 & 0.9240 & 0.0000 & 13.8921 \\
\hline-2697.93 & 280.2954 & 0.9881 & 0.0000 & 10.2016 \\
\hline-2698.13 & 288.5079 & 1.1470 & 0.0000 & 8.5685 \\
\hline-2698.33 & 288.9621 & 1.0531 & 0.0000 & 6.5018 \\
\hline-2698.5 & 274.9149 & 0.9595 & 0.0000 & 7.7304 \\
\hline
\end{tabular}




\section{Appendix C. Mercury Intrusion Porosimetry Data Collected by Poro-Technology}

Poro-Technology, Sugar Land, Texas, performed directional and omni-directional mercury capillary pressure measurements. Data was provided in Microsoft Excel spreadsheet format and as a hard copy, which is reproduced here. 


\section{Poro-Technology}

\section{MERCURY INJECTION CAPILLARY PRESSURE (MICP) DATA REPORT}

Company: Sandia Labs

Samples/Well: $\underline{\mathbf{8}}$ Kirtland Shale Core Samples;

(2048.35 - 2692.19ft)

Job Ref. No: $\quad$ SANDIA004

Date: October 20, 2008

Provided By: John W. Neasham PhD 104 Industrial Blvd., Ste G Sugar Land, Texas 77478 USA 281/240-3600_jnporotek@aol.com 


\section{POROTECHNOLOGY: 10/2008|| \\ SPL ID: Kirtland Shale Core Samples}

\begin{tabular}{|c|c|c|c|c|c|c|c|}
\hline & $T a b$ & Sample & SpI MICP & Sample Air & Calc MICP & MICP Bulk & MICP Gr. \\
\hline SamplelDepth & No. & Porosity(o) & Porosity (\%) & Perm(md) & Perm(md) & Den (glcc) & Den $(g \mid c c)$ \\
\hline Plug parallel to bedding* & 1 & N/A & 8.78 & N/A & 0.00043 & 2.433 & 2.667 \\
\hline Plug perpendicular to bed & $* * 2$ & & 8.52 & & 0.00043 & 2.435 & 2.661 \\
\hline Spl @ 2048.35ft & 3 & & 12.5 & & 0.199 & 2.24 & 2.56 \\
\hline @ 2052.35ft & 4 & & 10.7 & & 0.00051 & 2.342 & 2.623 \\
\hline @ 2055.37ft & 5 & & 10.2 & & 0.00054 & 2.397 & 2.669 \\
\hline @ $2062.40 \mathrm{ft}$ & 6 & & 9.02 & & 0.00065 & 2.412 & 2.652 \\
\hline @ 2068.05ft & 7 & & 8.89 & & 0.00054 & 2.416 & 2.652 \\
\hline @ 2692.19ft & 8 & & 8.84 & & 0.00045 & 2.455 & 2.694 \\
\hline & & & & & & & \\
\hline & & & IICP POROSIT & Y VS MICP F & PERM & & \\
\hline & & & & & & & \\
\hline & & & & & 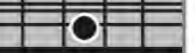 & & \\
\hline & & & & & & & \\
\hline & ن & 01 & & & & & \\
\hline & & t & 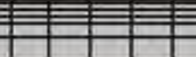 & 慗帮 & 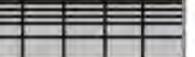 & & \\
\hline & 0.0 & 001 尿 & 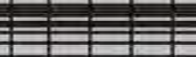 & $0=0$ & D帮帮 & & \\
\hline & $\frac{U}{\Sigma} 0.00$ & 001 & 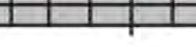 & $1+1$ & $+1+1$ & & \\
\hline & & 0 & 5 & 10 & 15 & & \\
\hline & & & MICP PORO & SITY (PV/B) & V) $-\%$ & & \\
\hline & & & & & & & \\
\hline & & & & & & & \\
\hline $\begin{array}{r}\text { NOTE 1: All samples u } \\
\text { may have bee }\end{array}$ & $\frac{\text { vere d }}{\text { en sub }}$ & Iried at & $\frac{100 \mathrm{C} \text { prior to }}{\text { andlor exam }}$ & $\frac{\text { MICP tes }}{\text { ined unde }}$ & $\frac{\text { ting. Addition }}{\text { r a binocular }}$ & microscope & dor samples \\
\hline proper MICP & analys & sis. ${ }^{*}$ Den & otes spls ja & cketed wi & th epoxy. & & \\
\hline & & & & & & & \\
\hline OTHER PC SYSTEMS & & & & & & & \\
\hline Pc gas $/$ brine $=$ & 0.1 & {$[(50 \backslash 480$} & $\mathrm{D}) \mathrm{X}(11.766) X$ & $\mathrm{Pc}$ airl $\mathrm{Hg}$ & & & \\
\hline Pc gas $/$ oil $=$ & 0.1 & {$[(24 \backslash 480$} & )$\times(11.766) X$ & $\mathrm{Pc}$ airl $\backslash \mathrm{Hg}$ & & & \\
\hline Pc oil/brine $=$ & 0.1 & {$[(30 \backslash 480$} & $x(11.766) X$ & $\mathrm{Pc}$ airlHg & & & \\
\hline & & & & & & & \\
\hline HEIGHT ABOVE FREE & WAT & TER(FT & & Brine Der & nsity $=1.11 \mathrm{~g}$ & & \\
\hline Height(gas/brine $)=$ & 0.3 & (XPc ai & $\mathrm{r} / \mathrm{Hg})$ & Gas Den & sity $=0.20 \mathrm{~g} / \mathrm{c}$ & & \\
\hline Height(oil/brine) $=$ & 0.7 & (XPc ai & $\mathrm{r} / \mathrm{Hg})$ & Oil Densi & ity $=0.85 \mathrm{~g} / \mathrm{cc}$ & & \\
\hline & & & & & \begin{tabular}{|l||} 
\\
\end{tabular} & & \\
\hline NOTE: SPL PERM(CALC & $=$ Air & Perm (m & d) $=$ Max val & ue of $(\mathrm{Sb} / \mathrm{l}$ & Pc); To 1.691 & 1 power; $\mathrm{Mu}$ & Itiply by 39 \\
\hline (After SWANSON, & SPE & 8234,19 & & & & & \\
\hline & & & & & & & \\
\hline NOTE: Leverett "J" Functi & ion $=1$ & [((k/por.) & $x 0.5 \exp ) X$. & Pc(psia) & $\times 0.2166] / 48$ & & \\
\hline \{The "k" value use & d for $\mathrm{J}$ & -Funct. C & alculations o & $\mathrm{n}$ the "RP & Tx" tables is t & that provide & d by client \\
\hline (ie, client's PPGD c & data). & If such d & lata not provic & ded, then " & 'MICP-Calcul & lated" k val & e used. Tr \\
\hline "por."(porosity) valu & ue use & ed is the & "MICP" poros & sity measu & red @ 600 & & \\
\hline
\end{tabular}




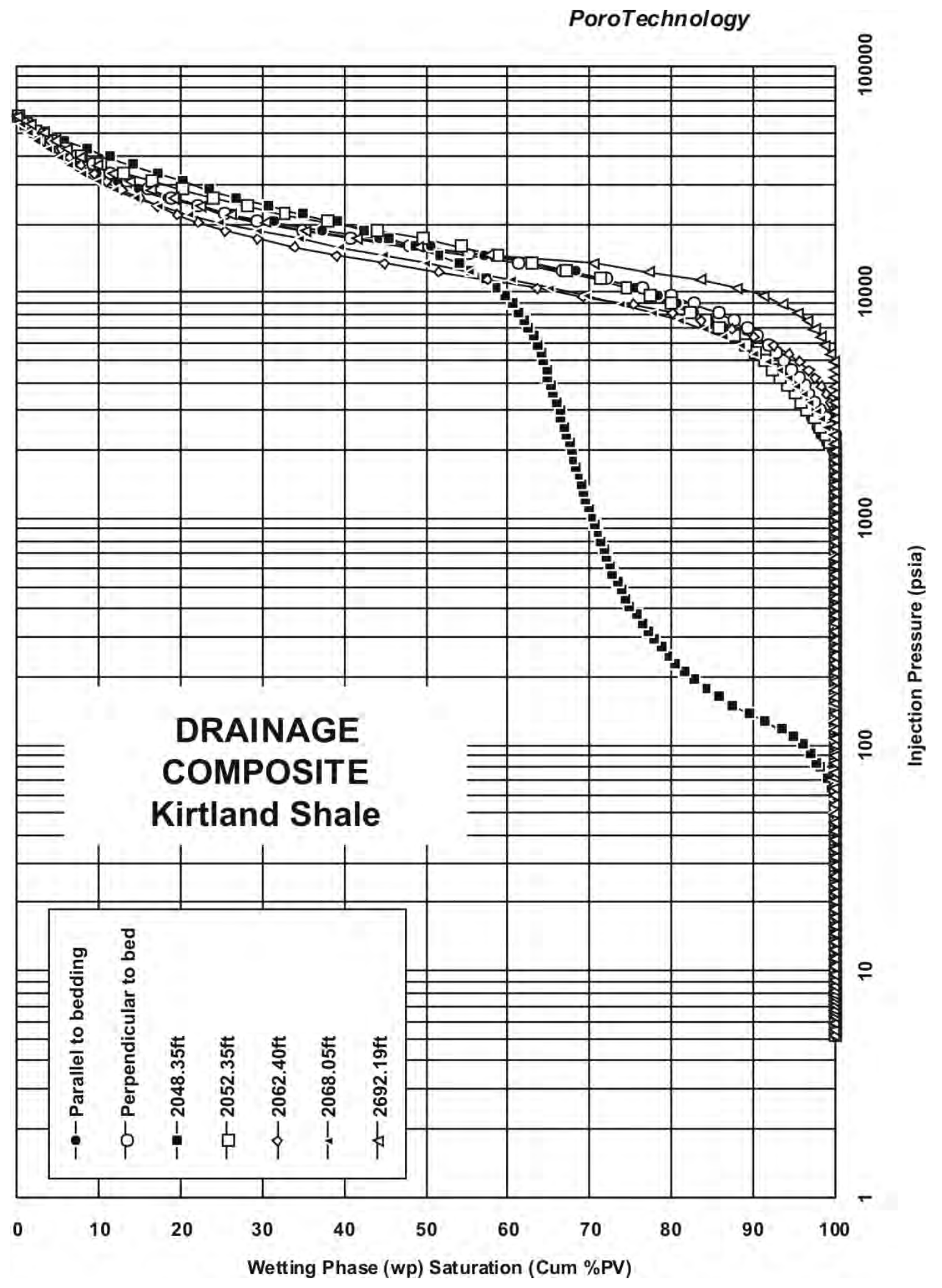




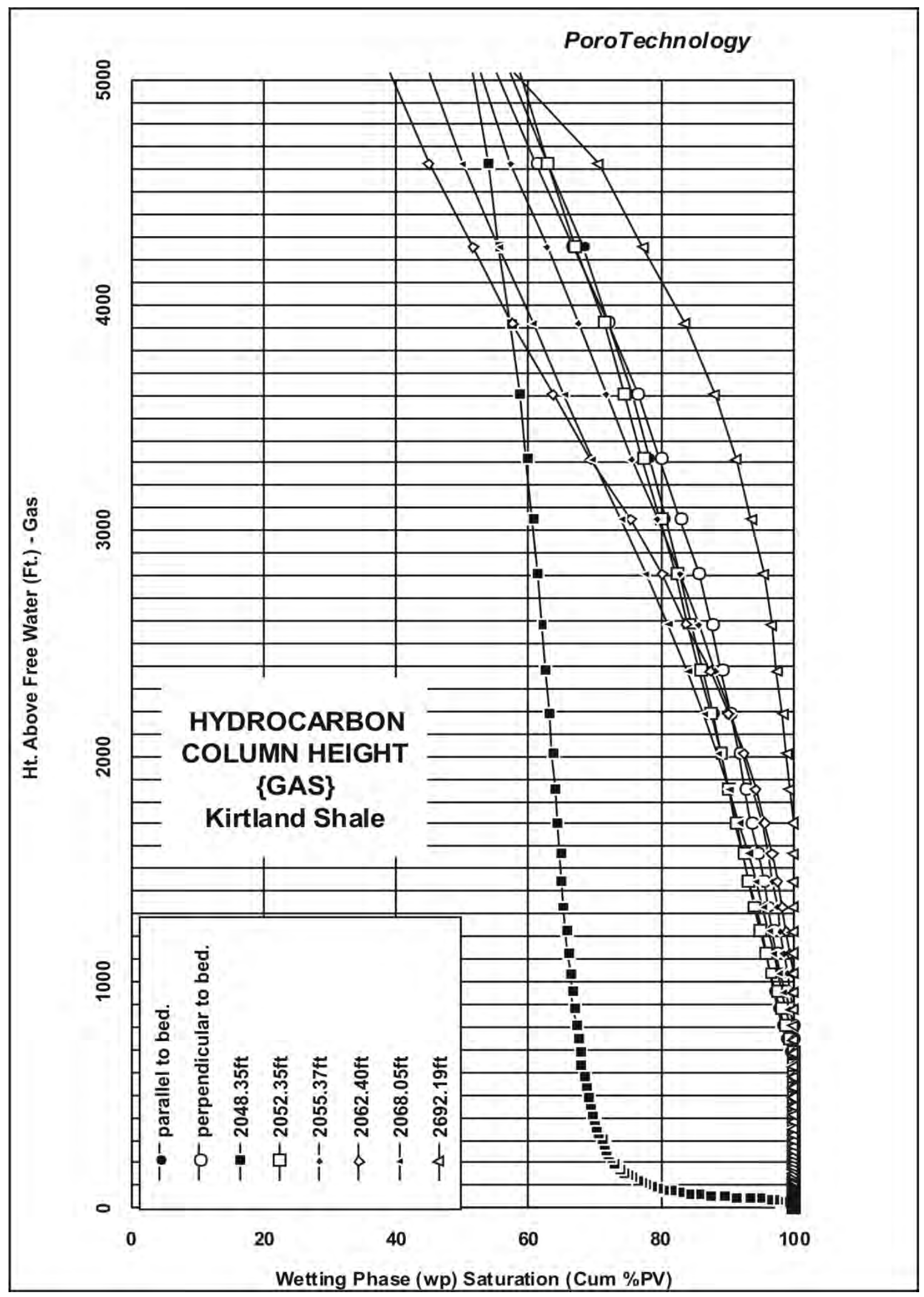




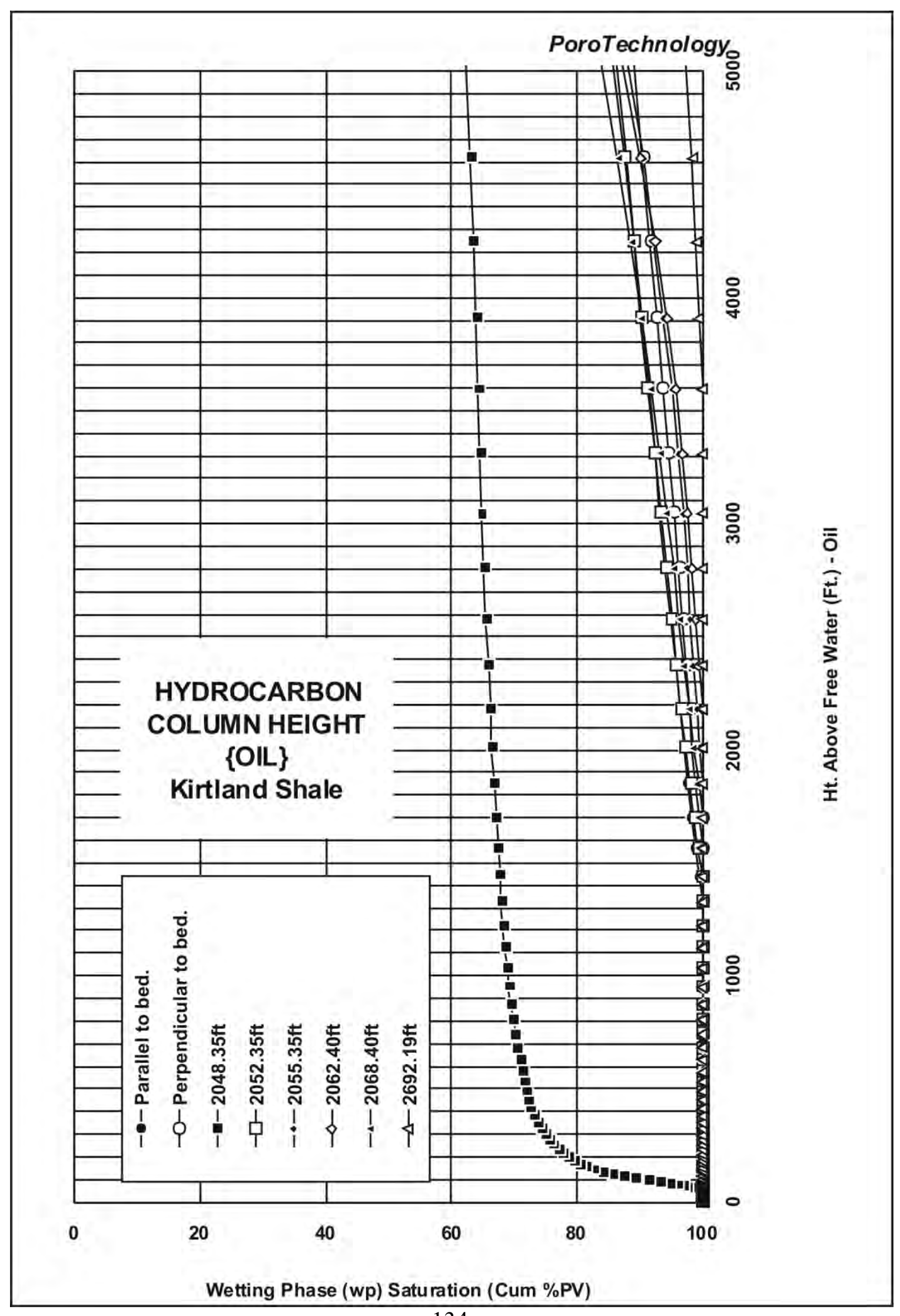




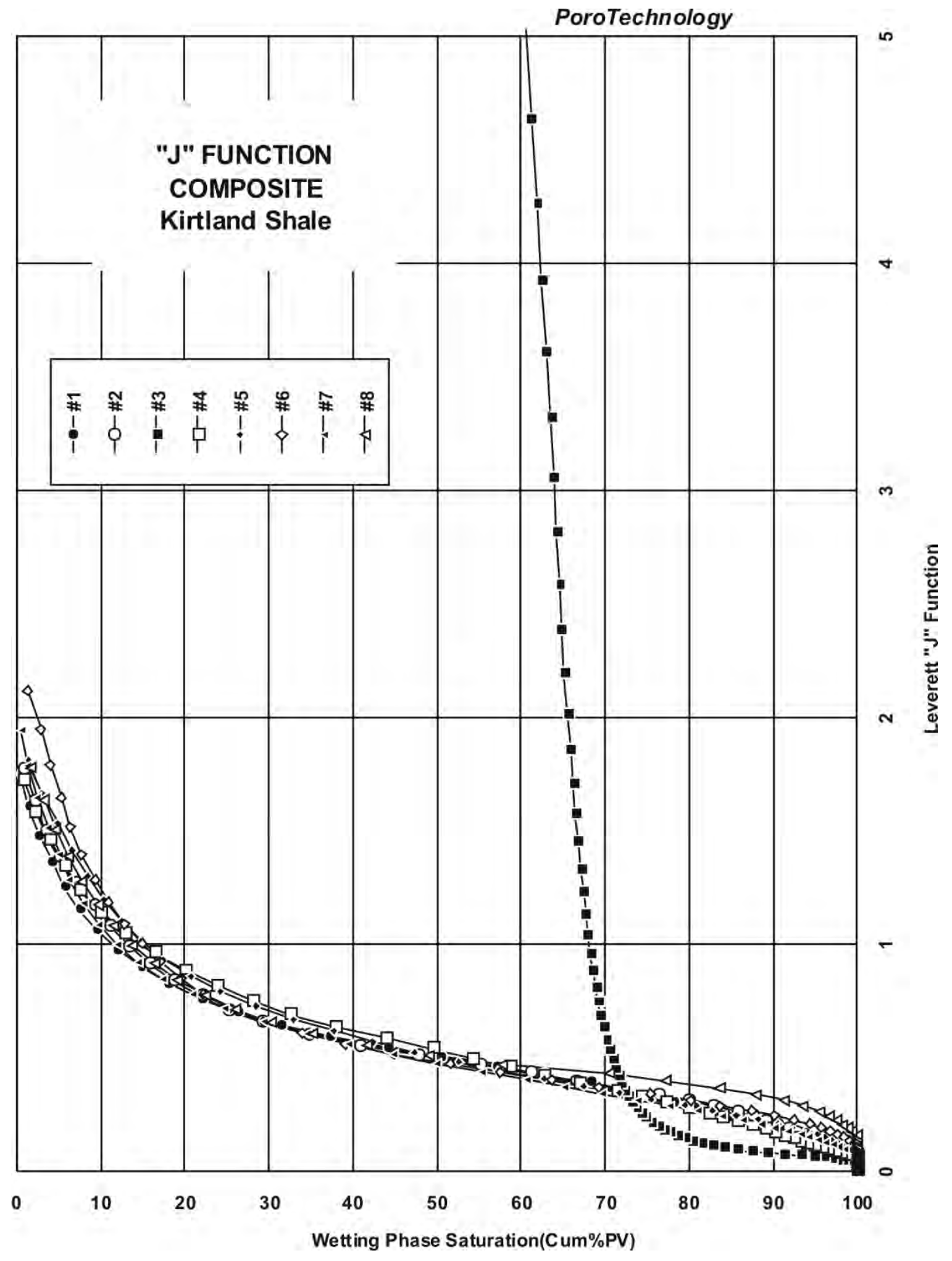


AIR|MERCURY CAPILLARY PRESSURE DATA : BY PoroTechnology

Jacketed Plug Parallel to Bedding

\begin{tabular}{|c|c|c|c|c|c|c|c|c|c|}
\hline \multicolumn{4}{|c|}{$\begin{array}{l}\text { MICP Closure }(\text { psia })=1820 . \\
\text { MICP Porosity }=8.78 \% \\
\text { MICP Gr. Den. }(\text { gmlcc })=2.667 \\
\text { MICP-Calc. Air Perm }=0.00043 \mathrm{md} \\
\text { Median Pore Aperture Dia. (microns) }=0.0134\end{array}$} & \multicolumn{4}{|c|}{ Spl Bulk Density = $2.433 \mathrm{gm} / \mathrm{cc}$} & \multirow[b]{2}{*}{$\begin{array}{l}\text { Ht. Above } \\
\text { Free Water } \\
\text { (ft.) } \\
\text { Gas/Brine }\end{array}$} & \multirow[b]{2}{*}{$\begin{array}{l}\text { Ht. Above } \\
\text { Free Water } \\
\text { (ft.) } \\
\text { OillBrine }\end{array}$} \\
\hline $\begin{array}{l}\text { Injection } \\
\text { Pressure } \\
\text { (psia) }\end{array}$ & $\begin{array}{c}\text { Pore } \\
\text { Diameter } \\
\text { (microns) }\end{array}$ & $\begin{array}{l}\mathrm{Hg} \text { (nwp) } \\
\text { Saturation } \\
\text { cum\%PV }\end{array}$ & $\begin{array}{c}100-\mathrm{Hg}(w p) \\
\text { Saturation } \\
\text { cum\%PV }\end{array}$ & $\begin{array}{l}\text { Leverett } \\
\text { "J" } \\
\text { Function }\end{array}$ & $\begin{array}{l}\text { Gas/Brine } \\
\text { Pc (psia) }\end{array}$ & $\begin{array}{l}\text { Gas/Oil } \\
\text { Pc (psia) }\end{array}$ & $\begin{array}{l}\text { Oil/Brine } \\
\text { Pc (psia) }\end{array}$ & & \\
\hline 5.19 & 41.12 & 0.0 & 100.0 & 0.00 & 0.71 & 0.34 & 0.43 & 1.8 & 3.8 \\
\hline 5.49 & 38.86 & 0.0 & 100.0 & 0.00 & 0.75 & 0.36 & 0.45 & 1.9 & 4.0 \\
\hline 5.84 & 36.54 & 0.0 & 100.0 & 0.00 & 0.79 & 0.38 & 0.48 & 2.0 & 4.3 \\
\hline 6.24 & 34.20 & 0.0 & 100.0 & 0.00 & 0.85 & 0.41 & 0.51 & 2.2 & 4.5 \\
\hline 6.49 & 32.87 & 0.0 & 100.0 & 0.00 & 0.88 & 0.42 & 0.53 & 2.2 & 4.7 \\
\hline 6.74 & 31.66 & 0.0 & 100.0 & 0.00 & 0.92 & 0.44 & 0.55 & 2.3 & 4.9 \\
\hline 7.04 & 30.31 & 0.0 & 100.0 & 0.00 & 0.96 & 0.46 & 0.58 & 2.4 & 5.1 \\
\hline 7.34 & 29.08 & 0.0 & 100.0 & 0.00 & 1.00 & 0.48 & 0.60 & 2.5 & 5.3 \\
\hline 7.59 & 28.11 & 0.0 & 100.0 & 0.00 & 1.03 & 0.49 & 0.62 & 2.6 & 5.5 \\
\hline 7.84 & 27.22 & 0.0 & 100.0 & 0.00 & 1.07 & 0.51 & 0.64 & 2.7 & 5.7 \\
\hline 8.19 & 26.06 & 0.0 & 100.0 & 0.00 & 1.11 & 0.53 & 0.67 & 2.8 & 6.0 \\
\hline 8.54 & 24.99 & 0.0 & 100.0 & 0.00 & 1.16 & 0.56 & 0.70 & 2.9 & 6.2 \\
\hline 9.08 & 23.50 & 0.0 & 100.0 & 0.00 & 1.23 & 0.59 & 0.74 & 3.1 & 6.6 \\
\hline 9.61 & 22.21 & 0.0 & 100.0 & 0.00 & 1.31 & 0.62 & 0.79 & 3.3 & 7.0 \\
\hline 10.44 & 20.44 & 0.0 & 100.0 & 0.00 & 1.42 & 0.68 & 0.86 & 3.6 & 7.6 \\
\hline 11.35 & 18.80 & 0.0 & 100.0 & 0.00 & 1.54 & 0.74 & 0.93 & 3.9 & 8.3 \\
\hline 12.33 & 17.30 & 0.0 & 100.0 & 0.00 & 1.68 & 0.80 & 1.01 & 4.3 & 9.0 \\
\hline 13.40 & 15.92 & 0.0 & 100.0 & 0.00 & 1.82 & 0.87 & 1.10 & 4.6 & 9.8 \\
\hline 14.57 & 14.64 & 0.0 & 100.0 & 0.00 & 1.98 & 0.95 & 1.19 & 5.0 & 10.6 \\
\hline 15.83 & 13.47 & 0.0 & 100.0 & 0.00 & 2.15 & 1.03 & 1.30 & 5.5 & 11.5 \\
\hline 17.21 & 12.40 & 0.0 & 100.0 & 0.00 & 2.34 & 1.12 & 1.41 & 5.9 & 12.5 \\
\hline 18.70 & 11.41 & 0.0 & 100.0 & 0.00 & 2.54 & 1.22 & 1.53 & 6.5 & 13.6 \\
\hline 20.32 & 10.50 & 0.0 & 100.0 & 0.00 & 2.76 & 1.32 & 1.67 & 7.0 & 14.8 \\
\hline 22.09 & 9.66 & 0.0 & 100.0 & 0.00 & 3.00 & 1.44 & 1.81 & 7.6 & 16.1 \\
\hline 24.01 & 8.89 & 0.0 & 100.0 & 0.00 & 3.27 & 1.56 & 1.97 & 8.3 & 17.5 \\
\hline 26.09 & 8.18 & 0.0 & 100.0 & 0.00 & 3.55 & 1.70 & 2.14 & 9.0 & 19.0 \\
\hline 28.96 & 7.37 & 0.0 & 100.0 & 0.00 & 3.94 & 1.88 & 2.37 & 10.0 & 21.1 \\
\hline 31.74 & 6.72 & 0.0 & 100.0 & 0.00 & 4.32 & 2.06 & 2.60 & 11.0 & 23.1 \\
\hline 34.76 & 6.137 & 0.0 & 100.0 & 0.00 & 4.73 & 2.26 & 2.85 & 12.0 & 25.3 \\
\hline 38.06 & 5.605 & 0.0 & 100.0 & 0.00 & 5.18 & 2.47 & 3.12 & 13.1 & 27.7 \\
\hline 41.56 & 5.133 & 0.0 & 100.0 & 0.00 & 5.65 & 2.70 & 3.41 & 14.3 & 30.3 \\
\hline 45.89 & 4.648 & 0.0 & 100.0 & 0.00 & 6.24 & 2.98 & 3.76 & 15.8 & 33.4 \\
\hline 48.61 & 4.389 & 0.0 & 100.0 & 0.00 & 6.61 & 3.16 & 3.99 & 16.8 & 35.4 \\
\hline 55.22 & 3.863 & 0.0 & 100.0 & 0.00 & 7.51 & 3.59 & 4.53 & 19.1 & 40.2 \\
\hline 59.56 & 3.581 & 0.0 & 100.0 & 0.00 & 8.10 & 3.87 & 4.88 & 20.5 & 43.4 \\
\hline 64.90 & 3.287 & 0.0 & 100.0 & 0.00 & 8.83 & 4.22 & 5.32 & 22.4 & 47.2 \\
\hline
\end{tabular}


AIR|MERCURY CAPILLARY PRESSURE DATA : BY PoroTechnologY

Jacketed Plug Parallel to Bedding

\begin{tabular}{|c|c|c|c|c|c|c|c|c|c|}
\hline $\begin{array}{l}\text { Injection } \\
\text { Pressure } \\
\text { (psia) }\end{array}$ & $\begin{array}{c}\text { Pore } \\
\text { Diameter } \\
\text { (microns) }\end{array}$ & $\begin{array}{l}\mathrm{Hg} \text { (nwp) } \\
\text { Saturation } \\
\text { cum\%PV }\end{array}$ & $\begin{array}{l}\text { 100-Hg(wp) } \\
\text { Saturation } \\
\text { cum\%PV }\end{array}$ & $\begin{array}{c}\text { Leverett } \\
\text { "J" } \\
\text { Function } \\
\end{array}$ & $\begin{array}{l}\text { Gas/Brine } \\
\text { Pc (psia) }\end{array}$ & $\begin{array}{l}\text { Gas/Oil } \\
\text { Pc (psia) }\end{array}$ & $\begin{array}{l}\text { Oil/Brine } \\
\text { Pc (psia) }\end{array}$ & $\begin{array}{l}\text { Ht. Above } \\
\text { Free Water } \\
\text { (ft.) } \\
\text { Gas/Brine }\end{array}$ & $\begin{array}{l}\text { Ht. Above } \\
\text { Free Water } \\
\text { (ft.) } \\
\text { Oil/Brine } \\
\end{array}$ \\
\hline 69.90 & 3.052 & 0.0 & 100.0 & 0.00 & 9.51 & 4.54 & 5.73 & 24.1 & 50.9 \\
\hline 78.74 & 2.709 & 0.0 & 100.0 & 0.00 & 10.71 & 5.12 & 6.46 & 27.2 & 57.3 \\
\hline 83.75 & 2.547 & 0.0 & 100.0 & 0.00 & 11.39 & 5.44 & 6.87 & 28.9 & 61.0 \\
\hline 90.66 & 2.353 & 0.0 & 100.0 & 0.00 & 12.33 & 5.89 & 7.43 & 31.3 & 66.0 \\
\hline 98.76 & 2.160 & 0.0 & 100.0 & 0.00 & 13.43 & 6.42 & 8.10 & 34.1 & 71.9 \\
\hline 106.05 & 2.012 & 0.0 & 100.0 & 0.00 & 14.4 & 6.89 & 8.70 & 36.6 & 77.2 \\
\hline 117.17 & 1.821 & 0.0 & 100.0 & 0.00 & 15.9 & 7.62 & 9.61 & 40.4 & 85.3 \\
\hline 125.48 & 1.700 & 0.0 & 100.0 & 0.00 & 17.1 & 8.16 & 10.29 & 43.3 & 91.3 \\
\hline 137.84 & 1.548 & 0.0 & 100.0 & 0.00 & 18.7 & 8.96 & 11.30 & 47.6 & 100.3 \\
\hline 149.41 & 1.428 & 0.0 & 100.0 & 0.00 & 20.3 & 9.71 & 12.25 & 51.5 & 108.8 \\
\hline 163.47 & 1.305 & 0.0 & 100.0 & 0.01 & 22.2 & 10.63 & 13.40 & 56.4 & 119.0 \\
\hline 178.08 & 1.198 & 0.0 & 100.0 & 0.01 & 24.2 & 11.58 & 14.60 & 61.4 & 129.6 \\
\hline 190.89 & 1.118 & 0.0 & 100.0 & 0.01 & 26.0 & 12.41 & 15.65 & 65.9 & 139.0 \\
\hline 208.12 & 1.025 & 0.0 & 100.0 & 0.01 & 28.3 & 13.53 & 17.07 & 71.8 & 151.5 \\
\hline 226.59 & 0.942 & 0.0 & 100.0 & 0.01 & 30.8 & 14.73 & 18.6 & 78.2 & 165.0 \\
\hline 246.64 & 0.865 & 0.0 & 100.0 & 0.01 & 33.5 & 16.03 & 20.2 & 85.1 & 180 \\
\hline 266.74 & 0.800 & 0.0 & 100.0 & 0.01 & 36.3 & 17.34 & 21.9 & 92.0 & 194 \\
\hline 289.44 & 0.737 & 0.0 & 100.0 & 0.01 & 39.4 & 18.8 & 23.7 & 99.9 & 211 \\
\hline 316.70 & 0.674 & 0.0 & 100.0 & 0.01 & 43.1 & 20.6 & 26.0 & 109.3 & 231 \\
\hline 343.46 & 0.621 & 0.0 & 100.0 & 0.01 & 46.7 & 22.3 & 28.2 & 118.5 & 250 \\
\hline 373.40 & 0.571 & 0.0 & 100.0 & 0.01 & 50.8 & 24.3 & 30.6 & 129 & 272 \\
\hline 408.03 & 0.523 & 0.0 & 100.0 & 0.01 & 55.5 & 26.5 & 33.5 & 141 & 297 \\
\hline 441.22 & 0.484 & 0.0 & 100.0 & 0.01 & 60.0 & 28.7 & 36.2 & 152 & 321 \\
\hline 479.59 & 0.445 & 0.0 & 100.0 & 0.02 & 65.2 & 31.2 & 39.3 & 165 & 349 \\
\hline 520.31 & 0.410 & 0.0 & 100.0 & 0.02 & 70.8 & 33.8 & 42.7 & 180 & 379 \\
\hline 566.70 & 0.376 & 0.0 & 100.0 & 0.02 & 77.1 & 36.8 & 46.5 & 196 & 413 \\
\hline 615.34 & 0.347 & 0.0 & 100.0 & 0.02 & 83.7 & 40.0 & 50.5 & 212 & 448 \\
\hline 670.82 & 0.318 & 0.0 & 100.0 & 0.02 & 91.2 & 43.6 & 55.0 & 231 & 488 \\
\hline 729.10 & 0.293 & 0.0 & 100.0 & 0.02 & 99.2 & 47.4 & 59.8 & 252 & 531 \\
\hline 791.27 & 0.270 & 0.0 & 100.0 & 0.02 & 107.6 & 51.4 & 64.9 & 273 & 576 \\
\hline 859.45 & 0.248 & 0.0 & 100.0 & 0.03 & 116.9 & 55.9 & 70.5 & 297 & 626 \\
\hline 933.65 & 0.229 & 0.0 & 100.0 & 0.03 & 127.0 & 60.7 & 76.6 & 322 & 680 \\
\hline 1014.20 & 0.210 & 0.0 & 100.0 & 0.03 & 137.9 & 65.9 & 83.2 & 350 & 738 \\
\hline 1102.76 & 0.193 & 0.0 & 100.0 & 0.03 & 150.0 & 71.7 & 90.4 & 380 & 803 \\
\hline 1201.67 & 0.178 & 0.0 & 100.0 & 0.04 & 163.4 & 78.1 & 98.5 & 415 & 875 \\
\hline 1303.10 & 0.164 & 0.0 & 100.0 & 0.04 & 177.2 & 84.7 & 106.9 & 450 & 949 \\
\hline 1416.12 & 0.151 & 0.0 & 100.0 & 0.04 & 192.6 & 92.0 & 116.1 & 489 & 1031 \\
\hline 1542.27 & 0.138 & 0.0 & 100.0 & 0.05 & 209.7 & 100.2 & 126.5 & 532 & 1123 \\
\hline 1672.23 & 0.128 & 0.0 & 100.0 & 0.05 & 227.4 & 108.7 & 137.1 & 577 & 1217 \\
\hline 1819.52 & 0.117 & 0.0 & 100.0 & 0.06 & 247.5 & 118.3 & 149.2 & 628 & 1325 \\
\hline 1977.77 & 0.108 & 0.6 & 99.4 & 0.06 & 269.0 & 128.6 & 162.2 & 682 & 1440 \\
\hline 2149.68 & 0.099 & 1.2 & 98.8 & 0.07 & 292.4 & 139.7 & 176.3 & 742 & 1565 \\
\hline 2336.09 & 0.091 & 1.8 & 98.2 & 0.07 & 317.7 & 151.8 & 191.6 & 806 & 1701 \\
\hline 2537.54 & 0.0841 & 2.4 & 97.6 & 0.08 & 345.1 & 164.9 & 208.1 & 875 & 1847 \\
\hline
\end{tabular}




\section{AIR|MERCURY CAPILLARY PRESSURE DATA : BY PoroTechnology}

\section{Jacketed Plug Parallel to Bedding}

\begin{tabular}{|c|c|c|c|c|c|c|c|c|c|}
\hline $\begin{array}{l}\text { Injection } \\
\text { Pressure } \\
\text { (psia) }\end{array}$ & $\begin{array}{c}\text { Pore } \\
\text { Diameter } \\
\text { (microns) }\end{array}$ & $\begin{array}{l}\mathrm{Hg}(\mathrm{nwp}) \\
\text { Saturation } \\
\text { cum\%PV }\end{array}$ & $\begin{array}{l}100 \mathrm{Hg}(\mathrm{wp}) \\
\text { Saturation } \\
\text { cum\%PV }\end{array}$ & $\begin{array}{l}\text { Leverett } \\
\text { "J" } \\
\text { Function }\end{array}$ & $\begin{array}{l}\text { Gas/Brine } \\
\text { Pc (psia) }\end{array}$ & $\begin{array}{l}\text { Gas/Oil } \\
\text { Pc (psia) }\end{array}$ & $\begin{array}{c}\text { Oil/Brine } \\
\text { Pc (psia) }\end{array}$ & $\begin{array}{l}\text { Ht. Above } \\
\text { Free Water } \\
\text { (ft.) } \\
\text { Gas/Brine }\end{array}$ & $\begin{array}{l}\text { Ht. Above } \\
\text { Free Water } \\
\text { (ft.) } \\
\text { Oil/Brine }\end{array}$ \\
\hline 2760.55 & 0.0773 & 3.0 & 97.0 & 0.09 & 375.4 & 179.4 & 226.4 & 952 & 2010 \\
\hline 2996.28 & 0.0712 & 3.6 & 96.4 & 0.09 & 407.5 & 194.8 & 245.7 & 1034 & 2181 \\
\hline 3256.51 & 0.0655 & 4.2 & 95.8 & 0.10 & 442.9 & 211.7 & 267.0 & 1123 & 2371 \\
\hline 3537.98 & 0.0603 & 4.8 & 95.2 & 0.11 & 481.2 & 230.0 & 290.1 & 1221 & 2576 \\
\hline 3851.07 & 0.0554 & 5.7 & 94.3 & 0.12 & 523.7 & 250.3 & 315.8 & 1329 & 2804 \\
\hline 4179.97 & 0.0510 & 6.6 & 93.4 & 0.13 & 568.5 & 271.7 & 342.8 & 1442 & 3043 \\
\hline 4544.44 & 0.0469 & 7.6 & 92.4 & 0.14 & 618.0 & 295.4 & 372.6 & 1568 & 3308 \\
\hline 4939.21 & 0.0432 & 8.5 & 91.5 & 0.16 & 671.7 & 321.0 & 405.0 & 1704 & 3596 \\
\hline 5368.60 & 0.0397 & 9.7 & 90.3 & 0.17 & 730.1 & 349.0 & 440.2 & 1852 & 3908 \\
\hline 5834.39 & 0.0366 & 10.9 & 89.1 & 0.18 & 793.5 & 379.2 & 478.4 & 2013 & 4247 \\
\hline 6338.73 & 0.0337 & 12.1 & 87.9 & 0.20 & 862.1 & 412.0 & 519.8 & 2187 & 4615 \\
\hline 6888.21 & 0.0310 & 13.6 & 86.4 & 0.22 & 936.8 & 447.7 & 564.8 & 2376 & 5015 \\
\hline 7487.09 & 0.0285 & 15.4 & 84.6 & 0.24 & 1018 & 486.7 & 613.9 & 2583 & 5451 \\
\hline 8138.55 & 0.0262 & 17.2 & 82.8 & 0.26 & 1107 & 529.0 & 667.4 & 2808 & 5925 \\
\hline 8845.11 & 0.0241 & 19.3 & 80.7 & 0.28 & 1203 & 574.9 & 725.3 & 3052 & 6439 \\
\hline 9612,22 & 0.0222 & 21.8 & 78.2 & 0.30 & 1307 & 624.8 & 788.2 & 3316 & 6998 \\
\hline 10447.48 & 0.0204 & 24.5 & 75.5 & 0.33 & 1421 & 679.1 & 856.7 & 3604 & 7606 \\
\hline 11353.03 & 0.0188 & 27.8 & 72.2 & 0.36 & 1544 & 737.9 & 930.9 & 3917 & 8265 \\
\hline 12339.43 & 0.0173 & 31.7 & 68.3 & 0.39 & 1678 & 802.1 & 1011.8 & 4257 & 8983 \\
\hline 13411.54 & 0.0159 & 37.2 & 62.8 & 0.42 & 1824 & 871.8 & 1099.7 & 4627 & 9764 \\
\hline 14575.33 & 0.0146 & 42.9 & 57.1 & 0.46 & 1982 & 947.4 & 1195.2 & 5028 & 10611 \\
\hline 15839.78 & 0.0135 & 49.5 & 50.5 & 0.50 & 2154 & 1029.6 & 1299 & 5465 & 11531 \\
\hline 17215.75 & 0.0124 & 55.9 & 44.1 & 0.54 & 2341 & 1119.0 & 1412 & 5939 & 12533 \\
\hline 18710.59 & 0.0114 & 62.8 & 37.2 & 0.59 & 2545 & 1216.2 & 1534 & 6455 & 13621 \\
\hline 20333.80 & 0.0105 & 68.6 & 31.4 & 0.64 & 2765 & 1322 & 1667 & 7015 & 14803 \\
\hline 22098.41 & 0.0097 & 73.7 & 26.3 & 0.70 & 3005 & 1436 & 1812 & 7624 & 16088 \\
\hline 24017.81 & 0.0089 & 77.9 & 22.1 & 0.76 & 3266 & 1561 & 1969 & 8286 & 17485 \\
\hline 26101.46 & 0.0082 & 81.9 & 18.1 & 0.82 & 3550 & 1697 & 2140 & 9005 & 19002 \\
\hline 28368.62 & 0.0075 & 85.2 & 14.8 & 0.90 & 3858 & 1844 & 2326 & 9787 & 20652 \\
\hline 30830.17 & 0.0069 & 87.9 & 12.1 & 0.97 & 4193 & 2004 & 2528 & 10636 & 22444 \\
\hline 33504.97 & 0.0064 & 90.3 & 9.7 & 1.06 & 4557 & 2178 & 2747 & 11559 & 24392 \\
\hline 36415.91 & 0.0059 & 92.4 & 7.6 & 1.15 & 4953 & 2367 & 2986 & 12563 & 26511 \\
\hline 39573.81 & 0.0054 & 94.3 & 5.7 & 1.25 & 5382 & 2572 & 3245 & 13653 & 28810 \\
\hline 43008.77 & 0.0050 & 95.8 & 4.2 & 1.36 & 5849 & 2796 & 3527 & 14838 & 31310 \\
\hline 46741.96 & 0.0046 & 97.3 & 2.7 & 1.48 & 6357 & 3038 & 3833 & 16126 & 34028 \\
\hline 50798.15 & 0.0042 & 98.5 & 1.5 & 1.60 & 6909 & 3302 & 4165 & 17525 & 36981 \\
\hline 55206.60 & 0.0039 & 99.4 & 0.6 & 1.74 & 7508 & 3588 & 4527 & 19046 & 40190 \\
\hline 59990.63 & 0.0036 & 100.0 & 0.0 & 1.89 & 8159 & 3899 & 4919 & 20697 & 43673 \\
\hline
\end{tabular}




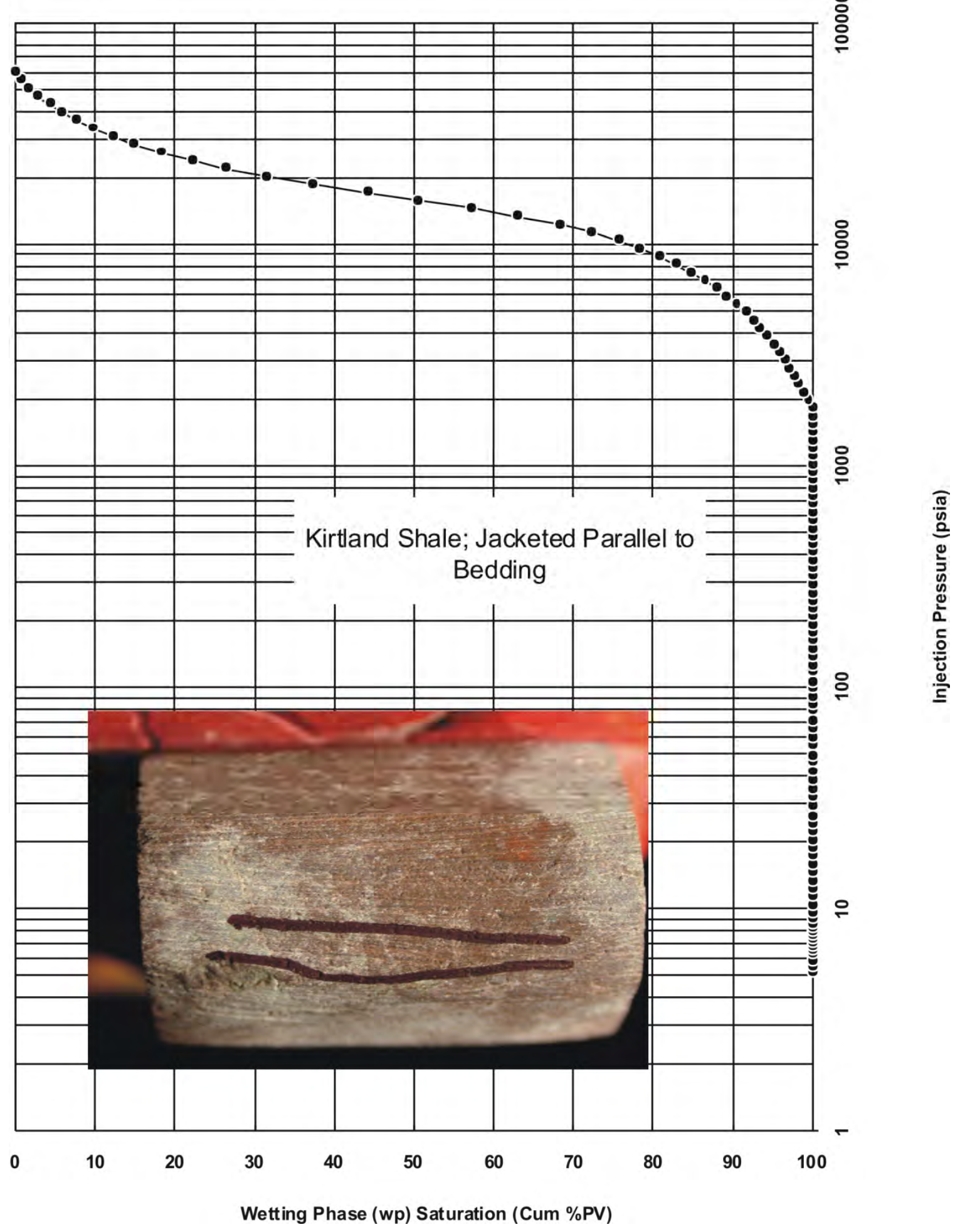




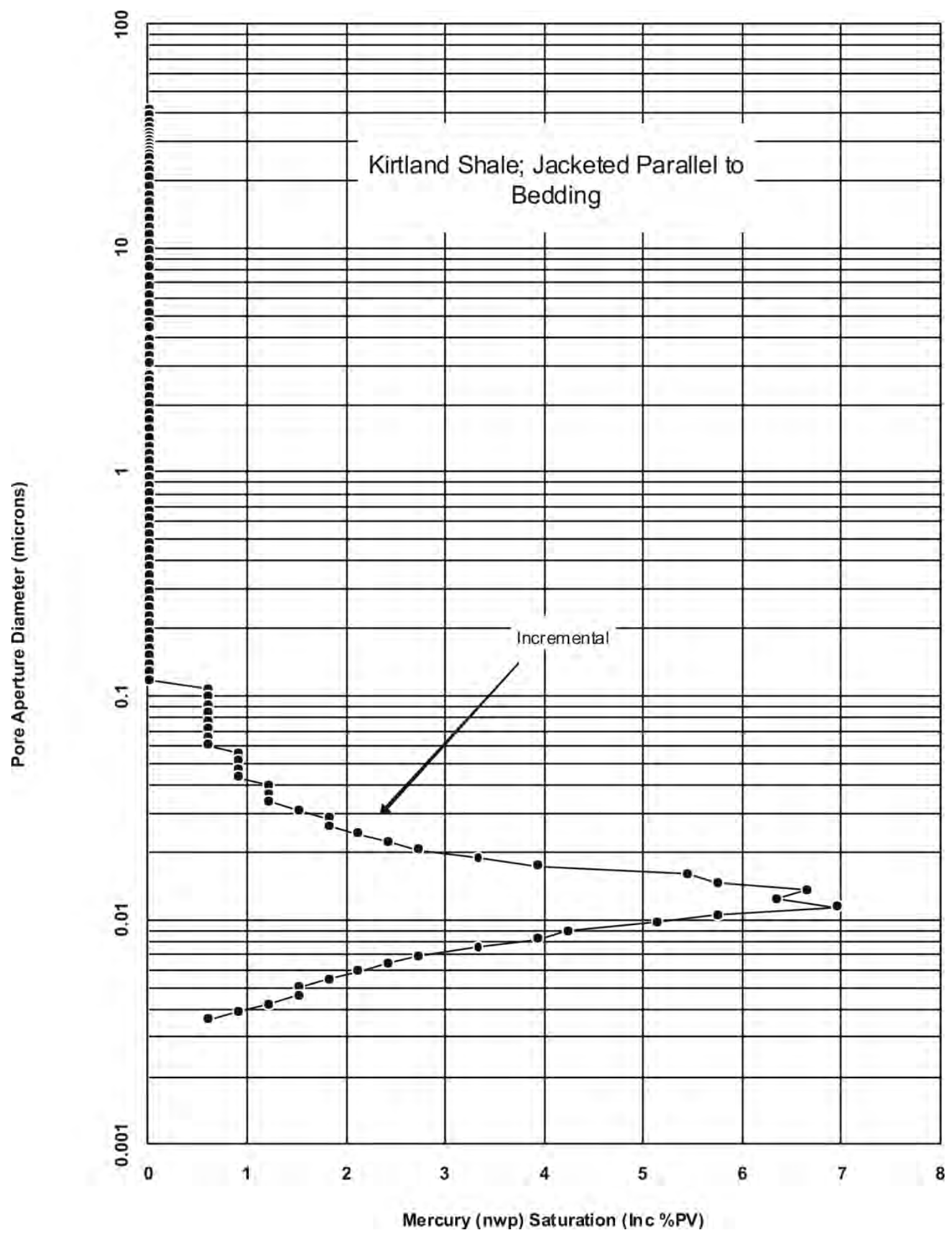




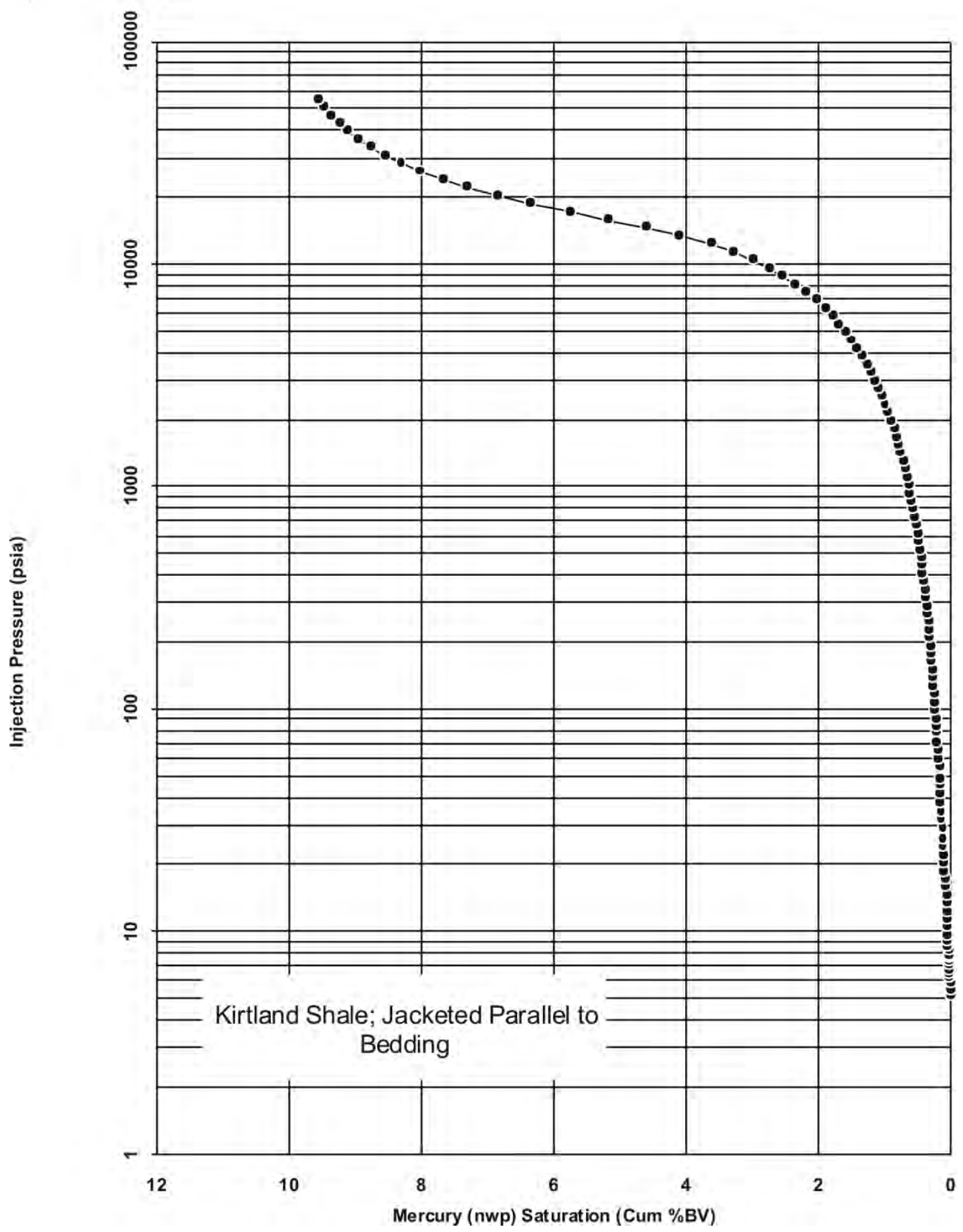




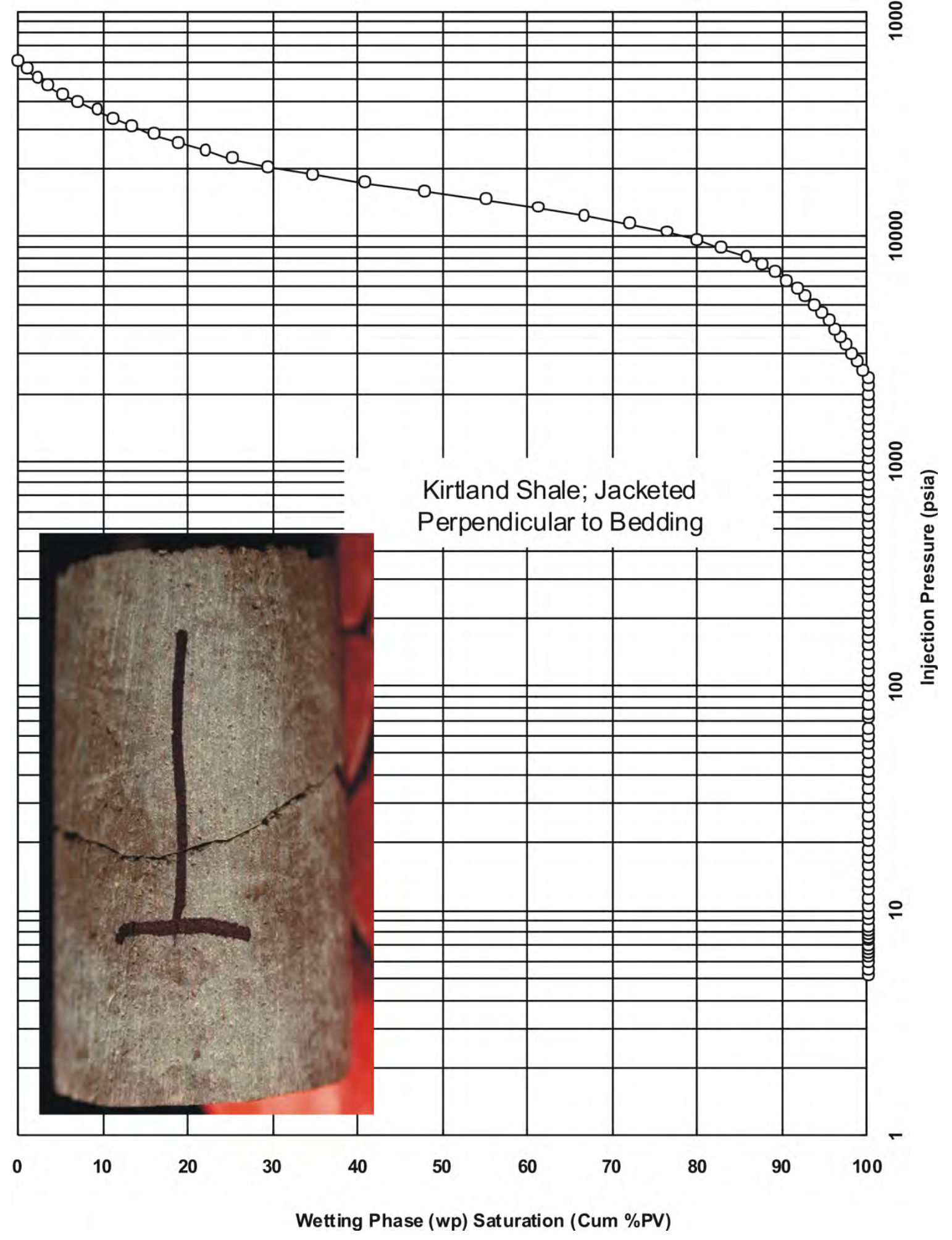




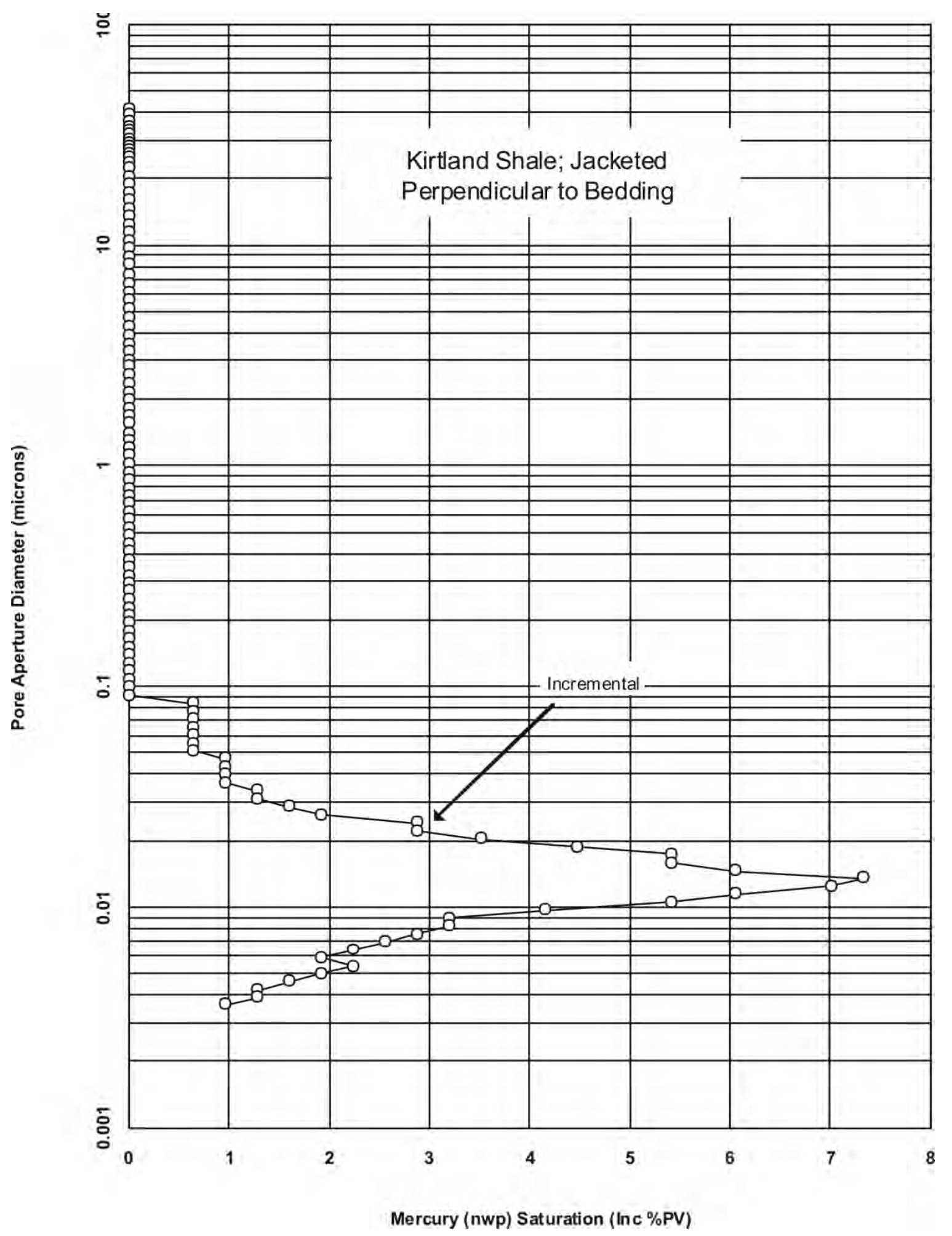




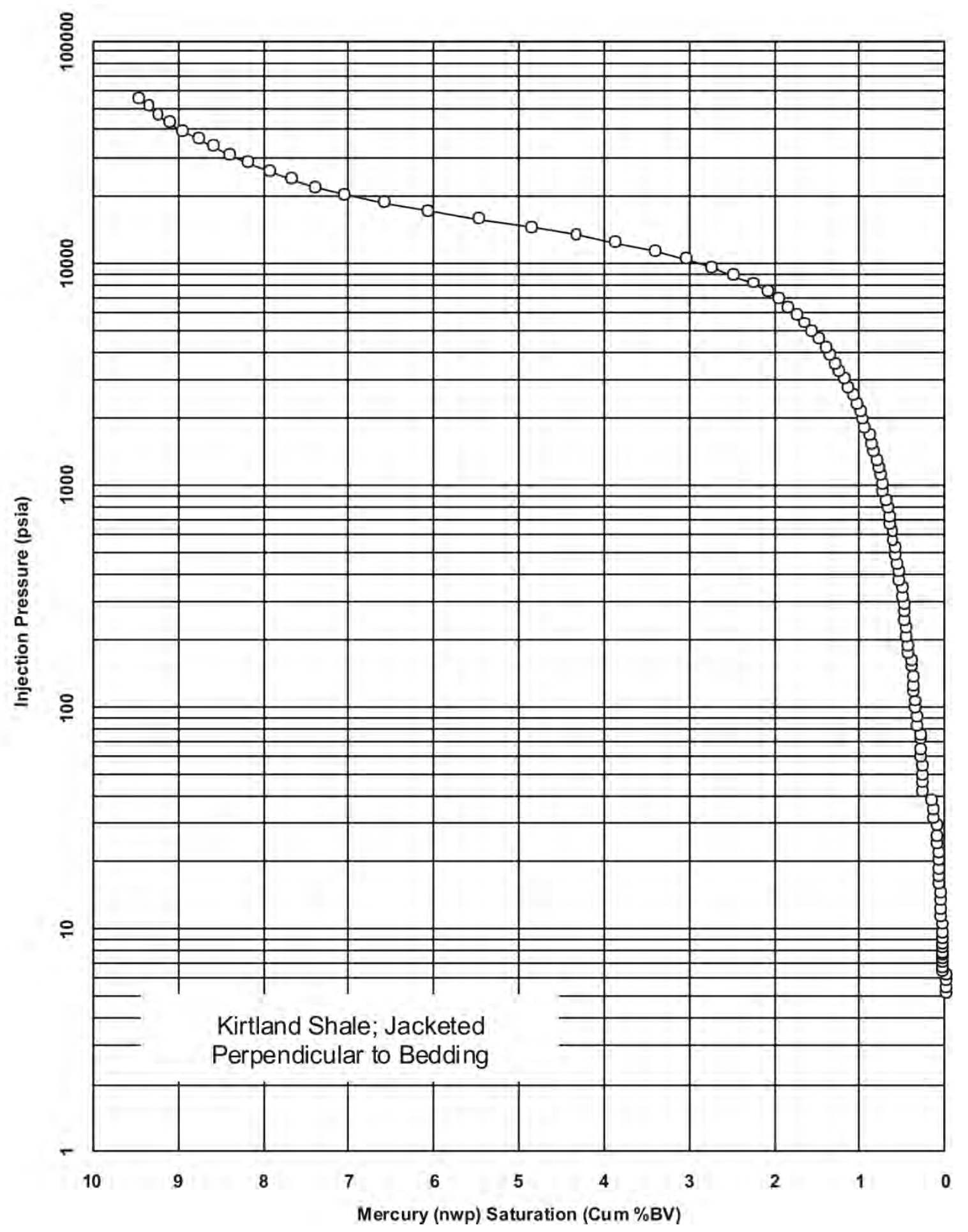




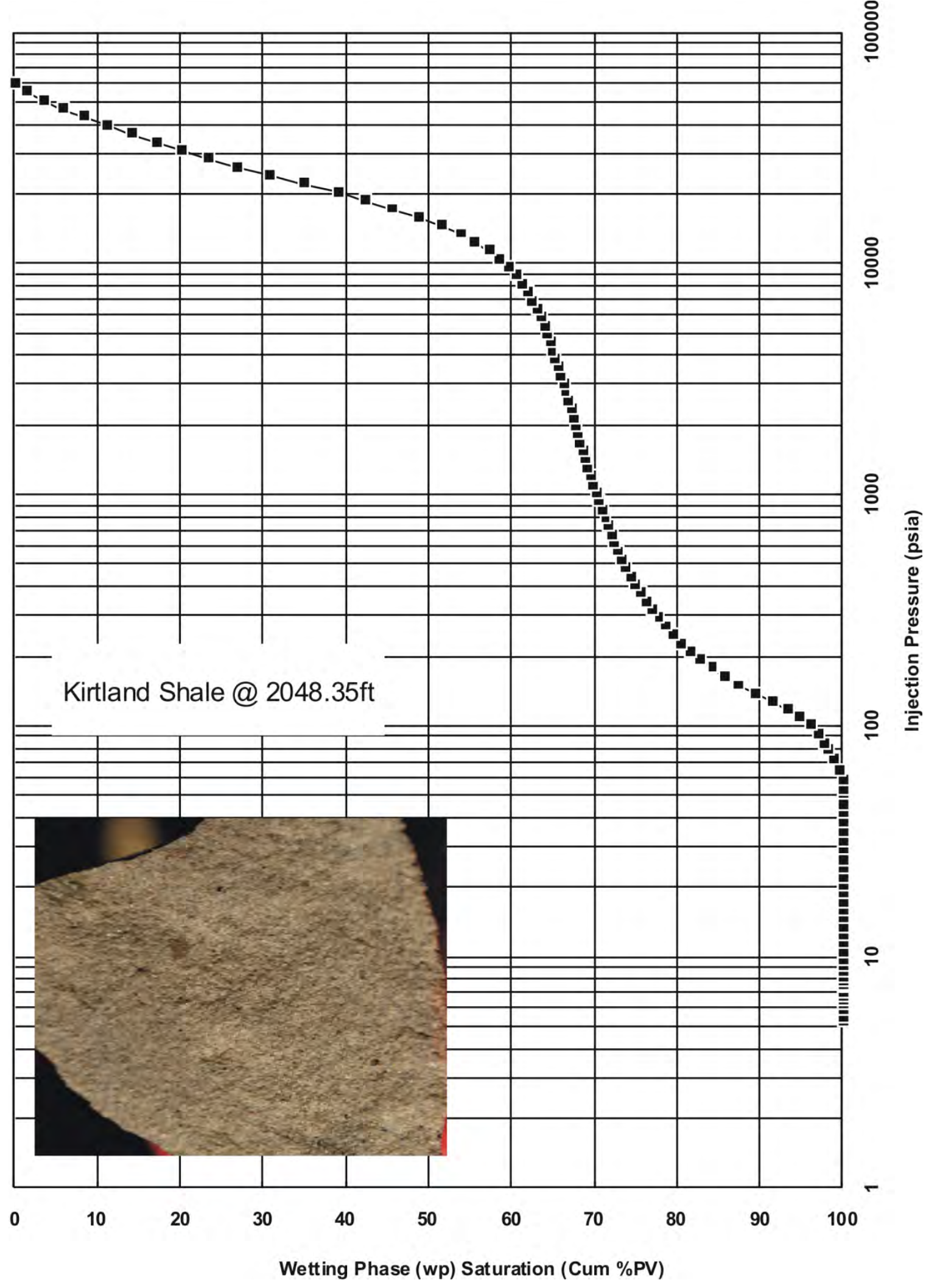




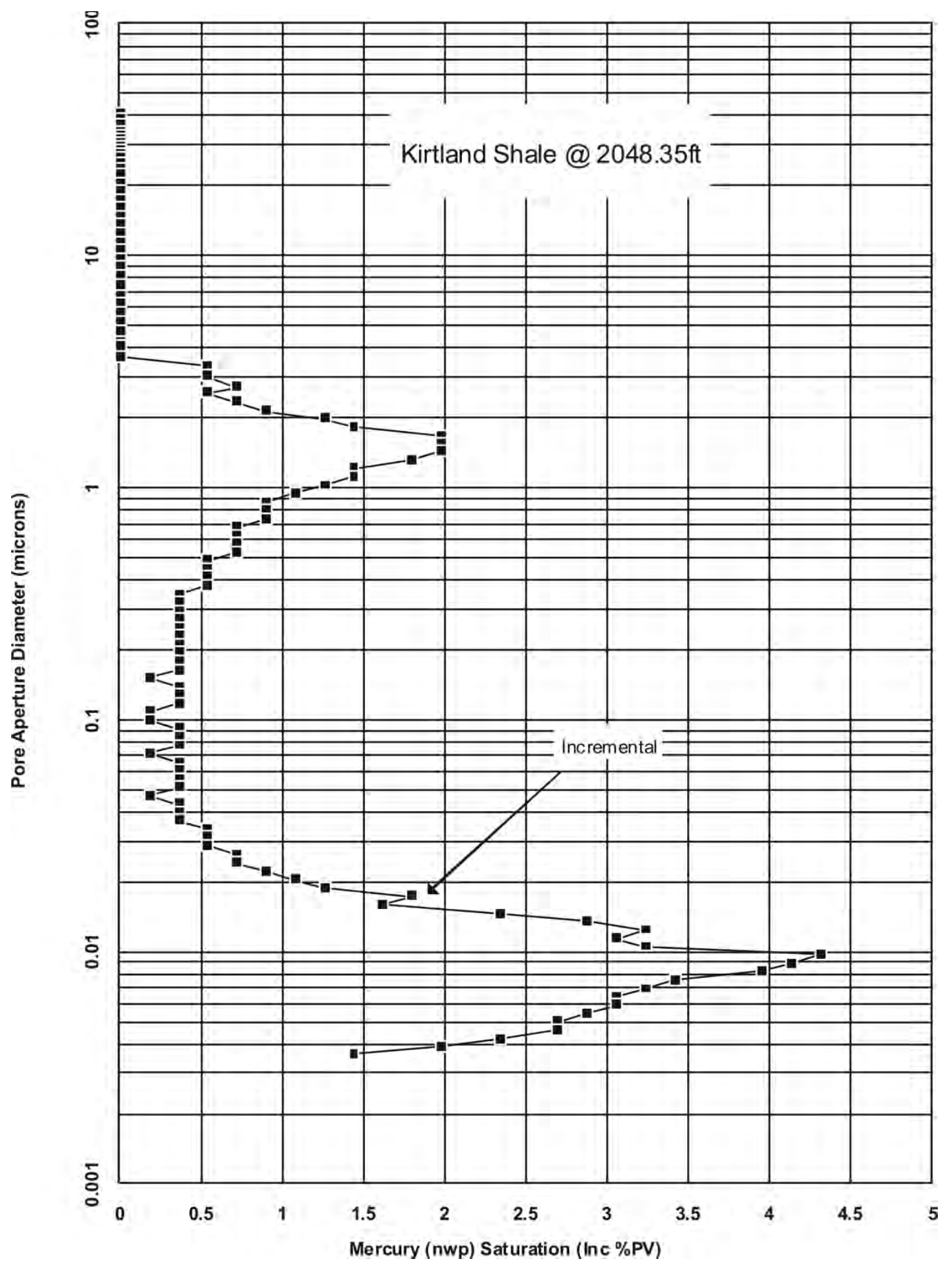




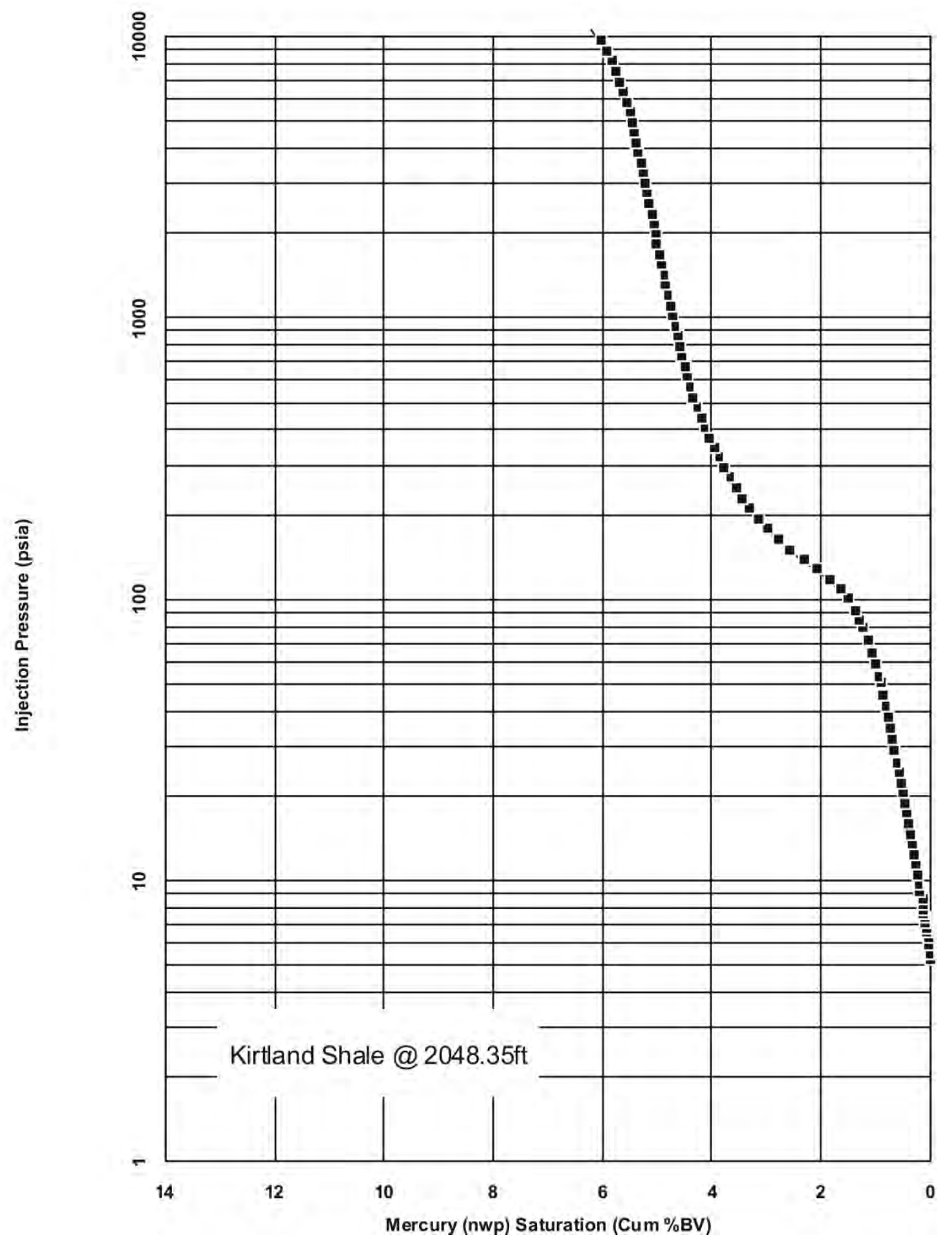



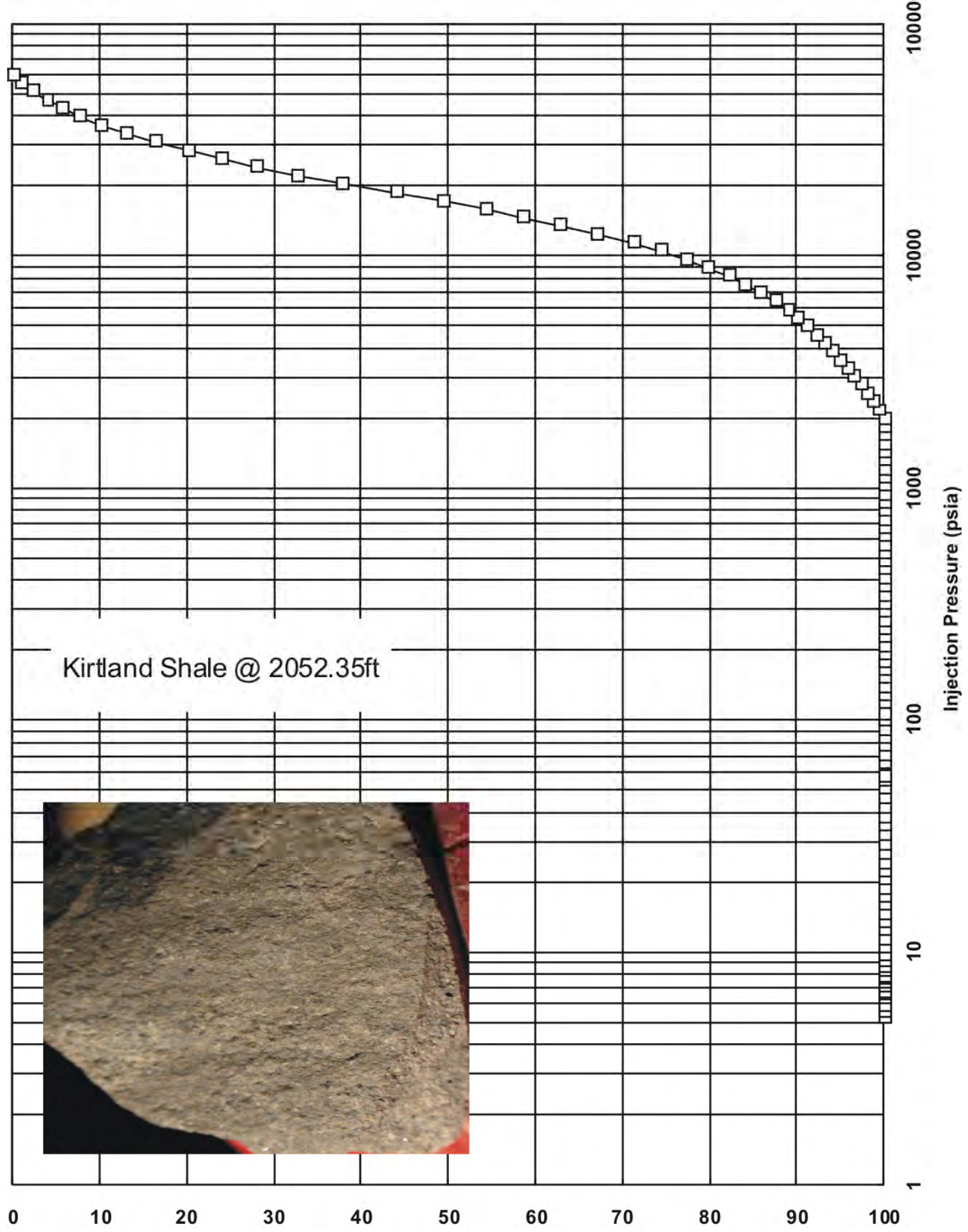

Wetting Phase (wp) Saturation (Cum \%PV) 


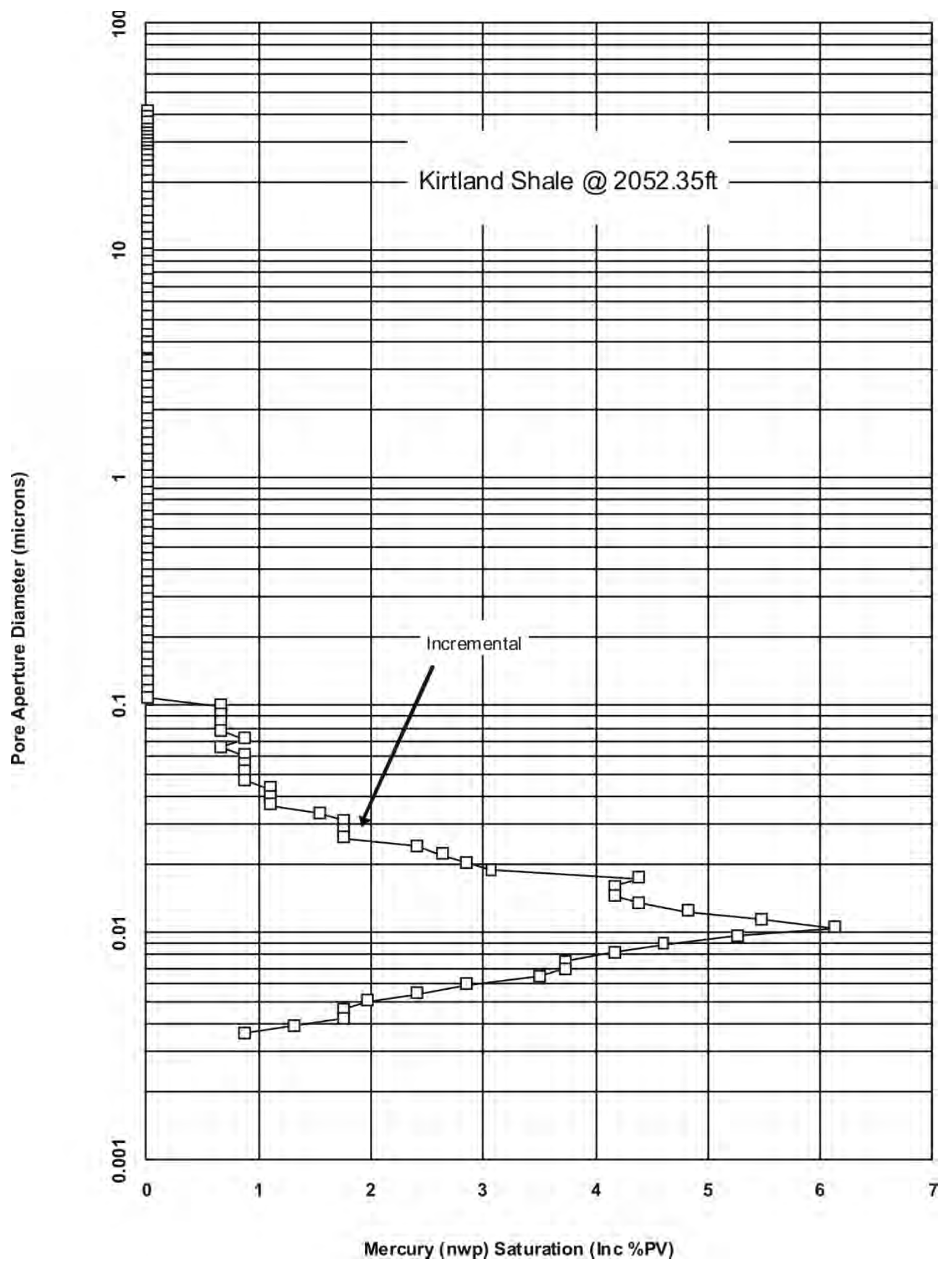




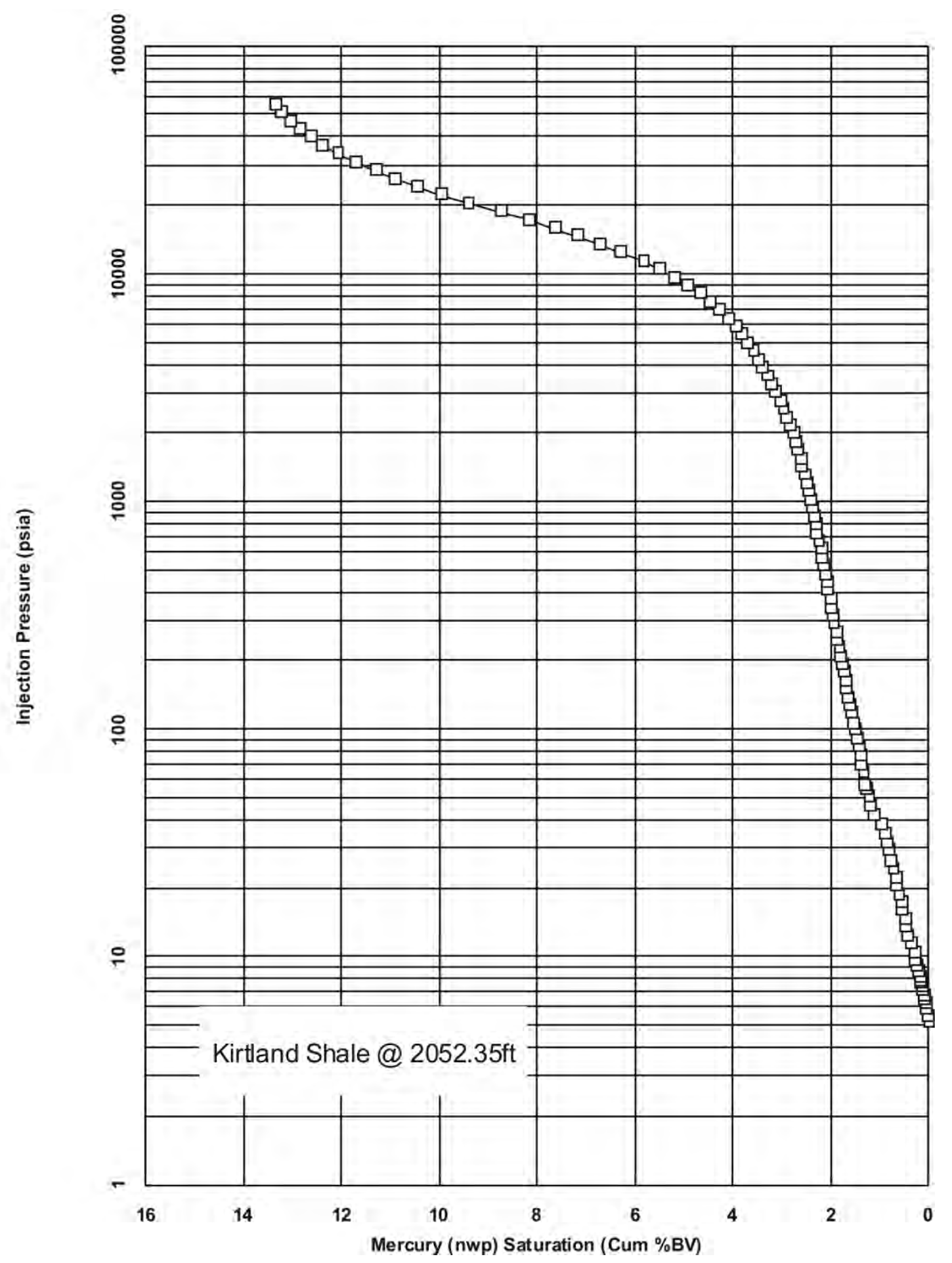




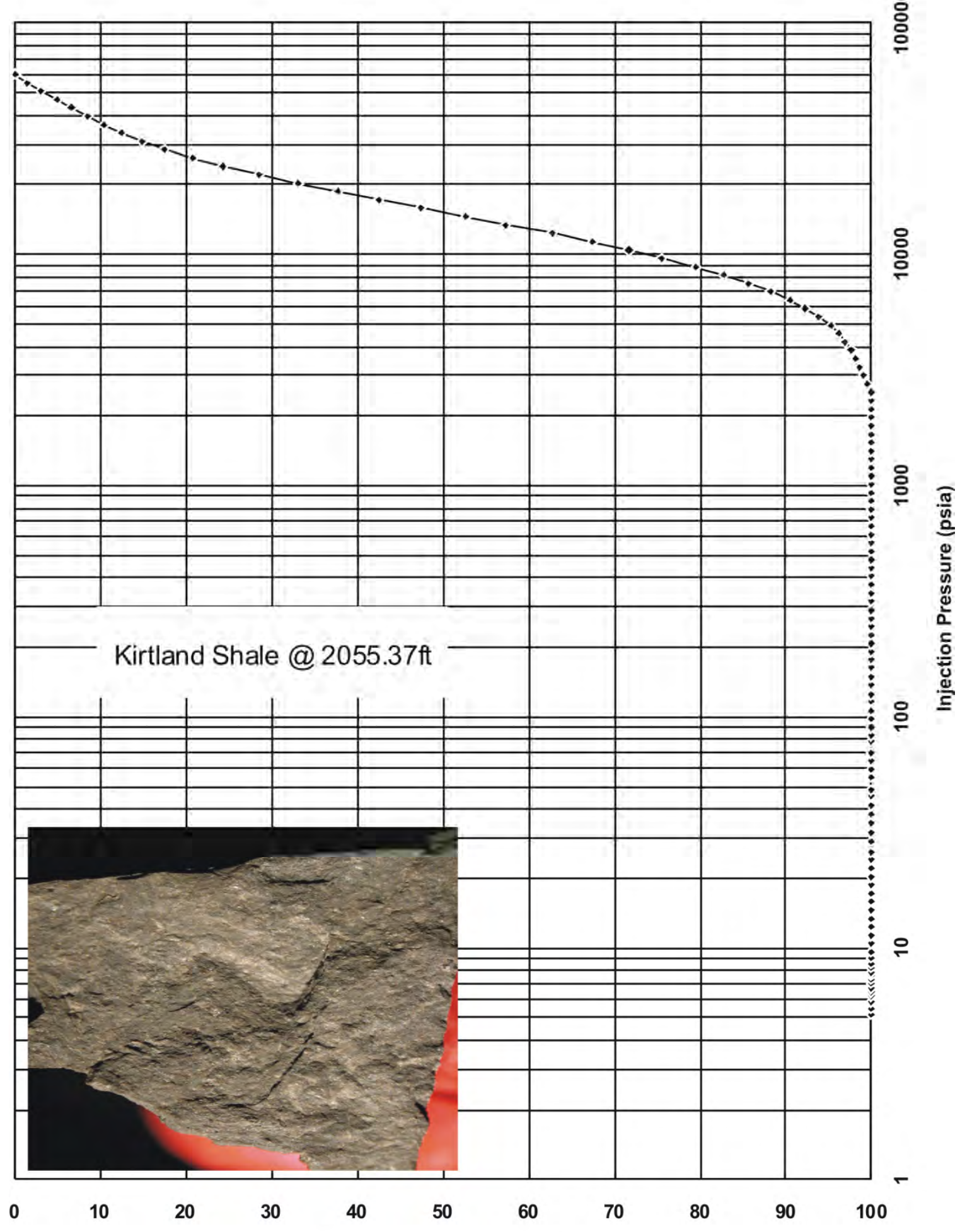

Wetting Phase (wp) Saturation (Cum \%PV) 


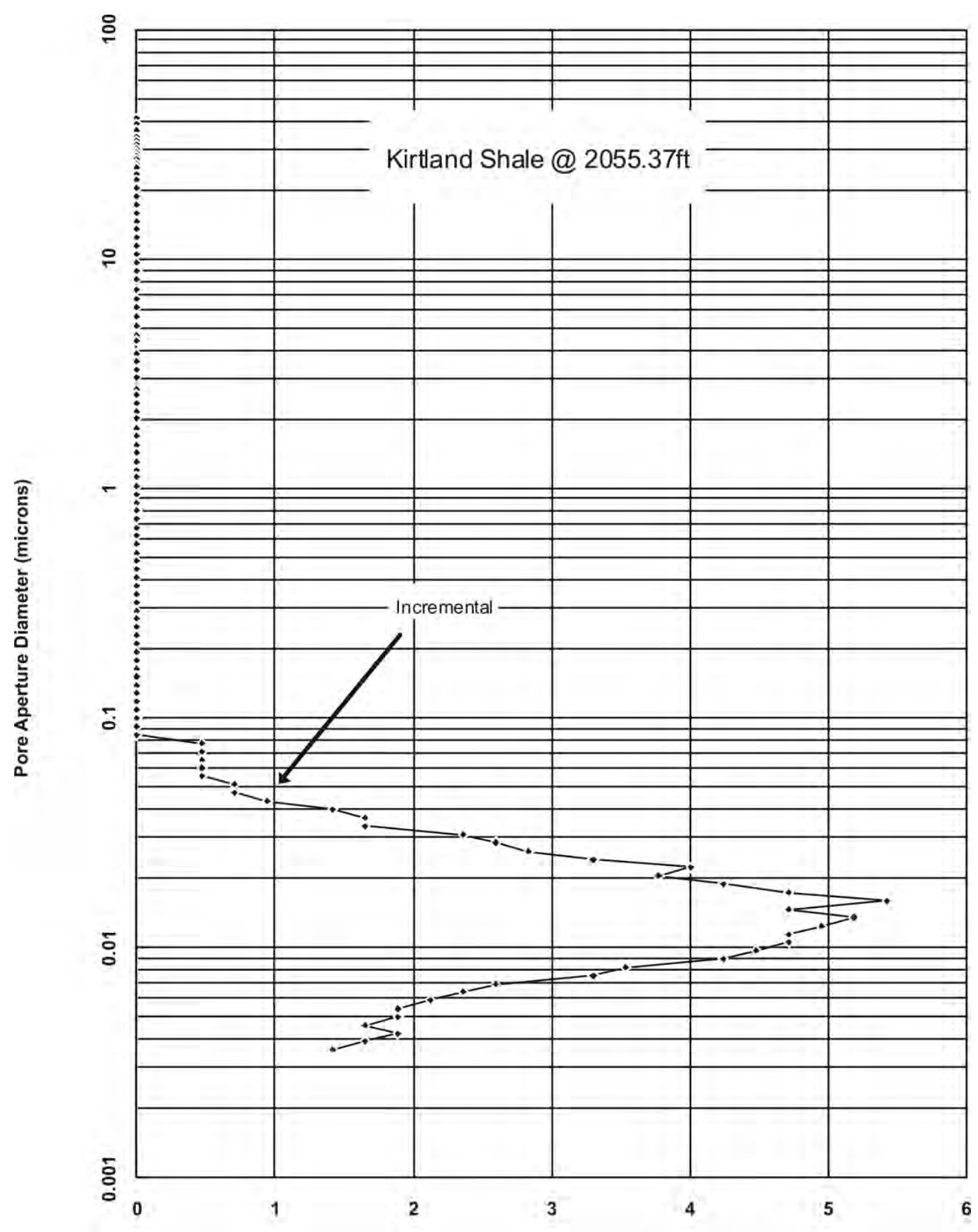

Mercury (nwp) Saturation (Inc \%PV) 


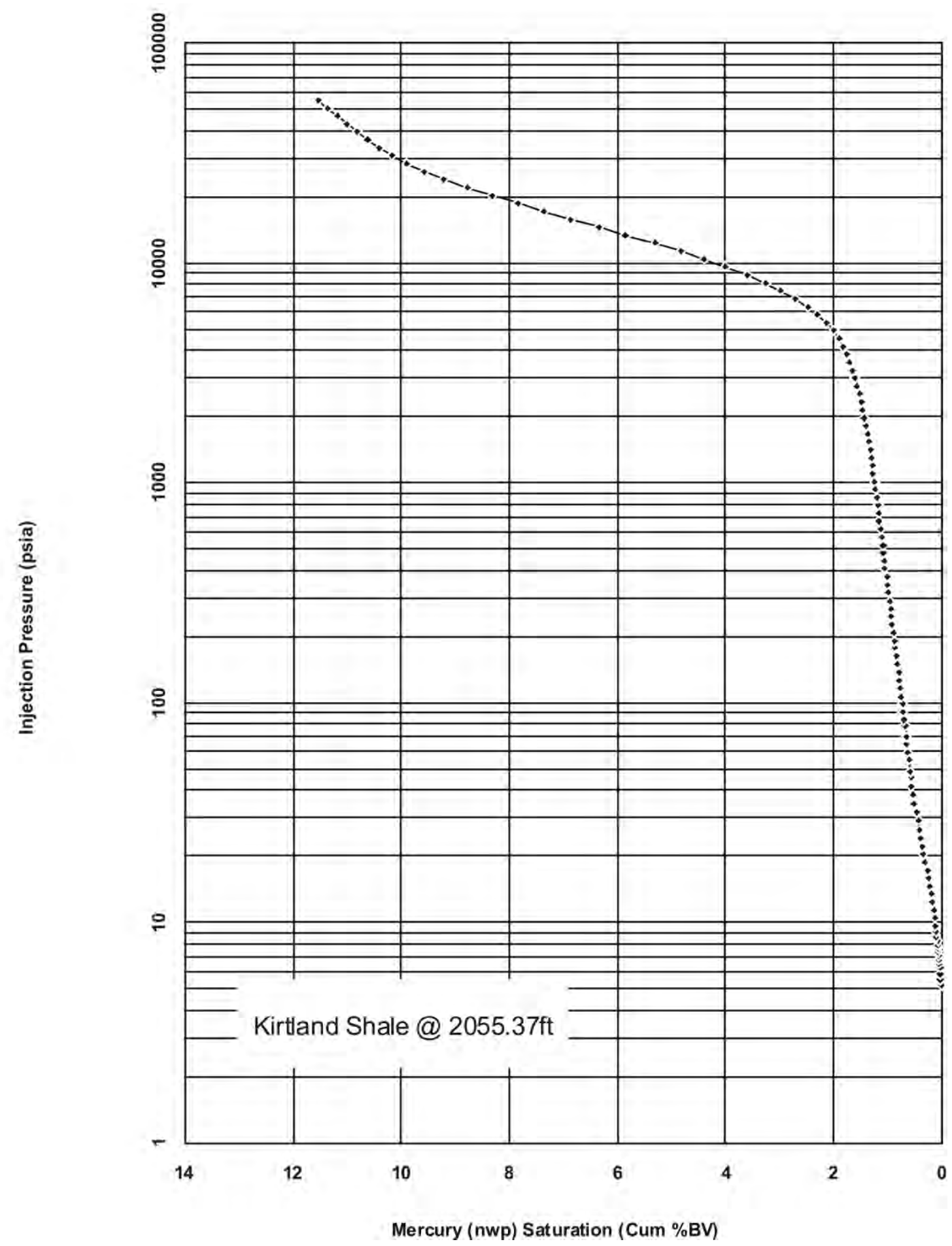




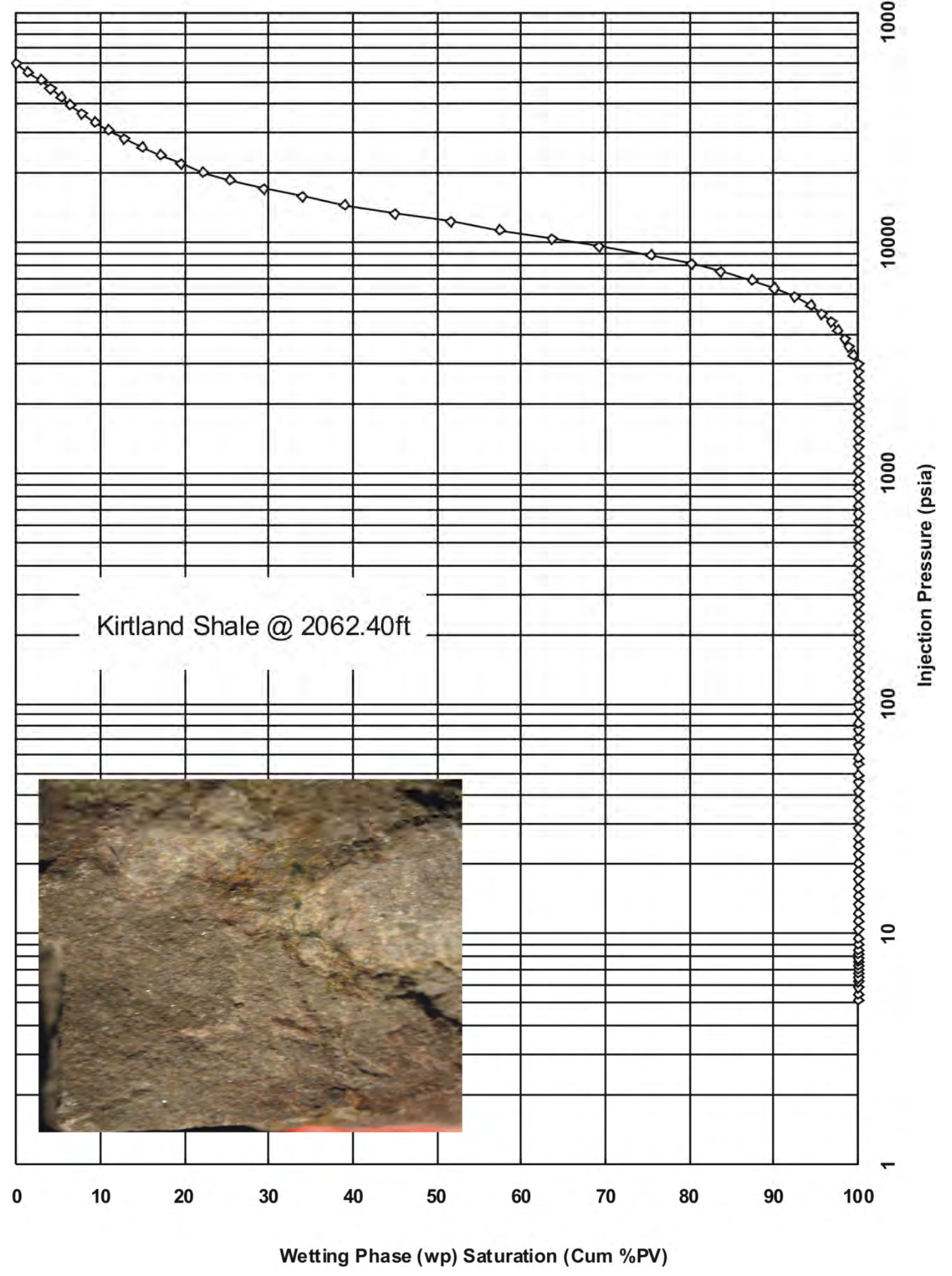




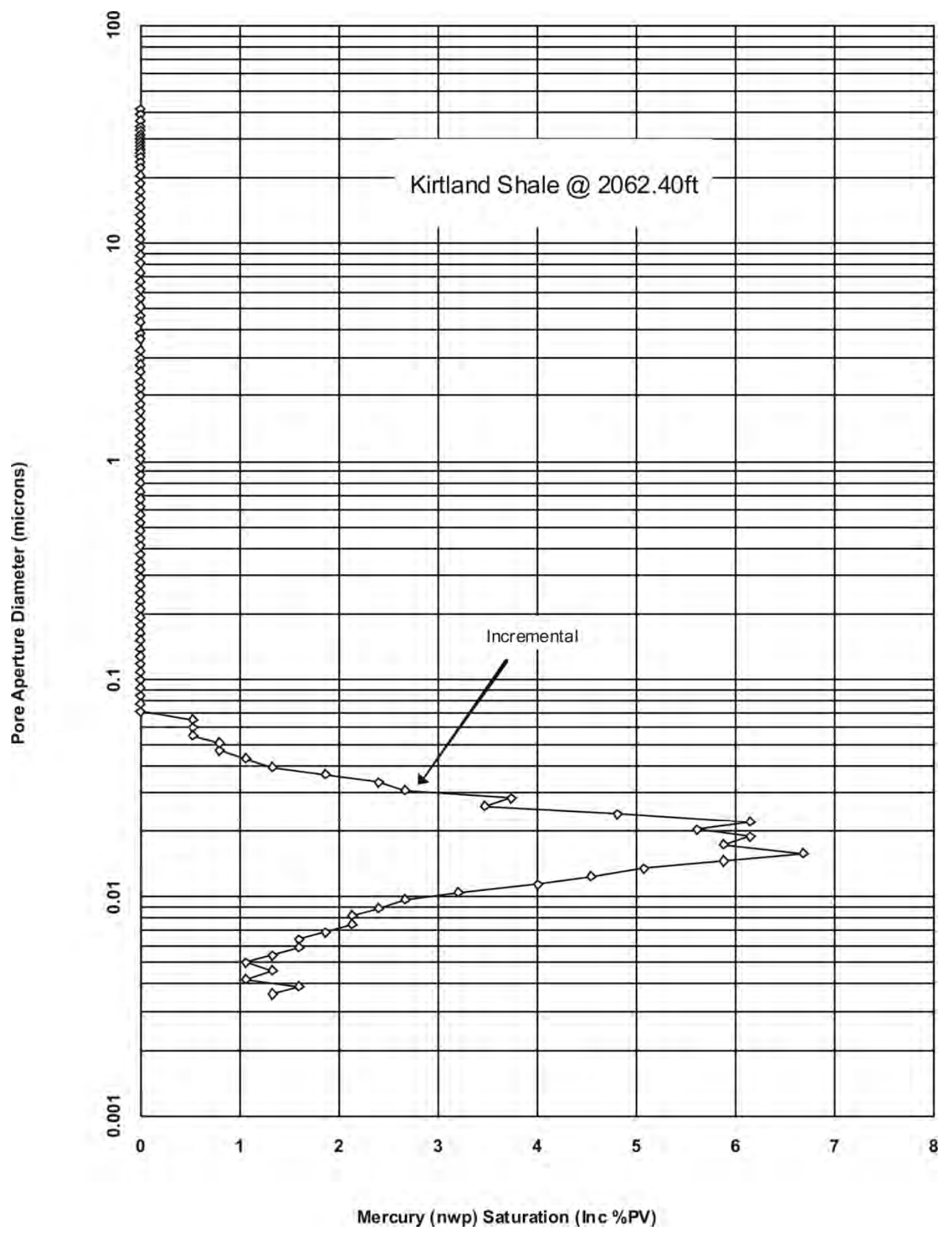




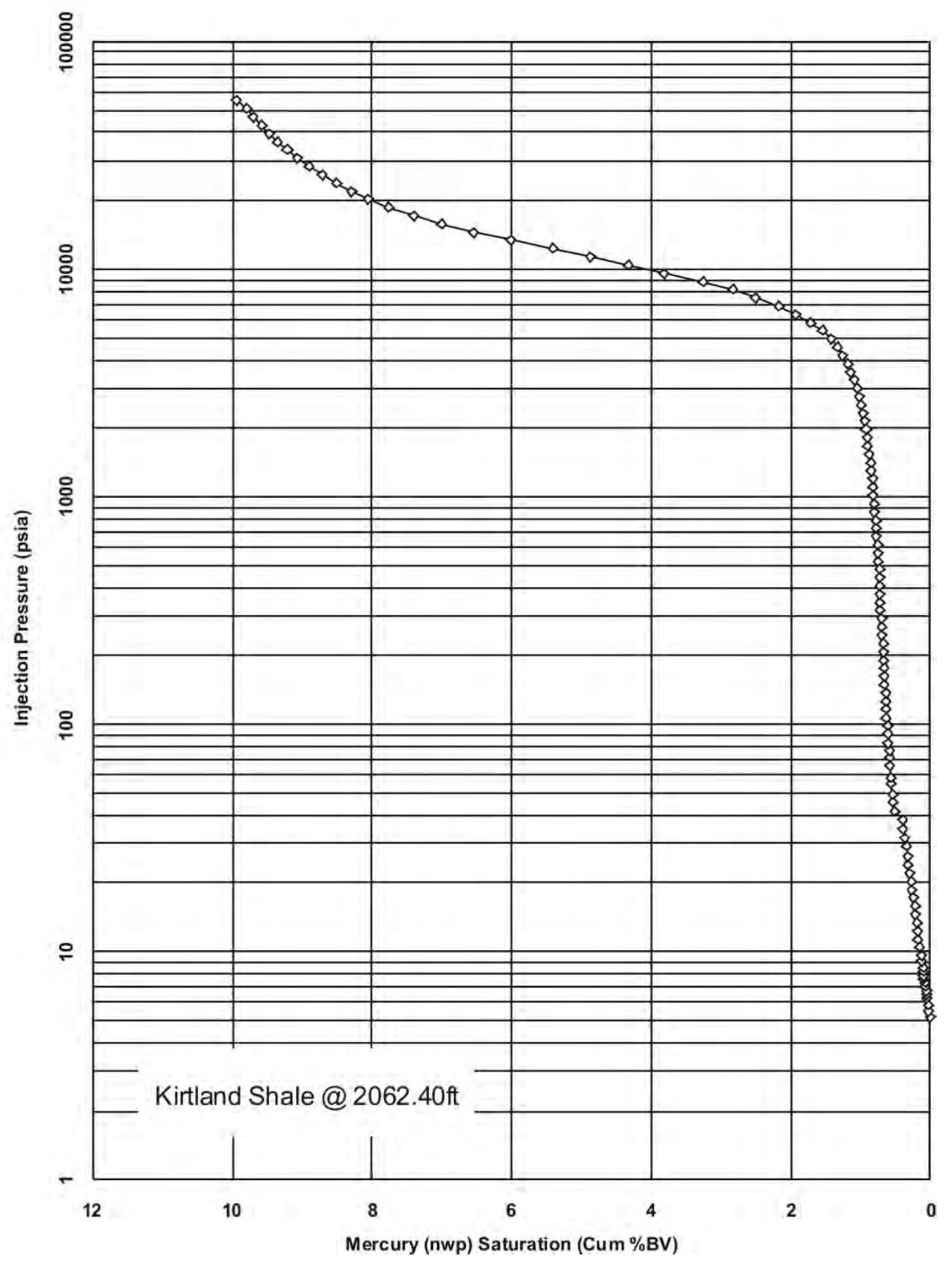




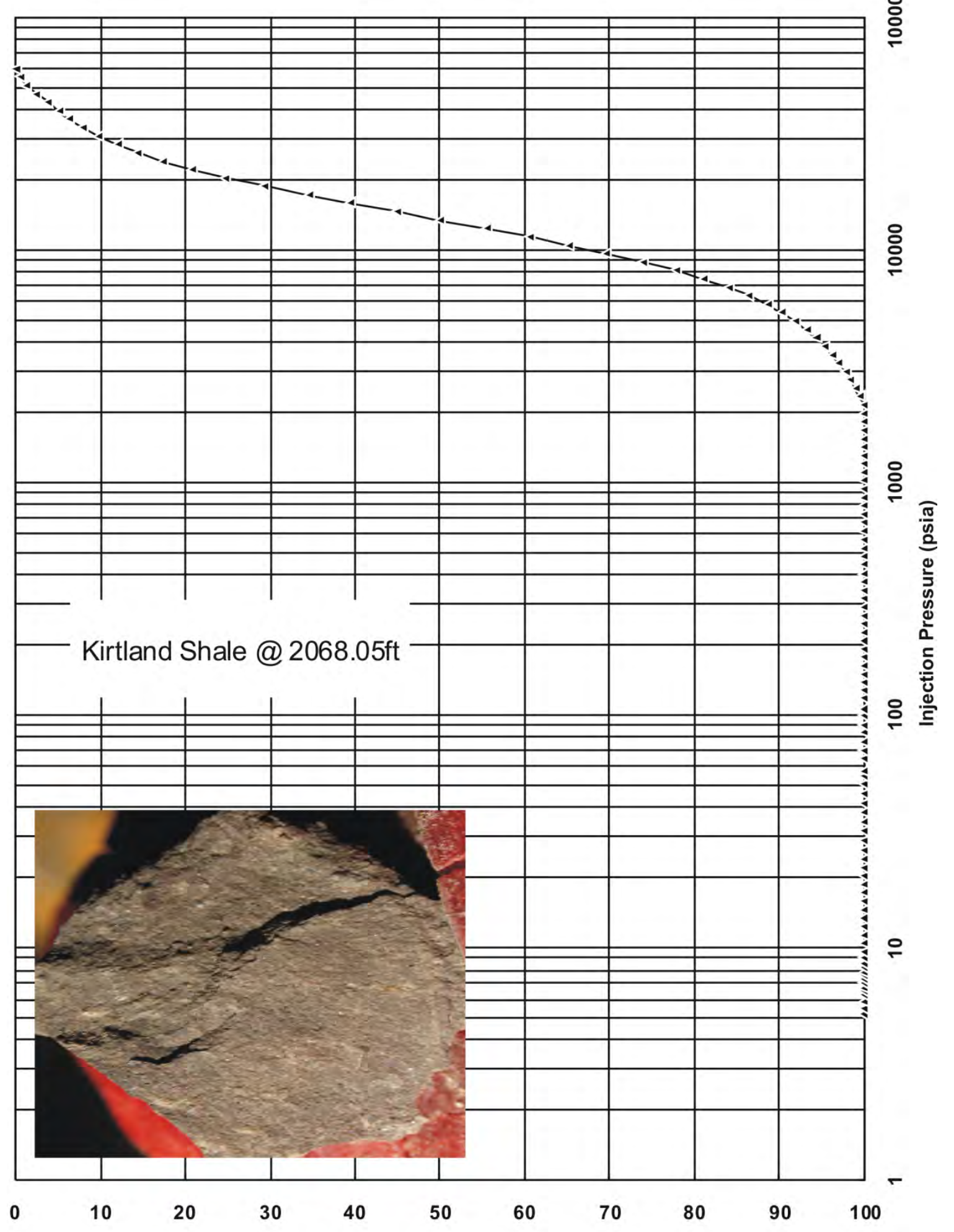

Wetting Phase (wp) Saturation (Cum \%PV) 


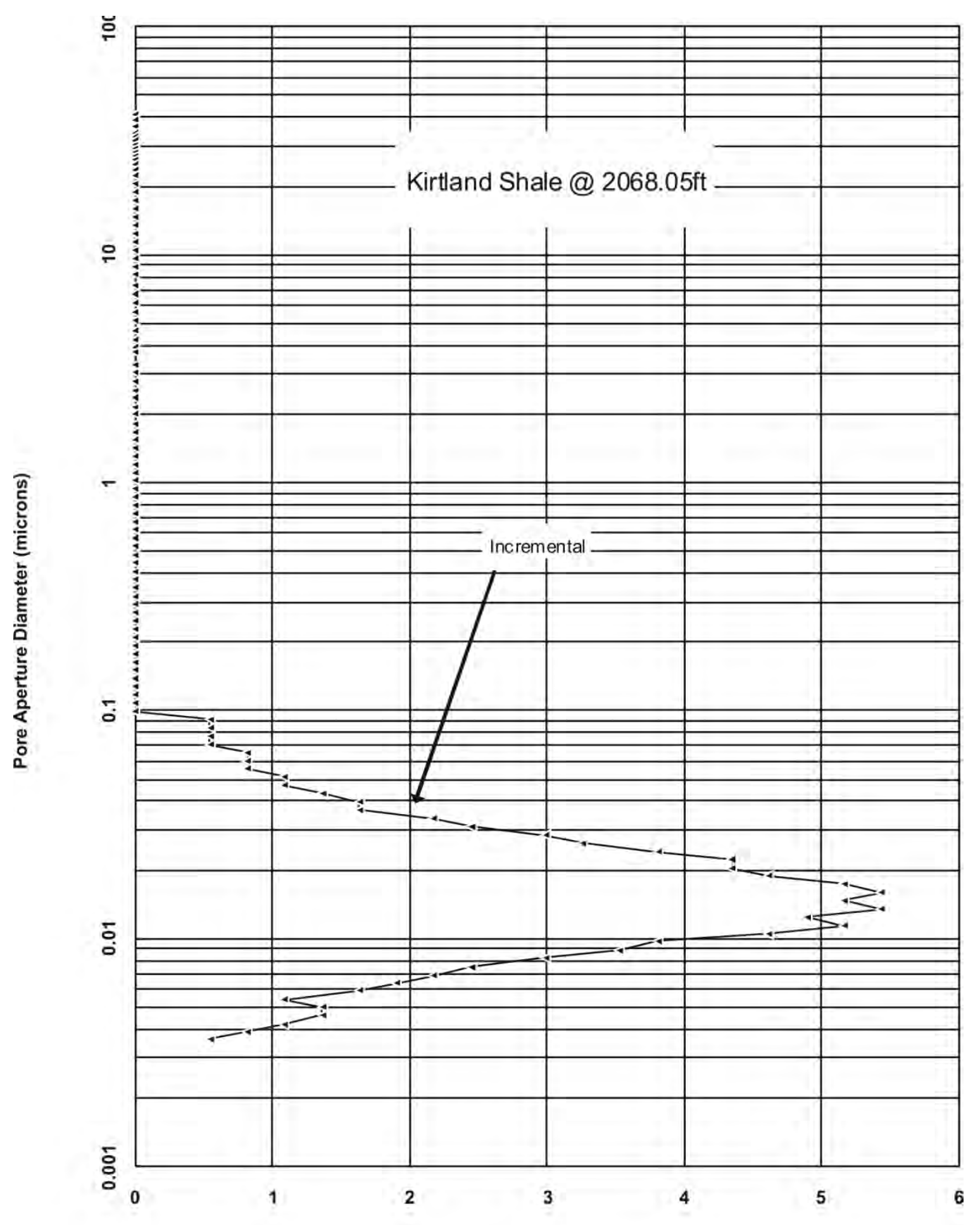

Mercury (nwp) Saturation (Inc \%PV) 


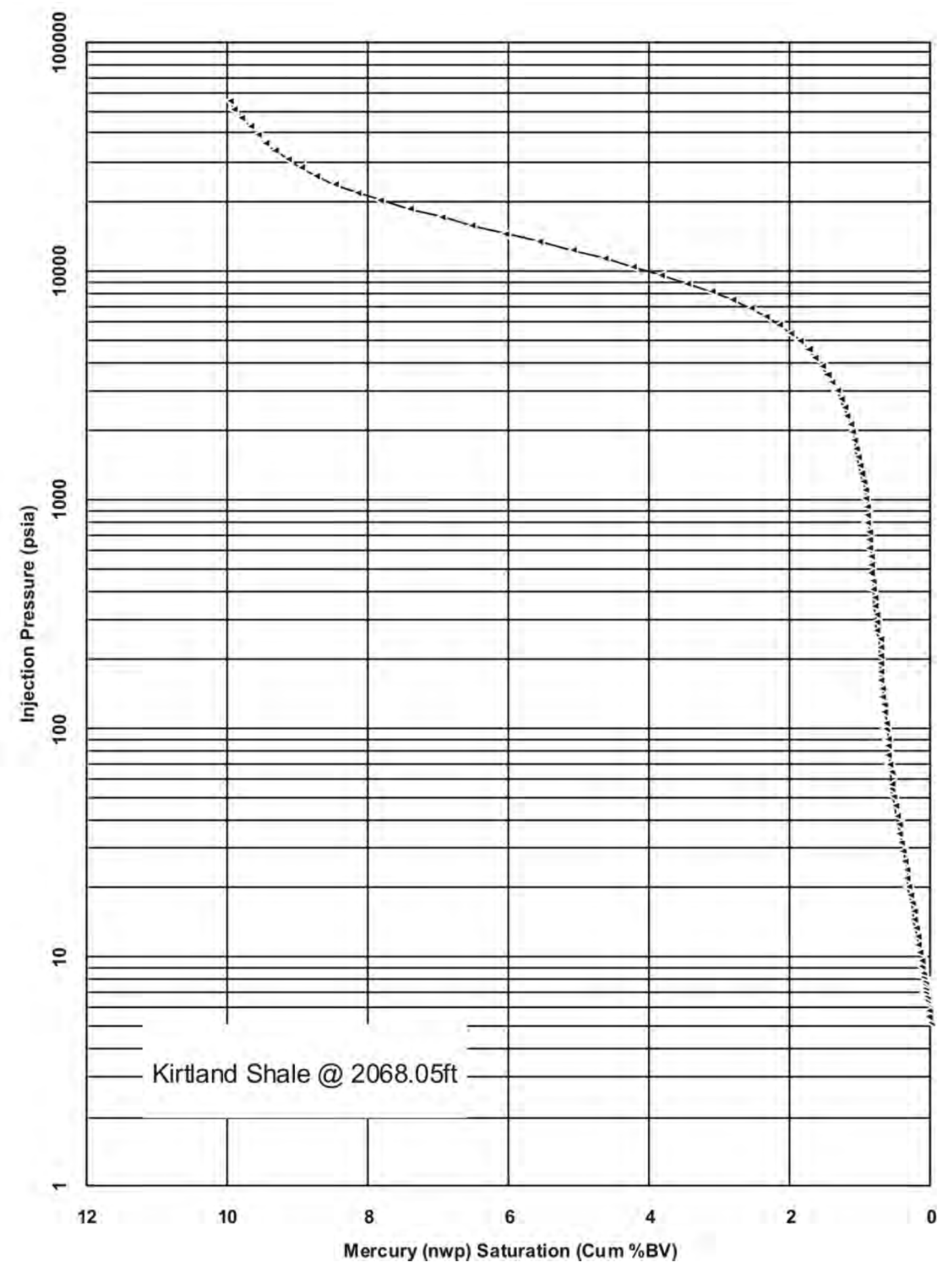




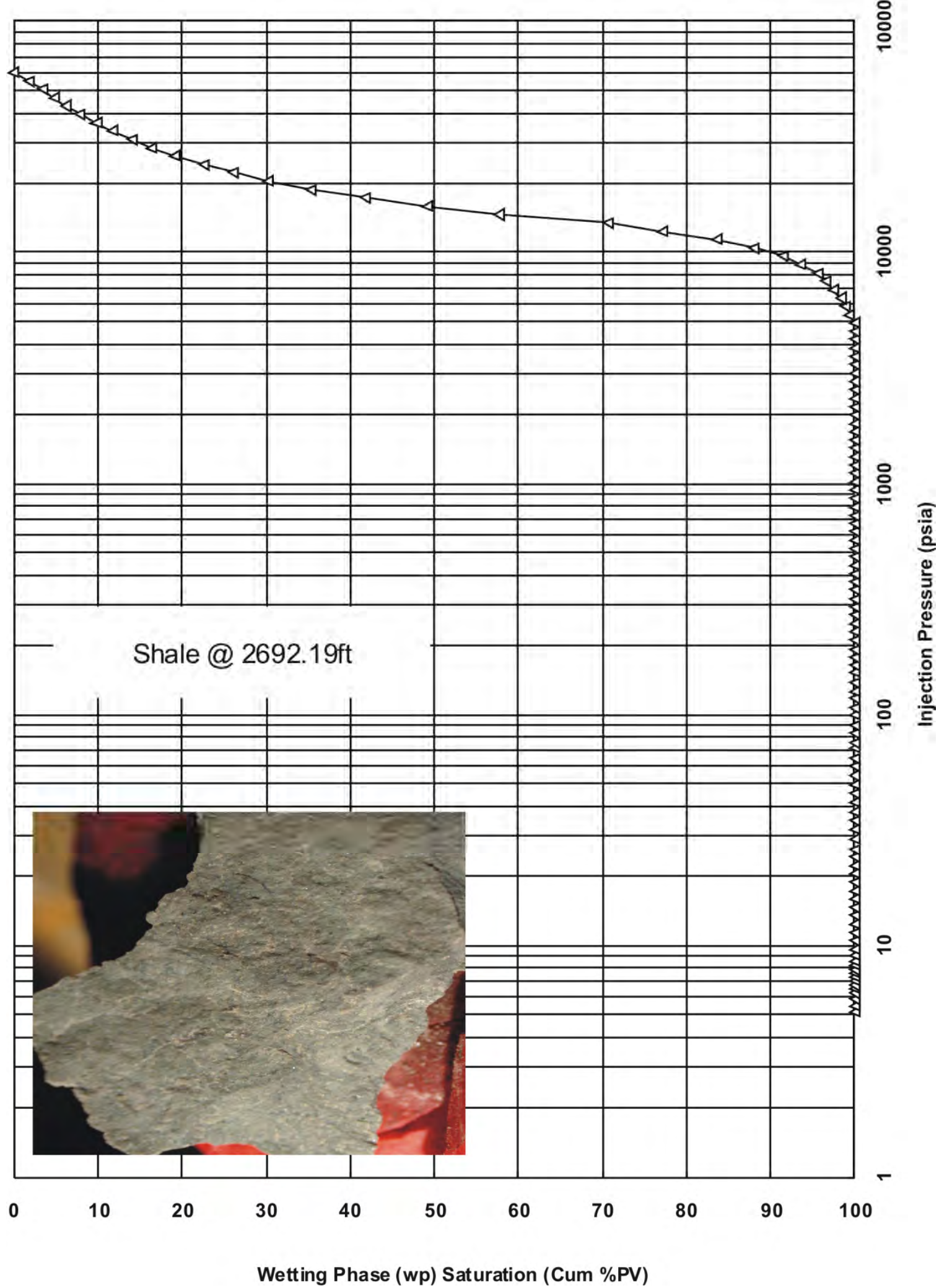




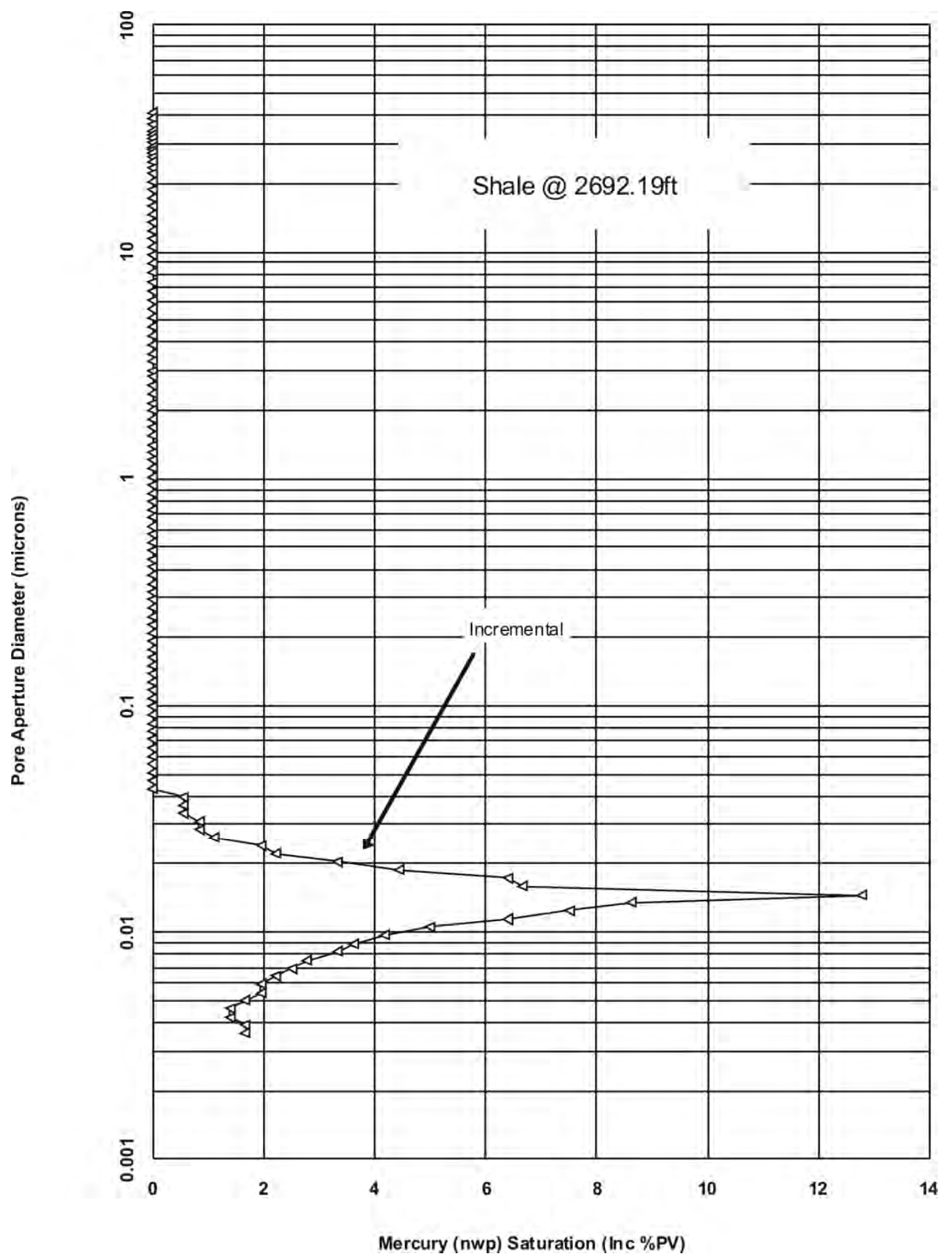




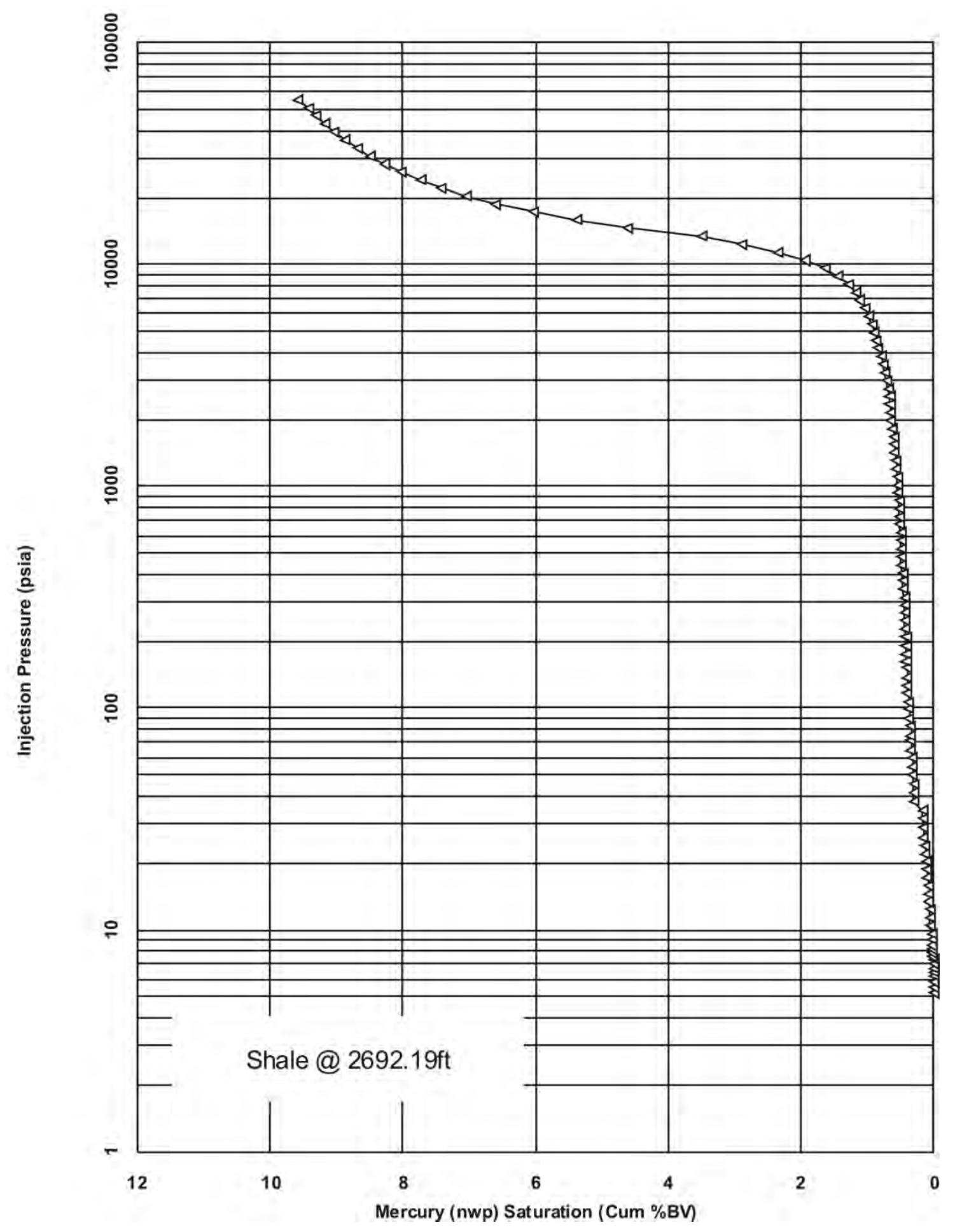




\section{Appendix D. Inventory of Thin Sections and Billets}

In addition to thin sections made by TerraTek, 21 additional thin sections and 21 billets (i.e., "thick" sections) were made by Wagner Petrographic, Lindon, UT, to support: 1) lithologic characterization of core at additional depths; 2) investigation of natural, mineralization fractures found in the core; and 3) laser scanning confocal microscopy at scanning penetration depths greater than the typical $30 \mu \mathrm{m}$ of a standard thin section.

Each billet corresponds to a thin section - a cut was made in the rock samples such that the two adjacent surfaces made from the cut would be polished surfaces of a thin section and billet. Thus, the surfaces of the thin sections and billets were essentially mirror images of each other except for the loss of rock material for the cut and polishing. Many of the thin sections and billets were studied with electron microscopy, standard petrographic techniques, and laser scanning confocal microsopy.

Preparation of thin sections commissioned by TerraTek followed methods given in Appendix B.1. Preparation of additional thin sections and billets followed similar methods except that they were not stained, and they were polished in oil. All samples were impregnated with a low-viscosity fluorescent red-dye epoxy resin under high vacuum. The billet size corresponded approximately with the $24 \mathrm{~mm} \times 46 \mathrm{~mm}$ of the standard thin sections, and the thickness was between $\sim 0.010$ to $<0.018 \mathrm{~m}$.

Figures in this appendix only show thin sections and not the corresponding billet. Billets were made for all thin section except those obtained by TerraTek. All thin sections were color scanned at 1200 dpi as "TIFF" files for use in documentation of locations of microscopic investigation (Figures D.1 through D.4). The first line of the annotation under the thin section images gives the code used by Wagner Petrographic to identify the thin sections. The second line denotes the formation and depth ranges in $\mathrm{ft}$ with the following abbreviations:

$\mathrm{OA}=$ Ojo Alamo Sandstone

$\mathrm{UK}=$ upper shale member of the Kirtland Formation

$\mathrm{LK}=$ lower shale member of the Kirtland Formation

The remaining annotation lines, when given, provide additional information on the thin sections, such as the younging (or up) direction of the sample, where "Y.D." represents "younging direction". Typically, the notch made in many of the samples indicates the general younging direction - the notch is at the "youngest" or stratigraphic highest portion of the thin sections. 
Table D.1. Inventory of thin sections

\begin{tabular}{cccc}
\hline Wagner Petrographic Code & Formation and Depth Range & Polished & Stained \\
\hline B1; CP-1 & UK-2048.25 & & $\mathrm{x}$ \\
B2; CP-2 & UK-2052.06 & & $\mathrm{x}$ \\
B3; CP-3 & UK-2055.2 & & $\mathrm{x}$ \\
B4; CP-4 & UK-2062.3 & & $\mathrm{x}$ \\
B5; CP-5 & UK-2067.98 & & $\mathrm{x}$ \\
B6; CP-6 & LK-2692.25 & & $\mathrm{x}$ \\
B7; CP-7 & LK-2697.15 & $\mathrm{x}$ & \\
L1A & QA-2030.13-2030.71 & $\mathrm{x}$ & \\
L2A & QA-2033.73-2034.44 & $\mathrm{x}$ \\
L3A & QA-2046.30-2046.67 & $\mathrm{x}$ & \\
L4A & UK-2052.06-2052.58 & $\mathrm{x}$ & \\
L5A & UK-2055.26-2055.74 & $\mathrm{x}$ & \\
L6A & UK-2056.97-2057.46 & $\mathrm{x}$ & \\
L7A & UK-2062.46-2063.01 & $\mathrm{x}$ & \\
L8A & LK-2693.77-2694.25 & $\mathrm{x}$ & \\
L9A & LK-2697.28-2697.50 & $\mathrm{x}$ & \\
M1 & UK-2056.16 & $\mathrm{x}$ & \\
M2 & UK-2056.30-2057.45 A & $\mathrm{x}$ & \\
M3 & UK-2056.30-2057.45 B & $\mathrm{x}$ & \\
W1 & LK-2698.22 A & $\mathrm{x}$ & \\
W2 & LK-2698.22 B & $\mathrm{x}$ & \\
W3 & LK-2698.22 C & $\mathrm{x}$ & \\
W4 & UK-2056.92 A & $\mathrm{x}$ & \\
W5 & UK-2056.92 B & $\mathrm{x}$ & \\
W6 & UK-2056.42 & $\mathrm{x}$ & \\
W7 & UK-2056.60-1 & \\
W8 & UK-2056.60-2 & \\
W9 & UK-2056.40 & &
\end{tabular}




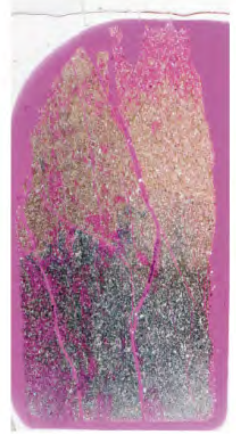

B1; CP-1

UK-2048.25

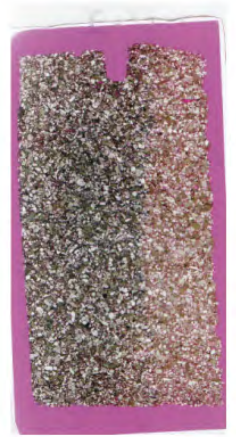

B2; CP-2

UK-2052.06

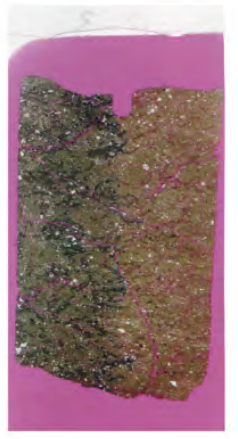

B3; CP-3

UK-2055.20

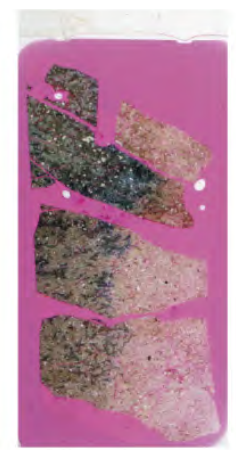

B4; CP-4

UK-2062.30

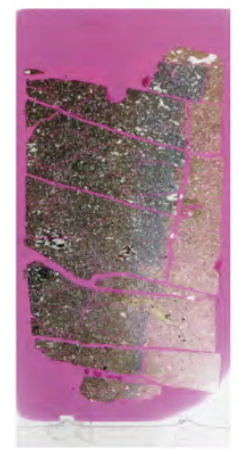

B5; CP-5

UK-2067.98

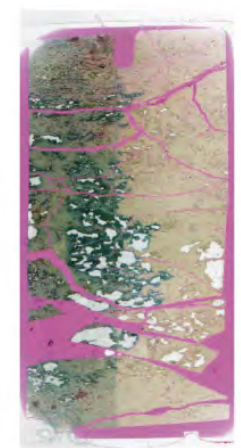

B6; CP-6

LK-2692.25
LK-2697.15

Figure D.1. Inventory of "B" set, which were obtained by TerraTek (see Appendix B.1). 


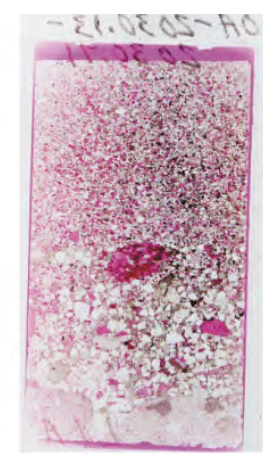

L1A

QA-2030.13-2030.71

Y.D.: Unknown; either upward or downward

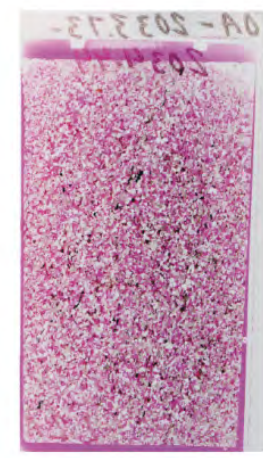

L2A

QA-2033.73-2034.44

Y.D.: Unknown

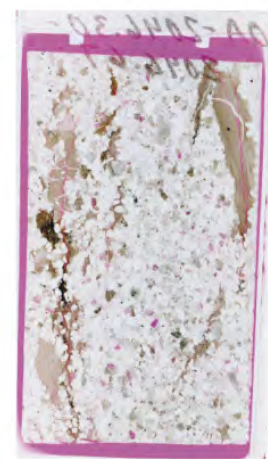

\section{L3A}

QA-2046.30-2046.67

Y.D.: Unknown; to the right or left

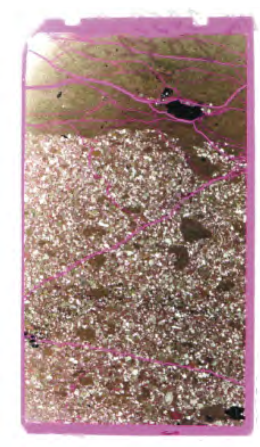

L4A

UK-2052.06-2052.58

Y.D: downward

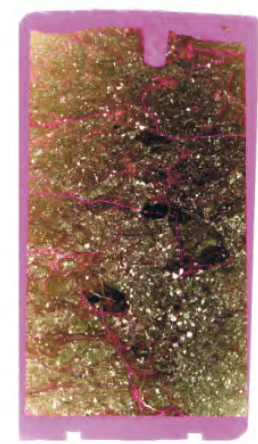

L5A

UK-2055.26-2055.74

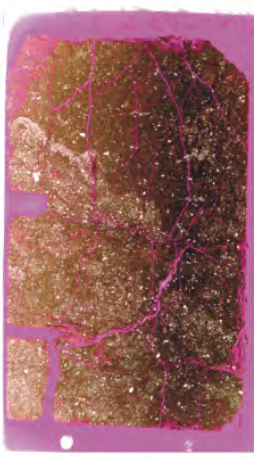

L6A

UK-2056.97-2057.45

Y.D.: To the left

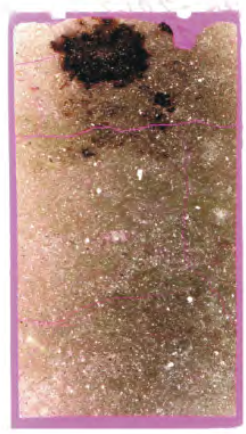

L7A

UK-2062.46-2063.01

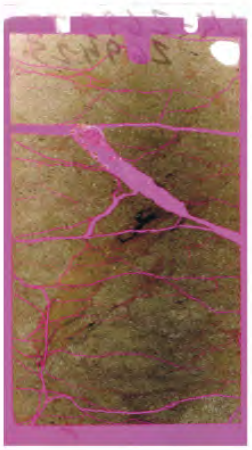

L8A

LK-2693.77-2694.25

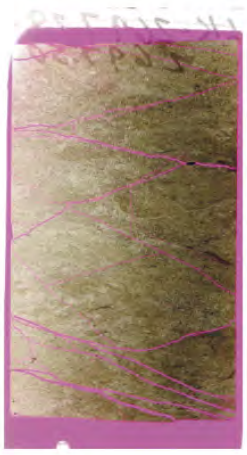

L9A

LK-2697.28-2697.50

Y.D.: Unknown; probably upward or downward

Figure D.2. Inventory of thin sections for the "L" set, which were obtained to further study of lithology at additional depths. 


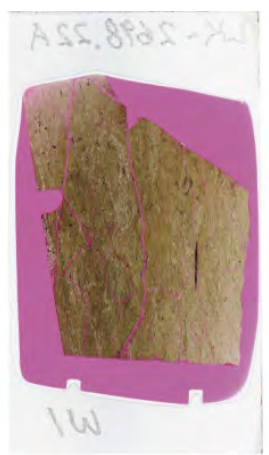

W1

LK-2698.22 A

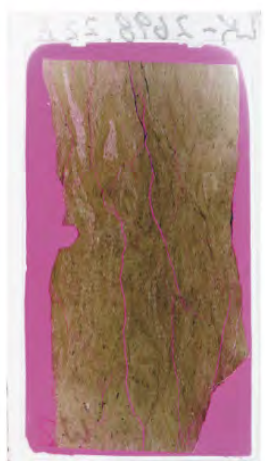

W2

LK-2698.22 B

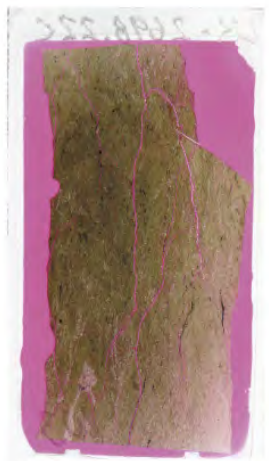

W3

LK-2698.22 C

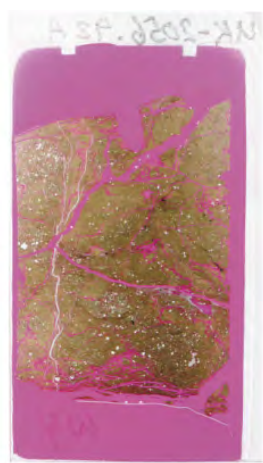

W4

UK-2056.92 A

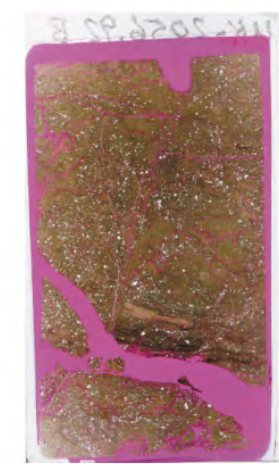

W5

UK-2056.92 B

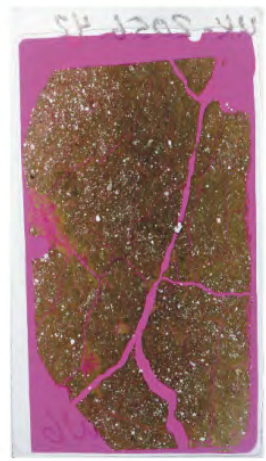

W6

UK-2056.42

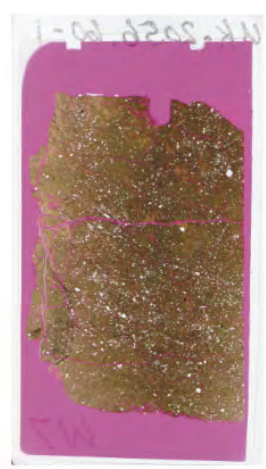

W7

UK-2056.70-1

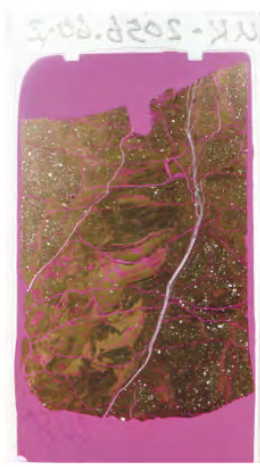

W8

UK-2056.60-2

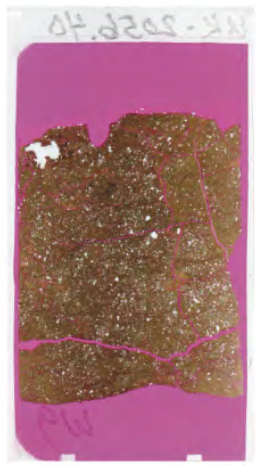

W9

UK-2056.40

Figure D.3. Inventory of thin sections for the "W" set, which were obtained to examine mineralized fractures observed in core. 


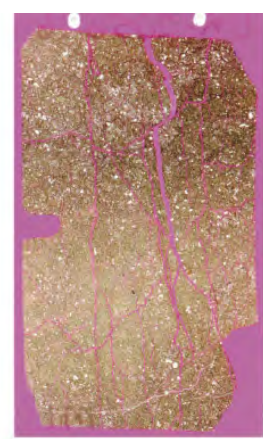

M1

UK-2056.16

Notch indicates natural fracture with dip of $\sim 11$ $15^{\circ}$

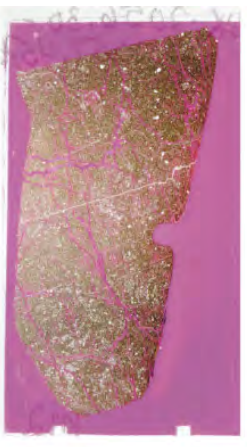

M2

UK-2056.30-2657.45A

Y.D.: Not definitely

known; notch marks

fracture that may dip $\sim 10$ $15^{\circ}$

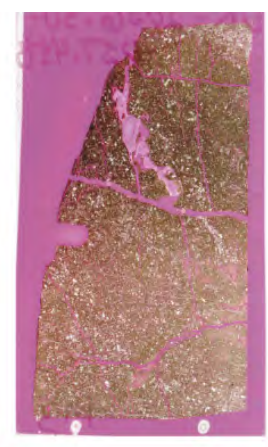

M3

UK-2056.30-2057.45B

Y.D.: Not definitely

known; notch marks

fracture that may dip $\sim 10$ $15^{\circ}$

Figure D.4. Inventory of thin sections for the " $M$ " set, which were obtained to examine mineralized fractures observed in core. Due to the friability of the core, the younging or up direction was lost during handle of the core. It is probable that the notch marks shallowly dipping fractures like that of M1. 


\section{Appendix E. Mud Log of Well EPNG Com A Inj \#1}

A mud log was taken during drilling and coring of well EPNG Com A Inj. \#1, which follows below. 


\section{SOFTROCK GEOLOGICAL SERVICES, INC.}

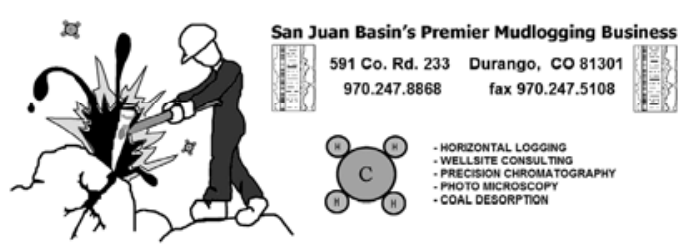

Scale 1:240 (5"=100') Imperial Measured Depth Log

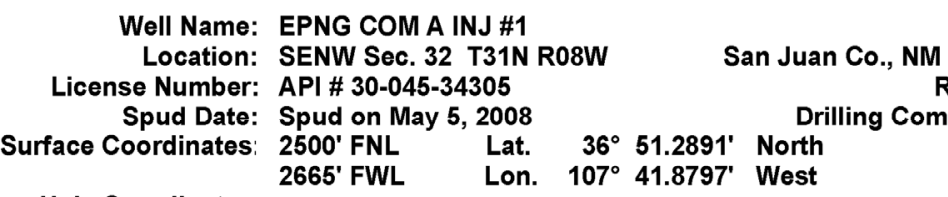

Well Name: EPNG COM A INJ \#1

Location: SENW Sec. 32 T31N R08W San Juan Co., NM

License Number: API \# 30-045-34305

Spud Date: Spud on May 5, 2008

Surface Coordinates: 2500' FNL Lat. $36^{\circ}$ 51.2891' North

2665' FWL Lon. $107^{\circ} 41.8797^{\prime}$ 'West

Bottom Hole Coordinates:

Ground Elevation (ft): 6321'

Logged Interval (ft): $1500^{\prime}$

To: 2943'

K.B. Elevation (ft): $6332^{\prime}$

Total Depth (ft): 3156

Formation: Cretaceous Nacimiento
Type of Drilling Fluid:

Printed by WellSight Log Viewer from WellSight Systems 1-800-447-1534 www.WellSight.co

CORE

Contractor: Coring Services (Midland, TX - 432.563.6280)

Core \#: 1 \& 2

Formation: Ojo Alamo/Kirtland, Lower Kirtland Shale

Core Interval:

From: 2018' / 2690'

Bit type: Ulterra CPM-1208P / Gearhart MO812CB

Size: $8(23 / 32)^{\prime \prime}$

Coring Time: 3 hrs / 7 hrs

\section{OPERATOR}

Company: Burlington Resources Oil and Gas Company

Address: San Juan Dvivsion---COAL Team ATTN: Mr. Eddie Pippin 3401 E. 30th Street

Farmington, NM 87401

GEOLOGIST

Name: Dan McGinn, Bob Bradley, Mason Auger

Company: Softrock Geological Services, Inc.

Address: 591 County Rd. 233

Durango, CO 81301

(970) 247-8868 fax (970) 247-5108 


\section{Contractors}

Aztec Well Services Rig \#580 / \#266

Burlington Co. Rep. : Mr. Mike Frankinburger / Mr. Keith Jackson / Mr. Ron Coffee

New Mexico Tech Univ.: Mr. Jason Heath, PhD Candidate / Dr. Reid Grigg, PhD

Sandia National Labs: Mr. Scott Cooper

US D.O.E. / NETL: Dr. Dustin Mclntyre / Mr. Brian Tennant

Schlumberger Wireline Logging

Instrument

i4 FID Chromatograph (Hydrogen fuel \& carrier gas)

Scotty Analyzed Gases Calibration Gas

$\rightarrow-\rightarrow(1 \%$ each C1, C2, C3, iC4, nC4 / balance Nitrogen)

ACCOUNTING:

FC AFE \#: WAN.CDR.7085

FC NW \#: 10197739 / 10198155

PO\#: BCURLEY

Activity Code: K200 Mudlogging

Hole / Casing Data

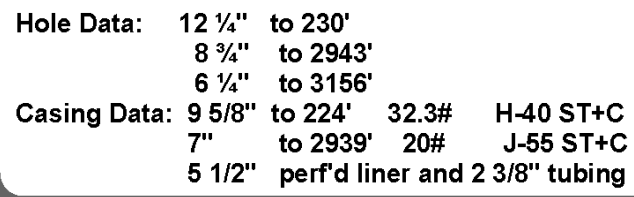

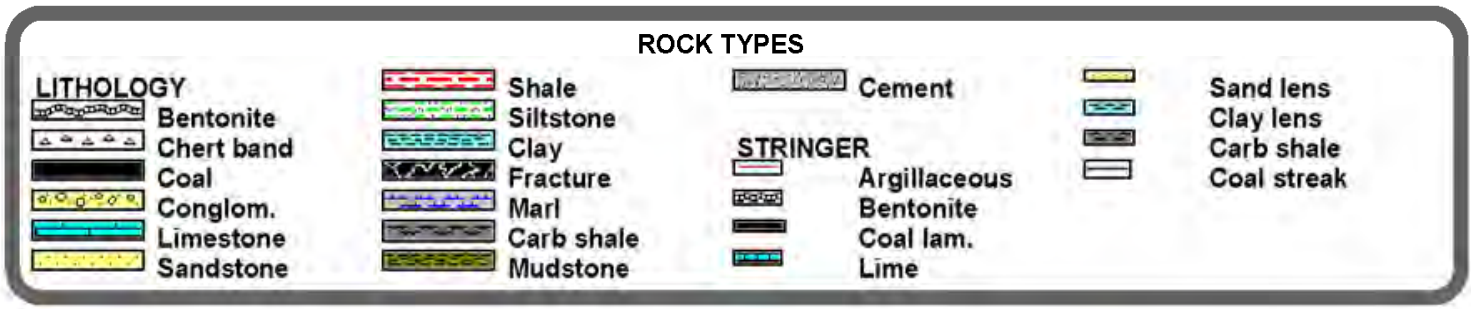

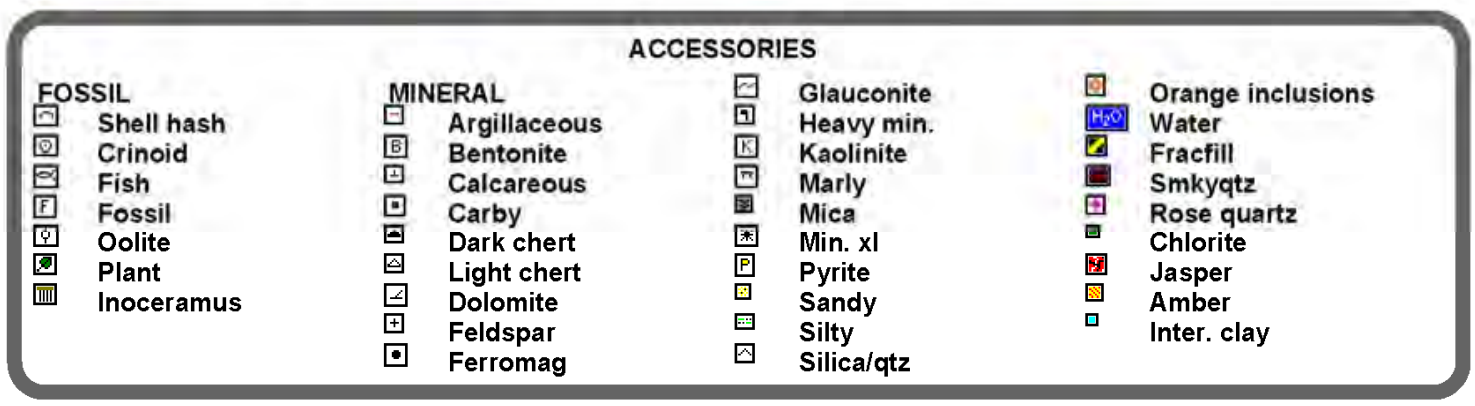

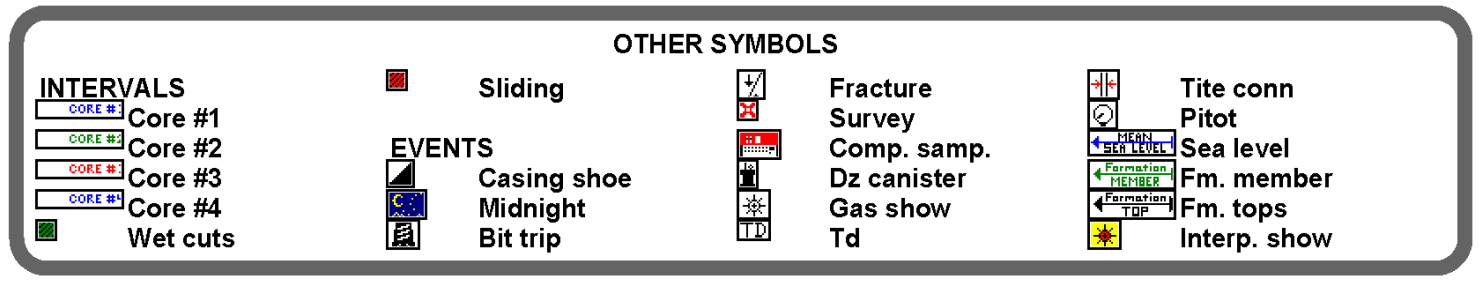




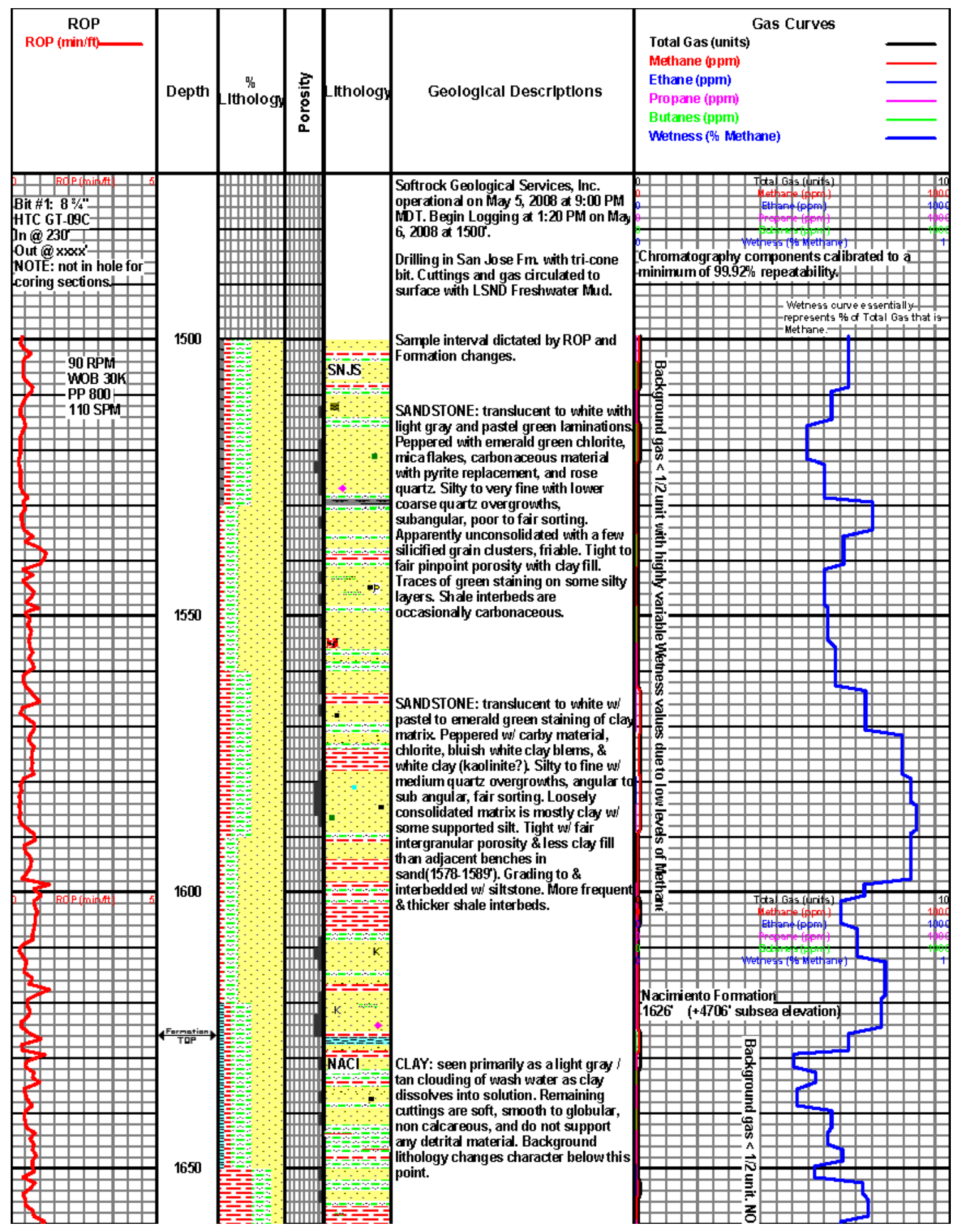



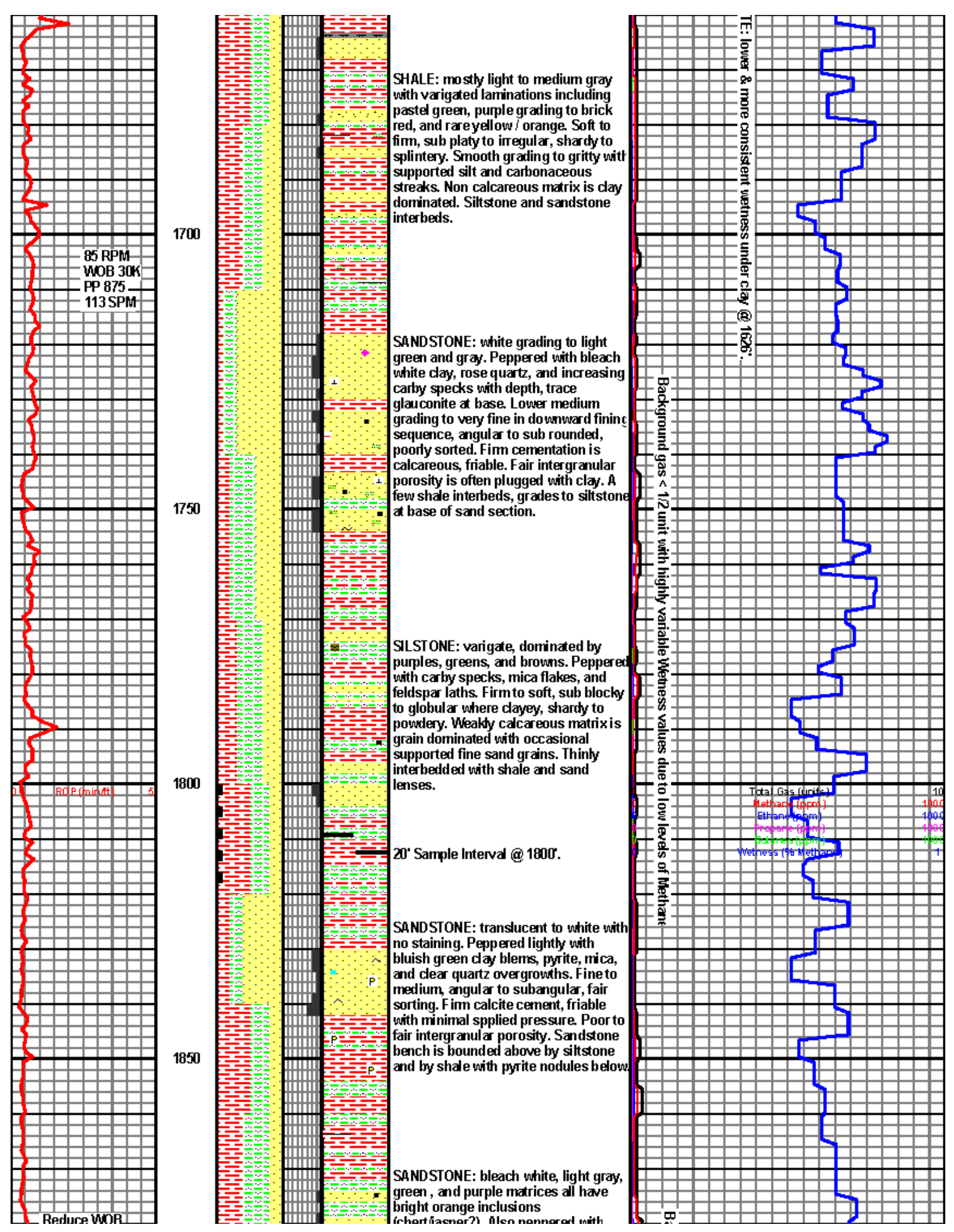


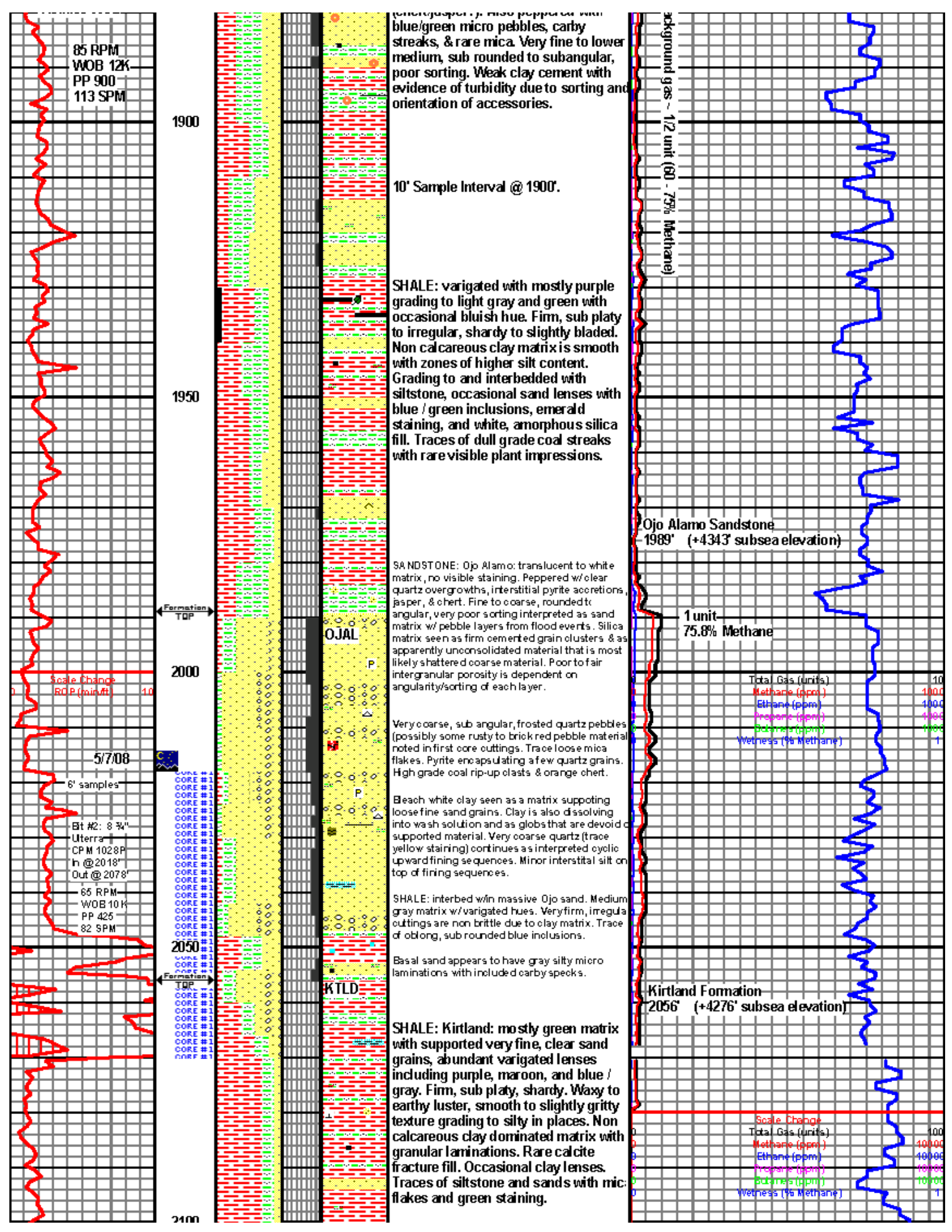




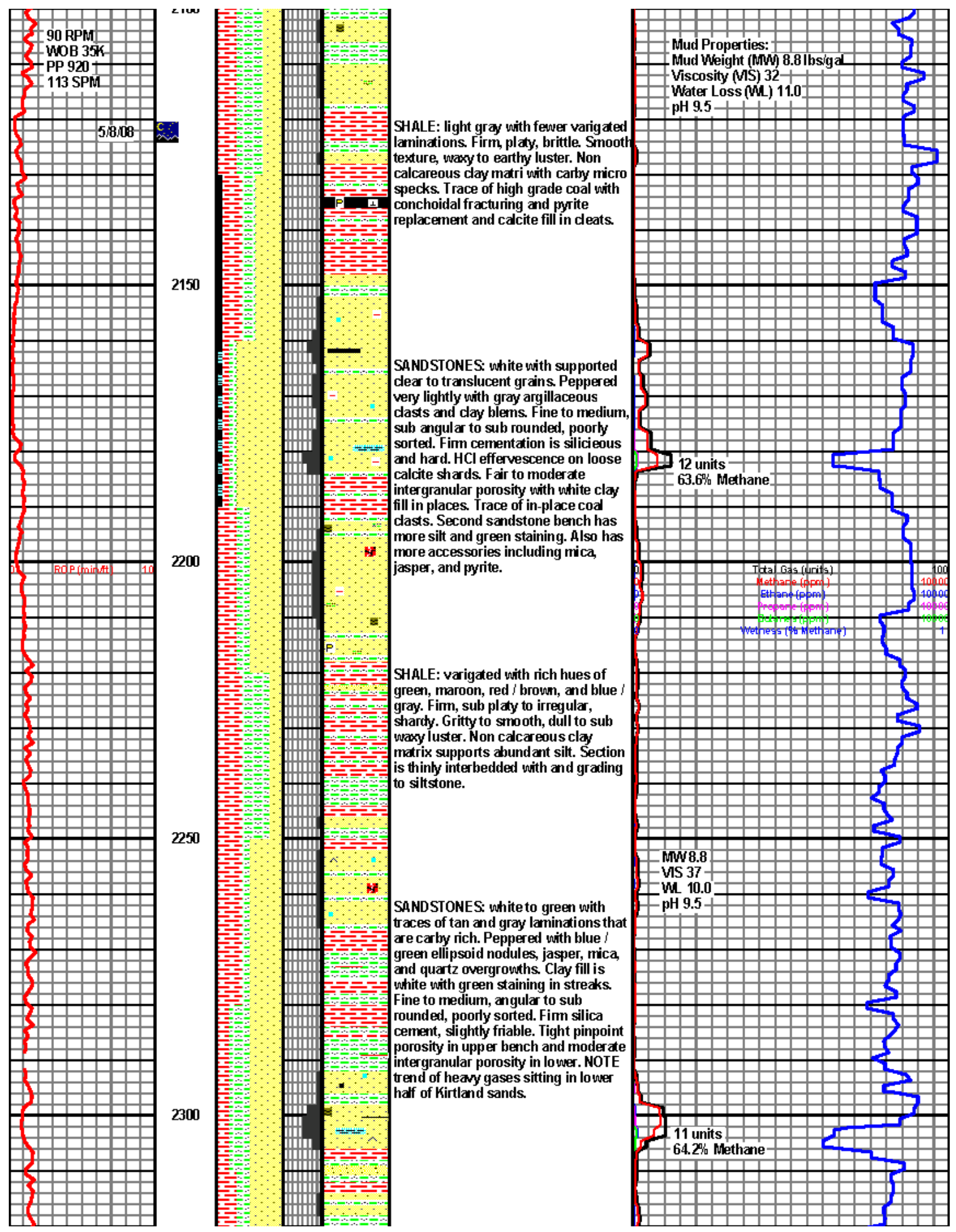



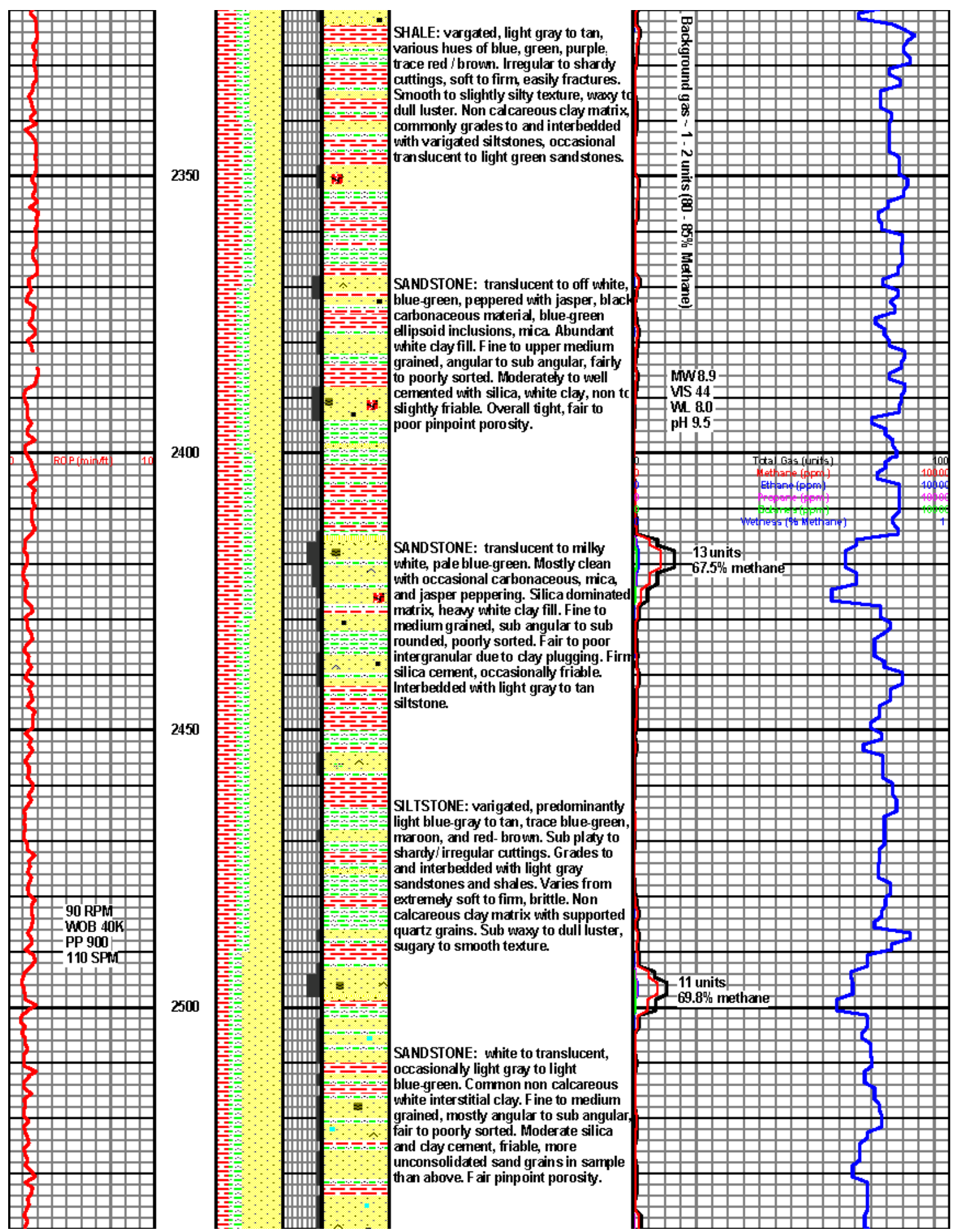


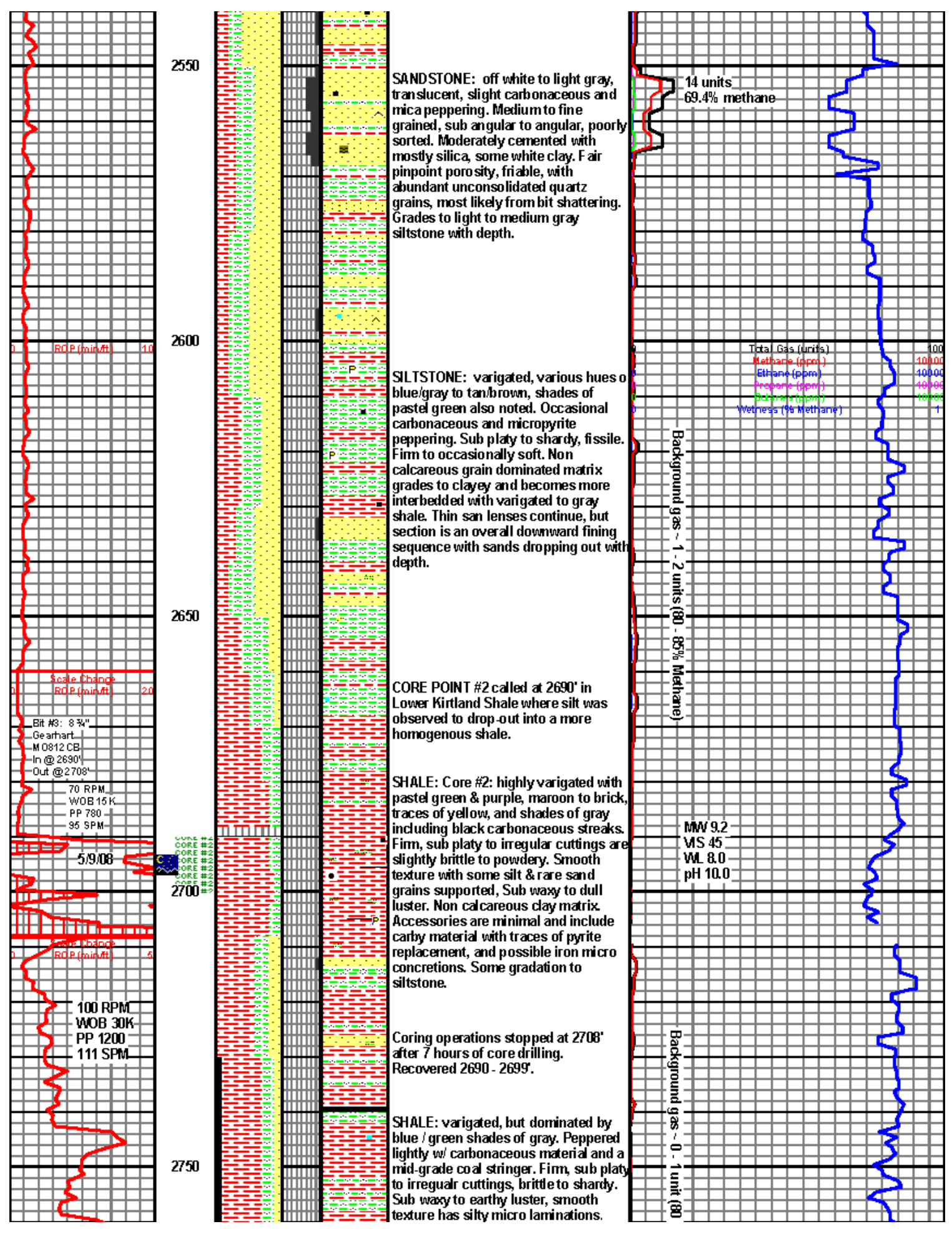




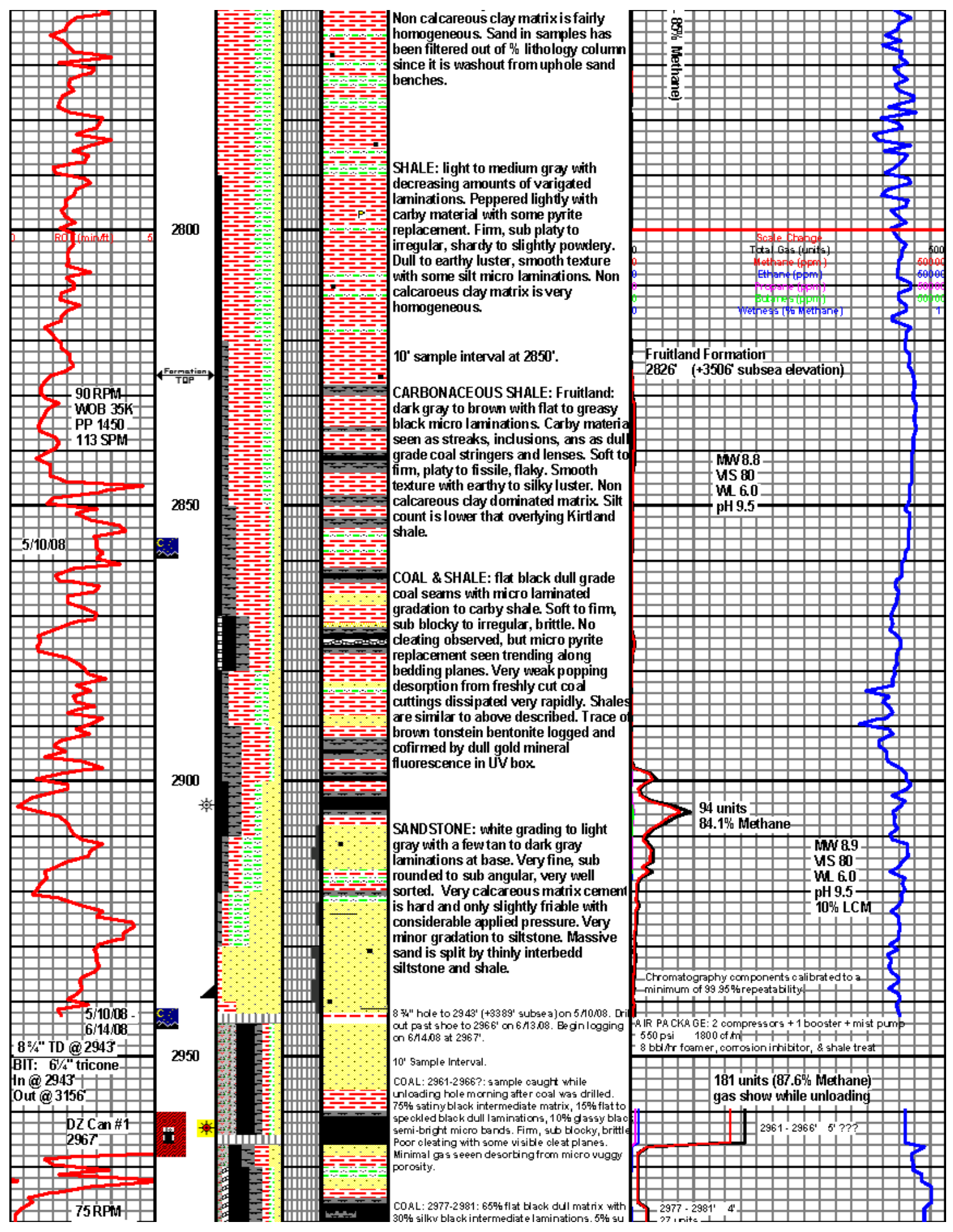




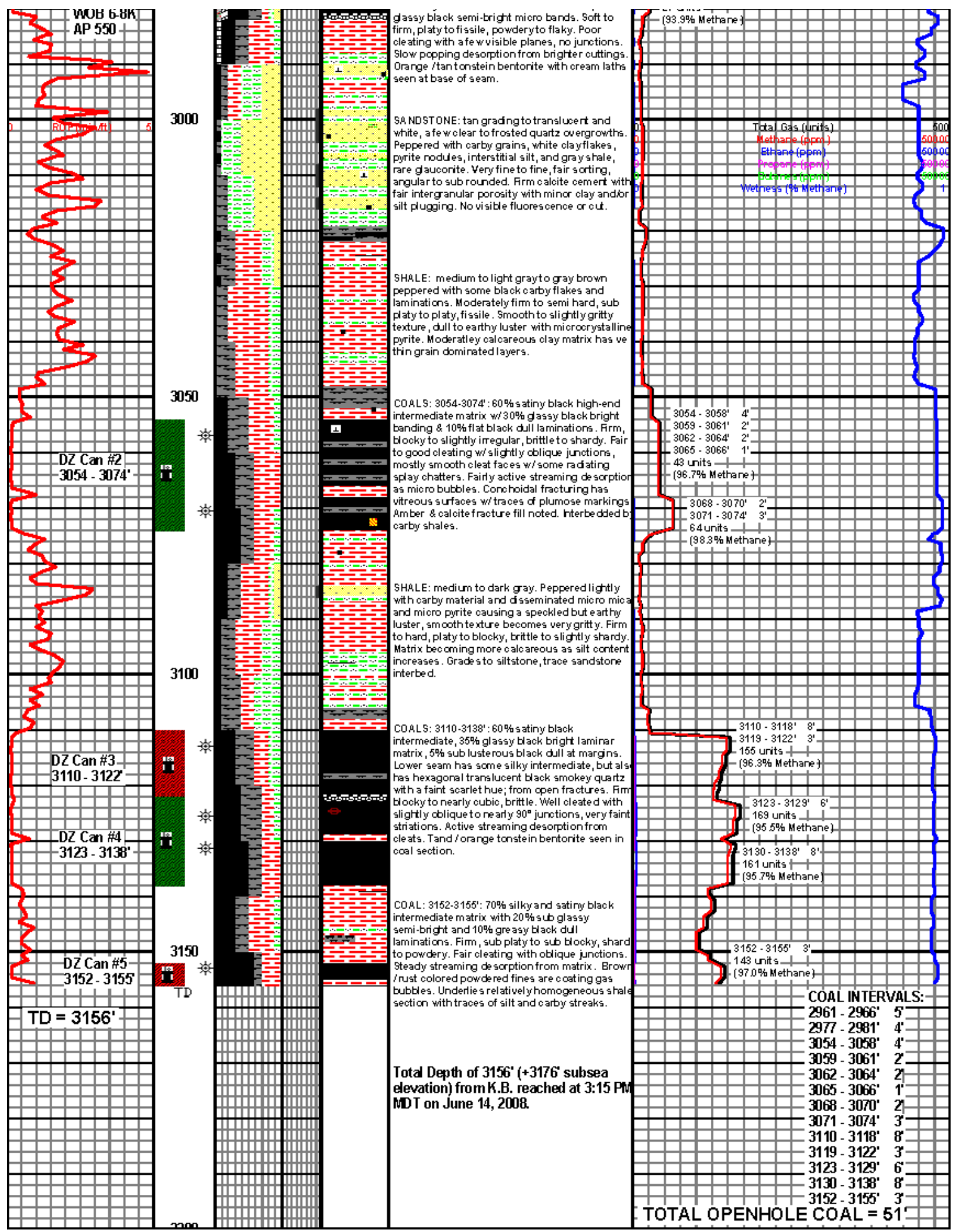

